\title{
Index to the
}

\section{Reports of the National Conference}

\section{on Weights and Measures}

\author{
From the First to the Thirty-sixth
}

1905 to 1951

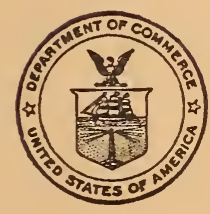

U. S. Department of Commerce

National Bureau of Standards

Miscellaneous Publication 203 



\title{
Index to the
}

\section{Reports of the National Conference}

\section{on Weights and Measures}

\author{
From the First to the Thirty-sixth \\ 1905 to 1951
}

William S. Bussey and Malcolm W. Jensen

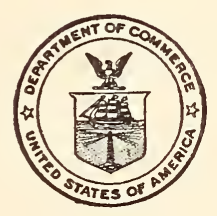

National Bureau of Standards Miscellaneous Publication 203 Issued April 21, 1952

(Supersedes Miscellaneous Publication 172) 


\section{Preface}

This publication supersedes National Bureau of Standards Miscellaneous Publication 172 with respect to the index of the several Reports of the National Conference on Weights and Measures. The earlier index covered the Conference Reports from the First to the Thirtyfirst, inclusive. The present publication covers all Conference Reports from the First to the Thirty-sixth, inclusive. Thus the large amount of information on a wide variety of weights and measures subjects, which is embraced within the published reports of the proceedings of the National Conference from the first meeting in 1905 through the meeting in 1951, is made more valuable by reason of the means herein provided for locating readily all material on any specific subject and all material presented by any particular speaker.

A. V. Astin, Acting Director.

\section{Contents}

Preface

Page

Introduction

Index by subjects

Index by names of speakers

List of Conference Reports 


\title{
Index to the Reports of the National Conference on Weights and Measures
}

\author{
From the First to the Thirty-Sixth (1905 to 1951)
}

\section{Introduction}

For ease of reference, the index is presented in two forms, first a subject index, and second an index by names of speakers. The subject index has been carefully cross-indexed, to enable those using it to locate the desired information under principal or associated words. In the name index, the names of speakers are arranged alphabetically, and under each name appear, in chronological order, references to the papers or addresses presented to the Conference by that speaker ; in those instances in which a speaker's official or business connection has changed during the period covered by the index listings, his name is entered once for each such connection, with appropriate listing of papers or addresses under each entry.

Citations to particular Conference Reports and to the pages in such Reports where the material in question begins are given in the following manner: The "number" of the Conference (That is, first, second, and so forth) is given first by means of figures printed in bold-faced type; immediately following, and printed in ordinary light-faced type, there is given the number of the page on which the material begins. Thus the citation " 20,87 " means that the material in question will be found beginning on page 87 of the Report of the Twentieth National Conference. When material carries over from one session of a Conference to a subsequent session, or when a presentation is interrupted and later resumed in the same session, a citation is given for the beginning of each portion of the material.

For information relative to the procurement or consultation of Conference Reports, and to the designation of the several Conference Reports according to the numeration followed in the series of Miscellaneous Publications of the National Bureau of Standards, see page 44.

\section{Index by Subjects}

\section{A}

Addresses of-

Assistant Director, National Bureau of Standards, 25, 1.

Assistant Secretary of Commerce, 23,$57 ; 25,61 ; 28,41$.

President of conference, 1,$5 ; 2,5 ; 4,5 ; 5,7 ; 6,7 ; 7,15 ; 8,15 ; 9,12$; 10,$17 ; 11,16^{4} ; 12,15 ; 13,13 ; 14,16 ; 16,16 ; 17,2 ; 18,1 ; 19,1 ; 20,32$; 21,$1 ; 22,1 ; 23,1 ; 24,1 ; 26,1 ; 27,1 ; 28,1 ; 29,1 ; 30,6 ; 31,13 ; 32,6$; 33,$1 ; 34,1 ; 35,1 ; 36,1$.

Secretary of Commerce, 3,$55 ; 5,8 ; 6,111 ; 7,11 ; 8,12 ; 9,11 ; 10,13 ; 11,13$; 12,$119 ; 13,57 ; 14,79 ; 15,25 ; 16,76 ; 17,135 ; 18,74 ; 19,116 ; 22,47$; 26,$73 ; 27,84$.

Adjustments by weights and measures officials, 34, 163. 
Administration of weights and measures :

board of adjustment, 25,95 .

conduct of departments, 8,$177 ; 10,122 ; 15,75 ; 16,28 ; 16,34 ; 18,170 ; 22,29$;

22,$62 ; 26,18$.

contests, 28, 125.

cooperation among officials, 21, 60;22, 29; 23, 29.

directing personnel, 31, 7 .

extension of, 24,72 .

fee system, 10,$134 ; 12,87 ; 26,9$.

in Canada, 24, 61; 36, 7 .

in Great Britain, 26, 83; 36, 15.

national unity in, 30,6 .

observations on, 22,$62 ; 23,48 ; 29,31$.

organization of departments, 8,$177 ; 10,122 ; 15,75 ; 16,28 ; 16,34 ; 18,170$; 22,$29 ; 22,62 ; 26,18 ; 35,103 ; 35,195 ; 35,107$.

radio programs, 29,$19 ; 31,44 ; 31,165$.

school, weights and measures, novel form, 30, 32 .

State aids for local departments, 26, 27.

State-wide inspection, 26, 29.

survey on, by Department of Agriculture, 27, 16;28, 28; 29, 48.

undercover buying, 25,$138 ; 26,13$.

uniformity of, 28,$5 ; 30,81$.

Air dissolved in gasoline, 22, 11.

Air elimination for-

large-capacity meters, 31, 25.

vehicle-tank meters, 26, 106.

Air eliminators, research on, resolution on, 26, 161.

Air releases on liquid-measuring devices, 23, 105.

Alcoholic beverages, containers for, resolution on, 31, 158 .

American Automobile Association cooperative program, 22, 86.

American Petroleum Institute, report on automotive transportation, 32, 23.

Annual reports of officials, 23,92.

Approval of type of commercial apparatus :

Federal, 4,$8 ; 8,85 ; 9,164 ; 10,159 ; 12,50 ; 12,134 ; 15,57 ; 15,66 ; 15,72$ : 18,$147 ; 20,43 ; 20,58 ; 21,75 ; 21,98$.

resolutions on 4,$58 ; 8,223 ; 12,205 ; 13,177 ; 14,109 ; 20,120$.

State, 15,$60 ; 20,43 ; 20,58 ; 30,184 ; 31,109$.

A.R.E.A. specifications for vehicle scales, 25,$88 ; 31,129$.

Assay Commission, 25, 122.

Assistance to the States, 28, $19 ; 29,144$.

committee on, reports of, 28,$80 ; 29,25 ; 30,29 ; 31,16$.

proposed legislation on, 27, 25 .

resolution on, 31, 158.

Assistant Secretary of Commerce, addresses, 23, 57 ; 25, 61 ; 28, 41.

Austin, John H.:

special resolution relative to, 25,$23 ; 25,53$.

tribute to, 25, 145 .

Automatic-indicating scales, 10, 95; 12, 73.

large-capacity, tolerances for, 14,$87 ; 15,34 ; 16,132 ; 22,72$.

printed weight indications and remote weight indications, 30, 19.

specifications for, 22,$119 ; 23,79 ; 23,150 ; 24,146 ; 25,104$. See also $26,117$. Automatic-recording scales, $30,19$.

Auxiliary automobile tanks for checking gasoline deliveries, use of, 19, 95 ; $19,99$.

\section{B}

Babcock glassware, specifications and tolerances, 19, 157.

Babcock test for milk and cream, 19, 13.

Baggage and freight scales, railroad supervision, 18,$34 ; 18,46$.

Balances. See Scales.

Barrels :

beer :

sizes 9, 146.

testing, 25, 113.

standard:

law, 9,$53 ; 9,56 ; 10,176$.

resolution on, 8,223 . 
Baskets :

berry, specifications and tolerances, 9,$59 ; 9,79 ; 9,90 ; 10,199$.

Federal law on $(1928), 22,13 ; 23,53 ; 23,65$.

standard, resolution on, 19, 168.

Beams, side, on counter scales, 22, 117 ; 23, 134 .

Beer barrels. See Barrels, beer.

Berry baskets or boxes. See Baskets.

Board of adjustment, 25, 95 .

Bottles :

alcoholic beverage, resolution on, 31, 158 .

lubricating-oil, 19, 17 ; 24, $15 ; 24,138$.

drainage characteristics of, 24, 22 .

resolutions on, 19,$170 ; 23,144$.

specifications and tolerances for, 20,$71 ; 20,137 ; 21,142 ; 22,70 ; 23,124$;

24,$27 ; 24,178 ; 25,103$.

milk and cream, 32,66 :

capping, 36, 92.

filling, National Bureau of Standards investigation, 16, 43.

paper, 27,$115 ; 31,109$.

specifications and tolerances, 9,$58 ; 9,73 ; 9,113 ; 10,140 ; 10,147 ; 10$,

$196 ; 11,134 ; 11$, App. 1,$11 ; 17,128 ; 22,121 ; 25,99 ; 26,128 ; 31,103$. testing, 16,47 .

uniformity or requirements, 15,$30 ; 16,45 ; 16,64 ; 17,26 ; 30,168$. resolutions on, 15,$125 ; 17,138$.

Boxes, berry, specifications and tolerances, 9,$59 ; 9,79 ; 9,90 ; 10,199$.

Bread :

Nebraska decision, 17, 51.

shrinkage, $18,164$.

standard weight, legislation, 13,$115 ; 13,188 ; 14,24 ; 14,72 ; 14,80 ; 14,83$; 15,$88 ; 16,98 ; 16,112 ; 17,40 ; 17,51 ; 17,76 ; 18,143 ; 18,154 ; 19,83$;

24,$162 ; 26,34 ; 26,95$.

resolutions, 13,$174 ; 19,170$.

tolerances, 14,$37 ; 14,84 ; 15,79 ; 15,91 ; 16,112 ; 17,51 ; 17,63 ; 17,126$;

18,$143 ; 18,154 ; 18,163$.

Brick molds for ice cream, standardization, 22, 24.

resolution, 23, 144.

Briggs, Lyman J., President, National Conference on Weight and Measures, 25, 4. resignation, 32,4 .

Bureau of Standards. See National Bureau of Standards.

Burgess, George Kimball :

life and work, 25, 2.

resolution in memory of, 25,141 .

Bushel weights, 8,$106 ; 8,109 ; 16,82 ; 22,13$. See also Dry commodities, sale by weight.

Butter, tolerance and shrinkage, 16, 60 .

Butterfat-test scales, 9, 39.

specifications, tolerances, and regulations, 8,$220 ; 9,62 ; 9,111 ; 10,216$; 11,$153 ; 11$, App. 1,$36 ; 17,132 ; 22,72$.

Calibration of

tank cars, 35, 145.

volumetric standards, 34, 75.

California Gasoline and Oil Substitution Act, 28, 134.

Canada, weights and measures administration, 24,61.

Canned foods, standardization of containers, 27,35 .

Cans : resolutions, 27, $109 ; 28,137$.

ice cream, standardization, $22,24$.

lubricating oil :

drainage characteristics, $26,76$.

sealed, for dispensing lubricating oil, 25, 65 .

Capacity measures. See Measures, capacity.

Carat, resolution, 8, 223.

Cartons for ice cream, standardization, 22, 24. resolution, 23,144 .

Centigrade temperature scale, use in government publications, 11, 39. 
Certification and labeling plan in connection with Federal specifications, 25, 42. Chain-store operation, weights and measures aspects, 21, 79.

Cheese, limburger, net weight, 31, 135.

Citations of court decisions, 19,$68 ; 20,80 ; 23,120 ; 26,160 ; 27,107 ; 31,156$.

City and county departments, organization and administration, 16,$34 ; 22,29$; 22,$62 ; 26,18$.

Civil service protection for sealers, necessity for, 8, 77 . resolution, 8,$223 ; 26,164$.

Clinical thermometers: resolution, 19,168 . testing, 19,48 .

Cloths, wiping, 34, $124 ; 35,122$.

Coal:

bootleg, control, 25, $110 ; 25,129$.

chemically treated, 23,66 . resolution, 23, 144.

interstate trucking, $\mathbf{3 1}, 140$.

quality, 18, 186.

resolution, 16, 149 .

retail sale, 16,$127 ; 23,66$.

tolerances on loads, 26, 102.

uniform ton, 15,$53 ; 15,124 ; 16,65$. resolution, $\mathbf{1 6 , 1 4 2 .}$

weighing, 13, 182;14, $54 ; 16,123$.

Coffee, packages, 36, 98 .

Coke:

retail sale, 16,$127 ; 26,100$.

weighing, 11, 159.

Commercial standards, 21, 66.

Committees: See entries as follows:

Assistance to the States, Committee on.

Constitution and By-Laws, Committee on.

Executive Committee.

Legislation, Committee on.

Methods of Sale of Commodities, Committee on.

Resolutions.

Specifications and Tolerances, Committee on.

Standardization of Packaged Goods, Committee on.

Standing committees.

Uniformity in Weights and Measures Requirements, Committee on.

Weights and Measures Education, Committee on.

Commodities :

dry. See Dry commodities.

methods of sale, 30,$130 ; 30,167 ; 32,28$.

committee on, reports, $\mathbf{3 1}, \mathbf{1 1 8}$

retail sale, by weight or measure, 29,16 .

tolerances, 34, 137.

Computing scales, specifications, tolerances, and regulations, 8, $219 ; 9,61 ; 9,104$;

10,$146 ; 10,214 ; 10,225 ; 11,109 ; 11$, App. 1,$33 ; 17,131 ; 24,91 ; 24,146 ; 26,121$.

Conditions in various weights and measures jurisdictions :

abroad, 2,$35 ; 17,81$.

Far West, 18, 69.

Latin-American countries, 12, 135.

New York City, 26, 50.

Philippine Islands, 10, 50.

Puerto Rico, 9, $138 ; 17,17$.

Richmond, Virginia, 18, 39.

South, 19, 73.

Virginia, 9, 146.

Condon, E. U., President, National Conference on Weights and Measures: nomination to president, 32,97 .

Conduct of weights and measures departments, 8,$177 ; 10,122 ; 15,75 ; 16,28$; 16,$34 ; 18,170 ; 22,29 ; 22,62 ; 26,18$.

Conference, change in name, $18,73$.

Constitution and by-laws, 26, 99.

committee, 5,$89 ; 20,134 ; 25,144$.

reports of, 5,$119 ; 9,115 ; 10,58 ; 10,110 ; 10,114 ; 11,168 ; 21,74 ; 26$, 148. 


\section{Containers :}

alcoholic bererage, resolution, 31,158 .

consolidation and amendment of Federal laws, 24,$44 ; 25,107 ; 30,8$.

deceptire, 30, 138.

Federal law (1928), 22, $13 ; 23,53 ; 23,65$.

fruit and vegetable, 12,$89 ; 22,13 ; 23,53 ; 23,65$. dimensional method of testing, 28, 128 . standardization, $32,18$.

glass, $32,67$.

measure, 35, 162.

paper, for milk, 27,$115 ; 31,109$.

resolutions on net content marking, 4,$59 ; 7,144 ; 19,160$.

standardization, 6,$46 ; 6,134 ; 12,89 ; 13,122 ; 13,189 ; 27,35 ; 32,18$. resolutions on, 19,$168 ; 27,109 ; 28,137$.

transparent, 33, 141.

Contests, weights and measures, 28, 125.

Cooperation among weights and measures officials, 21,$60 ; 22,29 ; 23,29$.

Coordination between departments in relation to interstate shipments, 29,9 .

Cordage and twine, 16,$63 ; 16,71$.

Cordage-measuring devices, 36,100 .

Corrections to standards, 30,114 .

Court decisions, citations, 19,$68 ; 20,80 ; 23,120 ; 26,160 ; 27,107 ; 31,156$.

Cotton:

standardization of bale, 23, 22.

weighing, 16,$26 ; 23,22$.

Counter scales:

side beams, 22,$117 ; 23,134$.

specifications, tolerances, and regulations, 8,$216 ; 8,265 ; 9,60 ; 9,95 ; 10,156$;

10,$207 ; 10,223 ; 11,108 ; 11,150 ; 11$, App. 1,$25 ; 21,151 ; 22,72 ; 24,91$;

24,$145 ; 25,106 ; 26,126$.

County and city departments, organization and administration, 16, 34; 22, 29 ; 22,$62 ; 26,18$.

Cream-test scales, specifications, tolerances, and regulations, 8,$220 ; 9,62 ; 9,111$; 10,$216 ; 11,153 ; 11$, App. 1,$36 ; 17,132 ; 22,72$.

Creameries, maintenance of scales in, 9,$39 ; 17,11$.

C'ustoms service, weighing in, 18, 104.

\section{D}

Deceptive containers, 30,138.

Decisions, court, citations, 19, 68; 20, $80 ; 23,120 ; 26,160 ; 27,107 ; 31,156$.

Design of scales, 8,123 . effect of highway and motor-truck design on, 22, 82.

fundamentals, 27,55 .

Development of large-capacity scales, 24, 99.

Dial scales, side beams, and hidden weights, 25,134 .

Digest of weights and measures cases, notes on, 21,155 .

Dimensional method of testing containers for fruits and regetables, 28, 128.

Drainage characteristics of-

dispensers for canned lubricating oil, 26, 76 .

lubricating-oil bottles, 24, 22.

Dry capacity measures :

abolition (See also Dry commodities, sale by weight of), resolution, 16, 146. specifications and tolerances, 8,$212 ; 9,59 ; 9,79 ; 10,197 ; 11,137 ; 11$, App. 1,$12 ; 24,91$.

Dry commodities :

sale by weight, 8,$106 ; 8,109 ; 9,147 ; 10,109 ; 10,189 ; 11,88 ; 12,212 ; 13,185$;

15,$17 ; 16,82 ; 17,37 ; 19,59 ; 22,13$.

resolution; 8,$200 ; 10,189 ; 12,205 ; 13,177 ; 16,139 ; 19,167$.

E

Education, weights and measures, committee on, 26, $164 ; 29,145$. reports of, 30,$103 ; 31,45 ; 31,52 ; 32,51 ; 33,115 ; 34,71 ; 35,99 ; 36,47$.

Education, weights and measures, in England, 36,15 .

Educational activities and publicity (See also Weights and measures education, committee on ), 9,$150 ; 11,45 ; 13,167 ; 14,21 ; 17,91 ; 19,86 ; 20,39 ; 20,67$; 20,$84 ; 21,62 ; 21,71 ; 27,69 ; 29,19 ; 30,100 ; 31,44 ; 31,165$. resolution, $12,206$. 
Eggs, regulating sale, 19, 118.

Electric light bulbs, labeling 28, 13. resolution, 27,110 .

Electric meters, 10,$52 ; 21,54$.

Electronic weighing, 35, 43.

Emblem, National Conference, 30, 167 ; 31, 52 ; 31, 139 ; 31, 161 .

Enforcement, uniformity of, 34, 90.

England, weights and measures education in, 36, 15 .

Essay contests among school children, 21, 62.

Evaporation of gasoline from delivery hose, 15, 111.

Executive committee, membership on, resolution, 20, 134.

Exhibit, manufacturer's', at Conference, 17, 106.

Extension of weights and measures administration, 24, 72.

\section{F}

Fabric-measuring devices :

method of test, 15,93 .

specifications and tolerances 14,$87 ; 15,126 ; 16,118 ; 17,21 ; 21,149 ; 22,69$. use, 11,$117 ; 13,169 ; 20,8$.

Facial tissues, $34,117$.

Farm products, irregular or diversified packing, 22, 53.

Federal aid, weights and measures programs, 34, 105.

Federal laws in relation to short weight in interstate commerce, 19, 160; 19, 166.

Federal meat inspection act, 26, 132.

Federal specification AAA-S-121 for weighing scales, 25, 23.

Federal Specifications Board:

organization and function, 25, 23.

technical committee on weighing and measuring devices, 18, 146.

Federal specifications, labeling and certification plan in connection with, 25, 42 .

Federal standard container act of $1928,22,13 ; 23,53 ; 23,65$.

Federal standard container legislation, consolidation and amendment of, 24, 44 ;

25,$107 ; 30,8$.

Federal Trade Commission, weights and measures work of, 22, 42.

Fee system of inspection, 12,$87 ; 26,9$. resolution 10,134 .

Financing weights and measures organization, $33,145$.

Fischer, Louis Albert, address memorializing, 15, 2.

Fish, frozen, 33,$33 ; 33,37 ; 33,39 ; 33,40$.

Flour :

packages, decimal weight, resolution, 12, 205.

shrinkage, 34, 65 .

Food and Drug Administration, activities, 32, 16 .

Food and Drugs Act (Federal) :

enforcement of net weight amendment, 9,$18 ; 12,148$.

weight and measures provisions of Copeland bill to revise, 25,119 .

Food, Drug, and Cosmetic Act, weights and measures requirements, 29, 5; 30, 135.

Food store, duties of an inspector in, 35,36 .

Fraudulent practices, 17,$140 ; 23,86 ; 27,24 ; 29,9$.

Freight and baggage scales, railroad supervision, 18, $34 ; 18,46$.

Freight weighing, National Bureau of Standards activities relating to, 18, 34 .

Frozen Food Institute, Inc., 33, 29.

Frozen foods, 33,$17 ; 33,42 ; 34,113$.

Fruit and Vegetable Branch, U. S. D. A., Regulatory Responsibilities, 33, 133.

Fruit crop in Michigan, regulation, 20, 133.

Fruits and vegetables. See also Containers.

dimensional method of testing containers, 28, 128.

method of sale, 11,88 .

packing, irregular or diversified, $22,53$.

standard shipping containers, 12,$89 ; 22,13 ; 23,53 ; 23,65$.

Fuel oil: resolution, $19,168$.

domestic sales, 33, 161.

household meters for, testing of, 26, $101 ; 27,24$.

methods for investigating short deliveries, 22, 96.

storage tanks, testing, 19, 22 . 
Gages and gaging, 24, 125.

Gas meters, 8,$90 ; 21,54$.

Gases, liquefied petroleum, 30,48 .

instruments for commercial measurement, 30,62 .

measurement problems of distribution industry, 30, 65 . physical properties, 30,48 .

testing dispensing systems for, by gravimetric method, $31,21$.

weights and measures regulation, 30,$71 ; 31,21$.

Gasoline :

air dissolved in, 22, 112.

deliveries, use of auxiliary automobile tanks for checking, 19, 95; 19, 99.

evaporation, from delivery hose, 15, 111 .

losses in storage and handling, 25, 55.

measurement, $19,57$.

temperature as factor, 16,50 .

measuring devices. See Liquid-measuring devices.

meters :

testing, 21, $104 ; 22,79 ; 22,104 ; 24,41$.

twin, 24, 138.

non-tax-paid, $25,50$.

pump industry, 32,56 .

temperature, in underground storage, $25,54$.

wholesale deliveries, in vehicle tanks, 15, 53.

Gasoline and Oil Substitution Act, California, 28, 134.

General regulations, weighing and measuring devices, 30, 112.

Glasses for liquor, 31, 143 .

Glassware, precision, manufacture, 31,54 .

Gold, old, supervision over buying, 25, 34 .

Graduates, glass :

for weight and measures officials, 9, 126.

specifications and tolerances, 11, 132; 11, App. 1, 7; 17, $127 ; 20,121$. testing, 9,$39 ; 23,74$.

Grain :

developments in terminal weighing, 22, 65.

problems in weighing, 12, 140 .

Grease-measuring devices, 20,$70 ; 23,16 ; 26,101$.

specifications, tolerances, and regulations, 21,$83 ; 21,165 ; 22,71 ; 22,89$; 23,$41 ; 23,63 ; 24,141 ; 31,104$.

Great Britain, weights and measures administration in, 26, 83.

Gross weight, elimination of sales by, 13,$118 ; 16,69$.

\section{H}

Hampers, standard :

Federal law (1928), 22, $13 ; 23,53 ; 23,65$.

resolution, 19,168 .

Handbook, National Bureau of Standards publications :

37 -resolution adopting, 33, 173.

45-resolution adopting, 36, 113.

Hassler, Ferdinand Rudolph, memorial, 33, 137.

Hay, sale, 18, 72.

Heavy-capacity, heavy-duty, scales. See Scales, large-capacity.

Highway planning survey, use of vehicle scales, $27,87$.

History of the standard weights and measures of the United States, 1, 6.

Holbrook, Fay Stanley, in memoriam, 30, 1.

memorial tablet, 31, 1 .

resolution, 30,61 .

Horological Institute of America, certification of watchmakers, 27, 66.

Hose, evaporation of gasoline from, 15, 111.

Hub odometers, 22, 119.

specifications and tolerances, 23,$43 ; 24,140$.

Ice :

scoring machines, $20,22$.

shortages in sales, 12,77 .

$984849-52-2$ 
Ice cream :

cartons, 22, 24. resolution, 23,144 .

method of sale, 18,$115 ; 32,88 ; 33,73 ; 36,35$. report of special committee, $19,146$. resolution, 20, 131.

molds, 22, 24. resolution, 23, 144 . on sticks, 36,97 .

regulation, in Wisconsin, $18,137$.

sale by weight:

viewpoint of manufacturer, 18, 122.

viewpoint of retailer, 18,133 .

viewpoint of weights and measures official, 18, 115.

standardization of cans, brick molds, and cartons, 22, 24 . resolution, 23, 144 .

work of Joint Committee on Definitions and Standards, 18, 135.

Ices, on sticks, $36,97$.

Identification by precision methods of comparison and measurement, 22, 49 .

Inch (United States), standardization, 28, 2.

Industrial weighing, 33, 107.

Industry :

development, 21, 99.

weighing apparatus, 11,$51 ; 19,120$.

Insignia, National Conference, 30, $167 ; 31,52 ; 31,139 ; 31,161$.

Installation and maintenance of-

large-capacity scales, 26,$38 ; 30,45$.

railway track scales, 11,73 .

International Bureau of weights and measures, 17, 81 .

Interpretation, uniformity of, 34, 90.

Interstate-

commerce, Federal laws in relation to short weight in, 19,$160 ; 19,166$.

shipments, coordination between departments in relation to, 29,9.

status of packages, 17,47 .

trucking of coal, 31,140 .

Investigation by National Bureau of Standards on-

filling of mill and cream bottles, 16, 43 .

scales :

mine, 12,$161 ; 13,182 ; 14,57$.

railway track, 10,$82 ; 12,64 ; 13,182 ; 18,34$.

vehicle, reports on, 26,$69 ; 27,45 ; 27,46 ; 28,75 ; 28,81 ; 29,57 ; 30,35$;

31,$61 ; 31,145$.

transmission drive for taximeters, 21, 21.

weights and measures, reports on, 5,$101 ; 6,41$.

Itinerant scale mechanic, 24, 154.

\section{$\mathbf{J}-\mathbf{K}$}

Jewelers' scales, 9, 39.

Jewelry, fraudulent marking, 17, 140.

$\mathrm{L}$

Labeling and certification plan in connection with Federal specifications, 25, 42.

Labeling:

electric light bulbs, 28, 13.

resolution, 27,110 .

meat products, wholesale, $35,148$.

prepackaged merchandise, 35,91 .

Large-capacity meters. See Meters, large-capacity.

Large-capacity scales. See Scales : large-capacity; platform; rehicle.

Latin-American countries, weights and measures conditions in, 12, 135.

Laws:

Model State. See Model State Law on Weights and Measures.

Weights and measures, Maryland, 36, 31.

Leather-measuring devices, testing, 15, 44 .

Legal status of rules and regulations as established by court decisions, 22, 132 .

Legislation, committee on, 29, 145.

reports, 30,$163 ; 31,110$. 
Length measures. See Linear measures.

Length standards, testing, 20, 28 .

Lerel and plumb conditions, demonstration of necessity for, 9,34 .

Licensing of scale repairmen and mechanics, 27,$62 ; 28,38$.

resolution on, $27,110$.

Limburger cheese, net weight, 31, 135 .

Linear measures, specifications, tolerances, and regulations, 8,$210 ; 9,57 ; 9$, $68 ; 10,193 ; 11$, App. 1,$4 ; 17,127 ; 21,148 ; 24,91$.

Liquefied petroleum gases, 30,48 .

dispensing equipment, retail, 36, 22.

distribution, 33,86 .

instruments for commercial measurement, 30, 62 .

measurement problems of distribution industry, 30, 65 .

methods of sale, 35, 128 .

physical properties, 30,48 .

supervision over sales, 34, 36 .

testing, 34, 28.

testing dispensing systems for, by grarimetric method, $31,21$.

units of measurement, 34, 22.

weights and measures regulation, 30,$71 ; 31,21$.

Liquid capacity measures :

nonstandard sizes, 24, $137 ; 27,103$.

specifications and tolerances, 8,$211 ; 9,58 ; 9,68 ; 10,195 ; 11,130 ; 11$, App. 1 , $3 ; 21,149 ; 22,120 ; 25,59$.

Testing of, 8, 181.

Liquid-measuring devices, 11, 57 ; 11, App. 2 ; 12, 169 ; 13, 59 ; 15, 111 ; 20, 95 ; 24, 138.

air releases on, 23,105 .

conversion, 34,45 .

price signs, $32,107$.

servicing, testing, and repair, 30, 121.

specifications, tolerances, and regulations, 8,$211 ; 10,196 ; 11$, App. 1,10 ;

12,$184 ; 12,223 ; 13,64 ; 13,83 ; 13,127 ; 13,142 ; 13,193 ; 14,89 ; 14,93$;

14,$104 ; 14,116 ; 14,119 ; 14,123 ; 15,120 ; 17,133 ; 19,127 ; 20,102 ; 21$, $128 ; 22,70 ; 22,101 ; 23,123 ; 24,91 ; 24,140 ; 24,147 ; 25,82 ; 25,101 ; 26$, $100 ; 26,130 ; 27,103 ; 28,123 ; 29,64 ; 30,98 ; 31,104 ; 32,86 ; 33,96 ; 33,98$; 35,$83 ; 36,108$.

testing of, 14,$64 ; 15,111 ; 21,104 ; 22,79 ; 22,104 ; 30,121 ; 36,25 ; 36,108$.

rapor meters, 35 , 159.

visibility of indications, 31, 108.

Liquor, glasses for, $31,143$.

Lirestock, problems in weighing, 19, 40.

Load, distribution, among supports of scale platform, 7, 169 .

Local sealer of weights and measures, problems, 22,$62 ; 26,18$.

Log rules, 23, 128.

Losses of gasoline in storage and handling, 25,55 .

Iubricating oil :

bottles. See Bottles, lubricating-oil.

canned, drainage characteristics of dispensers, 26, 76 .

sealed cans for dispensing, 25,$65 ; 36,95$.

specifications and tolerances, 25,$103 ; 32,86$.

Maintenance and installation of-

lar'ge-capacity scales, 26,$38 ; 30,45$.

railway track scales, 11,73 .

Markets, public, supervision, 16,$53 ; 16,58$.

Marking:

capacity of range boilers, storage tanks, etc., resolution, 9, 123.

jewelry, 17, 140 .

net content of-

containers, resolution on, 4,$59 ; 7,144 ; 19,160$.

packages, 7,$107 ; 8,79 ; 13,122 ; 17,47 ; 19,121 ; 24,42 ; 24,158$.

net weight on wrapped meats, 12,$145 ; 14,45 ; 20,121$.

resolution, 11, 158.

toilet paper and paper towels, 11, 113.

resolution, 11, 182.

weights and measures, and weighing and measuring devices, 33, 156. 
Maryland, State of, new weights and measures law, 36, 31.

Mass standards, testing, 19, 103.

Master vehicle scales, local, $31,87$.

Measure-containers :

paper, 28,44 .

single-service :

development, $31,41$.

Measures :

specifications and tolerances, 29,$134 ; 30,97 ; 31,102$.

capacity :

dry :

abolition, resolution, 16,146 .

specifications and tolerances, 8,$212 ; 9,59 ; 9,79 ; 10,197 ; 11,137$; liquid: 11 , App. 1,$12 ; 24,91 ; 32,81$.

nonstandard sizes, 24,$137 ; 27,103$.

specifications and tolerances, 8,$211 ; 9,58 ; 9,68 ; 10,195 ; 11,130$; testing, 8,181 .

11, App. 1,$3 ; 21,149 ; 22,120 ; 25,59 ; 33,97$.

pharmaceutical, 23, 74.

linear, specifications, tolerances, and regulations for, 8,$210 ; 9,57 ; 9,68$;

10,$193 ; 11$, App. 1,$4 ; 17,127 ; 21,148 ; 24,91 ; 36,105$.

pharmaceutical, testing, 23,74 .

Measuring pumps. See Liquid-measuring devices.

Meat-packing industry, weighing in, 22, 56.

Meats and meat products, supervision over, under Federal Meat Inspection Act, 26,$132 ; 35,148 ; 36,88$.

Meats, wrapped:

marking of net weight, 12,$145 ; 14,45 ; 20,121 ; 35,148 ; 36,71 ; 36,88$.

resolution, 11, 158 .

plastic wrappings and casings, 36,94 .

shrinkage, 20, 121.

Measure-containers, 35, 162.

Mechanics and repairmen:

itinerant, 24, 154 .

licensing, 27,$62 ; 28,38$.

resolution, 27,110 .

Merit system for weights and measures officials, resolution, 26, 164 .

Meters:

electric, 10,$52 ; 21,54$.

gas, 8,$90 ; 21,54$.

gasoline. See also Liquid-measuring devices.

conversion, $34,45$.

price signs, 32, 107.

testing, 21,$104 ; 22,79 ; 22,104 ; 24,41$.

twin, 24, 138.

household fuel oil, testing, 26,$101 ; 27,24$.

hydrocarbon, 32, 71.

large-capacity :

air elimination, 31, 25.

research program, $29,45$.

testing equipments, 26,$110 ; 28,17 ; 34,38$.

testing, 24,$41 ; 26,110 ; 28,17$.

parking, 28, 21.

standard, resolution on calibration, 26, 161.

taxicab. See Taximeters.

utility, regulation, $26,145$.

vapor, 35, 159.

vehicle-tank, 26, $104 ; 26,106 ; 26,110 ; 28,17$.

air elimination, 26, 106.

testing, 23, 108; 24, $41 ; 26,104 ; 26,110 ; 28,17$.

water, 8,$118 ; 21,54$.

Methods of sale of commodities, 30,$130 ; 30,167$.

committee on, reports, 31,$118 ; 32,27 ; 33,41 ; 34,112 ; 35,122 ; 36,92$. 
Metric system, $9,2 \tau ; 11,183 ; 12,112$.

resolutions, 11,$178 ; 12,206 ; 12,210$.

Michigan, regulation of fruit crop in, 20, 133.

\section{Milk :}

concentrated, 36, 93.

machine measurement, 36,67 .

Milk and cream:

bottles. See Bottles, milk and cream.

paper containers, 27,$115 ; 33,154$.

wholesale sales, and Babcock test, 19, 13.

Mine scales, National Bureau of Standards investigation, 12, 161; 13, 182; 14, 57.

Model State Law on weights and measures, 2, 53; 3, 64; 3, 88; 3, 107; 6, 109 ; 6,$151 ; 8,225 ; 8,275 ; 10,109 ; 10,235 ; 14,72 ; 14,119 ; 14,131 ; 18,77 ; 18$, $152 ; 20,92 ; 21,77 ; 26,32 ; 26,92 ; 30,180 ; 32,113 ; 35,24 ; 36,58$.

Molds, brick, for ice cream, standardization, $22,24$.

resolution, 23, 144.

Motor-truck scales. See Vehicle scales.

Motor-rehicle loads, two-draft weighing, 28, 63.

\section{$\mathrm{N}$}

National Association of Scale Manufacturers, activities, 32, 63.

National Bureau of Standards-

investigation on-

filling of milk and cream bottles, 16, 43 .

scales: mine, 12,$161 ; 13,182 ; 14,57$.

railway track, 10,$82 ; 12,64 ; 13,182 ; 18,34$.

vehicle, reports, 26,$69 ; 27,45 ; 27,46 ; 28,75 ; 28,81 ; 29,57 ; 30,35$; 31,$61 ; 31,145$.

transmission drive for taximeters, 21, 21.

weights and measures, reports, 5, 101; 6, 41.

master railway track scale, installation, $21,44$.

National Conference on Weights and Measures, 35, 133.

National Defense, weights and measures cooperation, 31, 2.

National Scale Men's Association :

activities, 23,$136 ; 24,168 ; 25,88 ; 26,46 ; 27,71 ; 28,9 ; 29,30 ; 30,78 ; 31,18$; 32,$20 ; 33,105 ; 34,42 ; 35,28 ; 36,5$.

resolution, 23,$147 ; 24,173$.

bulletin on repair of large-capacity scales, 22,33 . resolution, 22,145 .

National unity in administration of weights and measures, 30, 6.

Nebraska decision on bread, 17, 51 .

Net-content marking of-

containers, resolutions, 4,$59 ; 7,144 ; 19,160$.

packages, 7,$107 ; 8,79 ; 13,122 ; 17,47 ; 19,121 ; 24,42 ; 24,158$.

Net weight:

amendment to Food and Drugs Act, enforcement, 9, 18; 12, 148.

of cotton bales, 23, 22 .

of limburger cheese, $31,135$.

of wrapped meats, 12,$145 ; 14,45 ; 20,121$. resolution, 11,158 .

sales by 13,$118 ; 16,69 ; 36,113$.

News Letter, Weights and Measures, 30,183 ; 32, 3 ; 32, 98.

Odometers, 22, 119.

specifications and tolerances, 23,$43 ; 24,140$.

Office of Weights and Measures, improving service of, 35, 154.

Oil, See Lubricating oil ; Fuel oil.

Ordnance Department, work, 12,99.

Organization of weights and measures departments, 8, 177; 10, $122 ; 15,75 ; 16,28$; 16,$34 ; 18,170 ; 22,29 ; 22,62 ; 26,18$. 


\section{P-Q}

Packages. See also Standardization of packaged goods, committee on. deception, 32, 11.

interstate status, 17,$47 ; 36,74$.

markings, 32,32 . net content, 7,$107 ; 8,79 ; 13,122 ; 17,47 ; 19,121 ; 24,42 ; 24,158$. short weight, 32, 11.

shrinkage on wheat products, 34,62 .

slack-filled and deceptive, 29, 9. resolutions, 13,$178 ; 14,111$. soap, quantity declarations, 34,79 . standardization, 28,$53 ; 29,79 ; 29,89 ; 31,113 ; 31,129 ; 34,19$. Federal bill regarding, 33,124 . resolutions, 12,$207 ; 13,175 ; 14,110 ; 27,11 ; 27,109 ; 28,138$.

systematized supervision over, 34, 103 .

Packing of farm products, irregular or diversified, 22, 53.

Paper-

container's for milk, 27, $115 ; 31,109$.

measure-containers, 28,44 .

towels and toilet paper, uniform marking, 11, 113. resolution, 11, 182 .

weights of, 35,139

Parallax, 30, 131.

rarking meters, 28, 21.

Pattern approval. See Approval of type of commercial apparatus.

Peddlers, regulation, 18, 121.

Periodicals on weights and measures, 21,$71 ; 30,183$.

Person-weighers, 22, $128 ; \mathbf{2 3}, \mathbf{1 2 6} ; \mathbf{2 4}, 106$.

specifications, tolerances, and regulations, 23,$148 ; 24,113 ; 24,179 ; 25,13$ : 25,$33 ; 25,49 ; 27,98 ; 28,123$.

Personnel, weights and measures, direction, $31,7$.

Petroleum gases, liquefied. See Liquefied petroleum gases.

Petroleum products and weights and measures, 25,62 .

Petroleum products measurement, 15,$53 ; 16,50 ; 19,57$.

Pharmaceutical weights and measures, testing, 23, 74.

Philippine Islands, weights and measures conditions, 10, 50.

Photographer, official, selection, 22, 12.

Piping design for vehicle tanks, $31,33$.

Plate-fulcrum railway track scales, 20,$11 ; 20,15$.

Platform overhang of vehicle scales, $31,92$.

Platform scales, 7, 146.

specifications, tolerances, and regulations, 8,$214 ; 9,59 ; 9,91 ; 10,156 ; 10,203$;

10,$222 ; 11,150 ; 11$, App. 1,$20 ; 17,131 ; 21,151 ; 22,71 ; 24,91 ; 25,88$; 26,$122 ; 26,125 ; 27,75 ; 27,90 ; 28,26 ; 28,115 ; 29,72 ; 29,133 ; 29,140$; 30,$110 ; 30,112 ; 31,105 ; 31,106 ; 31,129$.

testing and testing equipment, 15,$32 ; 18,54 ; 18,65 ; 19,40 ; 20,84 ; 21,40$; 21,$48 ; 22,75 ; 24,130 ; 25,110 ; 26,47 ; 26,64 ; 27,45 ; 27,46 ; 27,117$; 28,$19 ; 28,75 ; 28,81 ; 28,99,31,67$,

National Bureau of Standards reports, 26,$69 ; 27,45 ; 27,46 ; 28,75$; 28,$81 ; 29,57 ; 30,35 ; 31,61 ; 31,145$.

Plumb and level conditions, demonstration of necessity, 9, 34 .

Popcorn, 36, 96.

Postal scales, testing, 8,$261 ; 17,34 ; 18,171 ; 24,97$. resolution on, 17,138 .

Potatoes, sweet, measurement, 16, 63.

Poultry : retail market, 36,78 . wrapped, 36, 94.

Precisionglassware, manufacture, $\mathbf{3 1}, 54$. standards, manufacture, 15, 102.

Prepackaged merchandise. Also see Packages. transparent containers, 33, 141. perishable commodities, 35,$84 ; 36,71$.

Prescription scales, 9, 39.

specifications, tolerances, and regulations, 11, 154; 11, App. 1, 37; 22, 73; 26,$121 ; 27,95$. 
President of Conference, addresses, 1,$5 ; 2,5 ; 4,5 ; 5,7 ; 6,7 ; 7,15 ; 8,15 ; 9,12$; 10,$17 ; 11,16 ; 12,15 ; 13,13 ; 14,16 ; 16,16 ; 17,2 ; 18,1 ; 19,1 ; 20,32 ; 21,1$; 22,$1 ; 23,1 ; 24,1 ; 26,1 ; 27,1 ; 28,1 ; 29,1 ; 30,6 ; 31,13 ; 33,1 ; 34,1 ; 35,1 ; 36,1$. Pricing charts, resolution on, 35,$166 ; 36,112$.

Problems of local sealer of weights and measures, 22,$62 ; 26,18$.

Prosecutions, 14, 50; 17, 85; 19, 89.

Protection of highways by means of portable weighing devices, 15, 26.

Public markets, supervision, 16,$53 ; 16,58$.

Public officials, training, 26, 22.

Public relations;

mutual problems of weights and measures officials and American agriculture, $34,56$.

new weights and measures organization, 35, 107.

Publicity and educational activities. (See also Weights and measures education, committee ) , 9,$150 ; 11,45 ; 13,167 ; 14,21 ; 17,91 ; 19,86 ; 20,39 ; 20,67 ; 20,84$; 21,$62 ; 21,71 ; 27,69 ; 29,19 ; 30,100 ; 31,44 ; 31,165$.

resolution on, $12,206$.

Publicity, committee. See Weights and measures education, committee.

Puerto Rico, weights and measures conditions, 9,$138 ; 17,17$.

Pumps, measuring. See Liquid-measuring devices.

Q

Quantity declarations, packages of soap, 34, 79.

\section{$\mathrm{R}$}

Radio programs, weights and measures, 29,$19 ; 31,44 ; 31,165$.

Railway track scales. See Scales, railway track.

Ramp garage, gasoline meter installations, 22, 79 .

Range boilers, marked capacity, resolution, 9, 123.

Reconditioning rejected or trade-in scales, 22, 122 .

Records, system of keeping, 7,$90 ; 10,171$.

Regulations :

legal status, as established by court decisions, 22, 132.

study of promulgation, 25, 38 .

U. S., weights and measures, 36,85 .

Regulations for weighing and measuring devices (See also Specifications, tolerances, and regulations ), 24,$83 ; 24,91 ; 30,112 ; 36,20$.

Repair of large-capacity scales, 22, 33. resolution, 22, 145 .

Repairmen and mechanics :

bonding, 33, 130; 33, 179 .

itinerant, 24, 154 .

licensing, 27, $62 ; 28,38 ; 33,179$.

resolution, 27,110 .

model bill, 33, 130 .

regulation of, 33,$122 ; 34,19$.

Reports of-

committees. See entries as follors:

Assistance to the States, Committee.

Constitution and By-Laws, Committee.

Education, Weights and Measures, Committee.

Legislation Committee.

Methods of Sale of Commodities, Committee.

Resolutions.

Specifications and Tolerances, Committee.

Standardization of Packaged Goods, Committee.

Trading by Weight, Committee.

Uniform Regulations, Committee.

Uniformity in Weights and Measures Requirements, Committee.

Weights and Measures Education, Committee.

officials, annual, 23, 92.

Secretary of conference, 5,$12 ; 6,13 ; 7,16 ; 8,15 ; 9,15 ; 10,46 ; 11,83$;

12,$25 ; 13,18 ; 22,36$.

Reports, test;

livestock scales, 34, 54 .

standardization of forms, 34,76 . 
Resolutions on-

air eliminators, research, $26,161$.

alcoholic beverages, containers, 31,158 .

approval of type of commercial apparatus, 4,$58 ; 8,223 ; 12,205 ; 13,177$;

14,$109 ; 20,120$.

assistance to the States, $31,158$.

Austin, John H., 25, $23 ; 25,53$.

barrel, standard, 8, 223 .

baskets, standard, 19, 168.

bottles:

alcoholic beverage, 31,158 .

lubricating-oil, 19,$170 ; 23,144$.

milk, uniform requirements for, 15,$125 ; 17,138$.

bread, standard weight loaves, 13, 174; 19, 170.

budgetary procedure, $35,165$.

Burgess, George K., in memory, 25, 141.

canned foods, standardization, 27,$109 ; 28,137$.

carat, 8, 223.

cartons and molds for ice cream, 23, 144.

civil service for weights and measures officials, 8,223 ; 26, 164 .

clinical thermometer, 19, 168.

coal :

chemically treated, 23, 144.

standards of quality, 16, 149.

uniform ton for, 16,142 .

containers :

alcoholic beverage, 31,$158 ; 32,124$.

net-content marking, 4,$59 ; 7,144 ; 19,160$.

standardization, 19,$168 ; 27,109 ; 28,137$.

dry commodities, sale by weight, 8,$200 ; 10,189 ; 12,20513,177 ; 16,139$; $19,167$.

dry measures, abolition, 16, 146.

education of public, 12, 206 .

electric-light bulbs, labeling, 27, 110.

Executive committee, membership, 20, 134.

fee system for weights and measures inspection, 10,134 .

flour packages, decimal-weight, 12, 205.

food pricing charts, 35,$166 ; 36,112$.

"Food Topics," 33, 173.

hamper's, standard, 19, 168.

Handbook 37, adoption, 33, 173.

Handbook 45, adoption 36, 113.

Holbrook, Fay Stanley, in memoriam, 30, 61.

ice cream:

method of sale, 20,131 .

molds and cartons, 23, 144.

labeling of electric-light bulbs, 27, 110 .

licensing of scale mechanics and repairmen, 27, 110.

lubricating-oil bottles, 19, $170 ; 23,144$.

marking-

net-content of containers, 4,$59 ; 7,144 ; 19,160$.

net weight of wrapped meats, 11,158 .

range boilers, storage tanks, etc., $9,123$.

toilet paper and paper towels, 11, 182 .

merit system for weights and measures officials, 26, 164 .

meters, standard, calibration, 26, 161.

metric system, 11, 178; 12, 206; 12, 210 .

milk bottles, uniform requirements, 15,$125 ; 17,138$.

molds and cartons for ice cream, 23, 144.

National Scale Men's Association, 23, 147 ; 24, 173.

net-content marking of containers, 4,$59 ; 7,144 ; 19,160$.

net weight of wrapped meats, 11, 158.

packages:

slack-filled and deceptive, 13,$178 ; 14,111$.

standardization, 12,$207 ; 13,175 ; 14,110 ; 27,109 ; 27,110 ; 28,138$.

paper towels and toilet paper, uniform marking, 11, 182.

postal scales, testing, 17, 138 .

pricing charts, 35,$166 ; 36,112$. 
Resolutions on-Continued

Publicity, committee, 26, 164.

range boilers, marked capacity of, 9, 123.

repair of large-capacity scales, specifications, 22, 145.

rules of procedure for National Conference, 25, 142.

sale by weight, 8,$200 ; 10,189 ; 11,158 ; 12,205 ; 13,177 ; 16,139 ; 19,167$;

20, $131 ; 36,113$.

scale mechanics and repairmen, licensing, 27, 110.

scales:

postal, testing, 17, 138 .

small-capacity spring, specifications, 27, 110.

seal, place for, on scales, 24, 173.

Special Committee on Uniform Regulations, 34, 166.

spring scales, small-capacity, specifications, 27, 110.

standard-

barrel, 8, 223.

baskets and hampers, 19, 168 .

containers for fruits and regetables, 19, 168.

standard-weight bread loaves, 13, 174; 19, 170.

standardization of-

containel's, 19, $168 ; 27,109 ; 28,137$.

packages, 12,$207 ; 13,175 ; 14,110 ; 27,109 ; 27,110 ; 28,138$.

standards of quality for coal, 16, 149.

standards of weights and measures, proposed legislation on, 27, 109; 28, 137.

storage tanks, marked capacity, 9, 123.

Stratton, Samuel W. :

In memory, 25, 141.

life and work, 15,36 .

taximeters, transmission drive, 21, 160.

testing of postal scales, 17, 138 .

testing of railway track scales, 35,166 .

thermometers, clinical, 19, 168.

toilet paper and paper towels, uniform marking, 11, 182.

ton, 2,000-pound, 16, 142.

trading by weight, 31,$158 ; 32,124$.

transmission drice for taximeters, 21, 160.

type of commercial apparatus, approval, 4, 58; 8,$223 ; 12,205 ; 13,177$;

14,$109 ; 20,120$.

uniform laws, regulations, etc., among the States, 10, $186 ; 21,161$.

weighing devices, used, sale, 27,$110 ; 28,52$.

weight, sale of dry commodities by, 8,$200 ; 10,189 ; 12,205 ; 13,177 ; 16,139$;

$19,167$.

weight and measures correspondence course, 18, 182.

weights and measures school, 33, 172.

weights and measures standards, proposed legislation on, 27, 109; 28, 137. wrapped meats, marking of net weight on, 11,158 .

Retail commodities, sale by weight or measure, $29,16$.

Rewording and/or rearrangement of specifications, tolerances, and regulations, 9,$62 ; 9,113 ; 15,129 ; 25,107 ; 26,117 ; 26,127 ; 28,103$.

Roofing, 34, 123.

Rug cleaning, 35,$143 ; 36,97$.

Rules and regulations:

legal status, as established by court decisions, 22, 132.

study of promulgation, 25, 38 .

Rules of procedure for National Conference, resolution, 25, 142.

Sale by weight :

\section{S}

dry commodities, 8,$106 ; 8,109 ; 9,147 ; 10,109 ; 10,189 ; 11,88 ; 12,212 ; 13$, $185 ; 15,17 ; 16,82 ; 17,37 ; 19,59 ; 22,13$.

resolutions on, 8,$200 ; 10,189 ; 12,205 ; 13,177 ; 16,139 ; 19,167$.

elimination of sales by gross weight, 13,$118 ; 16,69$.

general, resolution, 12,$205 ; 19,16 \tau$.

ice cream, 18,$115 ; 19,146 ; 32,38 ; 33,73 ; 36,35$.

resolution, 20,131 .

$984849-52-3$ 
Sale by weight-Continued

meats, wrapped, 12,$145 ; 14,45 ; 20,121$.

resolution, 11, 158.

retail commodities, 29,16 .

sales by net weight, 13,$118 ; 16,69$.

Sale of commodities, methods. See Commodities, methods of sale.

Salesmanship in weights and measures field, 27, 699.

Scale mechanics and repairmen:

formal qualifications, 32, 20.

itinerant, 24, 154.

licensing, 27,$62 ; 28,38$.

resolution, 27,110 .

Scale-testing device, 21,$40 ; 22,75$.

Scales :

automatic-indicating, 10, 95 ; 12,73

large-capacity, tolerances, 14,$87 ; 15,34 ; 16,132 ; 22,72$

printed weight indications and remote weight indications, 30,19

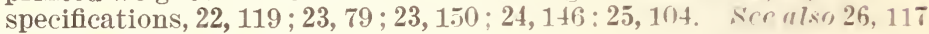

automatic-recording, $30,19$.

baggage, 18,$34 ; 18,46$.

belt conveyor, 36,53 .

butterfat test, 9, 39.

specifications, tolerances, and regulations. s, 200 : 9, (;2: 9, 111: 10, 21t; 11,$153 ; 11$, App. 1,$36 ; 17,132 ; 22,72$.

combination, for weighing motor trucks and railway freight cars, 32, 22:

computing, specifications, tolerances, and regulations, 8, 219:9, 1:1:9, 104:

10,$146 ; 10,214 ; 10,225: 11,100 ; 11$, App. $1,33: 17,131 ; 24,91: 24.146:$

$26,121$.

counter :

side beams on, 22,$117 ; 23,134$.

specifications, tolerances, and regulations, 8,$216 ; 8,265: 9,60: 9,4.5:$ 10,$156 ; 10,207 ; 10,223 ; 11,108: 11,150 ; 11$ App. 1. 2. : 21, 151; 22, $72 ; 24,91 ; 24,145 ; 25,106 ; 26,126 ; 33,100$.

cream-test and butterfat-test, 9,39 .

specifications, tolerances, and regulations. \&, 22:0): 9, (62: 9, 111: 10, 211;:

11,$153 ; 11$, App. 1,$36 ; 17,132 ; 22,72$.

creamery, maintenance, 9,$39 ; 17,11$.

customs service, 18, 104.

design and construction, 8,$123 ; 22,82: 27, \pi$.

dial, side beams and hidden weights, 25,134 .

distribution of load among platform supports. $7,169 \%$.

Federal specification AAA-S-121, 25, 23.

freight, 18,$34 ; 18,46$.

general specifications, tolerances, and regulations. 8,$213 ; 9,59: 9,(\Re) ; 9,99:$

9,$112 ; 10,139 ; 10,148 ; 10,151 ; 10,200: 10,220 ; 11,107 ; 11,137: 11$, App. 1 .

$15 ; 16,129 ; 17,130 ; 21,149 ; 23,122: 24,91 ; 24,145 ; 25,103 ; 26,118: 26$,

$124 ; 27,75 ; 27,90 ; 28,26 ; 28,115 ; 29,71: 30,1(18: 31,105 ; 32,91 ; 32,94$ : 33,$100 ; 36,109$.

grain, 12,$140 ; 22,65$.

heavy-duty. See Scales, large-capacity.

industrial, 11,$51 ; 19,120$.

jewelers', 9, 39 .

large-capacity: See also Platform scales; Vehicle scales.

Automatic-indicating, tolerances, 14,$87 ; 15,34 ; 16,132 ; 22,72$.

development, 24, 99 .

installation and maintenance, 26, 38 .

platform:

testing and testing equipment, $15,32: 18,54: 18,65: 19,40 ; 20,34$ : 21,$40 ; 21,48 ; 22,75 ; 24,130 ; 25,110: 26,47 ; 26,64: 27.45$ : 27,$46 ; 27,117 ; 28,19 ; 28,75 ; 28,81 ; 28,99 ; 31,67$.

National Bureau of Standards reports, 26. 69: $27,45: 27.40$ : repair, 22,33 , 28,$75 ; 28,81 ; 29,57 ; 30,35 ; 31,61 ; 31,145$.

resolution, 22,145 .

standardization, 29, 1.

test weights, 29,35 .

testing equipments, 26, 47 .

livestock, 18,$55 ; 19,40 ; 33,57 ; 34$, 50.

mine, National Bureau of Standards inrestigation, 12, 161: 13, 1s:2: 14, 57. 


\section{Scales-Continued}

notes, $\mathrm{s}, 135$.

person-Weighing, 22, 128; 23, 126; 24, 106.

specifications, tolerances, and regulations, 23, $148 ; 24,113 ; 24,179 ; 25$, $13 ; 25,33 ; 25,49 ; 27,98 ; 28,123$.

platform, 7,146 .

specifications, tolerances, and regulations, 8,$214 ; 9,59 ; 9,91 ; 10,156$;

10,$203 ; 10,222 ; 11,150 ; 11$, App. 1,$20 ; 17,131 ; 21,151 ; 22,71$; 24,$91 ; 25, S 8 ; 26,122 ; 26,125 ; 27,75 ; 27,90 ; 28,26 ; 28,115 ; 29,72$; 29,$133 ; 29,140 ; 30,110 ; 30,112 ; 31,105 ; 31,106 ; 31,129$.

testing of and testing equipment, 15,$32 ; 18,54 ; 18,65 ; 19,40 ; 20,84$; 21,$40 ; 21,48 ; 22$, $75 ; 24,130 ; 25,110 ; 26,47 ; 26,64 ; 27,45 ; 27$, $46 ; 27,117 ; 28,19 ; 28,75 ; 28,81 ; 28,99 ; 31,67$.

National Bureau of Standards reports, $26,69: 27,45 ; 27,46 ; 28,75$; 28,$81 ; 29,57 ; 30,35 ; 31,61 ; 31,145$.

postal, testing, 8,$261 ; 17,34 ; 18,171 ; 24,97$.

resolution, 17, 138 .

prepackaging, 36, $106 ; 36,110$.

prescription, 9, 39.

specifications, tolerances, and regulations, 11,$154 ; 11$, App. 1,$37 ; 22,73$;

26,$121 ; 27,95$.

railway track, 6,$67 ; 10,82 ; 10,86 ; 11,62 ; 11,73 ; 11,97 ; 12,64 ; 12,107$;

13,1 今 $; 18,34 ; 18,176 ; 20,11 ; 20,15 ; 26,124$.

developments in construction, 6,$67 ; 11,97 ; 12,107 ; 20,11 ; 20,15$.

freight weighing on, 18,34 .

installation and maintenance, 11, 73.

methods of adjusting, inspecting, and testing, 10, $86: 11,62$.

National Bureau of Standards-

investigation, $10, \$ 2 ; 12,64 ; 13,182 ; 18,34$.

master, installation, 21, 44 .

plate fulcrum, 20,$11 ; 20,15$.

report of special committee, 36,38 .

test cars, 18,176 .

tolerances. $29,7: 2$.

reconditioning of rejected, or trade-in, 22, 122.

repair of large-capacity, $22,33$.

resolution, 22, 14.

seal on, place for, resolution, 24, 173.

spring:

sperifications, tolerances, and regulations, 8, 217; 8, 219; 9, 60;9, 99,

10,1 tก: 10, 211: 10, 213: 11, 109: 11, 152: 11, App. 1, 30; 11, App. 1,$23 ; 17,131 ; 21,1.12 ; 24,91: 25,1116: 28,104 ; 31,105$.

resolution, 2i, 110 .

straight-face, specifications. tolerances, and regulations, 8,$219 ; 10,213$; 11, Appe. $33: 21,152 ; 26,124$.

stock, 18,$55 ; 19,40$.

suspension, lever type, sperifications, tolerances, and regulations, 10, 211;

11,$152 ; 11$, App. $1,29$.

testing device for large-capacity, 22,75 .

trade-in, reconditioning, $22,122$.

Vehicle:

A. R. F. A. specifications, 25,$88 ; 31,129$.

deflection of weighbridge member's, 31,129 .

end testing vel'sus corner testing, 26, 64.

master, local, 31,87 .

platform overhang; 31,92 .

selection, installation, and maintenance, 30,45 .

sperifications. tolerances. and regulations, 8,$214 ; 9,59 ; 9,91 ; 10,156$;

10,$203 ; 10,222 ; 11,150 ; 11$, App. 1,$20 ; 17,131 ; 21,151 ; 22,71$;

21,$91 ; 25,88 ; 26,122 ; 26,125 ; 27,75 ; 27,90 ; 28,26 ; 28,115 ; 29$,

$72 ; 29,133 ; 29,140: 30,110: 30,112 ; 31,105 ; 31,106 ; 31,129$.

testing and testing equipment, 15,$32 ; 18,54 ; 18,65 ; 20,84 ; 21,48$;

22,$75 ; 24,130: 25,110: 26,47 ; 26,64 ; 27,45 ; 27,46 ; 27,117 ; 28$,

$19 ; 28,75 ; 28,81 ; 28,99 ; 31,67$.

Nafional Bureau of Standards reports, 26,$69 ; 27,45 ; 27,46 ; 28$, $75 ; 28,81: 29,57 ; 30,35 ; 31,61 ; 31,145$.

use, in lighway planning survey, $27,87$. 


\section{Scales-Continued}

Wheel-load reighers, 15, 26; 24, 123.

specifications, tolerances, and regulations, 19, 156.

testing, 19, 151.

School, weights and measures :

novel form 30,32 .

resolution on, $33,173$.

suggested program, 33,5 .

Scoring machines for ice, $20,22$.

Scroll for National Bureau of Standards, 36, $6 ; 36,41$.

Sealing, methods, and seals, 8, 204; 27, 23.

$$
\text { resolution, } 24,173 .
$$

Seasonal aspects of weights and measures administration, 22, 62 .

Secretary of Commerce, addresses, 3,$55 ; 5,8 ; 6,111 ; 7,11 ; 8,12 ; 9,11 ; 10,13$; 11,$13 ; 12,119 ; 13,57 ; 14,79 ; 15,25 ; 16,76 ; 17,135 ; 18,74 ; 19,116 ; 22,47$; 26,$73 ; 27,84$.

Secretary of conference, reports, 5,$12 ; 6,13 ; 7,16 ; 8,15 ; 9,15 ; 10,46 ; 11,83$; 12,$25 ; 13,18 ; 22,36$.

Seeds, garden, 33,159 .

Selection, installation, and maintenance of vehicles scales, 30,45 .

Sensibility reciprocal, effect on, of packing pirots and bearings with grease, 30,88 .

Serialization of commercial apparatus. See Approval of type of commercial apparatus.

Service, sale, 16,$23 ; 33,155$.

Service station, duties of inspector in, 35,30 .

Shipping containers, standard, for fruits and regetables, 12, 89; 22, 13. resolution, 19, 168 .

Shrinkage of-

bread, $18,164$.

butter in prints, 16,60 .

soap, bar, 36,62 .

wheat products, packaged, 34, 62 .

wrapped meats, 20, 121.

Side beams, dial scales, and hidden weights, 25, 134 .

Side beams on counter scales, 22,$117 ; 23,134$.

Sight-glasses, function and operation, $30,15$.

Simplication and standardization, 16,94.

Single-service measure-containers. See Measure-contaners.

Soap :

bar, 34,$118 ; 36,62$.

packages, 34,79 .

Specifications:

AREA, for vehicle scales, 25, 88; 31, 129.

weighing machinery, impact on steel business, 34,96 .

Specifications and tolerances. committee on:

enlargement of, 10,$143 ; 15,121$.

leports, 7, 121; 8, 209; 9, 57:9, 89; 10, 137; 11, 127; 13, 64; 13, 83; 13, 127;

13,$142 ; 14,89 ; 14,93 ; 15,34 ; 15,79 ; 15,87 ; 15,120 ; 15,126 ; 16,89$;

16,$118 ; 16,129 ; 16,132 ; 16,151 ; 17,21 ; 17,100 ; 17,115 ; 17,126 ; 18,25$;

18,$97 ; 18,107 ; 18,163 ; 19,38 ; 19,127 ; 19,156 ; 20,71 ; 20,102 ; 20,121$;

21,$83 ; 21,128 ; 21,142 ; 21,147 ; 21,165 ; 22,68 ; 22,89 ; 22,101 ; 22,120$;

22,$121 ; 23,41 ; 23,43 ; 23,79 ; 23,122 ; 24,27 ; 24,83 ; 24,91 ; 24,113$;

24,$140 ; 24,147 ; 25,13 ; 25,33 ; 25,59 ; 25,70 ; 25,82 ; 25,99 ; 25,103$;

26,$117 ; 27,75 ; 27,90 ; 28,103 ; 29,64 ; 29,133 ; 30,97 ; 31,102 ; 32,72$; 33,$95 ; 34,40 ; 35,80 ; 36,103$.

Specifications, tolerances, and regulations:

complete revision, 34,141 .

specifications, tolerances, and regulations for-

automatic-indicating scales, 14,$87 ; 15,34 ; 16,132 ; 22,72 ; 22,119 ; 23,79$; 23,$150 ; 24,146 ; 25,104$.

See also 26, 117.

Babcock glassware, 19, 157.

balances, See Scales.

ber'ry baskets or boxes, 9,$59 ; 9,79 ; 9,90 ; 10,199$. 
Specifications, tolerances, and regulations for-Continued

bottles :

lubricating-oil, 20, $71 ; 20,137 ; 21,142 ; 22,70 ; 23,124 ; 24,27 ; 24,178$; $25,103$.

milk and cream, 9, 5S; 9, 73; 9, 113; 10, $140 ; 10,147 ; 10,196 ; 11,134$; 11 , App. 1,$11 ; 17,128 ; 22,121 ; 25,99 ; 26,128 ; 31,103$.

boxes, ber1 $y, 9,59 ; 9,79 ; 9,90 ; 10,199$.

bread, 14,$37 ; 14,84 ; 15,79 ; 15,91 ; 16,112 ; 17,51 ; 17,63 ; 17,126 ; 18,143$; 18,$154 ; 18,163$.

butter, 16,60 .

butterfat-test scales, 8,$220 ; 9,62 ; 9,111 ; 10,216 ; 11,153 ; 11$, App. 1, 36 ;

17,$132 ; 22,72$.

computing scales, 8,$219 ; 9,61 ; 9,104 ; 10,146 ; 10,214 ; 10,225 ; 11,109$;

11 , App. 1,$33 ; 17,131 ; 24,91 ; 24,146 ; 26,121$.

cordage-measuring derices, 35,$82 ; 36,105$.

counter scales, 8,$216 ; 8,265 ; 9,60 ; 9,95 ; 10,156 ; 10,207 ; 10,223 ; 11,108$;

11,$150 ; 11$, App. 1,$25 ; 21,151 ; 22,72 ; 24,91 ; 24,145 ; 25,106 ; 26,126$; cream-test scales, 8,$220 ; 9,62 ; 9,111 ; 10,216 ; 11,153 ; 11$, App. 1,$36 ; 17$, $132 ; 22,72$.

dry capacity measures, 8,$212 ; 9,59 ; 9,79 ; 10,197 ; 11,137 ; 11$, App. 1, 12 ; $24,91$.

fabric-measuring derices, 14,87 ; 15,$126 ; 16,118 ; 17,21 ; 21,149 ; 22,69 ; 35,82$. general, 35, 81.

glass graduates, 11,$132 ; 11$, App. 1,$7 ; 17,127 ; 20,121$.

grease-measuring devices, 21,$83 ; 21,165 ; 22,71 ; 22,89 ; 23,41 ; 23,63$; 24,$141 ; 31,104$.

heavy-capacity, heavy-duty. See Scales, large-capacity.

hub odometers, 23,$43 ; 24,140$.

identification of weighing and measuring devices, 32,73 .

large- capacity scales, 26,$122 ; 27,75 ; 27,90 ; 28,26 ; 28,115 ; 29,72 ; 29,133$; 29,$140 ; 30,110 ; 30,112 ; 31,105 ; 31,106$.

automatic-indicating (s'ee also automatic-indicating scales), 14, 87; 15, $34 ; 16,132 ; 22,72$.

linear measures, 8,$210 ; 9,57 ; 9,68 ; 10,193 ; 11$, App. 1,$4 ; 17,127 ; 21,148$; 24,$91 ; 36,105$.

liquid-capacity measures, 8,$211 ; 9,58 ; 9,68 ; 10,195 ; 11,130 ; 11$, App. 1, 3; 21,$149 ; 22,120 ; 25,99$.

liquid-measuring devices, 8,$211 ; 10,196 ; 11$, App. 1,$10 ; 12,184 ; 12,223$;

13,$64 ; 13,83 ; 13,127 ; 13,142 ; 13,193 ; 14,89 ; 14,93 ; 14,104 ; 14,116$;

14,$119 ; 14,123 ; 15,120 ; 17,133 ; 19,127 ; 20,102 ; 21,128 ; 22,70 ; 22$,

$101 ; 23,123 ; 24,91 ; 24,140 ; 24,147 ; 25,82 ; 25,101 ; 26,100 ; 26,130$;

27,$103 ; 28,123 ; 29,64 ; 30,98 ; 31,104 ; 32,86 ; 33,96 ; 33,98 ; 35,83 ; 36,108$.

lubricating-oil bottles, 20,$71 ; 20,137 ; 21,142 ; 22,70 ; 23,124 ; 24,27 ; 24$,

$178 ; 25,103 ; 32,86$.

measure containers :

prepackaged-ice-cream, 36, 103.

single serrice, 29,$134 ; 30,97 ; 31,102 ; 32,81$.

measures :

dry capacity, 8, 212; 9, 59; 9, $79 ; 10,197 ; 11,137 ; 11$, App. 1, $12 ; 24,91$.

linear, 8,$210 ; 9,57 ; 9,68 ; 10,193 ; 11$, App. 1,$4 ; 17,127 ; 21,148 ; 24,91$.

liquid capacity, 8,$211 ; 9,58 ; 9,68 ; 10,195 ; 11,130 ; 11$, App. 1,3 ; 21,$149 ; 22,120 ; 25,59 ; 33,97$.

measuring pumps. See Liquid-measuring devices.

milk and cream bottles, 9,$58 ; 9,73 ; 9,113 ; 10,140 ; 10,147 ; 10,196 ; 11,134$;

11 , App. 1,$11 ; 17,128 ; 22,121 ; 25,99 ; 26,128 ; 31,103 ; 32,83$.

odometers, 23,$43 ; 24,140$.

person weighers, 23,$148 ; 24,113 ; 24,179 ; 25,13 ; 25,33 ; 25,49 ; 27,98$; $28,123$.

platform scales, 8,$214 ; 9,59 ; 9,91 ; 10,156 ; 10,203 ; 10,222 ; 11,150 ; 11$,

App. 1,$20 ; 17,131 ; 21,151 ; 22,71 ; 24,91 ; 25,88 ; 26,122 ; 26,125 ; 27,75$;

27,$90 ; 28,26 ; 28,115 ; 29,72 ; 29,133 ; 29,140 ; 30,110 ; 30,112 ; 31,105$;

31,$106 ; 31,129$.

prescription scales, 11,$154 ; 11$, App. 1,37 ; 22, 73 ; 26, 121 ; 27, 95 .

pumps, measuring. See Liquid-measuring devices.

railway track scales, 29,72 . 
Specifications, tolerances, and regulations for-Continued

rewording and/or rearrangement, 9,$62 ; 9,113 ; 15,129 ; 25,107 ; 26,117$; 26,$127 ; 28,103$.

scales :

automatic-indicating, 14,$87 ; 15,34 ; 16,132 ; 22,72 ; 22,119 ; 23,79$; 23,$150 ; 24,146 ; 25,104 ; 35,83$. See also $26,117$.

butterfat-test, 8,$220 ; 9,62 ; 9,111 ; 10,216 ; 11,153 ; 11$, App. 1, 36; 17,$132 ; 22,72$.

computing, 8,$219 ; 9,61 ; 9,104 ; 10,146 ; 10,214 ; 10,225 ; 11,109 ; 11$, App. 1,$33 ; 17,131 ; 24,91 ; 24,146 ; 26,121$.

counter, 8,$216 ; 8,265 ; 9,60 ; 9,95 ; 10,156 ; 10,207 ; 10,223 ; 11,108$; 11,$150 ; 11$, App. 1, 25; 21, 151; 22, 72; 24, $91 ; 24,145 ; 25,106 ; 26,126$. cream-test and butterfat, 8,$220 ; 9,62 ; 9,111 ; 10,216 ; 11,153 ; 11$, App. 1,$36 ; 17,132 ; 22,72$.

general, 8,$213 ; 9,59 ; 9,90 ; 9,99 ; 9,112 ; 10,139 ; 10,148 ; 10,151$; 10,$200 ; 10,220 ; 11,107 ; 11,137 ; 11$, Аpp. 1,$15 ; 16,129 ; 17,130$; 21,$149 ; 23,122 ; 24,91 ; 24,145 ; 25,103 ; 26,118 ; 26,124 ; 27,75 ; 27,90$; 28,$26 ; 28,115 ; 29,71 ; 30,108 ; 31,105 ; 32,91 ; 32,94 ; 33100 ; 36,109$. large-capacity automatic-indicating (See also automatic-indicating), 14, $87 ; 15,34 ; 16,132 ; 22,72$.

livestock, 33, 100 .

person-weighing, 23,$148 ; 24,113 ; 24,179 ; 25,13 ; 25,33 ; 25,49 ; 27,98$; $28,123$.

platform, 8,$214 ; 9,59 ; 9,91 ; 10,156 ; 10,203 ; 10,222 ; 11,150 ; 11$, App. 1,$20 ; 17,131 ; 21,151 ; 22,71 ; 24,91 ; 25,88 ; 26,122 ; 26,125$; 27,$75 ; 27,90 ; 28,26 ; 28,115 ; 29,72 ; 29,133 ; 29,140 ; 30,110 ; 30,112$; 31,$105 ; 31,106 ; 31,129$.

prescription, 11, 154; 11, App. 1, 37 ; 22, 73; 26, $121 ; 27,95$.

railway track, $29,72$.

spring, 8,$217 ; 8,219 ; 9,60 ; 9,99 ; 10,140 ; 10,211 ; 10,213 ; 11,109 ; 11$, $152 ; 11$, App. 1,$30 ; 11$, App. 1,$33 ; 17,131 ; 21,152 ; 24,91 ; 25,106$; 28,$104 ; 31,105 ; 32,92 ; 33,96$.

resolution, 27,110 .

straight-face, 8,$219 ; 10,213 ; 11$, App. 1,$33 ; 21,152 ; 26,124$.

suspension, lever type, 10, 211; 11, 152; 11, App. 1, 29.

vehicle, 8,$214 ; 9,59 ; 9,91 ; 10,156 ; 10,203 ; 10,222: 11,150 ; 11$ App. 1,$20 ; 17,131 ; 21,151 ; 22,71 ; 24,91 ; 25,88 ; 26,122 ; 26,125 ; 27$, $75 ; 27,90 ; 28,26 ; 28,115 ; 29,72 ; 29,133 ; 29,140 ; 30,110 ; 30,112$; 31,$105 ; 31,106 ; 31,129$.

wheel-load weighers, 19,56 .

single-service measure-containers. See Measure-container's.

spring scales, 8,$217 ; 8,219 ; 9,60 ; 9,99 ; 10,140 ; 10,211 ; 10,213 ; 11,109$;

11,$152 ; 11$, App. 1,$30 ; 11$, App. 1,$33 ; 17,131 ; 21,152 ; 24,91 ; 25,106$;

$28,104: 31,105: 33,102$.

resolution, 27,110 .

straight-face spring scales, 8,$219 ; 10,213 ; 11$, App. 1, 33; 21, 152; 26, 124. suspension scales, lever type, 10, $211 ; 11,152 ; 11$, App. $1,29$.

tanks, vehicle, $14,88: 16,89 ; 16,151 ; 17,100 ; 17,115: 18,25 ; 21,149 ; 22,71$;

25,$70 ; 25,76 ; 26,104 ; 27,98 ; 28,106 ; 29,65 ; 29,129 ; 30,107$.

taximeters, 18,$97 ; 18,107 ; 19,38 ; 22,70 ; 24,91$.

rehicle scales, $8,214: 9,59 ; 9,91 ; 10,156: 10,203: 10,222 ; 11,150 ; 11$, App. 1,$20 ; 17,131 ; 21,151 ; 22,71 ; 24,91 ; 25,88 ; 26,122 ; 26,125 ; 27,75 ; 27$, $90 ; 28,26: 28,115 ; 29,72 ; 29,133 ; 29,140 ; 30,110 ; 30,112 ; 31,105 ; 31$, $106 ; 31,129 ; 32,94 ; 32,95 ; 33,103$.

rehicle tanks, 14,$88 ; 16,89 ; 16,151 ; 17,100 ; 17,115 ; 18,25 ; 21,149 ; 22,71$; 25,$70 ; 25,76 ; 26,104: 27,98 ; 28,106: 29,65 ; 29,129 ; 30,107$.

weighers, wheel-load, 19, 156.

weighing and measuring devices, 24,$83 ; 24,91 ; 30,112$.

weights, 8,$220 ; 9,62 ; 9,112 ; 10,216 ; 11,155 ; 11$, App. 1,$41 ; 17,132 ; 27,96$;

30,$110 ; 36,109$.

wheel-load weighers, 19,$156 ; 35,84$.

Spring scales, specifications, tolerances, and regulations, 8,$217 ; 8,219 ; 9,60 ; 9$, $99 ; 10,140 ; 10,211 ; 10,213 ; 11,109 ; 11,152 ; 11$, App. 1,$30 ; 11$, App. 1, 33; 17,$131 ; 21,152 ; 24,91 ; 25,106 ; 28,104 ; 31,105$.

resolution, 27,110 .

straight-face, specifications, tolerances, and regulations, 8,$219 ; 10,213 ; 11$, App. 1,$32 ; 21,152 ; 26,164$. 
SR, effect on, of packing pivots and bearings with grease, 30,88 .

Standard: (See also Standards)

barrel :

law, 9, $53 ; 9,56 ; 10,176$.

resolution, 8,223 .

baskets and hampers, resolution, 19, 168.

container act, Federal, of $1928,22,13 ; 23,53 ; 23,65$.

container legislation, Federal, consolidation and amendment, 24, 44; 25, 107 ; $30,8$.

container's for fruits and regetables, 12,$89 ; 22,13 ; 23,53 ; 23,65$. resolution, $19,168$.

meter's, resolution on calibration, 26, 161.

Standard-weight bread. See Bread.

standardization and simplification, 16, 94.

Standardization of-

bread weights. See Bread, standard weight, legislation.

containers, 6,$46 ; 6,134 ; 12,89 ; 13,122 ; 13,189 ; 27,35$. resolutions, 19,$168 ; 27,109 ; 28,137$.

containers for canned foods, 27,35 . resolutions on, 27,$109 ; 28,137$.

cotton bales, 23, 22.

ice-cream cans, brick molds, and cartons, 22, 24. resolution, 23, 144.

inch (United States), 28, 2.

large-capacity scales, $29,1$.

packaged goods, committee reports, 29,$79 ; 29,125 ; 30,145 ; 32,96$.

packages. See also Standardization of packaged goods, committee, 28, 53;

29,$79 ; 29,89 ; 31,113 ; 31,129$. resolutions, 12,$207 ; 13,175 ; 14,110 ; 27,109 ; 27,110 ; 28,138$.

Standards :

capacity, testing, 8,$181 ; 34,75$.

commercial, 21, 66.

corrections, 30, 114.

length, testing, $20,28$.

manufacture, 15,$102 ; 31,54$.

mass, testing, 19,$103 ; 36,42$.

of weights and measures, proposed legislation, $27,1$. resolutions, 27,$109 ; 28,137$.

precision, manufacture, 15,102 .

quality, for coal, resolution, 16, 149.

State, calibration of, 33,166 .

State primary, care of, $\mathbf{3 4 , 1 3 2}$.

United States, history of, 1, 6 .

volumetric, calibration of, 31, 142 .

Standing committees :

standardization of membership, 34, 4 .

number of, 34, 4 .

Stock scales, 18,$55 ; 19,40$.

Storage tanks:

fuel oil, testing, 19, 22.

resolution on marked capacity, 9, 123.

Straight-face spring scales, specifications, tolerances, and regulations, 8, 219 ; 10,$213 ; 11$ App. 1,$33 ; 21,152 ; 26,124$.

Strain load tests, $\mathbf{3 5}, \mathbf{1 5 6 .}$

Stratton, Samuel W.:

presentation of resolutions and medallion to, 17, 108 .

resolutions:

in memory, 25, 141.

life and work, 15,36 .

Sugar industry, weights, 20, 35.

Supervision of -

meats and meat products, Federal meat inspection act, 26, 132.

post office scales, 24,97 .

public markets, 16,$53 ; 16,58$.

Supervisional activities, 12,$57 ; 14,50 ; 16,53 ; 16,58 ; 17,85 ; 17,111 ; 18,44$; 19,$26 ; 19,89 ; 21,93 ; 23,86$.

suppression of fraudulent practices, 23,86 . 
Surrey, weights and measures, by Department of Agriculture, 27, 16; 28, 28; 29,48 .

Suspension scales, lever type, specifications, tolerances, and regulations, 10, 211; 11,$152 ; 11$, App. 1, 29.

Sweetpotatoes, measurement, 16, 63.

\section{$\mathrm{T}$}

Tank cars, calibration of, 35,145 .

Tanks:

fuel-oil storage, testing, 19, 22.

storage, marking, resolution, 9, 123.

rehicle, $15,53$.

meters for-

air elimination, 26, 106

testing, 23,$108 ; 24,41 ; 26,104 ; 26,110 ; 28,17$.

piping design, $31,33$.

specifications, tolerances, and regulations, 14,$88 ; 16,89 ; 16,151 ; 17$, $100 ; 17,115 ; 18,25 ; 21,149 ; 22,71 ; 25,70 ; 25,76 ; 26,104 ; 27,98$ : 28,$106 ; 29,65 ; 29,129 ; 30,107$.

testing equipments, $26,110$.

testing, 17,$94 ; 19,57 ; 23,112 ; 26,104 ; 26,110$.

Taximeters : valves for, 26,98 .

specifications, tolerances, and regulations, 18,$97 ; 18,107 ; 19,38 ; 22,70$ : $24,91$.

test and inspection, 12,$85 ; 17,117 ; 17,121 ; 18,78 ; 19,31$.

transmission drive, 19,$31 ; 20,80$.

National Bureau of Standards investigation, 21, 21.

resolution, 21, 160.

Temperature-

as factor in measurement of gasoline, 16,50 .

of gasoline in underground storage, 25,54 .

Terminal weighing of grain, 22, 65 .

Test cars, railway track scale testing, 18, 176.

Tests :

build-up, 35, 156 .

strain-load, 35, 156.

Test methods, 33, 59 .

Test weights of large denominations, 29, 35.

Testing derice for scales, 21,$40 ; 22,75$.

Testing equipment, stand-by service during repairs, 34, 68 .

Testing of-

beer barrels, 25, 113 .

bottles, milk and cream, $16,47$.

capacity measures, 8, 181.

pharmaceutical, 23,74 .

clinical thermometers, $19,48$.

container's for fruits and regetables, dimensional method, 28, 128.

electric meters, 10,$52 ; 21,54$.

fabric-measuring derices, 15, 93 .

fruit and vegetable containers by dimensional method, 28,128 .

fuel-oil storage tanks, 19, 22.

gas meters, 8,$90 ; 21,54$.

gasoline meters, 21,$104 ; 22,79: 22,104 ; 24,41$.

glassware, graduated, 9,$39 ; 23,74$.

grain scales, 12,140 .

grease-measuring derices, 23,16 .

jewelers' scales, 9, 39.

large-capacity platfor'm. S'ee scales, platform.

leather-measuring devices, 15, 44.

length standards, 20, 28.

liquefied petroleum gas dispensers, 31,$21 ; 35,53$.

liquid-capacity measures, 8,181 .

liquid-measuring devices, 14,$64 ; 15,111 ; 21,104 ; 22,79 ; 22,104 ; 30,121$; $36,25$.

livestock scales, 18,$55 ; 19,40$.

mass standards, $19,103$. 
Testing of-Continued

measures, capacity, 8, 181.

pharmaceutical, 23,74 .

measuring devices, resolution, 36, 103.

meters :

electric, 10,$52 ; 21,54$.

gas, 8,$90 ; 21,54$.

gasoline, 21,$104 ; 22,79 ; 22,104 ; 24,41$.

household, fuel oil, 26, 101; 27, 24.

large-capacity, 24,$41 ; 26,110 ; 28,17$.

taxicab, 12,$85 ; 17,117 ; 17,121 ; 18,78 ; 19,31$.

rehicle-tank, 23,$108 ; 24,41 ; 26,104 ; 26,110 ; 28,17$.

water, 8,$118 ; 21,54$.

milk and cream bottles, 16,47 .

pharmaceutical weights and measures, 23, 74 .

platform scales. See scales, platform.

postal scales, 8,$261 ; 17,34 ; 18,171 ; 24,97$.

resolution, 17,138 .

railway track scales, 10,$86 ; 11,62$.

scales:

grain, 12, 140.

jewelers', 9, 39 .

livestock, 18, 55 ; 19,$40 ; 35,111$.

platform, 15,$32 ; 18,54 ; 18,65 ; 19,40 ; 20,84 ; 21,40 ; 21,48 ; 22,75$;

24,$130 ; 25,110 ; 26,47 ; 26,64 ; 27,45 ; 27,46 ; 27,117 ; 28,19 ; 28,75$;

28,$81 ; 28,99 ; 31,67$.

by National Bureau of Standards, reports, 26,$69 ; 27,45 ; 27,46$;

28,$75 ; 28,81 ; 29,57 ; 30,35 ; 31,61 ; 31,145$.

postal, 8,$261 ; 17,34 ; 18,171 ; 24,97$.

resolution, 17,138

railway track, 10,$86 ; 11,62 ; 35$, 166.

resolution, 33, 173 .

stock, 18,$55 ; 19,40$.

vehicle, 15,$32 ; 18,54 ; 18,65 ; 20,84 ; 21,48 ; 22,75 ; 24,130 ; 25,110$;

26,$47 ; 26,64 ; 27,45 ; 27,46 ; 27,117 ; 28,19 ; 28,75 ; 28,81 ; 28,99$; 31,67 .

by National Bureau of Standards, reports, 26, $69 ; 27,45 ; 27,46$; 28,$75 ; 28,81 ; 29,57 ; 30,35 ; 31,61 ; 31,145$.

wheel-load weighers, $19,151$.

standards :

capacity, 8, 181.

length, 20, 28.

mass, $19,103$.

stock scales, 18,$55 ; 19,40$.

tanks :

fuel oil-storage, $19,22$.

vehicle, 17,$94 ; 19,57 ; 23,112 ; 26,104 ; 26,110$.

taximeters, 12,$85 ; 17,117: 17,121 ; 18,78 ; 19,31$.

thermometers, clinical, 19, 48.

rehicle scales. See scales, rehicle.

vehicle-tank meters, 23,$108 ; 24,41 ; 26,104 ; 26,110 ; 28,17$.

rehicle tanks, 17,$94 ; 19,57: 23,112 ; 26,104 ; 26,110$.

water meters, 8,$118 ; 21,54$.

weighers, wheel-load, 19, 151.

weights, standards and test weights, 19, 103.

pharmaceutical, 23,74 .

wheel-load weighers, 19, 151.

Textiles :

model law, 35, 24.

weights of, 35, 139.

Thermometers, clinical :

resolution on, 19,168 .

testing of, 19,48 .

Thread, 34, 113.

Tissue, association report, 32,54 .

Tobacco industry, weights, $20,35$.

$984849-52-4$ 
Toilet paper and paper towels, uniform marking, 11, 113. resolution, 11, 182.

Tolerances, 29, 12 .

and specifications. See Specifications, tolerances, and regulations.

commodity, 34, 137.

for large-denomination test weights, 29, 35.

neressity for, in excess, $18,110$.

Ton : on loads of coal, 26, 102 .

resolution on 2,000-pound, 16, 142 .

uniform, for coal, 15,$53 ; 15,124: 16,65$.

Track scales, railway track. See Scales, railway track.

Trade-in scales, reconditioning, 22, 122.

Trading by weight:

committee reports, 32,$25 ; 33,164 ; 34,75 ; 35,52 ; 36,7$.

resolution, 31,158 .

Training course, NBS, for office testing work, 33,$5 ; 34,135$.

Training of-

public officials, $26,22$.

weights and measures officials, 35, 105 .

Trading by weight, resolution, 31,158 .

Training of public officials, 26, 22 .

Transient vendors, regulation, 18, 121.

Transmission drive for taximeters, 19,31 ; 20, 80 ; 21, 21 ; resolution, 21, 160.

Twine and cordage, 16,$63 ; 16,71$.

Tro-draft weighing of motor-rehicle loads, 28,63 .

Trpe of commercial apparatus, approval. See Approval of type of commercial apparatus.

Undercover buying, 25, $138 ; 26,13$.

Uniform laws, regulations, etc., among the States, 21, 60. resolutions, 10,$186 ; 21,161$.

Uniform regulations, committee on : formation, 34, 166 .

reports, 35,$40 ; 36,20$.

Uniformity of weights and measures requirements, 28,$5 ; 30,81$.

committee, 21,$160 ; 21,161$. reports, 22,$116 ; 24,171$

for milk and cream bottles. 15,$30 ; 16,45 ; 16,64: 17,26 ; 30,168$. resolution, 15,$125 ; 17,138$.

Used weighing devices, sale of, resolutions, 27, $110: 28$, .22.

Utility meter's, regulation, 26, 145 .

Vegetables and fruits. See Fruits and regetables.

Vehicle scales:

A. R. E. A. specifications, 25,$88 ; 31,129$.

deflection of weighbridge member's, 31,129 .

end testing rersus corner testing, 26,64 .

four-section, 32,$21 ; 32,48 ; 34,47$.

local master, 31,87 .

platform overhang, 31,92 .

selection, installation, and maintenance, 30,45 .

specifications, tolerances, and regulations, 8,$214 ; 9,59: 9,91: 10,156 ; 10,203$;

10,$222 ; 11,150 ; 11$, App. $1,20: 17,131: 21,151: 22,71: 24,91: 25,88$;

26,$122 ; 26,125 ; 27,75 ; 27,90: 28,26 ; 28,115 ; 29,72 ; 29,133: 29,140$;

30,$110 ; 30,112 ; 31,105 ; 31,106 ; 31,129$.

testing of and testing equipment, 15,$32 ; 18,54 ; 18,65: 20,84: 21,48: 22,75$;

24,$130 ; 25,110 ; 26,47 ; 26,64 ; 27,45 ; 27,46 ; 27,117 ; 28,19: 28,75$;

28,$81 ; 28,99 ; 31,67$.

National Bureau of Standards. reports, $26,69: 27,45 ; 27,46: 28,75$; 28,$81 ; 29,57 ; 30,35 ; 31,61 ; 31,145$.

use, in highway planning survey. 27,87 .

weighbridges, $32,49$. 
Vehicle tanks, 15, 53.

calibration, 33,60 .

meters for-

air elimination 26,106 .

testing, 23,$108 ; 24,41 ; 26,104 ; 26,110 ; 28,17$.

piping design, 31, 33 .

specifications, tolerances, and regulations, 14,$88 ; 16,89 ; 16,151 ; 17,100$;

17,$115 ; 18,25 ; 21,149 ; 22,71 ; 25,70 ; 25,76 ; 26,104 ; 27,98 ; 28,106$;

29,$65 ; 29,129 ; 30,107$.

testing equipments, 26,110 .

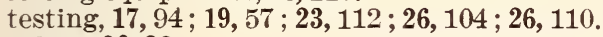

valves, 26,98 .

Vendors, transient, regulation, 18, 121.

Vice-Presidents, number of, 34, 4; 34, 95 .

Visibility of indications of-

counter scales, 22,117 .

liquid-measuring devices, 31, 108.

Volumeters, research program, 29,45 .

Watchmaker's, certification, 27,66 .

Water meters, testing, 8,$118 ; 21,54$.

Weighbeams, 31, 71 .

maintenance, $35,109$.

Weighbridges, rehicle scales, $32,49$.

Weighers, wheel-load:

protection of highways by, 15,$26 ; 24,123$.

specifications, tolerances, and regulations, 19, 156.

testing, 19, 151.

Weighing-

baggage and freight, 18,$34 ; 18,46$.

coal, 13,$182 ; 14,54 ; 16,123$.

coke, 11,159 .

cotton, 16,$26 ; 23,22$.

creamery, 9,$39 ; 17,11$.

freight, 18,$34 ; 18,46$.

grain, 12,$140 ; 22,65$.

in customs service, $18,104$.

in meat-packing industry, 22, 56 .

industrial, 11, 51; 19, 120.

large-capacity, factor's involved, 24, 147.

live stock, 18, $55 ; 19,40$.

motor-rehicle loads, two-draft, 28, 83.

multiple draft, 32, 23.

sugar, 20, 35 .

tobacco, 20,35 .

Weighing and measuring devices:

specifications, tolerances, and regulations, 24,$83 ; 24,91 ; 30,112$.

uniformity, 28,$5 ; 30,81$.

Weighing devices, used, sale of, resolution, 27,$110 ; 28,52$.

Weighmasters :

Chicago ordinance, 27, 11 .

Model Law, 35, $22 ; 36,62$.

supervision, 18, 12.

Weight : uniform legislation, 34, 20.

sale of dry commodities, 8,$106 ; 8,109 ; 9,147 ; 10,109 ; 10,189 ; 11,88$;

12,$212 ; 13,185 ; 15,17 ; 16,82 ; 17,37 ; 19,59 ; 22,13$.

resolutions, 8,$200 ; 10,189 ; 12,205 ; 13,177 ; 16,139 ; 19,167$.

sale of ice cream, 18,$115 ; 19,146$.

resolution, 20, 131 .

sales, general resolutions on, 12,$205 ; 19,167$.

sales by net weight, 13,$118 ; 16,69$.

Weights :

hidden, side beams, and dial scales, 25,134 .

pharmaceutical, testing, 23,74 .

specifications, tolerances, and regulations, 8,$220 ; 9,62 ; 9,112 ; 10,216$;

11,$155 ; 11$, App. 1,$41 ; 17,132 ; 27,96 ; 30,110 ; 36,109$.

standards and test weights, testing, 19, 103. 
Weights and measures-

administration :

board of adjustment, 25,95 .

conduct of departments, 8,$177 ; 10,122 ; 15,75 ; 16,28 ; 16,34 ; 18,170$; 22,$29 ; 22,62 ; 26,18$.

contests, 28,125 .

cooperation among officials, 21,$60 ; 22,29 ; 23,29$.

directing personnel, 31,7 .

extension, 24, 72 .

fee system, 10, $134 ; 12,87 ; 26,9$.

in Canada, 24, 61.

in Great Britain, 26, 83.

national unity, 30,6 .

observations, 22,$62 ; 23,48 ; 29,31$.

organization of departments, 8,$177 ; 10,122 ; 15,75 ; 16,28 ; 16,34$;

18,$170 ; 22,29 ; 22,62 ; 26,18$.

radio programs, 29,$19 ; 31,44 ; 31,165$.

school, weights and measures, novel form, 30, 32 .

State aids for local departments, 26, 27 ;

State-wide inspection, 26, 29.

survey by Department of Agriculture, 27, $16 ; 28,28 ; 29,48$.

undercover buying, 25,$138 ; 26,13$.

uniformity, 28, $5 ; 30,81$.

and petroleum products, 25,62 .

association :

responsibilities of the official, 35,94 .

Sisuthern Weights and Measures Association recommendation, 36, 106. cases:

digest, notes on, 21, 155 .

publication, 35, 120 .

chain store operation, aspects, 21, 79 .

conditions in various jurisdictions :

abroad, 2, 35; $17,81$.

Far West, 18, 69.

Latin-American countries, 12, 135.

New York City, 26, 50.

Philippine Islands, 10, 50.

Puerto Rico, 9, 138; 17, 17.

Richmond, Virginia, 18, 39.

South, 19, 73.

Virginia, 9, 146

contests, 28,125 .

correspondence course, resolution, 18, 182.

education, 32,49 .

committee, 26,$164 ; 29,145$.

reports, 30, $103 ; 31,45 ; 31,52 ; 32,51 ; 33,115 ; 34,71 ; 35,99 ; 36,47$.

federal aid, $\mathbf{3 4}, 105$.

inspection, financing, 27, 25.

international bureau, 17,81 .

laws, publication, 35,120 .

merit system for officials, 26,164 .

model State law, See Model State law on weights and measures.

News Letter, 30, 183.

officials' cooperation on National Defense, 31, 2.

organization :

problems involved, 35, 103.

public relations, $35,107$.

training, $35,105$.

periodicals, 21,$71 ; 30,183$.

problems of local sealer, 22,$62 ; 26,18$.

salesmanship, 27, 69.

school, novel form, 30,32 .

standards :

of the United States, history, 1, 6 .

proposed legislation, $27,1$.

resolutions, 27,$109 ; 28,137$.

supervision, consumers' interest, $27,16$.

survey by Department of Agriculture, 27,$16 ; 28,28 ; 29,48$. 
Wheel-load weighers :

protection of highways by, 15,$26 ; 24,123$.

specifications, tolerances, and regulations, 19,156 .

testing, 19, 151.

Wiping cloths, 34, 124; 35, 122.

Wood, sale, $12,61$.

Wrapped meats :

marking of net weight, 12,$145 ; 14,45 ; 20,121 ; 35,148 ; 36,71 ; 36,88$. resolution, 11, 158 .

shrinkage, 20,121 .

\section{Index by Names of Speakers}

\section{A}

Adams, O. C., The Great Atlantic \& Pacific Tea Co.: Weights and measures aspects of chain-store operation, 21, 79 .

Alexander, Hon. Joshua W., Secretary of Commerce: Address, 13, 57.

Algeo, J. S., Glass Container Association of America: Standardization of packages, $29,117$.

Allen, Kenneth C., Hobart Manufacturing Co.: Funclamentals of scale design, 27,55 .

Allen, L. J., Chief Inspector of Weights and Measures, City of Seattle, Wash.: Heary-capacity platform scales: Apparatus and methods for field tests, 18, 63.

Alsberg, C. L., United States Department of Agriculture: Enforcement of netweight amendment to the Food and Drugs Act, 9,$18 ; 12,148$.

Anderson, Herbert L., Federal Trade Commission: Work of the Federal Tiade Commission relating to weights and measures, $22,42$.

Andresen, Hon. A. H., Member of Congress, third district, Minnesota : Weights and measures prosecutions, $19,89$.

Austin, George F., Sealer of Weights and Measures, City of Detroit, Mich. :

Inspection and regulation of taximeter's, $12,85$.

Calibration of rehicle tanks in Detroit, Mich., 17, 94.

Heary-capacity platform scales: Apparatus and methods for field tests, $18,55$.

Transmission drive for taximeters, $19,31$.

Marked weight and shrinkage of hams and other wrapped meats 20,124 .

Austin, George F., Jr., Assistant Supervisor, Bureau of Weights and Measures, City of Detroit, Mich.: Inspection of weights and measures in pharmacies, 23,74 .

A ustin, George F., Jr., Supervising Inspector of Weights and Measures, City of Detroit, Mich. : Broken glass, 29, 31 .

\section{B}

Bacigalupo, A. W., Inspector of Weights and Measures, City of Memphis, Tenn.: Safeguarding the merchant, $18,44$.

Baker, C. A., Director, Bureau of Weights and Measures, State of Nery York: Frozen foods, 33, 17.

Baker, H. W., Ohmer Fare Register Co.: Transmission drive for taximeters, $20,83$.

Barnard, F. G., Sealer of Weights and Measures, City of Battle Creek, Mich.: Regulations for the weighing of coke, 11, 159 .

Farnard, H. E., American Institute of Baking:

Bread legislation from the standpoint of the baker, 14, 24.

Dirergence of bread-labeling requirements, 16,98 .

Application of scientific methods of law enforcement, 17, 63.

Proposed tolerances for loaves of bread, 18, 143.

Barnes, Miss Margaretta, Hutzler Bros., Baltimore, Md. : Department-store control of fabric measurement, 20,8 .

Barrett, H. F., Buffalo Meter Co.: Testing of gasoline meters in the factory, 21, 126.

Barron, R. F., Commissioner of Weights and Measures, State of Minnesota : Detecting shortages, securing evidence, and prosecuting offenders, 14,50 .

Sale of service on the basis of weight or measures, 16,23 . 
Batcheller, H. M., National Scale Men's Association: Activities of the National Scale Men's Association, 29, 30.

Isaucom, C. D., Superintendent of Weights and Measures, State of North Carolina :

A study of the promulgation of rules and regulations as applied to the various States of the Union, 25, 38.

Air elimination for vehicle-tank meters, $26,106$.

Vehicle-scale testing equipment, 28,$99 ; 31,69$.

The function and operation of sight-glasses, 30,15 .

Baumes, Harold L., League of Virginia Municipalities: The training of public officials, 26, 22 .

Bean, Howard S., Member, Joint ASME-API Committee for Volumetric Research : A tentative code on the installation, proving, and operation of positive displacement meters in liquid hydro-carbon service, $\mathbf{3 2}, \mathbf{7 1 .}$

Bean, Howard S., National Bureau of Standards :

Research program on volumeters of the ASME Special Research Committee on Fluid Meters, 29, 45.

Instruments for commercial measurement of liquefied petroleum gases, $\mathbf{3 0}$, 62.

Bearce, H. W.. National Bureau of Standards :

Glass graduates suitable for weights and measures officials, 9, 126.

Necessity for tolerances in excess as well as in deficiency, 18, 110.

The Annual Assay Commission, 25, 122.

Parking meters, 28, 21.

Corrections to standards, $30,114$.

Beaton, C. V., Shell Eastern Petroleum Products Inc.: Merchandising motor oil in sealed bottles, $24,20$.

Beck, T. C., Assistant Director, Marketing Division, State of Oklahoma: Problems involved in setting up a new weights and measures organization, 35, 103.

Behrmann, John F., National Association of Retail Grocers : Irregular or diversified packing of farm products, 21, 53 .

Bell, Raymond, United States Department of Agriculture: Wholesale sale of milk and cream, and the Babcock test, 19, 13.

Benjamin, Fred, Superintendent of Standards, State of Illinois: Operation of compulsory sales-by-weight statutes, 19, 59.

Berka, Frank, Deputy Sealer of Weights and Measures, City and County of Los Angeles, Calif.: Testing of gasoline meters in the field, 21,112.

Bernard, J. A., Commissioner of Weights and Measures, City of St. Louis, Missouri : Quantity declarations on packaged soap products, 34,79 .

Berry, Glenn I., Superintendent of Weights and Measures, County of Monmouth, N. J.: Seasonal aspects of county weights and measures administration, 22, 62.

Berryman, Nalls, Superintendent, Weights and Measures Division, State of Florida : Testing equipment for LPG measuring devices, 35, 62.

Blickles, J. F., Director. Bureau of Standard Weights and Measures, State of Pennsylvania : Liquefied petroleum gas, units of measurement, 34, 22.

Booth, John R., Sealer of Weights and Measures, City of Haverhill, Mass.: Portable testing equipments for large-capacity meters and vehicle-tank compartments, 26, 113.

Boughner, W. W., Supervisor, Division of Weights and Measures, State of Michigan: Care and use of primary State standards, 34, 135.

Bousfield, A., E. \& T. Fairbanks \& Co. :

Design and construction of scales, 8, 123.

Development in heavy track-scale construction, 11,97.

Heavs-capacity platform scales: Apparatus and methods for factory tests, 18,65 .

Development of industry, 21, 99 .

Development of large-capacity scales, 24, 99.

Boyer, I. R.. Fairbanks, Morse \& Co.: Plate-fulcrum principle in scale construction, 20, 11.

Boyle, James A., Sealer of Weights and Measures, Portland, Maine:

Supervision over domestic sales of fuel oil, 33, 161.

Brand, Hon. Charles, Member of Congress, Seventh District, Ohio :

Standard weight bread law, 17,$59 ; 19,83$.

Brandly, Dr. P. J., Poultry Pathologist, PMA, U. S. Department of Agriculture : U. S. regulations-weights and measures-poultry, 36,85 .

Brenneman, O. E., Chief Deputy Sealer, Bureau of Weights and Measures, State of Ohio: Not in the book, 28, 5 . 
Brenton, J. E., Chief, Bureau of Weights and Measures, State of California: Testing equipment for LPG measuring devices, 35, 53.

Bridge, M. A., Sealer of Weights and Measures, City of Columbus, Ohio: Use of auxiliary automobile tanks for checking gasoline deliveries, 19, 101.

Bridgeman, Oscar C., Research Associate at the National Bureau of Standards for the Society of Automotive Engineers : Dissolved air in gasoline, 22, 112.

Brigges, C. A., National Bureau of Standards :

Platform scales, 7, 146.

Car weighing, 7, 162.

Distribution of the load among the various points of support of a scale platform, 7, 169 .

Notes on scales, $8,135$.

Report of railroad track scale tests conducted by the Bureau of Standards, $10,82$.

Developments in specifications for railroad track scales, 12, 107.

Briggs, C. A., United States Department of Agriculture :

Heavy-capacity platform scales: Apparatus and methods for field tests, $18,55$.

Problems in livestock weighing, 19, 40.

Briggs, Lyman J., National Bureau of Standards :

President's address, 26, $1 ; 28,1 ; 31,13$.

A proposal for legislation to fix the standards of weights and measures in the United States, 27, 1.

Progress in the standardization of large-capacity scales, 29, 1.

Fay Stanley Holbrook-in memoriam, 30, 1.

National unity in the administration of weights and measures, 30,6 .

Resignation-32, 4.

Briggs, Lyman J., Director Emeritus, National Bureau of Standards :

Review of conference accomplishments, 32,7 .

Remarks, 34, 112.

Remarks, 35, 43.

Brooks, H. B., National Bureau of Standards : Testing of electric meters, 10, 52.

Brooks, P. C., Scale and Balance Manufacturer's' Association: Manufacturer's' attitude toward approval of type, 15, 72 .

Bruckart, William, Wester'n Newspaper Union : Dollar justice, 30, 100.

Bryant, G. Hodges, Chairman of the Board, Frozen Food Institute, Inc. : Frozen foods, 33, 29.

Bulson, Charles H., Sealer of Weights and Measures, County of Jefferson, N. Y. : Publicity as a means of increasing cooperation and efficiency, 17, 91.

Burgess, George K., National Bureau of Standards: President's address, 17, $2 ; 18,1 ; 19,1 ; 20,32 ; 21,1 ; 22,1 ; 23,1 ; 24,1$.

Bussey, W. S., Chief, Division of Weights and Measures, State of Texas :

The State aids in strengthening the local departments in Texas, 26, 27.

Licensing of scale mechanics, 28,38 .

Frozen foods, 33, 35.

Bussey, W. S., Assistant Chief, Office of Weights and Measures, National Bureau of Standards :

Care and use of State primary standards, 34, 132.

Improving the service of the National Bureau of Standards Office of Weights and Measures to officials and manufacturers, 35, 154.

\section{G}

Campbell, Carlos, National Canners Association: Standardization of packages, $29,85$.

Campbell, V. D., Deputy State Sealer, State of Ohio: The testing of wheel-load weighers, 35, 133.

Carey, L. C., United States Department of Agriculture:

The Byrd bill to consolidate Federal standard-container legislation, 25, 107.

Dimensional method of testing containers for fruits and vegetables, 28, 128.

Carpenter, George E., Supervisor, Division of Weights and Measures, State of Vermont: Vehicle tanks, 33, 70.

Carpenter, R. G., Meat Packaging Specialist, The Great Atlantic \& Pacific Tea Co. : Prepackaged perishable commodities-The marketer's viewpoint, 35,84 .

Cheyney, A. R., Post Office Department: Post Office Department program for checking and maintaining accuracy of scales in service, 18, 171.

Christie, S. H., Jr., Senior Inspector, Division of Weights and Measures, State of New Jersey : Strain-load tests and build-up tests, 35, 156 . 
Clark, W. G., Pure Oil Co. : Merchandising motor oil in sealed bottles, 24, 16.

Clark, Wm. D., Manager, Scale Department, Fairbanks, Morse \& Co., and Past President, NSIIA : A report from the National Scale Men's Association, 34, 42.

Cleveland, R. S., Testing and Specifications Section, National Bureau of Standards : Basis weights for paper and textiles, 35, 139.

Cluett, W. F., Chief Deputy Inspector of Weights and Measures, City of Chicago, Ill. :

Method of keeping sealer's' records, 7, 90 .

Proposed bread weight legislation in Illinois, 14, 30 .

Enforcing sales-by-weight legislation and the elimination of the dry measure, 15,17 .

Organization and conduct of city and county departments of weights and measures, 16,34 .

Method of test of taximeters in Chicago, 17, 117.

Supervision of weighmaster, 18, 12 .

Condon, Dr. E. U., Director, National Bureau of Standards :

Introduction, $32,6$.

President's address, 32,$6 ; 33,1 ; 34,1 ; 35,1 ; 36,1$.

National Bureau of Standards training course program, 33, 5 .

Considine, Douglas M., Chemical Engineer, Brown Instrument Co. :

Some aspects of industrial weighing, 33, 107.

Corwin, A. W., Sealer of Weights and Measures, County of Allegany, N. Y. :

Marked weight and shrinkage of hams and other wrapped meats, 20, 127.

A periodical on weights and measures by the sealers' association, 21, 71.

Log rules, 23, 128.

Cosby, Charles R., Labèl Manufacturer's National Association: Standardization of packages, 29, 121 .

Craig, James H., Deputy Secretary of Internal Affairs, State of Pennsylvania: Mandatory net-content marking of all commodities in package form, 19, 121.

Crawford, Howard E., Inspector of Weights and Measures, City of Jacksonville, Fla.:

The problems of local sealer in a State not having a State department of weights and measures, 26, 18.

Parallax, 30, 131.

Crittenden, E. C., National Bureau of Standards: Address, 25, 1.

Crittenden, E. C., Associate Director, National Bureau of Standards; Federal aid in weights and measures programs, 34, 108.

Crocker, D. A., Assistant Secretary, The Tissue Association, Inc.: A report from the Tissue Association, 32, 54 .

Cronin, P. D., United States Department of Agriculture: Federal laws in relation to short weight in interstate commerce, 19,$160 ; 19,166$.

Cruikshank, J. F., Fairbanks, Morse \& Co.: Automatic-indicating scales-printed weight indications and remote weight indications, 30, 19.

Cummings, John J., Inspector of Standards, State of Massachusetts :

Testing leather-measuring machines, 15, 44.

Testing of clinical thermometers, 19,52 .

Methods adopted for regulation of new types of devices, 20, 49.

Curry, T. C., Chief, Regulatory Division, Fruit and Vegetable Branch, U. S. Department of Agriculture: Regulatory responsibilities of the Fruit and Vegetable Branch, U. S. D. A., 33, 133.

\section{D}

Dalziel, William A., Deputy Sealer of Weights and Measures, State of Oregon: Progress of weights and measures in the far west, 18, 69.

Resulating the sale of eggs in Oregon, 19, 118.

Daniels, John M., Chief Inspector of Weights and Measures, Department of Agriculture, State of Michigan: Testing equipments for large-capacity scales, methods employed, and results obtained, 26, 59 .

Dartt, Carl E., Columbia Scale Co.: Use and abuse of person-weighing scales, $23,126$.

Davis, H. N., Deputy Commissioner of Weights and Measures, State of Vermont: Flood conditions as affecting, weights and measures officials in New England, 21, 153.

Testing rehicle-tank compartments by liquid meters, 23, 112. 
Davis, H. N., Supervisor, Division of Weights and Measures, State of Vermont: Vehicle-scale testing equipment, 31, 69.

Dawson, J. J., Inspector of Standards, State of Massachusetts :

Testing of clinical thermometers, 19, 52.

Promotion of interest in weights and measures supervision by essay contests among school children, 21, 62.

Dewey, Philip H., Secretary of Internal Affairs, State of Pennsylvania : Remarks, 24,61 .

Dickinson, H. C., National Bureau of Standards: Gasoline losses in storage and handling, 25, 55 .

Dickinson, Hon. John, Assistant Secretary of Commerce : Address, 25, 61.

Dietz, J. M., Superintendent of Weights and Measures, County of Union, New Jersey : Testing procedures for vehicle-tank compartments, 34, 126.

Diserio, Matthew J., Deputy Commissioner, Department of Public Markets, Weights, and Measures, City of New York, N. Y.: Testing equipment for largecapacity scales, methods employed, and results obtained, 26, 50.

Downer, J. H., Secretary, National Scale Men's Association: A report from the National Scale Men's Association. 36. 5.

Downing, F. P., Chief Inspector of Weights and Measures, State of Wisconsin: Creamery, prescription, and jewelers' weighing and measuring appliances, 9,39 .

Downing, F. P., United States Department of Agriculture: Movement toward obtaining standard shipping containers for marketing fresh fruits and vegetables, $12,89$.

Drake, Fred R., National Wholesale Grocers' Association: Metric system, 9, 27:

Draper, Hon. Ernest G., Acting Secretary of Commerce: Address, 26, 73.

Durgin, William A. National Bureau of Standards: Standardization and simplification,1 6, 94.

Egy, W. L., W. \& L. E. Gurley : Difficulties encountered by manufacturers of precision standards due to nonuniform requirements, 15, 102.

Ellingwood, Lloyd, Toledo Scale Co.: "Selection, Installation, and Maintenance of Vehicle Scales"-a sound-slide treatment of Form NBS 256, 30, 45.

Emery, J. Q., Superintendent of Weights and Measures, State of Wisconsin: Maintenance of accuracy of scales in creameries, 17, 11.

Emhardt, Edwin C., Supervisor, Bureau of Weights and Measures, County of Philadelphia, Pa.: A board of adjustment, 25, 95.

Engelhard, Charles H., Superintendent of Weights and Measures, County of Middlesex, N. J.: Vehicle-tank piping design, 31, 33.

Epright, A. W., Pennsylvania Railroad :

Railroad track scales, $6,67$.

Railroad supervision of baggage and freight scales, 18,46 .

Plate-fulcrum master scale installation at Altoona works of Pennsylvania Railroad, 20, 15.

Ernst, Morris L., Jewelers' Board of Trade, New York, N. Y.: Fraudulent marking of jewelry, 17,140 .

Essig, A., National Meter Co.: Testing of gasoline meters in the factory, 21, 119.

Estes, Howard R., Sealer of Weights and Measures, City of Flint, Mich.:

Temperature as a factor in the measurement of gasoline, 16, 50 .

Heavy-capacity platform scales: Apparatus and methods for field tests, $18,63$.

Bottles for the sale of lubricating oil, 19, 17 .

Evers, Clifford F., Technical Director, National Association of Frozen Food Packers ; Frozen foods, 33, 25.

Fairchild, I. J., National Bureau of Standards: Commercial standards, 21, 66. Ferner, R. Y., National Bureau of Standards: Testing of capacity measures, 8,181 .

Ferris, C. H., National Bottle Manufacturers' Association: Divergence of requirements affecting milk bottles, 15,30 .

Fetherston, Franklin R., Liquefied Petroleum Gas Association, Inc.: Measurement problems of the liquefied petroleum gas distribution industry, 30, 65 . 
Fischer, Louis A., National Bureau of Standards :

Secretary's report, 5,$12 ; 6,13 ; 7,16 ; 8,15 ; 9,15 ; 10,46 ; 11,83 ; 12,25$; $13,18$.

History of United States weights and measures, 1,6 .

Foreign weights and measures laws and regulations, 2, 35.

Mine scale work of the Bureau of Standards, 14, 57.

Fitzgerald, F. F., Can Manufacturers Institute, Inc.: Standardization of packages, 29,112 .

Flaherty, Thomas, Sealer of Weights and Measures, City and County of San Francisco, Calif.: Use of auxiliary automobile tanks for checking gasoline delireries, $19,99$.

Flurry, H. L., Chief, Division of Weights and Measures, State of Alabama :

Solving weights and measures problems in the South, 19, 73 .

Methods adopted for regulation of new types of devices, 20, 50 .

Foley, J. Harry, Superintendent of Weights and Measures, State of New Jersey:

Elimination of sales by gross weight, 16, 69 .

New Jersey sale-by-treight law, 17, 37.

Methods adopted for regulation of new types of devices, 20, 47.

Foster, William, Sealer of Weights and Measures, City of Springfield, Mass. :

Organization and conduct of city and county departments of weights and measures, $16,36$.

Testing of gasoline meters in the field, 21, 104.

Frisbie, W. S., United States Department of Agriculture :

Net-content marking of packages under Federal food and drugs act, 24, 158.

The weights and measures provisions of the Copeland bill to revise the Federal food and drugs act, 25, 119.

Weights and measures requirements of the Federal food, drug, and cosmetic act, 29,5 .

General regulations of the Federal food, drug, and cosmetic act, relative to net weight, 30,135 .

Friz, Nelson, Esso Standard Oil Co. and Member Joint ASME-API Petroleum P. D. Meter Committee, New York, N. Y.: Test procedures for liquid-measuring derices-retail, 36, 27.

Fullen, Robert L., Chief Sealer of Weights and Measures, City of Dallas, Tex.: Salesmanship in the weights and measures field, 27, 69.

Fuller, Charles M., Sealer of Weights and Measures, County of Los Angeles, Calif. :

Enforcement of bread legislation, including proper tolerances, 14, 37.

Organization and conduct of city and county departments of weights and measures, 16, 39.

Measurement of petroleum products, 19, 57 .

Devices for dispensing greases and similar products, 20, 70 .

Equipment for testing large-capacity meters for petroleum products, 24, 41.

Vehicle-scale testing equipment, 28, 96.

Weichts and measures regulation of liquefied petroleum gases, 30, 71 .

Testing liquefied petroleum gas meter systems by the gravimetric method, $31,21$.

Financing a weights and measures organization, 33, 145.

$\mathrm{LPG}$-Problems encountered in testing metered systems, 34, 28.

Fullmer, I. H., National Bureau of Standards: Gages and gaging, 24, 125.

G

Gast, Fred W., United States Treasury Department: Weighing in the customs serrice, 18, 104.

Gatewood, Lieut. Col. C. B., United States Army: Work of the Ordnance Department, 12, 99.

Gordon, B. B., Pennsylvania Railroad: Inspection and testing of track scales, 11,62 .

Gordon, E. D., National Bureau of Standards: Progress of track-scale investigation, 12,64 .

Gould, R. E., Horological Institute of America: Certification of watchmakers by the Horological Institute of America, 27, 66.

Greene, Edward L., National Better Business Bureau, Inc.: The business man and the weights and measures official, 21, 93.

Greene, F. M., Deputy Commissioner, Food and Drug Commission, State of Connecticut: Duties of an inspector in a retail food store, 35,36 . 
Griffith, C. P., S. F. Bowser \& Co., Inc. :

Testing of gasoline meter's in the factory, 21, 117.

Air elimination for large-capacity meters, $31,25$.

Griffith, C. P., Vice President in Charge of Engineering, Bowser, Inc. :

Meter type gasoline pumps, 33,79 .

Griffith, S. T., Chief, Division of Weights and Measures, City of Baltimore, Md.

Personal element in our work, 18, 170.

How the public is educated in Baltimore, 20, 84 .

Calibrating vehicle tanks by large-capacity measures, $23,115$.

The control of "bootleg" coal, 25, 129.

Paper measure-containers, 28, 44.

Hadlick, Paul E., American Petroleum Institute: Cooperation with weights and measures officials, 23, 29.

Hall, Thomas, National Association of Ice Cream Manufacturers: Methods of sale for ice cream, $19,148$.

Halsey, F. A., American Institute of Weights and Measures: Metric system, 12,112 .

Hammon, Frank L., Director, Bureau of Weights and Measures, State of Idaho: New rehicle-scale testing equipment of Idaho, $28,19$.

Hansen, Erling, Superintendent, Department of Weights and Measures, State of Minnesota : A program of livestock scale testing, 35, 111.

Hardwick, Hon. Thomas W., Chairman, Committee on Coinage, Weights, and Measures, House of Representatives : Address, 7, 54.

Harks, W. M., Vice President, Bowser, Inc., Fort Wayne, Ind. :

LPG dispensing equipment-retail, 36, 22.

Harrison, M. J. J., National Bureau of Standards: Mine scales and mine-scale inrestigation, $12,161$.

Harrison, M. J. J., National Scale Men's Association :

Standardization activities of the N. S. M. A., 23, 136.

End testing versus corner testing for motor-truck scales, 26, 64 .

Harrison, MI. J. J., Pennsylrania Railroad:

Factors involved in large-capacity weighing, $24,147$.

Tolerances, 29, 12.

Fay Stanley Holbrook-in memoriam, 30, 5.

Weighbeams, 31, 71 .

Harrison, M. J. J., American Railway Engineering Association: Motor-truck scales and National Scale Men's Association activities, 25, 88.

Harrison, M. J. J., Superrisor of Scales and Weighing, Pennsylvania Railroad: Weighbeam maintenance, 35, 109.

Hart, J. L., Secretary, Gloucester Fisheries Association : Frozen Fish, 33, 37.

Hartigan, Joseph, Commissioner, Mayor's Bureau of Weights and Measures, City of New York: Serialization of type, 9, 164.

Harvey, J. L., Director of Litigation, Federal Food and Drug Administration: Shrinkage on packaged wheat products, 34,62 .

Haskell, W. C., Superintendent of Weights, Measures, and Markets, District of of Columbia: Difference in the amount of a bushel of a commodity when sold by measure, $8,109$.

Hassler, Ferdinand Rudolph, M. D., M. P. H., Director, Bureau of Laboratories, Department of Health, State of Oklahoma: Ferdinand Rudolph Hassler, 1770 $1843,33,137$.

Hawkins, C. E., Sealer of Weights and Measures, City of Springfield, Mass.: Development of single-service measure-containers, $31,41$.

Hawkinson, C. F., National Scale Men's Association: N. S. M. A. Bulletin No. 1 , on repair of heavy-capacity scales, $22,33$.

Hayman, H. V., Assistant Sealer of Weights and Measures, City of Norfolk, Va. : Local "master" vehicle scales, 31, 90.

Heaslip, W. B., Supervising Inspector of Weights and Measures, City of Detroit, Mich.: Duties of an inspector in a service station, 35,30 .

Hedwall, F. H., Boston and Maine Railroad: Installation and maintenance of track scales, 11, 73.

Hem, H. O., Toledo Scale Co. :

Automatic scales, 12, 73.

Regulation of new types of devices, 20, 58 .

Activities of the National Scale Men's Association, 28, 9. 
Hem, H. W., Toledo Scale Co. :

A new scale-testing device, $21,40$.

Automatic-indicating scales-printed weight indications and remote weight indications, 30, 26.

Henrichson, W. T., Meter Inspector, Division of Weights and Measures, State of Texas: Supervision of gas, electric, and water meters in Texas, 21, 54 .

Henry, H. H., Commissioner of Weights and Measures, State of Vermont: Functions of a State sealer, 8,177 .

Hessee, Senior Chemist, Weights and Measures Division, State of North Carolina : Testing equipment for LPG measuring devices, 35, 65 .

Higbee, L. C., W. \& L. E. Gurley: Difficulties encountered by manufacturers of precision standards due to nonuniform requirements. $15,102$.

Hinds, Sherwood, St. Lotiis Pump \& Equipment Co: Regulation of new types of devices, 20,64 .

Holbrook, F. S., National Bureau of Standards :

State legislation, résumé, $7,18$.

Weights and measures of Puerto Rico, 9, 138.

Standard barrel law, 10, 176.

History of legislation in re approval of type, 15,66 .

Method of test in conformance with specification No. 8 for liquid-measuring devices, 15, 115.

Present status of negotiations toward obtaining uniform regulations for milk bottles, 16,45 .

Decision of the United States Supreme Court on Nebraska bread law, 17, 51 .

Practicability of proposed sale of commodities on basis of moisture-free ingredients, 18, 154.

Visible devices for indication of full delivery, and drainage period of liquidmeasuring devices, 20, 95 .

Report as Secretary of Conference-résumé of State legislation, 22, 36.

Drainage characteristics of lubricating-oil bottles, 24, 22 .

Present status of standard-weight bread legislation, 24, 162.

Newly installed motor-truck scales, 28, 88.

Holland, P. L., Chief Engineer, Public Service Commission, State of Maryland: The regulation of utility meters, 26, 145 .

Holmes, Edward H., United States Department of Agriculture: The use of vehicle scales in the highway planning survey, $27,87$.

Holmes, John, Swift \& Co.: Weighing in the meat-packing industry, 22, 56.

Holton, Elliott B., Assistant Superintendent of Weights and Measures, State of New Jersey : Supervision over the buying of old gold, 25, 36.

Holwell, Joseph J., Commissioner, Mayor's Bureau of Weights and Measures, City of New York, N. Y. :

Federal regulation of weighing and measuring devices, 12, 134.

Weights and measures education in the schools, $13,167$.

Relationship between weights and measures officials, merchants, and manufacturers, 15,75 .

Manner of sale of cordage, 16, 71.

Hoover, Hon. Herbert, Secretary of Commerce : Address, 14, 79; 15, 25; 16, 76 ; 17,$135 ; 18,74 ; 19,116$.

Hortigan, J. B., United States Department of Agriculture: Interstate status of package goods, 17,47 .

Horton, C. F., National Bureau of Standards :

Method of test and inspection of vehicle scales developed by the National Bureau of Standards, 28, 75.

Reminiscences, $31,145$.

Hosch, G. Carlton, Measuregraph Co. : Machine measurement for fabrics, 11, 117.

Hovey, V. F., National Association of Ice Cream Manufacturers: Shall ice cream be sold by weight? Viewpoint of the manufacturer, 18, 129.

Howard, H. E., Supervisor of Weights and Measures, City of Miami, Fla. : Pre packaged merchandise, informative labeling and enforcement procedures, 35, 91 .

Hubbard, Henry D., National Bureau of Standards: Graphical presentation of data in annual reports, 23,95 .

Hubbard, M. A., Supervisor of Weights and Measures, State of Virginia : Vehiclescale testing equipment, 31,70 .

Hunter, P. J., Chief Inspector, Bureau of Weights and Measures, County of Allegheny, Pa. : Local "master" vehicle scales, 31, 89. 
Intermann, E. A. G., Jr., New Jersey Retail Ice Cream and Candy Manufacturers' Association: Shall ice cream be sold by weight? Viewpoint of the retailer, 18, 133.

Irvine, T. L., Superintendent of Weights and Measures and Oil Inspection, City of Salt Lake City, Utah: Destination weighing of coal from the standpoint of the official, 14, 54 .

Jarrett, Howard S., Commissioner of Weights and Measures, State of West Virginia :

Scope and preparation of annual reports, $23,92$.

State requirements for net-content marking of packages other than food packages, 24,42 .

Jensen, Malcolm W., Sealer of Weights and Measures, City of Madison, Wisconsin: The retail poultry market, 36,78 .

Johnson, Charles G., Superintendent of Weights and Measures, State of California:

Proper publicity for a weights and measures department, 11, 45 .

Net weight, 13, 118.

Johnson, G. L., Director, Division of Weights and Measures, State of Kentucky : New weights and measures organization, public relations, 35, 107.

Jones, J. R., Commissioner of Agriculture, State of South Carolina: The responsibilities of the official to his weights and measures association, 35, 94 .

Johnson, Charles G., Superintendent of Weights and Measures, State of California:

Proper publicity for a weights and measures department, 11, 45.

Net weight, $13,118$.

Judson, L. V. National Bureau of Standards :

International Bureau of Weights and Measures and general impressions of weights and measures abroad, 17,81 .

Testing of standards of length, 20, 28.

\section{$\mathbf{K}$}

Kanzer, Barnett, Director, Bureau of Weights and Measures, State of New York: Vehicle-scale testing equipment, 28, 100.

Keene, A., United States Taximeter Corporation: Transmission drive for taximeters, 19,34 .

Kelly, Dennis, Sealer of Weights and Measures, City of Bridgeport, Conn.: Heavy-capacity platform scales: Apparatus and methods for field tests, 18,57.

Kennedy, J. Thomas, Director, Department of Weights, Measures, and Markets, District of Columbia :

Methods of sale of ice cream, 33, 73 .

Prepack meat counters, 36, 71 .

Kennedy, L. L., Superintendent of Construction and Maintenance, Standard Oil Company of New Jersey; the distribution of LPG, 33, 86.

Kennedy, Ridgway, International Association of Ice Cream Manufacturers: Standardization of ice-cream cans, brick molds, and cartons, 22, 24.

Kerlin, W. A., County Sealer of Weights and Measures, Alameda County, California : Ice cream-sale by weight, 36,35 .

Kerr, Robert H., United States Department of Agriculture: Supervision over meats and meat products under the Federal Meat Inspection Act, 26, 132.

Klein, Hon. Julius, Assistant Secretary of Commerce : Address, 23, 57.

Klocker, C. L., Inspector of Weights and Measures, State of Connecticut : Vehicle-scale testing equipment, 28,$94 ; 31,67$.

Retail sale of commodities by weight or measure, 29,16 .

Klueter, Harry, Assistant Dairy and Food Commissioner, State of Wisconsin: Regulation of sale of ice cream in Wisconsin, 18, 137.

Kremer, C. J., Retail Bakers' Association of America : Bread-weight legislation and the retail baker, 16,104 .

Kyrk, Hazel, American Home Economics Association: Standardization of packages, 29, 85. 
$\mathbf{L}$

Lamb, J. G., Scott Paper Co.: Need of a uniform method of marking toilet paper, $11,113$.

Lamont, Hon. Robert P., Secretar'y of Commerce : Address, 22, 47.

Lang, Martin L., Commissioner of Weights and Measures, State of Indiana: Sealed cans for dispensing lubricating oil, 25, 65.

Lawrence, David, The United States Daily :

The press and the official, 20, 39.

Radio talk on National Conference on Weights and Measures, 20, 67.

Lawrence, E. Kent, Baltimore and Ohio Railroad: Origin and destination weighing of coal in carload lots, $16,123$.

Lazo, Hector, Cooperative Food Distributors of America: Standardization of packages, 29,89 .

Leithauser, G. H., Senior Assistant Superintendent of Weights and Measures, City of Baltimore, Md.:

Charges for rug cleaning, 35, 143.

Retail sale of bar soap, 36,62 .

Letzkus, C. R., National Scale IIen's Association: Activities of the National Scale Men's Association, 27, 71.

Levitt, John J., Superintendent, Division of Standards, State of Illinois : Testing equipments for large-capacity scales, methods employed, and results obtained, 26,54 .

Levy, I. M., Sealer of Weights and Measures, City of Chicago, Ill.: Systematized package supervision, 34, 103 .

Lewis, Herbert B., Brown and Sharpe Manufacturing Co. : The viewpoint of industry concerned with interchangeable manufacturing toward the proposal to standardize the inch, 28, 2.

Liles, J. E., Inspector of Weights and Measures, State of Texas: Vehicle-scale testing equipment, 28,95 .

Lindsay, C. A., Howe Scale Co.: Heavy-capacity platform scales: Apparatus and methods for factory tests, 18,67 .

Lohmann, Henry, National Association of Retail Grocers: The retail grocer, $23,69$.

Luther, Harold, Member, Committee on Weights and Measures, National Fisheries Institute: Frozen fish, 33, 40.

Lutze, August, Sealer of Weights and Measures, City of Sheborgan, Wisconsin: Cooperation between State and local weights and measures departments, 16, 28.

M

Nackall, John N., Maryland State Roads Commission : Protection of highways by means of portable weighing devices, 15, 26.

MacLean, A. D., Pittsburgh Equitable Meter Co.: Testing of gasoline meters in the factory, 21, 122.

MacLean, R. W., Director, Standards Division, Department of Trade and Commerce, Ottawa, Canada: Weights and measures service in Canada, 36, 7.

Macurdy, L. B., Chief, Mass Section, National Bureau of Standards, Standards of mass, 36,42 .

Maguire, Leonard, Works Manager, Fairbanks, Morse \& Co., St. Johnsbury, Vt. : Belt Conveyor Scales, 36, 53.

Maroney, Edward J., Sealer of Weights and Measures, City of New Haven, Conn. : Problems arising in the supervision of public markets, $16,53$.

Heavy-capacity platfor'm scales: Apparatus and methods for field tests, $18,58$.

Mayer, A. J., Director, Division of Weights and Measures, State of Louisiana: New weights and measures organization-Training, 35, 105.

Mayer, Harry, National Scale Men's Association: Activities of the National Scale MIen's Association, 31, 18.

McAllister, A. S., National Bureau of Standards: The labeling and certification plan in connection with Federal specifications, 25, 42.

McBride, John P., Director of Standards and Necessaries of Life, State of Massachusetts : Fay Stanley Holbrook-in memoriam, 30, 3.

IcCarty, J. G., National Scale Men's Association: Actirities of the National Scale IIen's Association, 30, 78. 
McGrady, WV. B., Chief, Bureau of Standards, State of Pennsylvania: Pennsylvania serialization law, 15, 60 .

McLin, DeForest, Inspector of Weights and Measures, County of Huntington, Ind. : The itinerant scale mechanic, $24,154$.

ICWilliams, Arthur, Chief, Division of Dairies and Foods, State of Ohio : Elimination of short weight and measure, 17, 8.5.

Ieads, Albert H., Toledo Scale Co.: Proposed amendments to specifications for scales, $11,107$.

Ieek, J. H., Director, Division of Markets, State of Virginia :

Iarked reight and shrinkage of hams and other wrapped meats, 20, 121.

Some comments on cooperation among weights and measures officials, 21,60 .

How are the benefits of State-wide inspection best to be secured?, 26, 29 .

Proposed Federal legislation in relation to the financing of weights and measures inspections, $27,25$.

Federal aid in weights and measures programs, 34, 105.

Meek, Rollin E., Chief, Bureau of Weights and Measures, State of Indiana: The appearance in trade of liquid measures of nonstandard sizes, 27, 103.

Vehicle-scale testing equipment, 31, 67.

Meredith, Francis, Director of Standards, State of Massachusetts :

Testing vehicle-tank meters, 23, 108.

Equipment for testing large-capacity scales, 24, 136.

Mejer, J. Franklin, National Bureau of Standards: Labeling of incandescentfilament lamps, 28, 13.

Miller, I. I., Commissioner of Weights and Measures, State of Indiana : Attitude of the Middle West toward the abolition of bushel weights, 16, 82.

Enforcement of the Indiana bread law, 17, 40 .

Operation of compulsor's sales-by-weight statutes, $19 ; 61$.

Observations on certain air-operated gasoline-meter installations, 22, 104.

Sale of chemically treated coal, 23,66 .

Equipment for testing large-capacity scales, 24, 130.

Mills, J. B., Ohmer Fare Register Co. : Transmission drive for taximeters, 19, 36.

Moller, Col. I. L., Traffic Department, District of Columbia: Portable devices designed for determining the axle loads of loaded trucks on highways, 19, 151.

Iontgomery, D. E., United States Department of Agriculture :

Consumers' interest in adequate weights and measures supervision, 27, 16.

Surreying weights and measules from the consumer's' riewpoint, 28,28 .

The consumer looks at weights and measures administration. 29. 4 S.

Moore, Dr. E. V., Assistant Commissioner, Department of Agriculture and Markets, State of New York: Mutual public relations problems of weights and measures officials and American agriculture, 34, 56.

Moore, G. Denny, Gasoline Pump Manufacturers Association:

Testing, servicing, and repair of liqud-measuring devices, 30, 121.

The gasoline pump industry-one year after the war, 32, 56.

Moore, George B., Chief Inspector of Weights and Measures, County of Allegheny, Pa.:

Organization and conduct of city and county departments of weights and measures, $16,41$.

Heavy-capacity platform scales: Apparatus and methods for field tests, $18,64$.

Moran, J. J., Kimble Glass Co.: The manufacture of precision glassware, $31,54$.

Morey, F. C., Capacity, Densits, and Fluid Meters Section, National Bureau of Standards: Vapor meters, 35, 159.

Morgan, Cleo C., Sealer of Weights and Measures, City of Gary, Indiana: A novel form of weights and measures school, 30, 32.

Moss, J. E., Director, Division of Transportation, American Petroleum Institute: Report of central committee on automotive transportation of the API, 32, 23. Vehicle tanks, 33, 60.

Mote, John M., Assisstant Chief Inspector of Weights and Measures, State of Ohio: Reasons for standard-weight loaves of bread and enforcement of Ohio standard-weight bread law, 15๊, 88 .

Mueller, E. F., National Bureau of Standards: Testing of clinical thernometers, $19,48$.

Murphy, R. IV., Assistant Administrator for Industry, U. S. Department of Commerce: NPA regulations and weighing and measuring devices, 36, 56 . 
Nagel, Hon. Charles, Secretary of Commerce and Labor : Address, 5, 8; 6, 111 ; $7,11$.

Neale, Charles C., Commissioner of Weights and Measures, State of Minnesota :

Seals and methods of sealing, 8, 204.

Demonstration showing the necessity of maintaining scale levers level and lever connections plumb, 9, 34 .

Weight standardization of bread, 13,115.

Neale, Charles C., Toledo Scale Co.: Weighing in industry, 19, 120.

Neale, Charles C., Wayne Pump Co.: Fay Stanley Holbrook-in memoriam, 30, 4.

Norgord, C. P., Assistant Commissioner of Agriculture and Markets, State of New York: Some observations on weight and measures administration, 23, 48.

\section{$\mathbf{O}$}

( )akley, C. H., Inspector of Weights and Measures, State of Wyoming: Adjustments by weights and measures officials, 34, 163 .

('Keefe, James, Sealer of Weights and Measures, City of Chicago, Ill.:

Chicago ordinance, in relation to vehicle-tank meters and the enforcement thereof, 26, 104.

Recent decisions involving the Chicago weighmaster ordinance, 27, 11.

Fay Stanley Holbrook-in memoriam, $30,3$.

Directing the personnel of a weights and measures department, 31, 7 .

Vehicle-scale testing equipment, 31, 70.

Osborne, R. A., Food and Drug Administration, Federal Security Agency: Frozen foods, 33, 21.

\section{P-Q}

Paddock, James M., Superintendent of Standards, State of Illinois: Vehicle scales-testing equipment and procedures, 33, 112.

Palmer, Arthur W., United States Department of Agriculture: Sale of cotton by net weight, and standardization of the bale, 23, 22.

Parry, William, National Bureau of Standards:

Notes on digest of weights and measures cases, 21, 155.

Legal status of rules and regulations as established by decisions of the courts, $22,132$.

Patterson, Hon. Richard C., Jr., Assistant Secretary of Commerce: Address, $28,41$.

Paul, Lawrence, Chief, Bureau of Weight and Measures, City of Richmond, Va.: Problems arising in the supervision of public markets, 16, 58.

Payne, William A., Sealer of Weights and Measures, County of Monroe, N. Y.: Equipment for testing large-capacity scales, 24, 133.

Peet, R. W., Manager, Association of American Soap and Glycerine Producers, Inc.: Quantity declarations on packaged soap products, $34,82$.

Peffer, E. L., National Bureau of Standards :

Proposed method for testing milk and cream bottles, 16,47 .

Gauging of fuel-oil storage tanks, 19, 22.

Methods for investigating reported short deliveries of fuel oil, 22, 96.

Perkins, Hon. Randolph, Chairman, Committee on Coinage, Weights, and Measures, House of Representatives : Address, 23, 46.

Plenkowsky, A. T., National Bureau of Standards: Testing standards of mass (office standards and test weights), 19, 103.

Pisciotta, Alex, Deputy Commissioner, Department of Public Markets, Weights, and Measures, City of New York, N. Y.: Recently enacted ordinance requiring licensing of scale repairmen, 27,62 .

Pisciotta, Alex, Director, Bureau of Weights and Measures, City of New York, N. Y.: Demonstration of fuel-oil meter-testing equipment of the city of New York, 28, 17.

Pommersheim, John, Engineering Department, Pittsburgh Equitable Meter Division of Rockwell Mfg. Co. : Testing LPG measuring devices, 35, 73.

Prause, Jack H., Assistant General Manager, Martin \& Schwartz, Inc., Salisbury, Md.: Price signs on gasoline service stations, 32, 107 .

Queen, W. A., Chief, Division of State Cooperation, Food and Drug Administration: Recent activities of the Food and Drug Administration regarding short weight and deceptive packaging, 32, 11. 
$\mathbf{R}$

Rafferty, James J., Collector of Internal Revenue for the Philippine Islands:

Weights and measures conditions in the Philippine Island, 10, 50.

Ragland, B. W., Chief, Bureau of Weights and Measures, City of Richmond, Va.: Activities of bureau in Richmond, 18, 39 .

Gasoline meter installations in a ramp garage, 22, 79.

Temperature of gasoline in underground storage, 25, 54 .

Promoting contests, 28, 125.

Rask, R. O., National Scale Men's Association: Recent activiites of the National Scale Men's Association, 26, 46.

Rasmussen, Fred, National Association of Ice Cream Manufacturers: Shall ice cream be sold by weight? Viewpoint of the manufacturer, 18, 122 .

Reck, Dickson, Office for Emergency Management: The weights and measures officer and the program for national defense, 31, 2 .

Redfern, E. L., Sealer of Weights and Measures, State of Iowa: Training the prospective housewife, 19,86 .

Redfield, Hon. William C., Secretary of Commerce : Address, 8, 12 ; 9, 11; 10, 13 ; 11,$13 ; 12,119$.

Reed, Willard E., Superintendent of Weights and Measures, City of Newark, N. J. : The testing of beer barrels, 25, 113.

Regar, R. S., Post Office Department: Supervision of Post Office scales, 24, 97.

Reichmann, Fritz, Superintendent of Weights and Measures, State of New York: Content of container law, 8,79 .

Reichmann, Fritz, former Superintendent of Weights and Measures, State of New York :

Selection and maintenance of apparatus in industrial plants, 11, 51.

Machine measurements in retail dry goods stores, 13, 169.

Renfrew, Paul, Chief Engineer, Ralph N. Brodie Co., Inc. : Testing equipment for large-capacity meters, 34, 38.

Rice, Thomas D., Executive Secretary, Massachusetts Fisheries Association: Frozen fish, 33, 39.

Richard, C. L., National Bureau of Standards :

Test car accuracy, 18, 176.

Two-draft weighing of motor-vehicle loads, 28, 63 .

The effects on SR of packing pivots and bearings with grease, 30,88 .

Platform overhang of vehicle scales, $31,92$.

Richard, C. L., National Scale Men's Association: Current activities of National Scale Men's Association, 24, 168.

Richard, C. L., Supervisor of Scales and Weighing, Livestock Branch, U. S. Department of Agriculture :

Tests of livestock scales, 33,57 .

Testing procedures for livestock scales, 34, 50.

Developments in electronic weighing, 35, 43.

Richards, W. S., (Glass Container Association of America: The manufacturer of lubricating-oil bottles, 24, 15 .

Roberts, George M., Superintendent of Weights, Measures, and Markets, District of Columbia :

Retail sale of coal and coke, 16,127 .

Regulatory activities of a weights and measures department, 19, 26.

Coin-controlled person-weighing scales, 22, 128.

Undercover buying as an aid to law enforcement, 25, 138.

The fee system of inspection of weights and measures, 26,9 .

Roberts, Wm. H., Inspector of Weights and Measures, Vigo County, Ind.: Sale of garden seeds, 33,159 .

Roeser, H. M., National Bureau of Standards :

What the Bureau of Standards is doing to increase the accuracy of weighing revenue freight, 18,34 .

Testing methods and tolerances for portable devices designed for determining the axle loads of loaded trucks on highways, 19, 153.

Notes on apparatus for testing heavy-capacity scales, $20,84$.

Installation of Bureau of Standards master scale, 21, 44.

Roeser, H. M., Secretary-Treasurer, National Scale Men's Association : Activities of the National Scale Men's Association, 32, 20.

Roeser, H. M., Supervisor of Scales, Inland Steel Co. : Impact on the steel business of formal specifications for weighing machinery, 34,96 
Roeser, H. M., Streeter-Amet Company: Automatic-indicating scales-printed weight indications and remote weight indications, 30, 22.

Rogers, Joseph G., Secretary, Department of Weights and Measures, State of New Jersey :

Shall ice cream be sold by weight? Viewpoint of the weights and measures official, 18, 115.

New equipment for testing heavy-capacity scales in New Jersey, 21, 48.

Rogers, Joseph G., Assistant Superintendent and Secretary, Department of Weights and Measures, State of New Jersey: Twisted strands, 30,81.

Roper, Hon. Daniel C., Secretary of Commerce : Address, 27, 84.

Rowe, Sumner C., United States Department of Agriculture: Deceptive containers, 30, 138.

Rowe, Sumner C., Chemist, Food Division, U. S. Food and Drug Administration: Foods and drugs, 36, 89.

Roylance, William M., Western Fruit Jobbers Association of America: Sales by weight, 10, 109.

Runkel, H., United States Department of Agriculture: Enforcement of law in re marking of weights on wrapped meats, 14,45 .

Russell, H. Haig, Chief, Scale Section, National Bureau of Standards :

Testing procedures for four-section vehicle scales, $34,47$.

Calibration of tank cars, 35, 145.

Testing cordage-measuring devices, 36,100 .

\section{$\mathbf{S}$}

Saldana, E. J., Executive Secretary of Puerto Rico :

Administration of weights and measures in Puerto Rico, 17, 17.

Weights in the sugar and tobacco industries, 20,35.

Sanders, Arthur, Secretary and Counsel, National Association of Scale Manufacturers: Activiites of the National Association of Scale Manufacturers, 32, 63.

Sattler, Chas., Commissioner, Department of Labor, Bureau of Weights and Measures, State of West Virginia : Interstate packages, 36, 74.

Sauthoff, Hon. Harry, Member of Congress, Second District, Wisconsin : Remarks relative to standardization of containers for canned foods, 27, 35 .

Saybolt, J. W., Special Representative, Glass Container Manufacturers Institute, Inc. : Forward march, 32, 66.

Schindler, Alfred, Acting Secretary of Commerce: Greetings, 20, 5.

Schlink, F. J., National Bureau of Standards :

Automatic scales, 10,95 .

Liquid-measuring pumps, 11, 57; 11, App. 2.

Schmitz, J. A., Chicago Board of Trade:

Problems of weights in the handling of grain, 12,140 .

Developments in terminal weighing of grain, 22, 65 .

Schneider, J. C., Past President, Association of Food and Drug Officials of the United States: Activities of the Association of Food and Drug Officials of the United States, 32, 16.

Schwartz, A. W., Assistant Superintendent of Weight and Measures, State of New Jersey :

Standardization of containers for foodstuffs and the marking of the weight of commodities in package form, 13,122 .

Heary-capacity platform scales; Apparatus and methods for field tests, $18,57$.

Air releases on power-operated gasoline-dispensing units, 23, 105.

Schwarz, Mrs. Kathryn M., Attorney-Editor, Office of Weights and Measures, National Bureau of Standards; The laws and the case book, 35, 120.

Scott, G. D., Sales Manager, Pure-Pak Division, Ex-Cell-O Coroporation, Detroit, Mich. : Machine measurement of market milk, 36, 67.

Scott, Dr. J. R., Bureau of Animal Industry, U. S. Department of Agriculture:

Wholesale labeling of meat products, 35,148 .

Packing House Products, 36, 88.

Searle, F. A., Landers, Frary, and Clark: Regulation of new types of devices, 20,61 .

Sener, A. G., Sanitary Scale Co.: Reconditioning rejected or trade-in scales, $22,122$.

Seraphin, Theo. A., District Supervisor of Weights and Measures, City and County of Philadelphia, Pa.:

Use of auxiliary automobile tanks for checking gasoline deliveries, 19, 95.

Testing of gasoline meters in the field, 21, 110. 
Shankle, H. L., Chief, Gasoline and Oil Inspection Division, State of North Carolina: Supervision over sales-LPG, 34, 36.

Sharp, Benjamin M., Chief Clerk, Bureau of Weights and Measures, City and County of Philadelphia, Pa.: System of keeping records, 10, 171.

Sherman, John H., Superintendent of Weights, Measures, and Markets, District of Columbia: Weights and measures work from the standpoint of efficiency engineer, 10, 122.

Siegel, Charles, National Association of Retail Grocers: Prepackaged perishable commodities-The marketer's viewpoint, 35, 89.

Sieger, W. H., Staff Assistant Manager of Engineering, Neptune Meter Co., and Chairman of the Meter Manufacturers Weights and Measures Committee, New York, N. Y.: Test procedures and equipment for liquid-measuring deviceswholesale, 36, 25.

Sinclair, J. W., Central Committee on Automotive Transportation, API: Test procedures for vehicle tank compartments, 34, 129 .

Siren, J. N., Sr., Inspector of Weights and Measures, State of Louisiana : Weighing of cotton, 16, 26.

Skinner, W. W., United States Department of Agriculture: Work in relation to ice cream of the Joint Committee on Definitions and Standards, 18, 135.

Slough, R. K., Sealer of Weights and Measures, City of Akron, Ohio : Commodity tolerances, 34, 137.

Small, A. R., Underwriters' Laboratories: Gasoline pumps from the standpoint of safety, $13,59$.

Smedley, William, Retail Merchants' Association of Pennsylvania: The retail merchant, 17, 111.

Smith, Albert B., Chief, Bureau of Standard Weights and Measures, State of Pennsylvania: Raising the standard for local weights and measures officials, $22,29$.

Smith, Allan R., Executive Secretary, National Truck Tank and Trailer Tank Institute: Vehicle tanks, 33, 68.

Smith, Archie T., Inspector, Department of Weights and Measures, State of New Jersey: Testing equipments for large-capacity scales, methods employed, and results obtained, 26,47 .

Smith, Archie T., Assistant State Superintendent, Department of Weights and Measures, State of New Jersey : Vehicle tanks, 33, 63.

Smith, C. B., President, National Scale Men's Association: Activities of the National Scale Men's Association, 33, 105.

Smith, C. P., Sealer of Weights and Measures, County of Suffolk, New York: New testing device for large-capacity scales, 22,75 .

Smith, Ernest N., American Automobile Association: Cooperative program of the American Automobile Association, 22, 86.

Smith, Leslie C., National Association of Ice Industries: Short weighing in ice scales, 12,77 .

Smith, Ralph W., Deputy Commissioner of Weights and Measures, State of Minnesota : Uniformity of State laws in weights per bushel of commodities, 8, 106.

Smith, Ralph W., National Bureau of Standards :

Testing of liquid-measuring derices, 14, 64 .

Proposed procedure for field test of fabric-measuring devices, 15, 93.

Evaporation of gasoline from delicery hose of liquid-measuring devices, 15, 111.

Bureau of Standard investigation on commercial filling of milk and cream bottles, 16, 43 .

Uniformity of regulations for milk bottles, 17, 26.

Proposed method of test of taximeters, 18, 78 .

Bureau of Standards investigation on the transmission drive for taximeters, $21,21$.

Notes on grease-measuring devices, 23, 16.

Extension of weights and measures supervision, $24,72$.

Federal specification AA_A-S-121 for weighing scales, 25, 23.

Drainage characteristics of dispensers for canned lubicating oil, 26,76 .

Report on the testing of vehicle scales by the National Bureau of Standards in cooperation with the States, 27,$46 ; 28,81 ; 29,57 ; 30,35 ; 31,61$.

Test weights of large denominations, $29,3.5$.

Smith, Ralph W., Secretary, National Conference on Weights and Measures :

Report on the Secretary, 32, 2.

The regulation of repairmen, 33,122 .

A common problem, 33, 179 . 
Snyder, A. Edward, Inspector of Weights and Measures, City of Terre Haute, Ind. :

The value of weights and measures radio programs, $29,19$.

Souder, Wilmer, National Bureau of Standards:

Identification by precision methods of comparison and measurement, 22,49 .

Calibration of State standards, 33, 166.

Spilman, H. A., United States Department of Agriculture :

Federal Standard Container Act of $1928,22,13 ; 23,53$.

Consolidation and amendment of Federal Standard Container legislation, 24,44 .

The consolidated Standard Container Bill, 30,8 .

Staples, George H., Inspector of Weights and Measures, State of Minnesota: Salary system versus fee system of inspection, 12,87 .

Starr, M. H., Howe Scale Co. : Effect on scale design of highway and motor-truck design, 22, 82.

Steel, Raymond E., Acting General Manager, National Fisheries Institute, Inc.: Fish, frozen, 33, 33.

Stephenson, John H., Sealer of Weights and Measures, City of Rochester, N. Y. : Testing of gasoline meters in the field, 21, 115.

Stier, Dr. H. L., Chief, Department of Markets, State of Maryland: The new Maryland weights and measures law, 36,31 .

Stillman, M. H., National Bureau of Standards: Testing of dry gas meters, 8, 90. Stratton, S. W., National Bureau of Standards:

President's address, 1,$5 ; 2,5 ; 4,5 ; 5,7 ; 6,7 ; 7,15 ; 8,15 ; 9,12 ; 10,17 ; 11$, $16 ; 12,15 ; 13,13 ; 14,16 ; 16,16$.

Address memorializing Louis Albert Fischer, 1864-1921, 15, 2.

Stratton, S. W., Massachusetts Institute of Technology : Address, honorary president of Conference, 17, 89.

Straus, Hon. Oscar S., Secretary of Commerce and Labor : Address, 3, 55.

Stringer, Arthur, National Association of Broadcasters: "You're on the air," 31, 44.

Strobridge, Edward K., Sealer of Weights and Measures, County of Alameda, Calif. :

Heavy-capacity platform scales : Apparatus and methods for field tests, 18, 59.

Testing equipments for large-capacity scales, methods employed, and results obtained, 26, 58.

Strong, L. P., Chief, Division of Weights and Measures, State of Michigan :

Regulating the fruit crop in Michigan, 20, 133.

Wheel weigher's on highways, 24, 123.

Stroop, D. V., American Petroleum Institute: Weights and measures and petroleum products, $25,62$.

Stutz, W. F., National Bureau of Standards : Testing of water meters, 8, 118.

Sullivan, George H., Packaging Engineer, Frozen Food Foundation, Inc. : Frozen foods, 33,39 .

Sweeney, James A., Sealer of Weights and Measures, City of Boston, Mass. : Meeting the problem of peddlers and transient vendors, 18, 21.

Swoger, William F., Director, Bureau of Standard Weights and Measures, State of Pennsylrania: Methods adopted for regulation of new types of devices, 20, 43.

\section{$\mathbf{T}$}

Taylor, Tyre, Counsel, National Association of Retail Grocers: Frozen foods, $33,36$.

Theilmann, R. H., Inspector of Weights and Measures, State of Arizona: Progress of weights and measures in the Far West, 18, 71.

Thompson, R. D., Superrisor, Weights and Measures Division, Commonwealth of Virginia:

Adoption of test methods by the National Conference on Weights and Measures, 33, 59.

Standardization of report forms, 34, 76.

Thompson, W. E., Supervisor of Scales, State of Minnesota: Heary-capacity platform scales: Apparatus and methods for field tests, 18, 60 .

Tinkey, J. C., Deputy State Sealer, State of Ohio :

Side-beam and hidden-weight scales, 23,134 .

Side beams, hidden weights, and dial scales, 25,134 .

Tough, W. H., Sanitary Scale Co., Belvidere, Ill.: Weights and measures education in England, 36, 15.

True, J. F., State Sealer, Weights and Measures Division, State of Kansas: Stand-by service of testing equipment during repairs, 34,68 . 
Truman, Harry S., President of the United States : Greetings, 32, 5.

Trump, R. J., Controller, Standards Department, Board of Trade of England: Weights and measures administration in Great Britain, 26, 83.

Tucker, C. E., Chief, Division of Weights and Measures, State of California :

California gasoline and oil substitution act, 28, 134 .

Coordination between departments in relation to interstate shipments, $29,9$.

U

Usher, Edmund F., Sealer of Weights and Measures, Highland Park, Mich.: Transparent containers for prepackaged merchandise, 33, 141.

\section{V}

Van Keuren, H. L., National Bureau of Standards : Method of adjusting railroad track scales, 10,86 .

Vanderslice, J. M., District Supervisor, Bureau of Weights and Measures, County of Philadelphia, Pa. :

Suppression of fraudulent practices, $23,86$.

Testing equipment for large-capacity scales, $25,110$.

Vestal, Hon. Albert H., Chairman, Committee on Coinage, Weights, and Measures, House of Representatives :

Approval of type, 15, 57.

Veth, Albert, Fair Scale Company: The installation and maintenance of largecapacity scales, $26,38$.

Votaw, G. A., Commissioner of Markets, Weights, and Measures, City of Cleveland, Ohio: Scoring machines for ice, 20, 22.

\section{W}

Walsh, J. L., Commissioner of Weights and Measures, City of New York, N. Y.: Federal regulation of weighing and measuring apparatus, 8, 85 .

Warner, G. W., Supervisor, Weights and Measures Inspection, State of Wisconsin : Wisconsin equipment for testing heary-capacity scales, 15, 32.

Heavy-capacity platform scales: Apparatus and methods for field tests, $18,54$.

Methods adopted for regulation of new types of devices, 20, 56 .

Standardization of packages of canned foods, 27,36 .

Measure-containers and nonmeasure-containers, 35, 162.

Way, E. O., Director, Weights and Measures Inspection Service of Canada : Administration of weights and measures in Canada, 24, 61.

Weaver, E. R., National Bureau of Standards: Physical properties of liquefied petroleum gases, $30,48$.

Webster, H. A., Commissioner of Weights and Measures, State of New Hampshire : Sale of wood, 12,61.

Weibley, John W., Pittsburgh Taximeter Co. : Transmission drive for taximeters, 19,$38 ; 20,81$.

Wells, W. C., Pan American Union: Weights and measures of Latin-American countries, 12, 125.

West, Hon. Charles, Member of Congress, seventeenth district, Ohio: Address, $24,77$.

Wheeler, Hon. William R., Assistant Secretary of Commerce and Labor: Address, 4, 77.

White, W. T., Director, Bureau of Weights and Measures, State of New York: Education of public to appreciation of necessity for accuracy, 14, 21.

Wholesale deliveries of gasoline, with special reference to vehicle tanks, 15, 53.

White, Walter G., Commissioner of Weights and Measures, State of New Hampshire: Portable testing equipments for large-capacity meters and vehicle-tank compartments, 26, 110.

Williams, Arthur P., National-American Wholesale Grocers' Association; Standardization of packages, 29, 104.

Williams, William O., Deputy Sealer of Weights and Measures, County of Trum. bull, Ohio: Sealer's responsibility relative to person-weighing scales, 24, 106.

Wilson, S. H., State Oil Chemist, State of Georgia : Nontax-paid gasoline, 25, 50. 
Winslow, M. H., Winslow Government Standard Scale Works, Inc.: Heavycapacity platform scales: Apparatus and methods for factory tests, 18, 68.

Witt, Louis E., Sealer of Weights and Measures, City of Milwaukee, Wis. :

Local "master" vehicle scales, 31, 87.

Uniformity of interpretation and enforcement, 34, 90.

\section{Y}

Young, Hon. John Russell, President, Board of Commissioners, District of Columbia: Addres of welcome, 36. 1 .

\section{List of Conference Reports}

Some of the Reports of the proceedings of the National Conference on Weights and Measures are still available for purchase at the prices shown below. Purchase orders, accompanied by remittance (stamps are not accepted), should be sent to the Superintendent of Documents, U. S. Government Printing Office, Washington 25, D. C.

The publications of the National Bureau of Standards are sent to leading scientific, technical, and public libraries, and, in addition, the Superintendent makes available to Government Depository Libraries publications issued by the Government. It is possible, therefore, that copies of the Conference Reports may be available for reference use in such libraries. 
Reports of the National Conference on Weights and Measures

\begin{tabular}{|c|c|c|c|}
\hline Designation in NBS miscellaneous series of publications & $\begin{array}{l}\text { Number of } \\
\text { conference }\end{array}$ & $\begin{array}{l}\text { Date of } \\
\text { conference }\end{array}$ & $\begin{array}{l}\text { Purchase } \\
\text { price }^{1}\end{array}$ \\
\hline 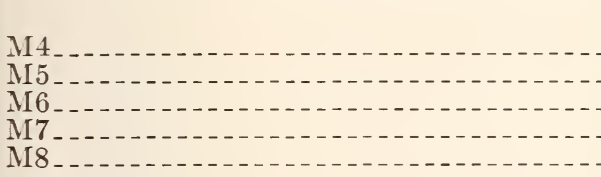 & $\begin{array}{l}1 \\
2 \\
3 \\
4 \\
5\end{array}$ & $\begin{array}{l}1905 \\
1906 \\
1907 \\
1908 \\
1910\end{array}$ & $\begin{array}{c}\text { Cents } \\
---- \\
---- \\
---- \\
---- \\
----\end{array}$ \\
\hline 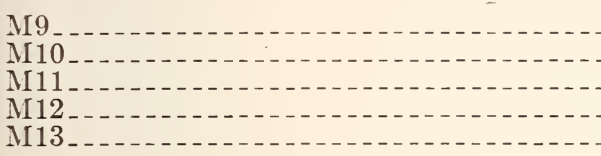 & $\begin{array}{r}6 \\
7 \\
8 \\
9 \\
10\end{array}$ & $\begin{array}{l}1911 \\
1912 \\
1913 \\
1914 \\
1915\end{array}$ & $\begin{array}{l}--- \\
--- \\
--- \\
--- \\
---\end{array}$ \\
\hline $\begin{array}{l}\text { M14 } \\
\text { M413 } \\
\text { M481 }\end{array}$ & $\begin{array}{l}11 \\
12 \\
13 \\
14 \\
15\end{array}$ & $\begin{array}{l}1916 \\
1919 \\
1920 \\
1921 \\
1922\end{array}$ & $\begin{array}{l}--1 \\
--1 \\
--1 \\
--1 \\
-\cdots\end{array}$ \\
\hline $\begin{array}{l}\text { M55 } \\
\text { M599 } \\
\text { M700 } \\
\text { M740 } \\
\text { M80 }\end{array}$ & $\begin{array}{l}16 \\
17 \\
18 \\
19 \\
20\end{array}$ & $\begin{array}{l}1923 \\
1924 \\
1925 \\
1926 \\
1927\end{array}$ & $\begin{array}{l}--1 \\
--- \\
--- \\
--- \\
---\end{array}$ \\
\hline $\begin{array}{l}\text { M87 } \\
\text { M101 } \\
\text { M1169 } \\
\text { M1296 } \\
\text { M156 }\end{array}$ & $\begin{array}{l}21 \\
22 \\
23 \\
24 \\
25\end{array}$ & $\begin{array}{l}1928 \\
1929 \\
1930 \\
1931 \\
1935\end{array}$ & $\begin{array}{l}--1 \\
--- \\
--- \\
--- \\
---\end{array}$ \\
\hline $\begin{array}{l}\text { M157 } \\
\text { M1591 } \\
\text { M16164 } \\
\text { M167 }\end{array}$ & $\begin{array}{l}26 \\
27 \\
28 \\
29 \\
30\end{array}$ & $\begin{array}{l}1936 \\
1937 \\
1938 \\
1939 \\
1940\end{array}$ & $\begin{array}{ll}--- \\
-\cdots \\
-\cdots\end{array}$ \\
\hline $\begin{array}{l}\text { M170 } \\
\text { M186 } \\
\text { M189 } \\
\text { M195 } \\
\text { M199 } \\
\text { M202 }\end{array}$ & $\begin{array}{l}31 \\
32 \\
33 \\
34 \\
35 \\
36\end{array}$ & $\begin{array}{l}1941 \\
1946 \\
1947 \\
1949 \\
1950 \\
1951\end{array}$ & $\begin{array}{l}35 \\
40 \\
40 \\
35 \\
50 \\
-\end{array}$ \\
\hline
\end{tabular}

1 Where the price is not given, the publication is no longer available for purchase. 


Annual Report 1951

National Bureau of Standards

Miscellaneous Publication 204 

UNITED STATES DEPARTMENT OF COMMERCE

Charles Sawyer, Secretary

NATIONAL BUREAU OF STANDARDS

A. V. Astin, Director

\title{
Annual Report 1951
}

\section{National Bureau}

\author{
of \\ Standards
}

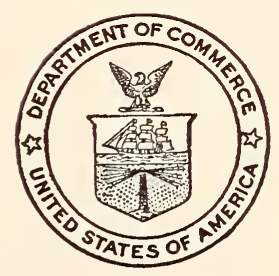

Miscellaneous Publication 204 


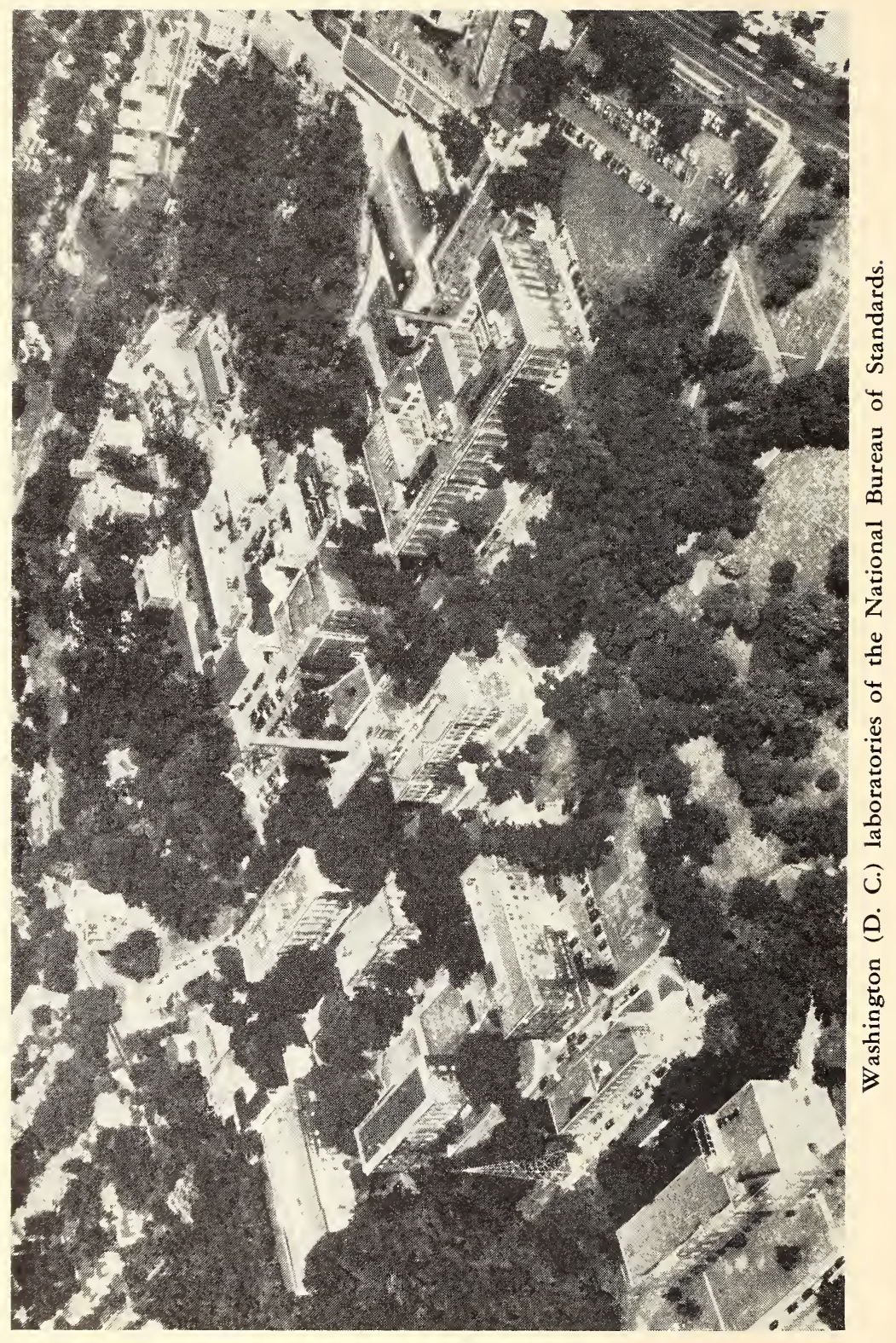




\section{CONTENTS}

1. General Review................................ 1

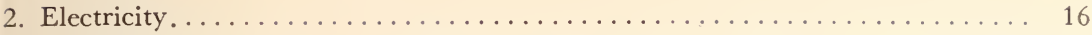

Beam intensification in a high-voltage oscillograph 17, Low-temperature dry cells 17, High-rate batteries 17, Battery additives 18 .

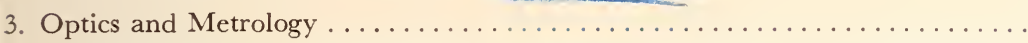

The kinorama 19, Measurement of visibility for aircraft 20, Antisubmarine aircraft searchlights 20, Resolving power chart 20, Refractivity 21, Thermal expansivity of aluminum alloys 21 .

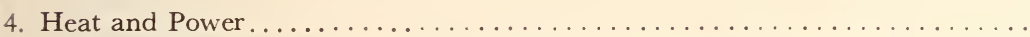

Thermodynamic properties of materials 22, Synthetic rubber and other high polymers 23, Combustors for jet engines 24 , Temperature and composition of flames 25, Engine "knock" 25, Low-temperature physics 26, Medical physics instrumentation 28.

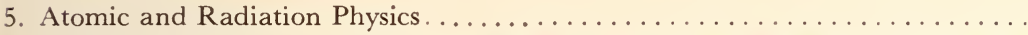
Atomic standard of length 29, Magnetic moment of the proton 29, Spectra of artificial elements 31, Photoconductivity of semiconductors 31, Radiation detecting instruments 32 , Protection against radiation 32, X-ray equipment 33, Atomic and molecular ions 35, Electron physics 35, Tables of nuclear data 35, Atomic energy levels 36.

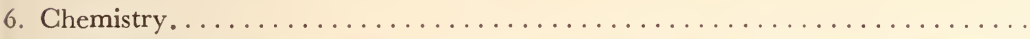

Radioactive carbohydrates 36, Dextran as a substitute for blood plasma 37, Acidity and basicity in organic solvents 37 , Interchangeability of fuel gases 38, Los Angeles "smog" 39, Infrared spectra of alcohols 39, Electrodeposition 39, Development of analytical methods 40, Physical constants 42.

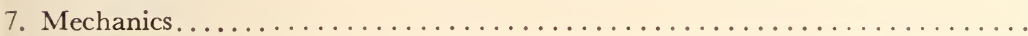

Turbulent flow 43, Turbulence at supersonic speeds 43, Dynamic properties of materials 43, High-frequency vibrations 44, Hearing loss 44, Physical properties by sonic methods 44, Water waves 46, Density currents 46, Precision weighing 46, Viscosity of gases 46, Evaporated thin films 47.

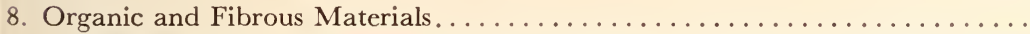

Glass-fiber paper 48, Preservation of historical documents 48, Blood plasma substitute 48, Effect of moisture and ozone on cotton textiles 49, Vibratory ball mill 50, Silicone resin pigment for clinical thermometers 50, Degradation of polystyrene 51, Analytical methods 51, Electrical properties of collagen and leather 53, Sampling of shoe upper leather 53, Synthetic rubber tires 54, Structure of tooth enamel and dentin 54, Dental materials for the military services 54 .

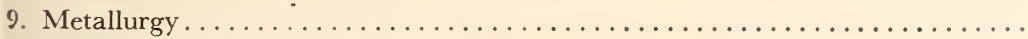
Mechanism of the deformation and failure of metals 56, Corrosion 57, Pure iron 57, Nodular cast iron 58. 
10. Mineral Products.............................. 58

Graphite crucibles 58, Optical glass 59, Durability of ceramic coatings 60, High-temperature equilibrium studies 60, Formation of chemically active phosphates and silicates 61.

11. Building Technology

Strain gage for embedment in concrete 63 , Impact resistance of concrete 63 Spontaneous ignition of fibrous materials 64, Cigarette hazards of mattresses 64, Heating devices 64, Air infiltration in houses 65, Water-vapor barrier materials 65, Asphalt stabilizers 65.

12. Applied Mathematics . . . . . . . . . . . . . . . . . . . . .

Numerical analysis 67, Computation 67, Statistical engineering 68.

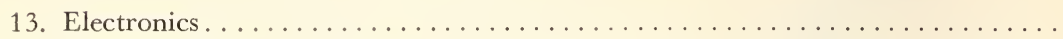

Miniaturization of airborne electronic equipment 69, Adhesive tape resistor 71, Circuit printers for flat and cylindrical surfaces 71, Microphonic study of microwave tubes 72, Miniature piezoelectric accelerometer 72, Radioactivity survey instrument 72, Analogue-to-digital converter 73, Temperature monitor set 74, High-speed crystal clutch 74, Low-cost casting resin 74, Rapid adjustment of pinted resistors 75, Card sorting machine 75.

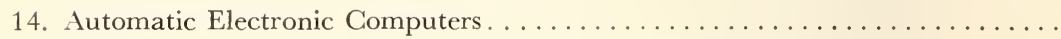

15. Radio Propagation. . . . . . . . . . . . . . . . . . . . . .

Propagation effects on air navigation and traffic control 78, Theoretical investigations of radio wave propagation 79, Radio astronomy 79, Radio observations of meteors 80, Storms in the ionosphere 81, Dielectric measurements 81, Microwave equipment 81, Microwave spectroscopy 82, Atomic standards of frequency and time 82, Noise standards 83, Impedance standards 83 .

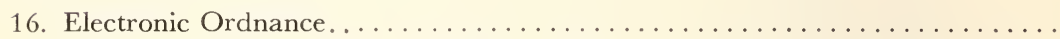

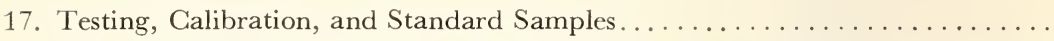
Electricity 86, Optics and metrology 86, Heat and power 87, Atomic and radiation physics 87 , Chemistry 87 , Mechanics 88 , Organic and fibrous materials 89, Metallurgy 89, Mineral products 89, Building technology 90, Electronics 90, Radio propagation 90, Weights and measures 91.

18. Cooperative and Consulting Activities . . . . . . . . . . . . . . .

Advisory Services. . . . . . . . . . . . . . . . . . . . . . .

Federal specifications 93, Radio propagation 93, Color television 93, Operation Greenhouse 93, Ballisto-cardiography measurements 94, Building technology 94, Federal color card for paint 94, Architectural acoustics 95, Mineral products 95, Fire protection 95, Army shoes 96, Bristle brushes 96.

National Cooperation . . . . . . . . . . . . . . . . . . . .

Weights and measures 97, Research associate program 98, Scientific and technical groups 99, National Committee on Radiation Protection 99, NBS semicentennial 100.

International Cooperation. ........................ 100

International intercomparison of standards 100, Unification of standards for screw threads 101, European aid 101, International relations 101. 


\section{General Review}

The National Bureau of Standards is engaged in fundamental and applied research in physics, mathematics, chemistry, and engineering. It also has custody of the national standards of physical measurement, in terms of which all working standards in research laboratories and industry are calibrated, and carries on necessary research leading to improvement in such standards and measurement methods and to their extension to new areas in line with the continual progress of science. In addition to its general responsibility for basic research, NBS undertakes specific research and development programs, develops improved methods for testing materials and equipment, determines physical constants and properties of materials, tests and calibrates standard measuring apparatus and reference standards, develops specifications for Federal purchasing, and serves the Government and the scientific institutions of the Nation in an advisory capacity on various technical matters.

Most of the Bureau's work was conducted at its laboratories in Washington. However, research in certain fields of applied mathematics was conducted at the Bureau's Institute for Numerical Analysis in Los Angeles, Calif. Laboratories were under construction at Boulder, Colo., for studies in low-temperature physics and engineering while architectural designs for a major radio laboratory were underway. At the close of the fiscal year, a new NBS research center was established at Corona, Calif., concerned primarily with various phases of electronic research and development of importance to the Department of Defense. In addition, 20 field stations were maintained in this country and abroad.

\section{Research and Development}

The greater part of the 1951 program was concerned with problems of national defense, conducted for the Department of Defense and the Atomic Energy Commission. Major defense programs, details of which are necessarily classified, included nuclear and atomic studies for the AEC, guided missiles projects for the Department of the Navy, and proximity fuze development for the Department of the Army. At the same time, a wide variety of unclassified projects was carried on, providing results of significant value to science, industry, and the public.

An example is the continuing program on high-speed electronic computers for the solution of complex problems in such fields as atomic energy, ballistics, aerodynamics, and industrial management. This program is aimed at the development of faster, simpler, and more versatile automatic 
computers and the more effective use of the machines already in existence. In addition to fundamental research and engineering development in electronic computing and the design and construction of NBS computers, the Bureau's responsibilities in this area include the coordination of contracts placed with industry for other large-scale computers to be used by Government agencies.

During its first year of operation, SEAC (National Bureau of Standards Eastern Automatic Computer) was operated on a 24-hour-a-day, 7-day-aweek schedule to solve a number of important technical, scientific, and rnanagement problems arising in connection with the defense effort. The greater part of this time was spent on problems of a production-scheduling nature for the Air Force-a pioneer effort in the application of mathematical techniques to large-scale problems of military procurement and administration.

The new electronic computers are highly intricate, with tremendous numbers of components and connections, and the reliability demanded of parts and wiring is exceptionally high. SEAC, for example, contains some 11,000 germanium diodes, 800 vacuum tubes, 500-pulse transformers, and 100,000 soldered connections. Failure of a single one of these myriad connections and components, even for a millionth of a second, will result in computer misfunction. Despite these severe operating requirements, SEAC was maintained in good working condition over 4,000 hours during the past 9 months. In addition to classified problems for the military agencies and the $\mathrm{AEC}$, work was done on electronic circuit design problems, optical lens calculations, statistical sorting and tabulating studies for the Social Security Administration and the Bureau of the Census, design of supersonic nozzles, crystallography of cement compounds, penetration of X-rays, and calculations relating to the relative abundance of the elements.

As a result of the national emergency, increased emphasis was given a general program on electronic miniaturization and printed circuits. This program has been sponsored at NBS by the Navy to provide techniques applicable to the manufacture of equipment for use in aircraft, where space is limited and must be readily available. A major disadvantage of the printed circuit process has been the difficulty of incorporating satisfactory resistors in the circuits. During the year, this difficulty was largely overcome by the development of an adhesive tape resistor method.

In the new technique, circuits are first printed in narrow metallic bands on insulating bases, leaving a small gap at each point where a resistance is required; a self-adhesive resistor is then cut from a strip and pressed into position. Much better control of resistance values is possible than with previous printed resistor methods, and higher yields of acceptable assemblies are assured. The new method thus appears to combine the advantages of printed resistors and of separately manufactured resistors.

Another distinct aid in the mass-production of printed circuits was the development of pilot models of two semi-automatic machines for printing 

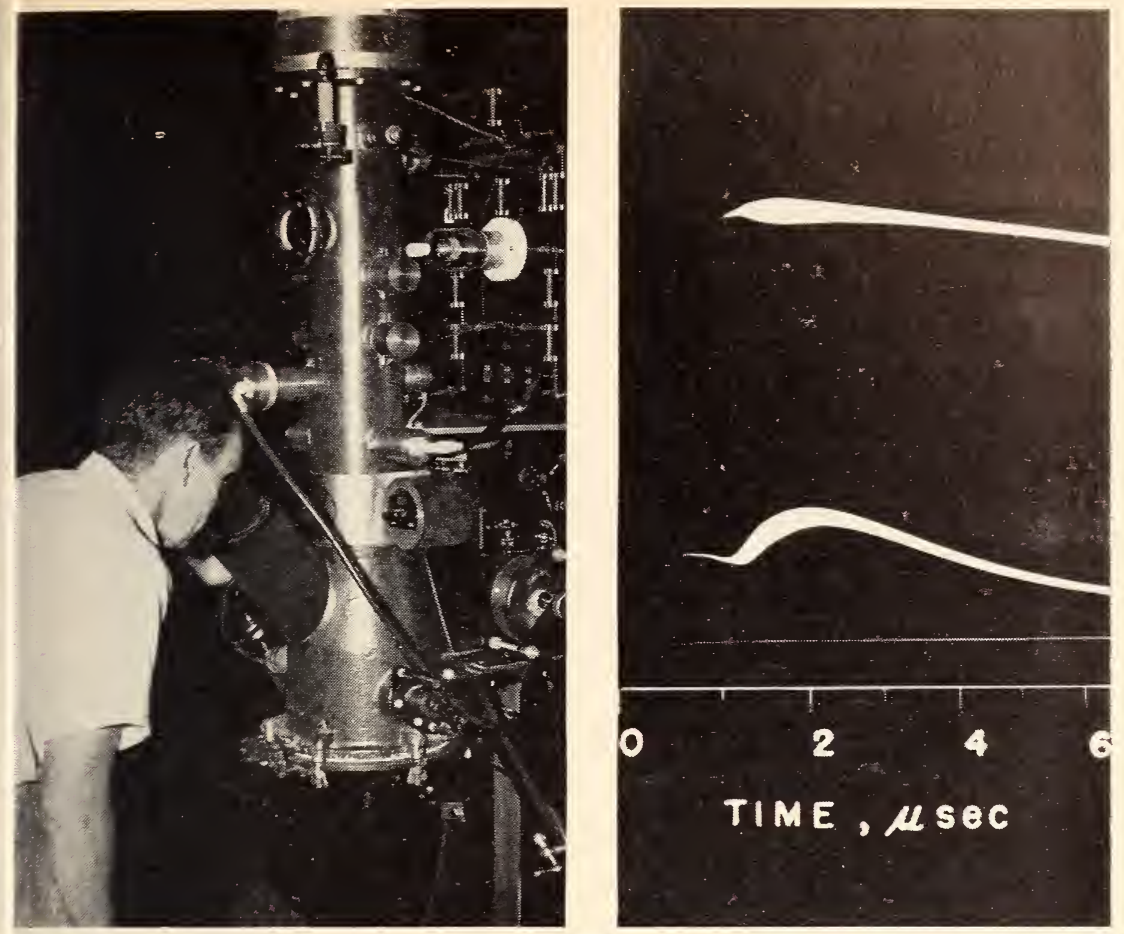

Left: Traces of the sharp, intense changes in current and voltage which accompany "artificial lightning" are observed on a special high-voltage cathode-ray oscillograph. A new NBS technique (p. 17) increases the writing speed of this type of instrument to three-fourths the velocity of light by high intensification of the electron beam. Right: The sudden increase in brightness of traces of voltage (above) and current (below) at 1 microsecond illustrates the beam intensification.

the circuits, one for flat surfaces and the other for cylindrical surfaces. Until now, the circuits have usually been printed manually by a stenciledscreen process. The automatic printers appear to offer two important advantages over this method. First, they are faster than hand printers and more economical for use in quantity production. Second, and perhaps equally important, they give a more uniform product.

Important to industry as well as the armed services was the development, in cooperation with the Naval Research Laboratory, of a paper composed entirely of glass fibers without the use of additives. Production was attained on the NBS semicommercial Fourdrinier paper mill. The all-glass paper-until now considered an impossibility-has unusual filtering properties. Only one particle of smoke in 100,000 passes through a filter made of this paper-with no increase in normal resistance to air. The paper should thus be particularly valuable for gas masks and respirators used by firefighters, industrial and medical workers, and military personnel. Until now, many air filters have relied considerably on imported raw materials. Glass, however, can be produced from raw materials found abundantly in the United States. Another important advantage of the 
all-glass paper is its high resistance to effects of heat, moisture, chemicals, and microorganisms. It also has excellent dielectric properties and is expected to have extensive uses in electronic and electrical equipment.

NBS is currently engaged in a broad program of fundamental research and standardization dealing with X-rays, radioactivity, atomic and molecular spectra, radiometry, physical electronics, electron optics, mass spectrometry, and atomic and nuclear constants. Basic studies of radiation phenomena and the measurement of atomic and nuclear constants are illustrative of this work. Emphasis was also placed on those long-range investigations which not only produce results of obvious value in peacetime applications but also represent important contributions to the defense effort. Typical programs of this nature are the studies of protection against radiation, the development of radiation detecting instruments, research on semiconductors and solid state electronics, and the development of new techniques in electron physics and mass spectrometry.

Problems of radiation protection have both a safety and an economic aspect. New methods of medical treatment utilizing high-energy X-rays require new protective regulations for both the patient and the radiologist. In the absence of exact knowledge regarding the penetrating power of high-energy X-rays, installations are overprotected, with excessively thick walls and barriers, which add greatly to the cost. With the aid of a new 50-million-rolt betatron, experiments were carried out to determine the mechanism of penetration of high-energy X-rays through barriers and to establish methods and standards of protection against harmful effects of such radiation.

An extensive radiation instrumentation program was carried on, involving both the development of new types of instruments and the prototype study and calibration of radiation instruments developed by other Government agencies. During the year, for example, a new type of photographic film dosimeter was developed which reports the actual amount of radiation delivered at a given point more directly than any film meter heretofore available. This instrument will be of value under many conditions where radioactive substances are present, both for industrial safety programs and for monitoring in civilian defense.

At present, one of the most active fields of research in physics is the study of the semiconductors. This field has been greatly stimulated by the recent development of crystal diodes, which possess important advantages over vacuum tubes for certain electronic applications. A laboratory has been set up at NBS to investigate promising semiconductor materials and to evaluate their utility as rectifiers, transistors, and photocells. Studies of the Hall effect are now in progress, and solid state rectifiers and transistors are under development. During 19j1, the program on semiconductors was extended to include a study of photoconductivity in semiconductors, particularly in the infrared region of the spectrum. In addition to providing data for the development of useful photocells, these infrared 


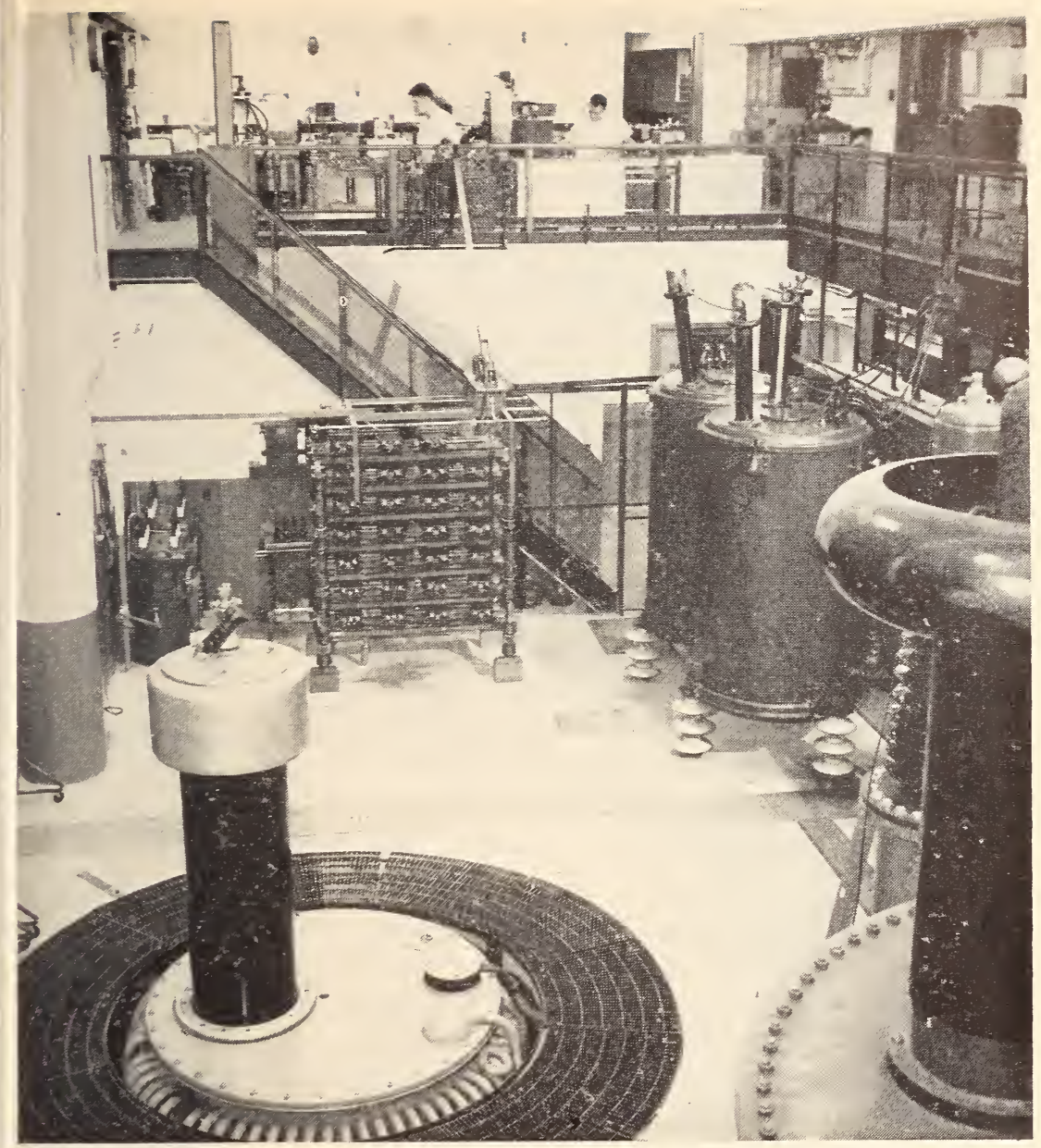

Calibration of high-voltage transformers (right background) in the NBS highvoltage laboratory. On the basis of these measurements, the Bureau certifies standard transformers used in industrial laboratories throughout the United States for measuring high voltage and checking high-voltage equipment.

investigations are contributing much valuable information on the electronic structure of solids.

The nuclear physicist, the reactor engineer, and the industrial or medical user of radioactive tracer materials have long been in need of a compilation of all available nuclear data which could be kept up to date automatically. Publication of new properties in this rapidly expanding field has been widely scattered, and this has led to much duplication of effort. The need is now being met in a program initiated at NBS by the Atomic Energy Commission for the exhaustive compilation of nuclear constants and properties. The first edition of the tables of Nuclear Data, issued on September 1. 1950, contained all the more recent experimental values then available. On April 25, 1951, this compilation was brought up to date 
by issuance of the first supplement. Additional supplements are to be issued periodically.

Since 1889 the world's standard of length has been the distance between two lines 1 meter apart on a platinum-iridium bar at the International Bureau of Weights and Measures at Sèvres, near Paris. Although this metal bar still provides the official standard, recent experiments at NBS have shown that the wavelength of green radiation from the mercury isotope of mass 198 offers an ultimate standard of length superior in precision, reproducibility, and convenience to the standard meter. During the year the new tentative standard was made available to science and industry in the form of a spectroscopic lamp containing about 1 milligram of mercury 198. Thirteen of the lamps were distributed to qualified laboratories. These lamps enable any research organization which has the auxiliary optical equipment to have for the first time an ultimate primary standard of length in its own laboratories. Length measurements based on this standard can readily be made to an accuracy of 1 part in 100 million. New apparatus under construction at the Bureau is expected to extend the accuracy to one part in a billion.

Although jet engines are being increasingly utilized for high-speed flight, much work remains to be done on both engines and fuels in order to attain the desired reliability, economy, performance, and safety. Through a continuing program, sponsored by the military services, NBS is aiding in the solution of these problems. Thus, operation of the combustion chamber has been the subject of much investigation. In one project, for example, the performance of cylinders and spheres as flame holders for ramjet burners was studied, providing results which should be useful in the design of both ramjets and thrust augmenters. In connection with turbojet combustor design, studies were made of the rates of interchange of temperature and velocity between coaxial streams of hot and cold gas under a wide variety of operating conditions. Further development of temperaturesensing devices for protection and control of jet engines was also under way.

For several years, an extensive program on ceramic coatings has been sponsored at NBS by the National Advisory Committee for Aeronautics. Out of this work have come a number of unusual coatings now being used by the aircraft industry for jet and other aircraft components that must withstand corrosive atmospheres at very high temperatures. During 1951, two fundamental investigations were carried out which should lead to more durable and resistant ceramic coatings for both military and commercial use. One of these studies dealt with the fundamental mechanism of the adherence of ceramic coatings to metals. It is known that small amounts of such metallic oxides as cobalt oxide are necessary for the firm adherence of ceramic coatings to metals, but the reason has been obscure. The present investigation employed radioactive tracer techniques, using isotopes of cobalt and iron. It was shown that part of the cobalt is reduced to the metallic form at the enamel-metal interface during firing. The nature 
of this extremely small deposit and the mechanism by which it promotes adherence are still under investigation. Complete information on this topic will not only contribute to further improvement of the coatings but will aid in the conservation of critically short supplies of cobalt.

The second investigation concerned the source of the hydrogen which is a major cause of coating defects when pcrcelain enamels are applied to a steel base. Previous attempts to eliminate the hydrogen have been largely unsuccessful because little was known as to its source. This uncertainty was eliminated by substituting heavy hydrogen (deuterium) for ordinary hydrogen at each of five possible hydrogen-producing operations in the coating process. The results show very clearly that the hydrogen is generated during the firing operation by a reaction between the hot iron base and the dissolved water in the coating material.

In automotive research, studies were directed toward the improvement of engines, fuels, tires, and accessories and the development of better methods for their evaluation. The Bureau has contributed materially to the design and development of the test engines, equipment, and instrumentation now used to rate motor, aviation, and Diesel fuels. Since the development of standardized engine tests in 1932, NBS has served as the agency for the calibration of reference fuels, such as normal heptane and isooctane, used throughout the country for the knock rating of gasolines. These reference fuels are now available at a purity of 99.99 percent as a result of improvements in the Bureau's purification process.

At present, one of the chief limitations to the maximum power which can be realized from an automotive engine is its compression ratio. If the compression ratio is increased beyond the limit allowed by the fuel, detonation or "knock" occurs, with consequent loss in power and possible damage to the engine. This problem has been recognized for many years and is still not completely understood. However, during 1951 increased understanding of the mechanism by which knock is produced resulted from compression-ignition studies initiated at NBS the previous year.

In knocking combustion, some of the unburned charge in the combustion chamber, known as the "end gas," is compressed to a high pressure. which causes it to autoignite and to burn with explosive violence. To obtain further information on the basic nature of detonation, NBS is studying the conditions prevailing in the end gas. Special apparatus has been constructed in which the end gas is simulated and pressure and light emission during autoignition are shown on oscilloscope screens. In this way, two distinct stages in autoignition have been recognized, and processes occurring during the first stage have been related to the detonation tendencies of the individual fuels. Ultimately this investigation should point the way toward more efficient utilization of automotive fuels, either through improvement of engines or fuels, or perhaps of both.

New experimental techniques and mathematical methods are being applied by NBS in an integrated program which seeks to provide a better 

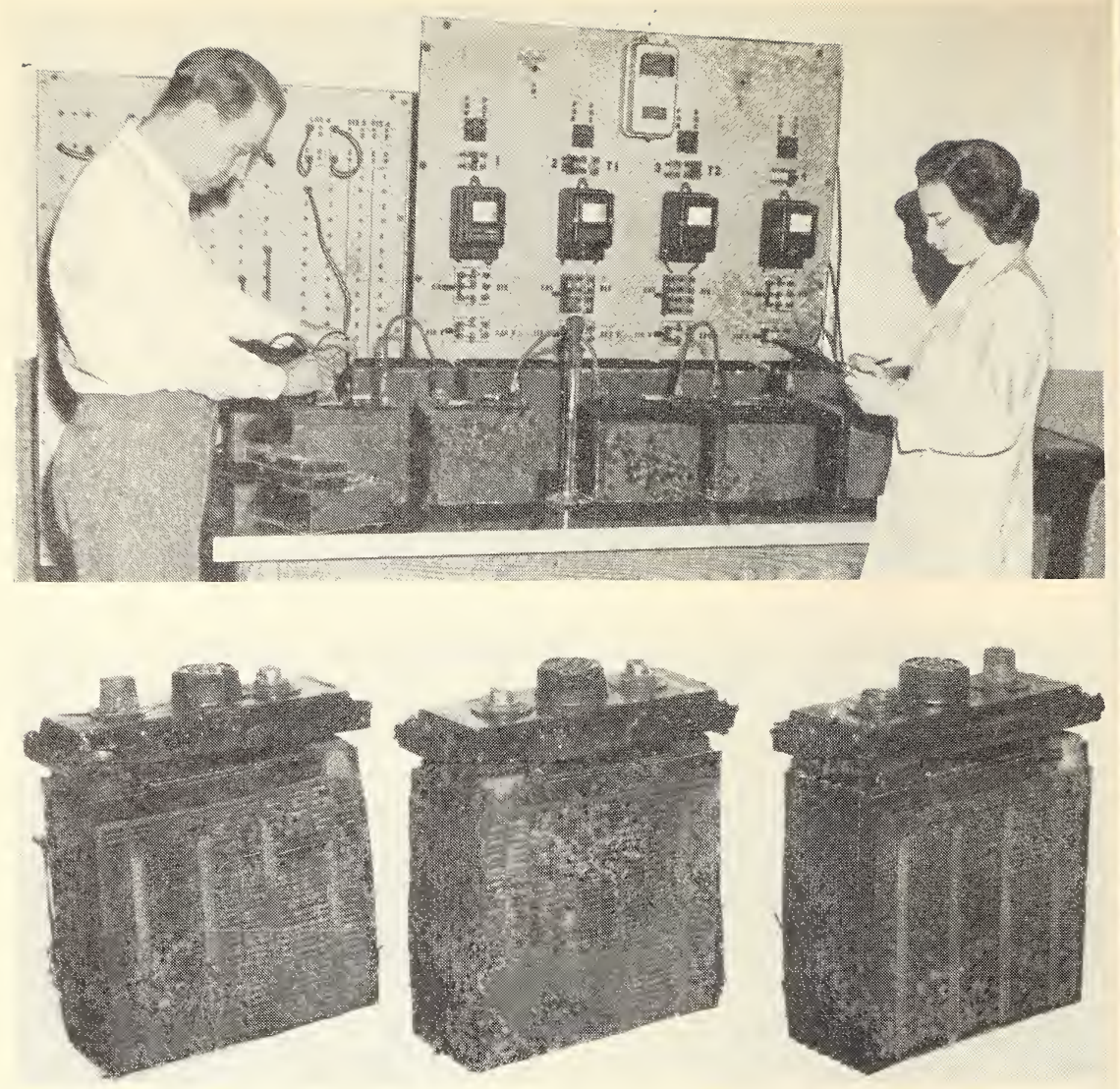

Above: Extensive laboratory studies simulating actual service conditions were made on a wide variety of commercial battery additives (p. 18). Below: Cell groups from a standard automotive battery at the end of its useful life. The positive plates (left end of each cell) are corroded, and the negative plates (front of each cell) are badly sulfated. The NBS investigation showed that the additives have no effect on these conditions.

understanding of the fundamental properties of rubbers, plastics, textiles, leathers, and papers. Efforts are made not only to improve present knowledge of high polymers but to develop new materials of this type and to provide for their practical application. During 1951, applied research on polymeric materials was given added impetus because these materials have important military applications and because the supply of most of them has been adversely affected by dislocations in international trade. These needs have led to efforts to make papers and plastics having properties cutside the range of those previously thought possible. Other research was undertaken to extend the uses of organic materials to replace metals and cther substances that are in even shorter supply.

The reopening of the Government synthetic rubber plants greatly increased the demand for sandard rubber samples and called for investigations leading to better methods of quality control. A simple, rapid method 
for the quantitative determination of rubber hydrocarbon in crude natural rubber was developed, and an improved apparatus for precise determination of moisture in rubber was designed and constructed. Heat-capacity measurements were made on synthetic rubbers and other high polymers in order to derive their thermodynamic properties, which are of value in polymer technology, and to obtain information regarding the fundamental nature of the polymer. Extensive investigations were also carried out on the theological properties of various rubbers and rubber solutions; these measurements should aid in explaining the superior qualities of the "cold" rubbers.

Research on the durability of plastics and rubbers is becoming increasingly important as these materials find new applications. A knowledge of the mechanisms of their degradation is needed in order to predict more accurately the service life of the polymers, to select stabilizers that will increase their service life, and to develop better methods of accelerated testing. While the problem has been investigated extensively by means of accelerated tests involving one or more physical properties, empirical investigations of this type do not reveal the basic changes in the material and cannot be used to predict behavior in actual service. A complete understanding of the fundamental reactions involved is needed. To obtain such information, NBS has been conducting a program of research on the degradation of polymers under the sponsorship of the Office of the Quartermaster General, Department of the Army.

During the year, an extensive investigation was made of the decomposition products formed when polystyrene is exposed to heat and ultraviolet energy in the presence of oxygen. The information thus obtained not only provides an insight into the general problem of polymer degradation but will also be of value in interpreting the reactions which occur in the degradation of GR-S synthetic rubber.

Deterioration of cotton textiles also received attention. To learn more about the chemical changes which occur when cotton deteriorates, NBS applied the techniques of infrared spectroscopy to cotton cellulose. In the course of this work a vibratory ball mill was developed which rapidly and completely grinds cotton into particles a few microns in length with little or no oxidative change or contamination of the cellulose. The new mill produces a more uniform powder and is more efficient and easier to operate than previous devices of this kind. It is expected to find extensive application in the grinding and blending of a variety of substances such as pigments, ceramic materials, metal powders, resins, and plant and animal tissues.

Significant progress was achieved in a program of research and development in basic instrumentation, initiated at the close of the previous fiscal year with the cooperation of the Department of Defense and the Atomic Energy Commission. A number of research projects on various types of 
instrumentation were begun, and an instrumentation reference service was established.

Until recently, the problem of designing instruments to measure different quantities and for use under different conditions has been largely left to the individual scientist working in the particular field of science involved. Now, however, it is coming to be more and more widely recognized that the problems met with in designing various kinds of scientific instruments have much in common and that the designer of an instrument for a particular purpose can often benefit from the experience gained by others with instruments built for quite unrelated purposes. The NBS program in basic instrumentation has three objectives: (1) systematic analysis of available methods and devices in terms of their precision and reliability; (2) studies of materials, components, and elements which are known to impose serious limitations on instrumentation; and (3) development of specific instruments not now available. The program is carefully coordinated and is conducted in such a way as to take full advantage of the Bureau's broad experience in the field of physical measurements and to make use of the new ideas and developments which are constantly originating in all technical fields. During the past year, considerable effort was expended in research and development on a series, or family, of new instruments based on the principles of gas flow at sonic velocity through orifices. Utilization of these principles promises to provide improved instruments for the measurement of pressure; temperature, rate of flow, humidity, gas composition, mechanical displacement, and other quantities. A humidity measurement instrument has now been completed, providing a background of information that should be of value in the development of other instruments using the sonic flow principles.

\section{Testing, Calibration, and Standard Samples}

The NBS testing and calibration activities stem from its custody of the Nation's basic physical standards. In many cases, master standards used in industry must be checked periodically against these national standards. The Bureau is also responsible for testing many of the materials purchased by the Bureau of Federal Supply and other Federal agencies. In the course of this test, calibration, and standard samples work, new methods of measurement and new instruments are devised, and new technical data on the properties of materials are obtained.

Over 300,000 tests and calibrations were performed for other Government agencies and the public. This work provides the basis for accurate measurement in industry, laboratories, and institutions throughout the Nation. In addition, about 25,000 standard samples were prepared and distributed by the Bureau. Typical services of this kind included the sample-testing of over 300,000 clinical thermometers purchased by the Government, the life-testing of about 6,000 light bulbs (a sampling of nearly 7,000,000 purchased by the Government this year), the calibration 
of approximately 4,500 gage blocks, over 800 measurements of radon in breath samples from radium dial painters or in the workroom air, the distribution of about 1,300 samples of radioactive materials, the testing of 150 ores and sludges for radium content, the calibration of more than 900 water current meters, the testing of about 270 master beer meters for the Bureau of Internal Revenue, the calibration of 35,000 capacity measuring devices, and the sample-testing of about 10,000,000 barrels of cement purchased by the Government.

\section{Codes and Specifications}

The results of a large part of the research and testing carried on by NBS have a direct bearing on the development of technical requirements designed to assure safe working and living conditions. Through membership on numerous committees of national standardizing bodies, the Bureau has been able to put these results before qualified persons for interpretation and pratical use. It thus provides a central source of information to which Federal, State, and municipal authorities, as well as industrial and trade associations, can turn when dealing with problems of safety or with building and plumbing codes. During the year, for example, NBS rendered technical assistance in connection with the drafting of the National Plumbing Code and the development of the New York State Building Code. Similarly, the Bureau has participated in the development of numerous national standards and specifications that are universally used as bases for intelligent purchase of commodities.

\section{Cooperative and Consulting Services}

One of the important factors in the successful prosecution of the diversified programs at the National Bureau of Standards is the availability of experts in nearly every special field of physics, applied mathematics, chemistry, and engineering. This combination of experts means that almost any problem in the physical sciences can be undertaken within the Bureau. At the same time, the results of investigation and the knowledge of its experts are available for additional uses. Thus, NBS serves, or is available to serve, every agency of the Federal Government and many State and municipal governments by rendering advisory and technical services. An important role of this type is played in the development and establishment of Federal specifications, which are necessary for economy in Federal purchasing. The Bureau also cooperates extensively with scientific and technical associations both in this country and abroad, on problems of concern to the Government and the Nation.

During the year, services of an advisory or consulting nature were rendered to almost every agency of the Federal Government. Typical services included assistance to the Reconstruction Finance Corporation in finding uses for short abaca fibers; advicé to the Office of the Quartermaster General on refrigeration and air conditioning problems; aid to the Army 

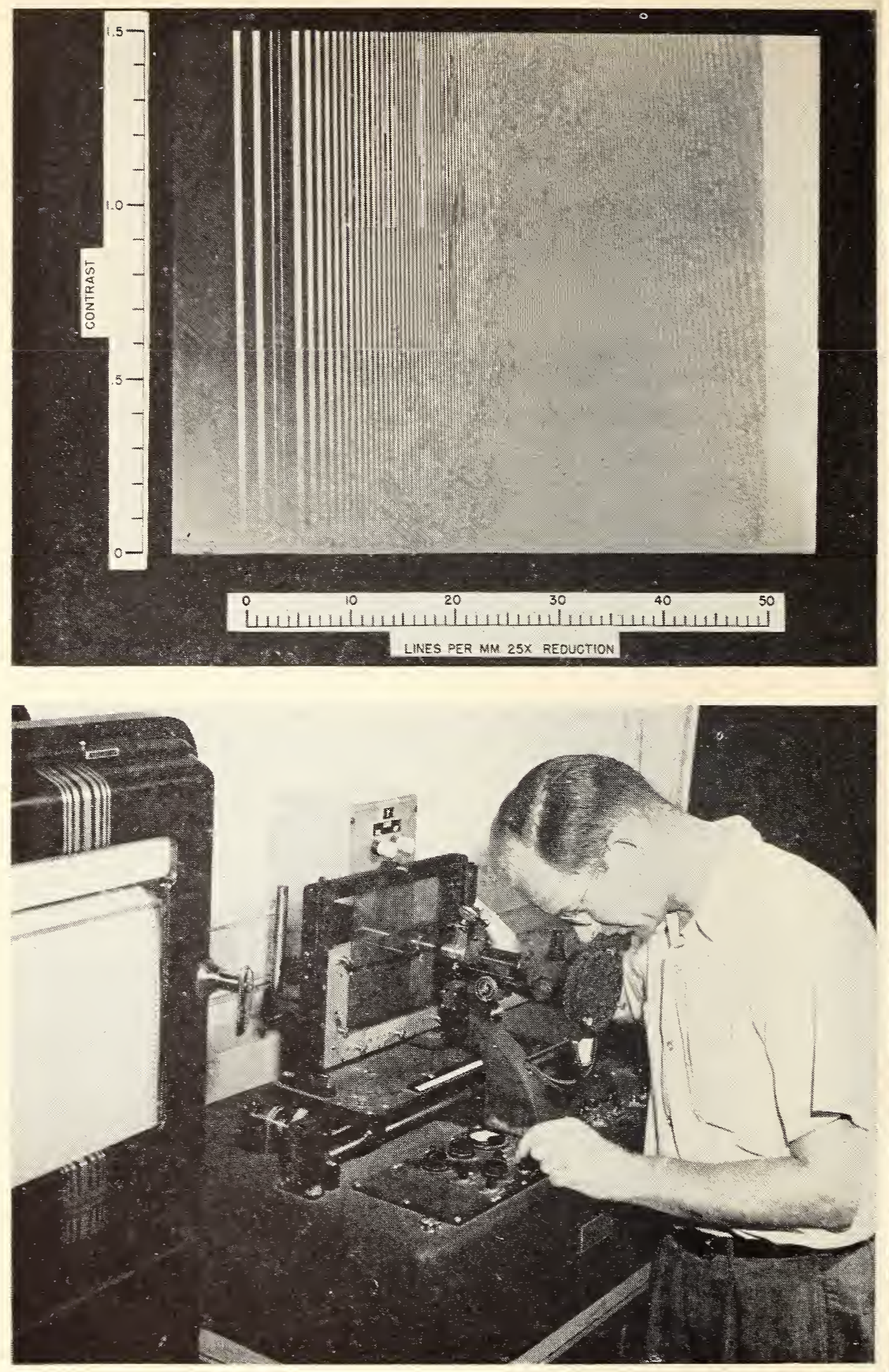

A new variable-contrast test chart (above) was developed (p. 20), making possible more effective measurement and study of the resolving power of photographic lenses. Below: The contrast at various parts of the new chart is measured on a densitometer in the NBS optical instruments laboratory. 
Medical Center in the planning of an instrument system for measurement of cardiac output; technical tests on color-television systems for the Advisory Committee on Color Television: participation in the Atomic Energy Commission's "Operation Greenhouse"; assistance to the Federal Civil Defense Administration on radiation instrumentation problems; consultative assistance to the Architect of the White House and the Committee on Alterations of the White House regarding sound insulation, sandstone weathering problems, and damage to stone masonry from roof leaks; and technical advice to the Patent Office in connection with certain patent claims.

NBS also participated in the work of hundreds of technical committees, societies, associations, and commissions organized to bring new advances of science into the technology of industry, to standardize materials and products for greater economy and improved quality, and to establish uniform scientific standards throughout the world. Bureau staff members now hold 1,687 positions on such national and international groups. An example is the Bureau's participation in the American Society for Testing Materials, in which NBS is represented by 445 committee memberships. NBS also holds about 250 memberships on sectional committees and working groups of the American Standards Association and is the sponsoring agency for several ASA projects.

\section{Work in Progress}

Several major programs, each encompassing a large number of specific projects, were in progress during the year. Programs in electronic computing, atomic and radiation physics, electronics, jet engines, ceramic coatings, automotive research, high polymers, and basic instrumentation have already been mentioned. Other important current programs deal with radio propagation, metallurgy, building technology, optical instruments and optical glass, low-temperature physics, and dental materials.

Comprehensive programs are being carried on in radio physics and related geophysical phenomena of the upper atmosphere and troposphere. In addition, primary standards and measurement methods are under development for electrical quantities at all radio frequencies. Important problems in this field still remain unsolved; and, as a result of the tremendous postwar extension of the available frequency range, new problems are constantly arising in measurement, instrumentation, standards, and calibration services.

Microwave standards of frequency, power, attenuation, dielectric, and other electric quantities for frequencies up to 100,000 megacycles or more have been intensively developed since World War II. In connection with this work, an atomic clock, invariant with age and independent of astronomical observations, has been developed which promises to provide an atomic standard of frequency and time. An intensified program is now being carried on, embracing the investigation of four different types of atomic clocks. One of these clocks-a new type which makes use of atomic beam techniques-has a potential accuracy of one part in a billion, or 
perhaps even 10 billion, with a variation of not more than 2 seconds in 300 years.

During the past year, a new theory was developed which explains experimentally observed propagation of very-high-frequency radio waves beyond the horizon and has significant practical applications with respect to television and other high-frequency communications. A broad program of propagation research was also under way in the 1,000- to 1,600-megacycle frequency range-important for future air navigation systems. A beginning was made toward a world-wide program for the study of atmospheric radio noise, and an investigation of storms in the ionosphere was initiated.

An extensive program has been carried on for many years in metallurgy. In addition to studies of the behavior and properties of metals under normal and abnormal conditions of service, this program has included studies of the mechanism and prevention of corrosion and investigations of failures of airplanes, automotive parts, and welded ships. The work on corrosion of aluminum alloys in marine atmosphere, sponsored by the Navy Bureau of Aeronautics, the Air Force, and the National Advisory Committee for Aeronautics, has been useful in the development of modern high-strength, corrosion-resistant, lightweight alloys for aircraft use. Efforts are being made to determine why metals fail in fatigue and how incipient damage can be detected and corrected. Another investigation deals with the behavior of metals at low temperatures. During 1951, both fundamental and applied research in metallurgy was greatly stimulated by the need for new and improved metals and alloys in connection with the defense effort. New theories were developed regarding the mechanism of underground corrosion and the protection of underground metallic structures, and an evaluation of the use of aluminum and its alloys in housing construction was completed.

Another major continuing program at NBS involves a unified approach to the problems of the construction industry. The work is so organized that groups are simultaneously engaged in investigations of properties of materials; structural strength; fire resistance; acoustics and sound insulation; heating, ventilating, and air conditioning; durability; exclusion of moisture; building and electric equipment; and other related projects. Attention is focused on methods of saving materials, on the use of less expensive and more readily available materials wherever feasible, and on the development of more economical designs based on information concerning the properties of materials which was not known a decade ago. Engineering principles are being applied to the design of houses, providing a complete and logical method for determining allowable loads for walls, floors, and roofs. This, in turn, makes it practicable to develop structural designs and to make use of nonconventional building materials that provide sufficient strength but require a minimum amount of material and labor.

The problem of research in optical instruments and optical glass is an important one. Peacetime requirements for precision optical instruments 

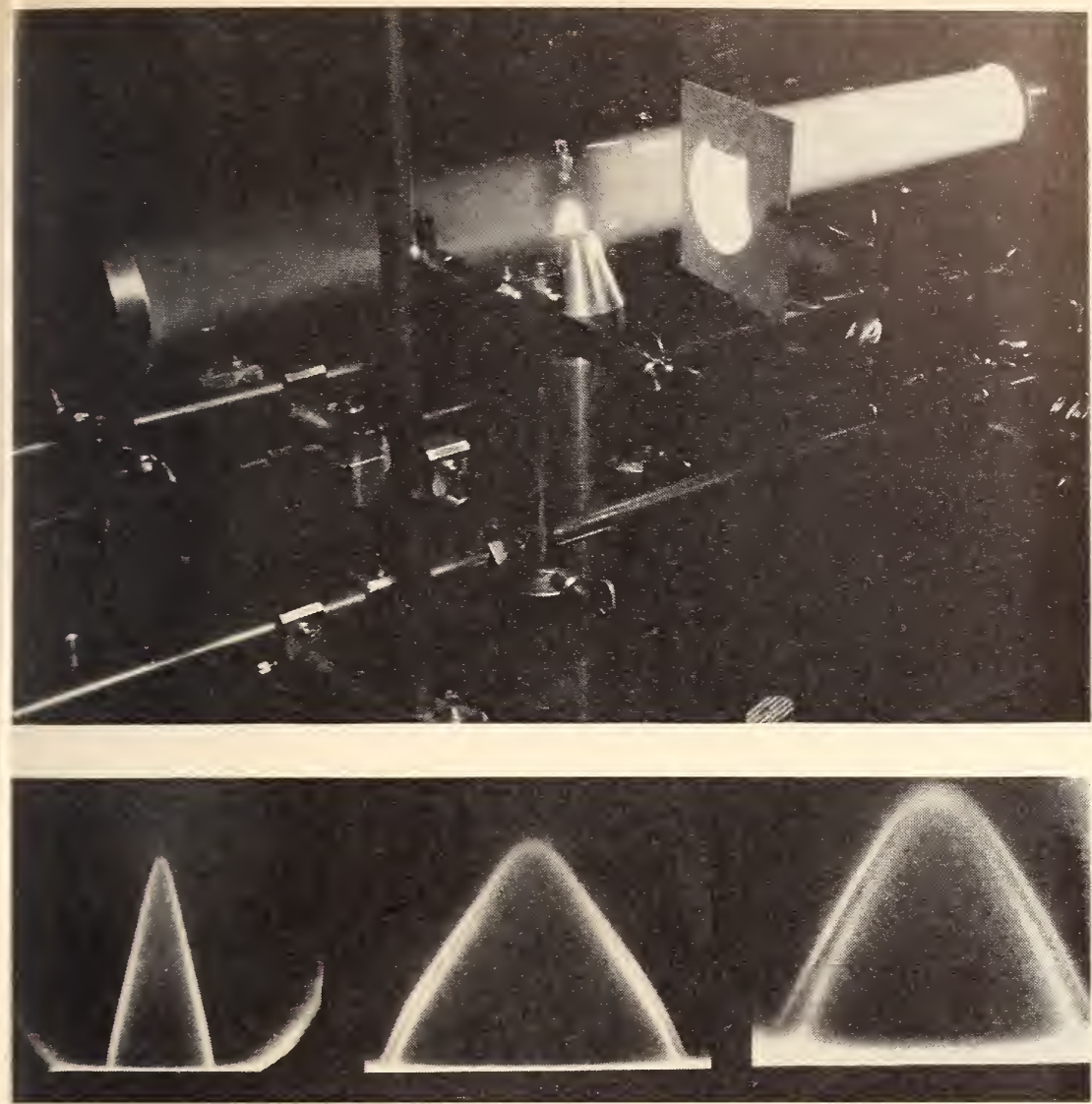

Above: Schlieren apparatus used at NBS to study flame structure in connection with research on the fundamentals of combustion (p. 21). Below: Schlieren photographs showing (left to right) the widening of the reaction zone when increasing quantities of helium are added to a methane-air flame.

are almost negligible in comparison with the need for military optical instruments in wartime. Moreover, the demands made on industry for the production of nonmilitary optical instruments are relatively stable, for the required characteristics of the various instruments do not change greatly within short periods of time. In military optical work the reverse is true, and the necessity for specialized laboratory research is correspondingly increased.

With the cooperation of the Army and Navy, the Bureau has therefore conducted for many years a coordinated series of projects basic to the production of all types of optical instruments, with special emphasis on military fire-control devices. The Bureau has complete facilities for making an optical instrument beginning with the raw materials and producing, in turn, the glass, the optical design, lenses and prisms, mechanical parts, and finally the finished instrument. 
A program of research on the properties of matter at extremely low temperatures is being actively pursued. At the temperature of liquid helium, metals such as lead and tin, ordinarily poor conductors of electricity, become superconductors with a complete loss of electrical resistance. NBS is making studies seeking a more complete explanation of this and other lowtemperature phenomena. Several new and promising theories of superconductivity have been suggested as a result of the discovery of the isotope effect in superconductivity in 1950. At that time it was shown that the heavier isotopes of mercury become superconducting at lower temperatures than do the lighter ones. More recently, the investigations have been extended to isotopes of tin and thallium, and special experimental techniques have been developed for measuring the very small isotopic shifts in the superconducting transition temperature.

The annual cost of dental materials to the people of this country is over $\$ 100,000,000$. Yet for many years the only information available to the practicing dentist on the properties of these products came from the limited amount of research, mostly clinical, that was done in a few dental schools and from the research that could be financed by manufacturers of dental products.

To meet the needs of the dental profession, NBS established a broad program of research on dental materials, which over the past 30 years has aided in the solution of many of the problems encountered in dentistry. This program-sponsored by the American Dental Association, the Veterans' Administration, and the dental services of the Army, Navy, and Air Force-includes investigations of the fundamental physical, chemical, and engineering properties of dental products, the development of special equipment and methods for evaluating these properties, and the clinical application of the findings. During the past year, for example, studies were made on acrylic denture resins, plastic teeth, base metal alloys, hydrocolloid compounds, waxes, gypsum products, amalgams, precious metal alloys, cements, denture reliners, and a variety of dental instruments.

The remainder of this report attempts to suggest the nature and scope of the Bureau's work through examples of typical projects, arranged according to fields of technical activity corresponding to the major Bureau divisions.

\section{Electricity}

The work in electricity is primarily concerned with improvement of standards and methods of electrical measurement, the development of electrical standards for industry, and studies of the properties of materials. This includes establishment and maintenance of the units of resistance and voltage; their application in the development of standard apparatus for measuring inductance, capacitance, electric current, power, energy, magnetizing force, and magnetic induction; and the dissemination of standard values of these quantities. During 1951 much time was also spent on defense projects requested by the Armed Forces. Thus, to provide basic 
information for the development of new weapons, systematic studies of the magnetic properties of a variety of iron and steel alloys were carried out, and the dielectric properties of new insulating materials were measured.

\section{Beam Intensification in a High-Voltage Oscillograph}

Insulation breakdown due to lightning discharge is a frequent cause of power outages and failure of electrical equipment. Thus, for development of insulation designs, as well as for routine tests on high-voltage components, most manufacturers of high-voltage equipment now maintain surge generators which enable them to produce in the laboratory electrical surges having the same voltage and current magnitudes as those occurring on transmission lines as a result of natural lightning. For measurement of such rapid changes in artificially produced current or voltage, special highvoltage cathode-ray oscillographs are used in which a cold-cathode discharge tube is the source of the electron beam. In order to have a readable photographic record of the steeply rising front of the surge, it is necessary to use a very high-intensity electron beam for recording fast phenomena.

During the year, a new technique was developed which increases the "writing speed" of a high-voltage oscillograph to three-fourths the velocity of light. High intensification of the electron beam is obtained momentarily by superimposing a steeply rising voltage pulse on the steady voltage applied to the discharge tube of the oscillograph. The resultant increase in the intensity of the trace makes writing speeds up to 9,100 inches per microsecond easily visible. These high writing speeds can be used to study more effectively rapidly varying electrical surges and to learn more about the insulation breakdown the surges produce.

\section{Low-Temperature Dry Cells}

Conventional dry cells give reduced capacity at $0^{\circ} \mathrm{C}$ and become inoperative at about $-20^{\circ} \mathrm{C}$. Ordinarily the demand for cells to operate at these low temperatures is small. However, with increased interest in weather forecasting, cells that will operate at the low temperatures of the stratosphere are needed. Low-temperature cells are also needed in arctic regions. At the request of the Bureau of Ships, Department of the Navy, NBS developed a low-temperature dry cell that gives 30 percent of normal capacity at $-37^{\circ} \mathrm{C}$ and 100 percent at $0^{\circ} \mathrm{C}$. This improved performance was achieved by altering the electrolyte, depolarizer, and separator of conventional cells.

\section{High-Rate Batteries}

At the request of the Bureau of Aeronautics, Department of the Navy, investigations of electrochemical systems suitable for high-rate primary and secondary batteries were undertaken. The lead-acid storage battery is inherently unsuitable for high-rate discharges. However, another battery 
has been developed which shows great promise. This battery, identical in size with a lead-acid battery, delivers currents of 100 amperes for about 10 times as long as the lead-acid type. Its weight is 40 percent that of a lead-acid battery of equal capacity, and it may be used either as a primary or secondary battery.

\section{Battery Additives}

Investigations were carried out which show that battery additivespreparations frequently sold with claims that they will rejuvenate "dead" batteries - in fact have no effect on battery life or performance. Laboratory tests simulating actual service conditions were made on a wide variety of conmercial additives consisting of combinations of magnesium and sodium sulfates in various stages of hydration. The results show no significant difference between the batteries treated with these mixtures and similar untreated batteries used as controls.

During the last 30 years, more than 100 different battery additives, both powders and solutions, have appeared on the market. Most of the solutions have consisted of sulfuric acid, sometimes with additions of sodium sulfate, magnesium sulfate, or coloring matter. In connection with a broad program of research on the properties of batteries, NBS investigated the liquid preparations several years ago and found that they produced no essential difference in the charging, voltage, efficiency, or operating temperature of a battery. Today, however, most of the common additives consist of combinations of magnesium and sodium sulfates. The present investigation was therefore concentrated on these substances as representative of the powdered additives.

\section{Optics and Metrology}

A large part of NBS activity in optics and metrology was concerned with measurement, instrumentation, and standardization problems in photometry, colorimetry, illumination, optical design, photographic technology, interferometry, thermal expansivity, and measurement of length. Specific development programs were also carried on for other Government agencies. For example, at the request of the Weather Bureau, a new and less expensive system for measurement of visibility at airport weather stations was devised. A program, sponsored by the Navy, for the improvement of antisubmarine aircraft searchlights was continued. A new resolving power chart was developed for photographic lenses. An investigation was made of the thermal expansion of aluminum and some aluminum alloys for various temperature ranges between $-50^{\circ}$ and $+400^{\circ} \mathrm{C}$. High-precision equipment was applied to the measurement of the refractive indices of optical media, such as lithium fluoride and magnesium oxide, which are useful in the transmission of infrared radiation. 


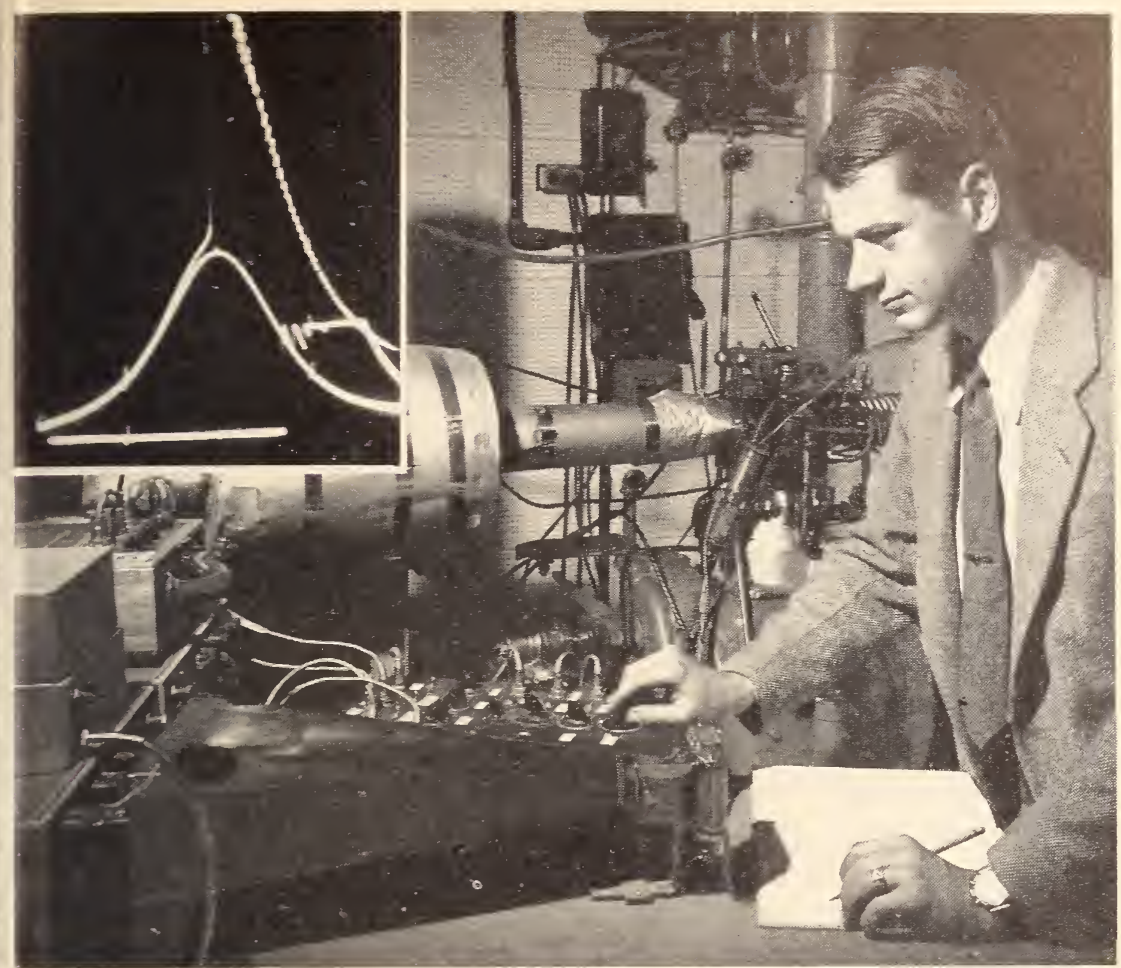

Apparatus used at NBS to study the mechanism of knock in automotive engines (p. 25). Pressure changes within the cylinder of a test engine (background, lower center) and the light caused by the reaction are shown on oscilloscopes. Upper left: Oscillogram of engine knock (jagged portion of curve).

\section{The Kinorama}

Fog at airports constitutes a serious hazard to air traffic. Extensive flight tests have been made to determine which of several approach-light systems is best designed for landing in fog, but thus far these tests have failed to bring about agreement on any one system. To compare the various systems, the Bureau developed the kinorama, a device with which a stationary pilot can evaluate the guidance provided by a system of lights. The kinorama makes it possible for the pilot to see a varying approach-light configuration as he would in flying over it in fog. The course followed in such a simulated flight is determined by the pilot himself, who acts in response to the lights that are visible to him. By recording the paths thus followed, it is possible to obtain objective records reflecting the merits of the light system. While the device is not a substitute for flight testing in the final approval of a system, it is inexpensive, objective, and free from hazards, and is not dependent upon the occurrence of fog. The project was sponsored by the Nary. 


\section{Measurement of Visibility for Aircraft}

Routine measurements of visibility at airport weather stations are made visually, the observer noting the maximum distance at which objects or lights are discernible. However, in many locations there are not sufficient properly located lights of suitable candlepower, and the cost of installing special lights is frequently prohibitive. At the request of the Weather Bureau, a system using a light at the observation station with a number of reflectors located at suitable distances from this station was developed. The reflectors are very accurately made retro-reflectors of the corner-of-cube type having an aperture of about $1 \frac{1}{4} 4$ inches. They return the light in the direction of the source without requiring precise alinement. The system uses these small reflectors, a light source similar to a flashlight, and a smallaperture telescope for viewing the reflectors. With this equipment, visibilities from a few hundred feet to 15 miles may be determined.

\section{Antisubmarine Aircraft Searchlights}

An intensive program, sponsored by the Department of the Nary, has been concerned with the development of carbon-arc searchlights used in aircraft for antisubmarine warfare. One of the developments resulting from this work was the use of a massive copper obturator for both heat protection of the searchlight mechanism and probe-type focus control of the positive carbon. The obturator-probe is mounted so that the ionized positive tail flame grazes the controlling edge of the obturator. If the positive carbon burns short, the edge of the obturator lies within the tail flame, and a relay in the probe circuit is energized; this causes the positive carbon to feed more rapidly until the edge of the obturator lies just outside the ionized portion of the tail flame. The copper obturator-probe provides extremely stable and accurate control. Moreover, unlike other probe focus controls used in the past, the copper obturator-probe does not require periodic replacement and is not subject to wear or deterioration.

\section{Resolving Power Chart}

The method now in general use for designating the quality of definition of a photographic lens is based on an evaluation of the image the lens forms of a high-contrast resolution chart. This chart contains patterns of parallel lines having various spacings. As the contrast between the lines and spaces is higher than that usually found in natural objects, it has been suggested that a test of a lens under these conditions might lead to ratings not applicable for natural objects.

NBS therefore devised a new variable-contrast resolving power chart. The new chart enables the user to obtain in a single photograph a complete record of the resolution characteristics of the lens for any value of target contrast in the range from 0.0 to 1.5 . In addition, the spacings of the lines are so arranged that the "instantaneous" value of the line frequency 
in lines per $\mathrm{mm}$ is a linear function of the distance from a "zero" abscissa line. This chart has proved successful and is being recommended for possible adoption as an international standard.

\section{Refractivity}

High-precision equipment was applied to the measurement of the refractive indices of various optical media useful in the transmission of infrared radiation. In particular, a study of lithium fluoride at $23.6^{\circ} \mathrm{C}$ was made at wavelengths from 0.4 to 5.9 microns, and a table of indices was prepared by means of a dispersion formula. For wavelengths between 0.4 and 0.7 micron, the indices were determined and tabulated at 5-degree intervals from 20 to $60^{\circ} \mathrm{C}$. Similar data on magnesium oxide from 0.36 to 5.3 microns and at temperatures of $20^{\circ}, 30^{\circ}$, and $40^{\circ} \mathrm{C}$ were determined.

\section{Thermal Expansivity of Aluminum Alloys}

An investigation was made of the thermal expansion of aluminum and some aluminum alloys (binary, ternary, quaternary, etc.) for various temperature ranges between $-50^{\circ}$ and $+400^{\circ} \mathrm{C}$. It was found that the addition of beryllium, copper, or silicon to aluminum causes a decrease in the coefficients of expansion. Copper has a greater effect than beryllium, and silicon has the greatest effect of these three alloying elements. By the use of ternary diagrams, the effects of composition on the coefficients of expansion of aluminum-copper-nickel and aluminum-silicon-copper alloys were shown. The effects of additions of two or three elements (copper, nickel, manganese, and molybdenum) on the coefficients of expansion of aluminum-silicon alloys were also determined.

\section{Heat and Power}

To provide a fundamental basis for precise measurements of heat and power, NBS has established and maintains a scale of temperature from the lowest obtainable to the highest temperatures of incandescent bodies and flames. Instruments are certified for the measurement of temperatures in this range on the International and Kelvin scales. From the measurement of temperature alone, the work broadens to include the determination of quantities of heat by calorimetry in temperature regions extending over a large part of the scale. Coordinate with the work in calorimetry is the study of the thermodynamic properties of solids, liquids, and gases. From these basic fields of research, the work branches into engineering applications, including automotive and aircraft engines. One branch extends into the fundamentals of combustion, with applications to gas turbines, jet engines, and jet propulsion. Another branch covers lubrication problems that arise not only in automotive engines but in all mechanical devices.

The Bureau is also responsible for determining and maintaining standards of viscosity and for certifying the viscosities of fluids used for calibrating viscometers. It maintains standards for the metering and carburetion of 
liquid fuels in internal combustion engines and for the determination of the octane and cetane numbers of automotive, aviation, and Diesel engine fuels. Research is conducted to increase the accuracy of these standards and to develop improved measuring instruments and apparatus. Thermal properties of pure substances and commercial materials are determined either by direct experiment or by calculation from the fundamental atomic and molecular properties of the substances; and published data on thermal properties are critically reviewed and compiled.

\section{Thermodynamic Properties of Materials}

There has long been a need for standard materials to be used by the various laboratories which make precise heat-capacity measurements. While water has been useful in the ordinary temperature range, extension of heat measurements to very low and very high temperatures has made it highly desirable to have other standards more suitable for the extreme temperatures. In 1948, the Fourth Conference on Calorimetry (U. S.) recommended three other substances to be used for heat capacity standards, namely, $n$-heptane, benzoic acid, and aluminum oxide. The $n$-heptane and benzoic acid are for the low-temperature range, while the aluminum oxide will be of value primarily at the high temperatures. Pure samples of the three materials have now been prepared and are being issued on a limited basis. Their thermal properties have been measured down to $14^{\circ} \mathrm{K}$ and up to $1,173^{\circ} \mathrm{K}$. In addition to these three materials, pure diphenyl ether has also been investigated as a standard in the low- and moderatetemperature ranges.

As a result of the application of atomic energy to both civilian and military needs, it has been necessary to learn more about the heat transfer properties of materials at increasingly high temperatures. These properties, which include heat capacity and thermal conductivity, are especially important in connection with the efficient utilization of the heat from sources of atomic energy. Among the promising heat transfer materials at high temperatures are liquid metals, especially the alkali metals. Measurement of heat capacities at temperatures as high as $1,173^{\circ} \mathrm{K}$ have now been made on sodium, potassium, and three sodium-potassium alloys. These measurements are not only more accurate than any previous measurements, but they have greatly extended the temperature range. Additional heat capacity measurements will be made on a number of other materials which are of interest. Another program has recently been initiated to measure the thermal conductivities of liquids up to about $1,300^{\circ} \mathrm{K}$. This program, like the heat capacity program, will emphasize both accuracy and extension of the temperature range of existing data.

The heat capacity of gaseous carbon dioxide is of importance in calculations of power obtainable by combustion. The values of heat capacity listed in the "NBS-NACA Tables on Properties of Gases" are calculated from spectroscopic data. In order to check these calculations by direct 

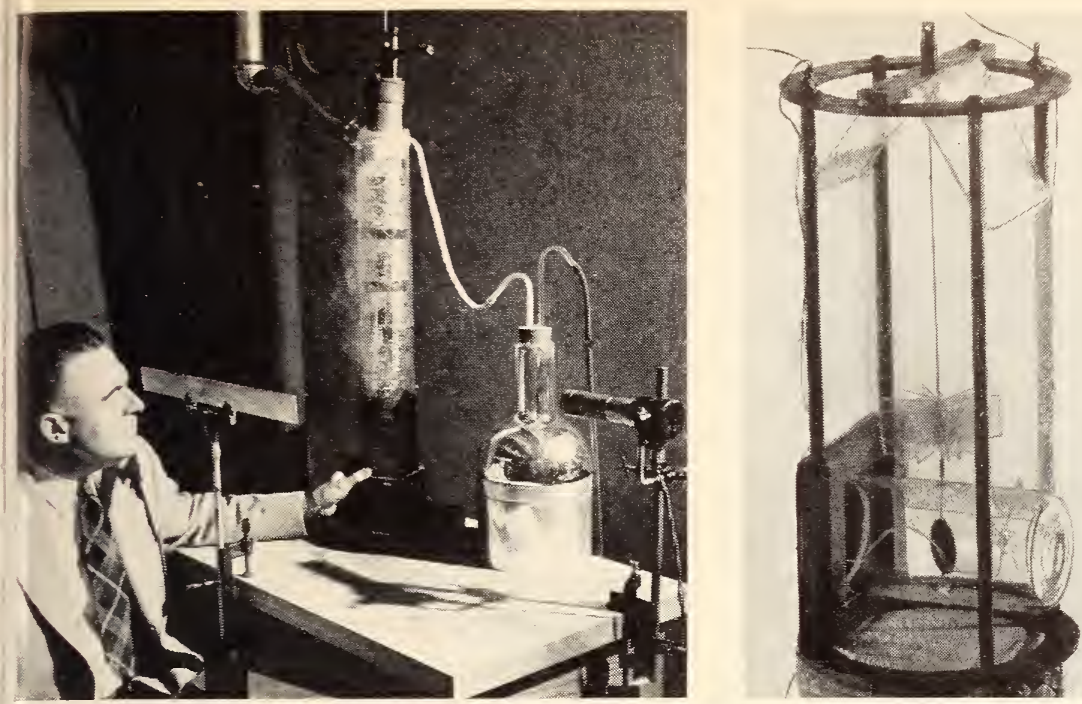

Left: Thermal Raleigh disk apparatus developed by NBS for the study of second sound and the properties of liquid helium II near absolute zero (p. 26). The new technique measures the torque exerted on a light disk (right) by standing waves of second sound set up within a resonant cavity.

experiment, accurate heat capacity measurements were made on carbon dioxide from $-50^{\circ}$ to $+100^{\circ} \mathrm{C}$ and at pressures from 0.5 to 1.5 atmospheres. These measurements showed that the generally accepted spectroscopic calculations were in error by about 0.3 percent. The spectroscopic calculations were then rechecked and brought into substantial agreement with the direct experimental values. This agreement in the ordinary temperature range should improve the values calculated spectroscopically at very high temperatures, where they are most useful and where direct measurements are impossible.

A new calorimeter was developed which measures small amounts of heat with high accuracy. This calorimeter is similar to the Bunsen ice calorimeter developed at NBS several years ago for the accurate measurement of heat capacities at high temperatures, but it uses diphenyl ether as the calorimetric medium instead of water. This has the advantages, first, that the operating temperature of the calorimeter (about $27^{\circ} \mathrm{C}$ ) is close to $25^{\circ} \mathrm{C}$, the standard temperature for thermochemical measurements; and second, that much smaller quantities of heat can be measured with high accuracy. With the new apparatus, it is now possible to investigate the heats of solution of polymers in different solvents, a field as yet unexplored but important in the study of polymers.

\section{Synthetic Rubber and Other High Polymers}

Heat-capacity measurements were made on a number of high polymers in order to derive their thermodynamic properties, which are of value in 
polymer technology and which also give information regarding the fundamental nature of polymers.

In connection with a study of polymeric materials suitable for electrical insulation at high operating temperatures, the heat capacities of raw and fabricated polytetrafluoroethylene were determined. Further studies are planned on monomeric substances suitable for the manufacture of polymers that will be resistant to high temperatures.

Under the sponsorship of the Office of Rubber Reserve, the heat capacities of three synthetic butadiene-styrene rubbers were measured. Glass transformation and crystallization temperatures were disclosed. All three rubber polymers were found to have a wide temperature range of crystallization. Since these transitions involve drastic changes in mechanical properties, they are very important in practical applications. Heats of copolymerization of butadiene and styrene, which combine to form GR-S rubbers, were derived from accurate heats of combustion of the rubbers.

Extensive investigations were carried out on the rheological properties of various rubbers and rubber solutions. These investigations revealed a striking difference in the rheological behavior of the so-called "cold" and "hot" synthetic rubbers, i. e., rubbers prepared by polymerization at $5^{\circ} \mathrm{C}$ and $50^{\circ} \mathrm{C}$, respectively. It was found that the decrease in viscosity of rubber solutions with increasing rate of flow is consistently less for cold than for hot rubbers. Measurements are being extended to other pairs of polymers showing some of the same differences in molecular structure that exist between hot and cold rubbers. These measurements may determine which structural differences are responsible for the rheological differences observed, and thus may help in explaining the superior qualities of the "cold" rubbers.

Two tire-testing installations, one for truck tires and the other for passenger tires, were completed and put in operation. Measurements of power loss and running temperatures were made on 76 truck tires and 16 passenger tires.

\section{Combustors for Jet Engines}

The performance of cylinders and spheres as flame holders for ramjet burners was observed by measuring flame stability as a function of mixture composition, temperature, and velocity. The results are expected to be useful in the design of both ramjets and thrust augmenters. In connection with turbojet combustor design, studies were made of the rates of interchange of temperature and velocity between coaxial streams of hot and cold gas under a wide variety of operating conditions.

Apparatus is being developed for measuring the rate of heat transfer between flame gas and water-cooled gas-sampling tubes. This program also involves an investigation of the quenching of chemical reactions taking place in flames. 
Equipment for measuring burning velocities was improved to reduce the effects of the apparatus itself on the measured quantities. Principal modifications include means for removing heat from the burner nozzle and for adding heat to the unburned mixture, the taking of simultaneous direct and Schlieren pictures of the flames, better control of moisture content, more accurate metering systems, the addition of sodium chloride in such a way as to color the flame locally instead of totally, and the development of more precise methods of interpreting flame shape in terms of burning velocity.

\section{Temperature and Composition of Flames}

Studies of flame temperatures were carried out by spectroscopic methods in the ultraviolet region of the spectrum, where such short-lived intermediates and reactants in the combustion process as $\mathrm{OH}, \mathrm{CH}, \mathrm{C}_{2}$, and $\mathrm{O}_{2}$ emit radiation from states with excess electronic energy. In the infrared region, where the longer-lived reactants and products of combustion, such as $\mathrm{OH}$, $\mathrm{H}_{2} \mathrm{O}, \mathrm{CO}$, and $\mathrm{CO}_{2}$, emit radiation from states with excess vibrational energy, studies with a high-resolution spectrometer revealed much hitherto unrecognized structure and also permitted temperature determinations. Additional experiments now under way should make possible the determination of the concentrations of the various gases in flames from the intensities of emitted radiation, thus providing further basic information concerning the chemical and physical processes in burning.

\section{Engine "Knock"}

Increased understanding of the mechanism by which "knock" is produced in automotive engines resulted from compression-ignition studies initiated the previous year. One of the chief limitations to the maximum power which can be realized from an automotive engine is its compression ratio. If the compression ratio is increased beyond the limit allowed by the fuel, detonation, or knock, occurs, with consequent loss in power and possible damage to the engine. Although this problem has been recognized for many years, it is still not completely understood.

In normal, nonknocking combustion, the flame initiated at the spark plug travels evenly across the combustion chamber, generating pressure which pushes the piston down. In knocking combustion the flame progresses for a time in the usual way, burning most of the charge evenly. Ultimately, however, some of the unburned charge, known as the "end gas," is compressed to a high pressure, which causes it to autoignite and to burn with explosive violence. The sudden release of energy acts as a hammer blow on the piston, rather than a gradual push, and a shock wave is initiated which is reflected back and forth across the combustion space. A large portion of the energy released in this way is not converted to power but causes a wasteful increase in temperature. 
Seeking further information on the basic nature of detonation, NBS is studying the conditions prevailing in the end gas. To provide the necessary data, apparatus has been constructed in which the end gas is simulated. In this apparatus, a mixture of fuel and air is inducted into a single-cylinder test engine driven by a dynamometer. While the piston compresses the mixture to the conditions of temperature and pressure at which autoignition takes place, the pressure in the cylinder and the light emitted by the reaction are shown on oscilloscopes as functions of crankangle, or time.

From this study two distinct stages in autoignition can be recognized. In the first stage, a low-intensity blue luminescent glow is apparent. This is followed by a sharp rise in light emission as the reaction goes into the second stage. A small increase in pressure accompanies the emission of light in the first stage. At the start of the second stage, light-emission and pressure increase sharply unil the reaction is complete.

A spectogram of the light emitted by the first stage showed that the emission is caused by activated formaldehyde. This spectogram is identical, in the 3,650- to 5,000-angstrom range, to that reported by workers who made measurements on the light from "cool-flame" oxidation of other fuels in glass tubes. Thus, the first stage in the autoignition process is identificd as equivalent to the previously recognized "low-temperature" oxidation phase of combustion.

\section{Low-Temperature Physics}

Investigation of the isotope effect in superconductivity was continued. The discovery of this phenomenon in 1950 demonstrated a connection between the isotopic constitution of a superconductor and the superconducting transition temperature. It was shown that the heavier isotopes of a given element become superconducting at lower temperatures than the lighter ones. This knowledge has led to a better understanding of the nature of the superconducting state and has stimulated theoretical physicists in this country and abroad to suggest new and promising theories of superconductivity.

The NBS investigations, originally made with mercury isotopes, were extended during 1951 to isotopes of tin and thallium, loaned by the Atomic Energy Commission. Special experimental techniques were developed for measuring the very small isotope shifts. Measurements of the critical magnetic field for the destruction of superconductivity are yielding interesting information on the thermodynamic properties of isotopic mass.

Studies of the properties of liquid helium II, sometimes referred to as a fourth state of matter, provided further substantiation for the present concept of this substance and brought to light methods for measuring its basic thermodynamic properties. During the year the observation of internal counterflow between the two fluid components of liquid helium II by means of the thermal Rayleigh disk was put on a quantitative basis. This internal counterflow constitutes the mechanism for the anomalous wavelike 


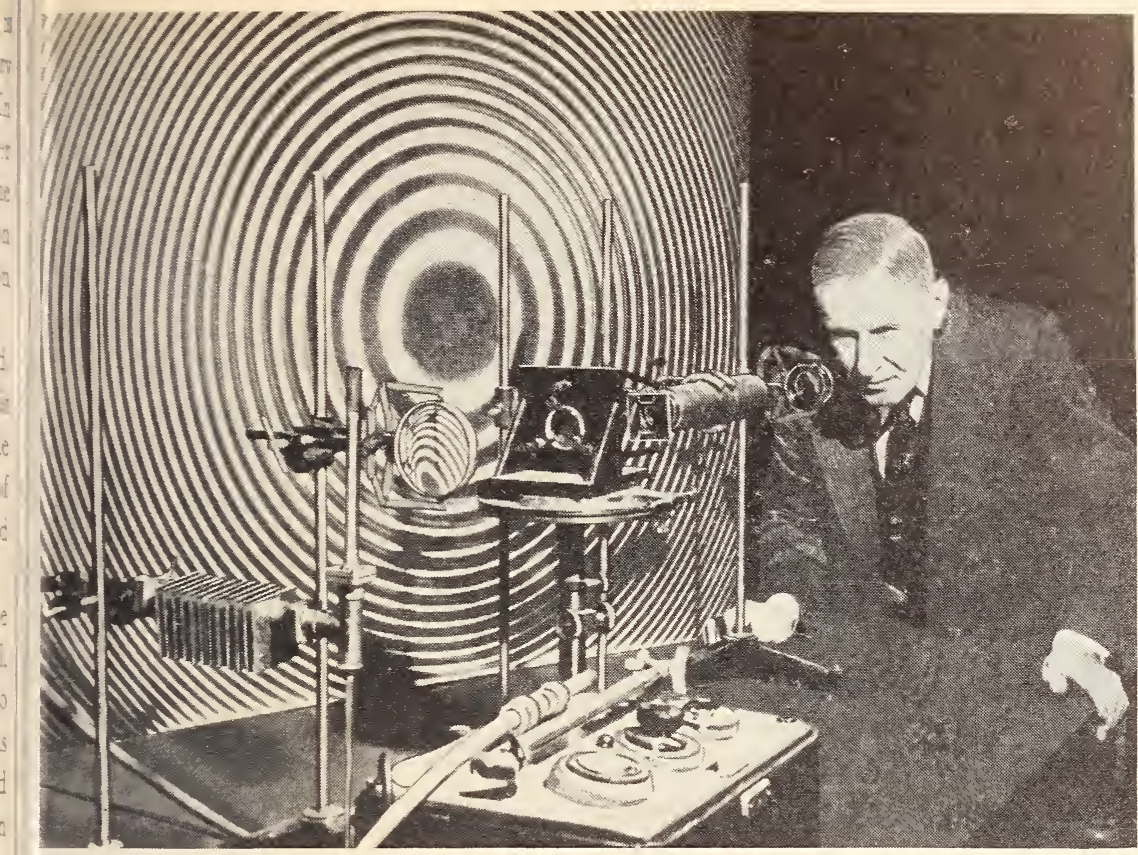

An electrodeless mercury 198 lamp (left foreground) was made available to science and industry as an ultimate standard of length (p. 29). Length measurements based on the circular interference fringes (background) of green light from the lamp can be made with an accuracy of one part in 100 million.

method of heat transfer known as second sound. The resultant torque exerted on the Rayleigh disk provides a direct measure of the heat current and of second-sound intensity.

Such observations have now thoroughly verified the generalized expression for the hydrodynamics of helium II in the temperature range from the $\lambda$-point $\left(2.19^{\circ} \mathrm{K}\right)$ down to $1.2^{\circ} \mathrm{K}$. This expression relates the hydrostatic pressure in helium II to second sound. The precision of measurement has in fact reached the point where the thermal Rayleigh disk actually functions as a calorimeter, measuring heat capacity in an isothermal system in terms of the small temperature fluctuations of second sound. Use of a semipermeable thermal Rayleigh disk, which responds selectively to the two fluid components, was introduced for the measurement of the other thermodynamic properties of liquid helium II.

At the request of the Atomic Energy Commission, the Bureau undertook and completed a short program for the measurement of some previously undetermined properties of hydrogens. This program consisted of three parts: measurement of vapor pressures of hydrogen $\left(\mathrm{H}_{2}\right)$, deuterium $\left(\mathrm{D}_{2}\right)$, and hydrogen deuteride (HD) from low pressures to their critical points; measurements of dew points of a number of binary mixtures of these substances at pressures below 1 atmosphere; and measurement of critical constants of the same substances. 


\section{Medical Physics Instrumentation}

Several projects in medical physics were undertaken during the past year. These projects have been concerned primarily with research and development leading to the construction of new or improved instruments, and with the testing of the completed units for reliability and safety.

In cooperation with anesthesiologists, an instrument is being developed to measure continuously, to indicate visually, and to record systolic and diastolic pressure, pulse rate, arrhythmia, and respiration rate and volume. During surgical procedures it is important that the condition of the patient be known at all times. The anesthesiologist, who is responsible for this part of the operative procedure, periodically checks pertinent physiological variables. Unfortunately, during a crisis, at which time it is vital to know the trend of these variables, the anesthesiologist is intensely occupied with his other duties. At such times an automatic recording instrument would be valuable. It would also be a distinct aid in those phases of clinical research that require a knowledge of the behavior of certain physiological variables over long periods.

Two pumps to be used as artificial hearts have been designed and constructed. These pumps make possible a wide and independent variation in rate (beats per minute), stroke output, and the fraction of the total cycle during which blood is being injected. With these instruments, it will be possible to study the effects of such variables on circulatory dynamics, e. g., arterial pressure, blood flow to other organs, and rate of venous return. They may also provide a valuable tool for the study of shock and hypertension.

A study of the skin-temperature differences between corresponding points on the limbs of patients having peripheral vascular disorders was made at the Naval Medical Center, Bethesda, Maryland, in cooperation with members of the hospital staff. This provided an opportunity to compare three temperature measuring instruments - a radiometer, a thermocouple, and a special resistance thermometer-under the conditions prevailing in a hospital ward. The comparison indicated that a thermocouple is reliable to within 0.3 degree $\mathrm{C}$ when compared with the radiometer. The difference between the resistance thermometer and the radiometer amounted to as much as 1 degree $\mathrm{C}$ at times.

\section{Atomic and Radiation Physics}

The results of basic research in atomic and nuclear physics are being applied to an increasing extent in medicine, industry, and national defense. This has made necessary new techniques, instruments, standards of measurement, safety provisions for workers and consumers, standard samples for calibration purposes, and methods of testing and evaluation in this rapidly expanding field. NBS is now engaged in a broad program of fundamental research and standardization dealing with atomic and molecular spectra, 
radiometry, physical electronics, electron optics, mass spectrometry, X-rays, radioactivity, and atomic and nuclear constants. During the year, the increased emphasis on national defense was reflected in this program. Several classified projects were undertaken for immediate application to military use. Other lines of investigation-for example, basic studies of radiation phenomena and measurement of atomic and nuclear constantsreceived special attention because they provide a stockpile of fundamental knowledge. Typical programs are the studies of protection against radiation, the development of radiation detecting instruments, research on semiconductors and solid state electronics, and the development of new techniques in electron physics and mass spectrometry.

\section{Atomic Standard of Length}

An ultimate standard of length was made available to science and industry. The standards consist of spectroscopic lamps containing a single pure isotope of mercury known as mercury 198. These lamps enable any research organization which has the auxiliary optical equipment to have for the first time an ultimate primary standard of length in its own laboratories. They will be available to qualified government, industrial, and educational laboratories, both in this country and abroad, which are engaged in precision length measurements and related research.

Although the world's official primary standard of length is still the distance between two lines on a metal bar, practically all precise measurements of length in the 20th century have been made and will continue to be made with light waves. When accuracy greater than the part in 10 million possible with the standard meter is necessary, only the new spectroscopic standard meets the need.

The NBS-Meggers Mercury 198 Lamps contain about one milligram of mercury 198, obtained by the transmutation of gold in a nuclear chainreacting pile at the Oak Ridge National Laboratory. The mercury 198 is sealed in a small glass tube and caused to glow brightly by the application of high-frequency radio waves. The light waves emitted by the single isotope have very sharply defined wavelengths which can be used for length measurements of great precision. These particular light waves are uniquely characteristic of the mercury and remain unaltered with time.

The new standard of length is based upon the wavelength of the green light emitted by the lamp. This wavelength, near 21 millionths of an inch, is consistently emitted with a reproducibility greater than one part in a billion. Length measurements based upon it can readily be made with an accuracy of one part in 100 million. New apparatus now under construction at NBS is expected to extend the accuracy to one part in a billion.

\section{Magnetic Moment of the Proton}

Experiments which provide the best values ever obtained for the magnetic moment of the proton both in absolute units and in nuclear magnetons were 


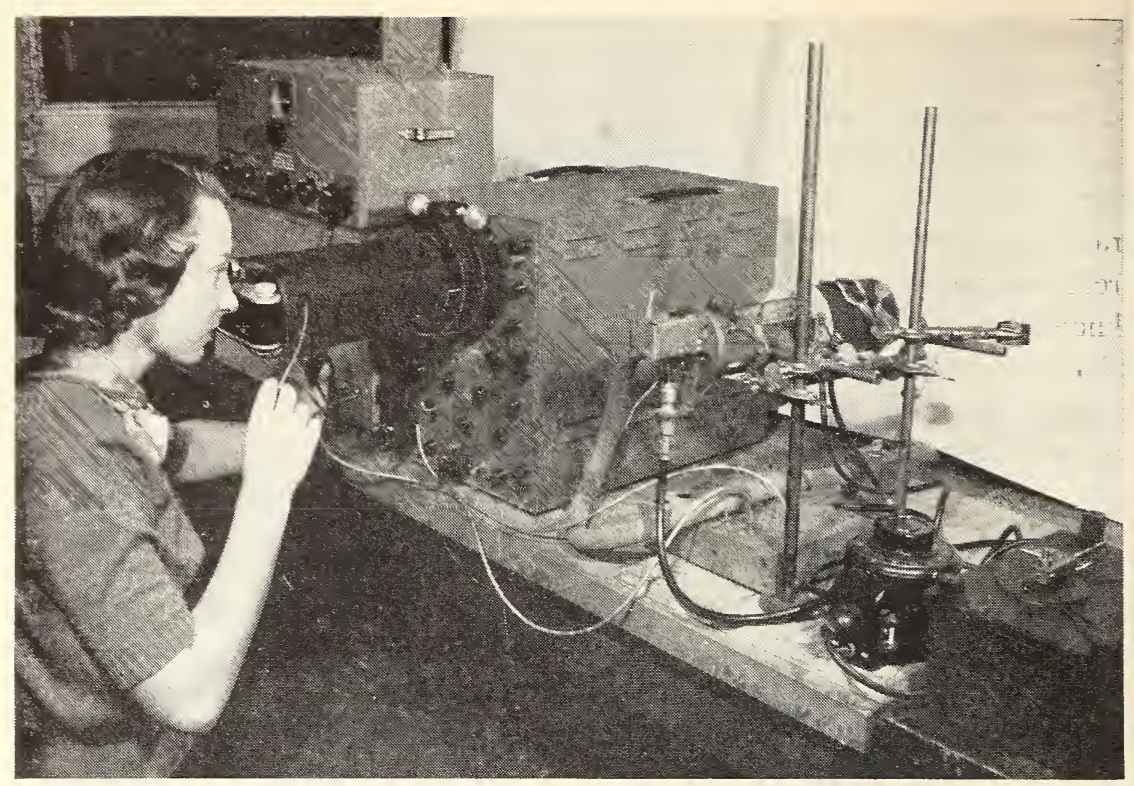

Specially designed apparatus used at NBS to study the effects of crystal imperfections on the electrical properties of semiconductors (p. 31).

completed during the year. Since the proton moment is intimately related to other atomic constants, these experiments have been a major factor in the re-evaluation of all atomic constants.

Two years ago NBS measured the proton moment in absolute units by means of nuclear resonance techniques, attaining an accuracy of one part in 13,000. By persistent effort and improvements in technique and instrumentation, the accuracy has now been increased to one part in 45,000, and the magnitude of a small frequency shift-the diamagnetic correction-has been determined. This shift is present because the determination must be made on bound protons, usually in water or mineral oil, rather than on the free proton directly. It was found possible to calculate the diamagnetic correction for molecular hydrogen gas from theoretical considerations. By accurate measurement of nuclear resonance frequencies in water and oil as well as in hydrogen gas, the theoretically determined value for hydrogen gas could then be used to establish the frequency shift between the free proton and the protons in water and oil. The diamagnetic correction for water was thus found to be one part in 1,600,000. This result removed any possibility of a significant error in the reported value of the proton moment due to the frequency shift.

The experimental determination of the magnetic moment of the proton directly in nuclear magnetons required an entirely different technique. The omegatron, developed the previous year for this purpose, was used. The definitive value obtained is $2.79276 \pm 0.00006$ nuclear magnetons. 


\section{Spectra of Artificial Elements}

The first comprehensive and authoritative descriptions of the optical spectra of technetium and promethium, two artificially produced chemical elements, were completed. Small samples of these elements, isolated from uranium fission products at the Oak Ridge National Laboratory, were made available for spectroscopic investigation by the Atomic Energy Commission. The spectroscopic studies identify the strongest emission lines of the two fission products, thus providing a sensitive test as well as a new incentive in the search for technetium and promethium in natural sources.

Although actinium was discovered more than 50 years ago, no pure sample has ever been segregated from natural ores or minerals. However, a sample was recently prepared by transmutation of radium in the Argonne National Laboratory, and the arc and spark spectrograms were sent to NBS for measurement and analysis. More than a thousand new spectral lines characteristic of actinium were measured. Most of the stronger radiations of neutral atoms and of singly ionized atoms were identified as transitions between derived energy levels which arise uniquely from certain electron configurations. It is found that the electron binding energies in actinium atoms parallel those in yttrium more closely than in either lanthanum or scandium.

\section{Photoconductivity of Semiconductors}

The research program on the properties of semiconducting materials was extended to include a study of photoconductivity in semiconductors, particularly in the infrared region of the spectrum. In addition to providing data for the development of useful photocells, these optical investigations are contributing much valuable information on the electronic structure of solids. They thus form an important complement to the studies of the Hall effect which are now in progress and the current development work on solid-state rectifiers and transistors.

The photoconductivity studies are concerned chiefly with the infrared region because of the scientific importance of photocells sensitive in this rather inaccessible portion of the spectrum. While most of the work thus far has been concerned with the assembly of the complex optical and electrical instrumentation needed for making measurements of infrared photoconductivity, some time has been spent on the exploration of possible materials of interest for further detailed study. It had been known since World War II that various heavy-metal sulphides, selenides, and tellurides are infrared sensitive. Now several intermetallic compounds have been found to have a similar sensitivity, and the previously unrecognized semiconducting nature of some of these compounds has been established. These compounds are being studied by the conventional Hall-effect and conductivity methods to determine their suitability for use in other solid state electronic devices. Although this investigation is in a very early stage, 
it is apparent that an interesting and possibly very useful group of compounds has been encountered. In particular, the high electron and hole mobilities, approaching those in germanium, are noteworthy, as this is one of the properties that make germanium so useful in transistors and rectifiers.

\section{Radiation Detecting Instruments}

As a result of the wide industrial and medical uses of atomic radiations, it is becoming increasingly important to have adequate instruments for their measurement and detection. Extensive radiation instrument programs are being carried out by the military services, the Atomic Energy Commission, and the Federal Civil Defense Administration. Such instruments are sent to the National Bureau of Standards for prototype study and calibration. By concentrating all of this work in one laboratory, more effective coordination of the efforts of the various Government agencies concerned is achieved.

During the past year several new types of instruments were submitted for study at various stages of development. Through analysis of their performance, it was possible to guide the manufacturers into effective improvements, thereby making available more accurate and suitable instruments. Among the devices studied were instruments for use in personnel monitoring, survey meters used in locating and determining the extent of radiation, pocket ionization chambers, pocket dosimeters, and other related detectors.

Under many conditions where radioactive substances are present, particularly in cases involving the explosion of atomic weapons, it is necessary to use some type of photographic film meter for measuring radiation at a given point. This has been difficult to accomplish with photographic emulsions as used in the past. A new type of film container was therefore developed which uniformly measures radiations covering a wide range of penetrations. Measurements made with this film meter report the actual dose delivered at a given point more directly than any other film meter heretofore available.

To provide the military services with suitable means for instrument calibration under military field conditions, a radiation source was developed containing 10 curies of radioactive cobalt. Various types of associated gear which can be broken down into sufficiently small units to permit transportation, erection, and utilization under field conditions were also developed. These include containers, jigs for holding instruments, and shielding devices.

\section{Protection Against Radiation}

$\mathrm{X}$-ray shielding studies are being made with the aid of the new NBS 50 -million volt betatron. Walls used as protective barriers against radiation from X-ray machines must be thick enough to provide sufficient shielding for the safety of personnel; yet, in the interest of economy, care must be taken to avoid superfluous protection. In the present experiments 
concrete barriers varying in thickness from 1 inch to 4 feet are bombarded with X-rays from the betatron having energies from 10 to 50 million volts, and the intensity of the radiation which goes through the concrete is measured. Analysis of data accumulated in these attenuation studies is expected to provide the National Bureau of Standards with additional information for assisting those who plan X-ray installations.

For the successful design of X-ray-protective barriers, it is necessary to know the spatial distribution of the radiation from the target and the absorption curves for the different directions in which the radiation will be scattered. Attenuation curves are now available for million-volt $\mathrm{X}$-rays in the direction of the useful beam. Preliminary investigations over the past few years had seemed to indicate that the radiation which is scattered $90^{\circ}$ should be much softer than that of the useful beam and should therefore require a thinner protective barrier for safe operation. However, measurements recently completed at NBS indicate that the $90^{\circ}$-scattered radiation and the useful beam are quite similar in energy and that therefore barrier requirements are nearly equal.

In the design of shields for nuclear reactors or "piles," it is necessary to. know how much radiation is scattered in and from large masses of material. From the standpoint of safety and economy, the simplest method for obtaining such information is to perform experiments on a small scale, rather than with an actual pile. At the request of the Office of Naval Research, a program designed to secure this data has been undertaken. In one of the experiments, gamma rays from radioactive cobalt are scattered from a slab of lumber, and the intensity of the rays which are scattered back in the direction of the source is measured with respect to their angle of incidence. Another experiment is a study of a radiation source approaching the edge of a medium-in this case, water. A source of radiation and a detector are moved upward toward the surface of water in a large tank, and the amount of radiation which is scattered out of the medium through the surface is determined. Analysis and interpretation of data obtained from these experiments are applicable to the solution of large-scale design problems.

\section{$\mathrm{X}$-Ray Equipment}

During World War II it was evident that ordinary civilian X-ray apparatus, although appropriate for permanent installations in noncombat areas, is not adequate for military field use. It is too heavy and bulky; nor is it rugged enough to withstand rough field-handling. At the request of the Department of the Army, a program was initiated at NBS for the development of X-ray equipment suitable for operation in the field. As the result of work extending over the past four years, a standardized line of X-ray equipment for military field-use has been developed, providing facilities far more suited to the purpose than those available during World War II. 


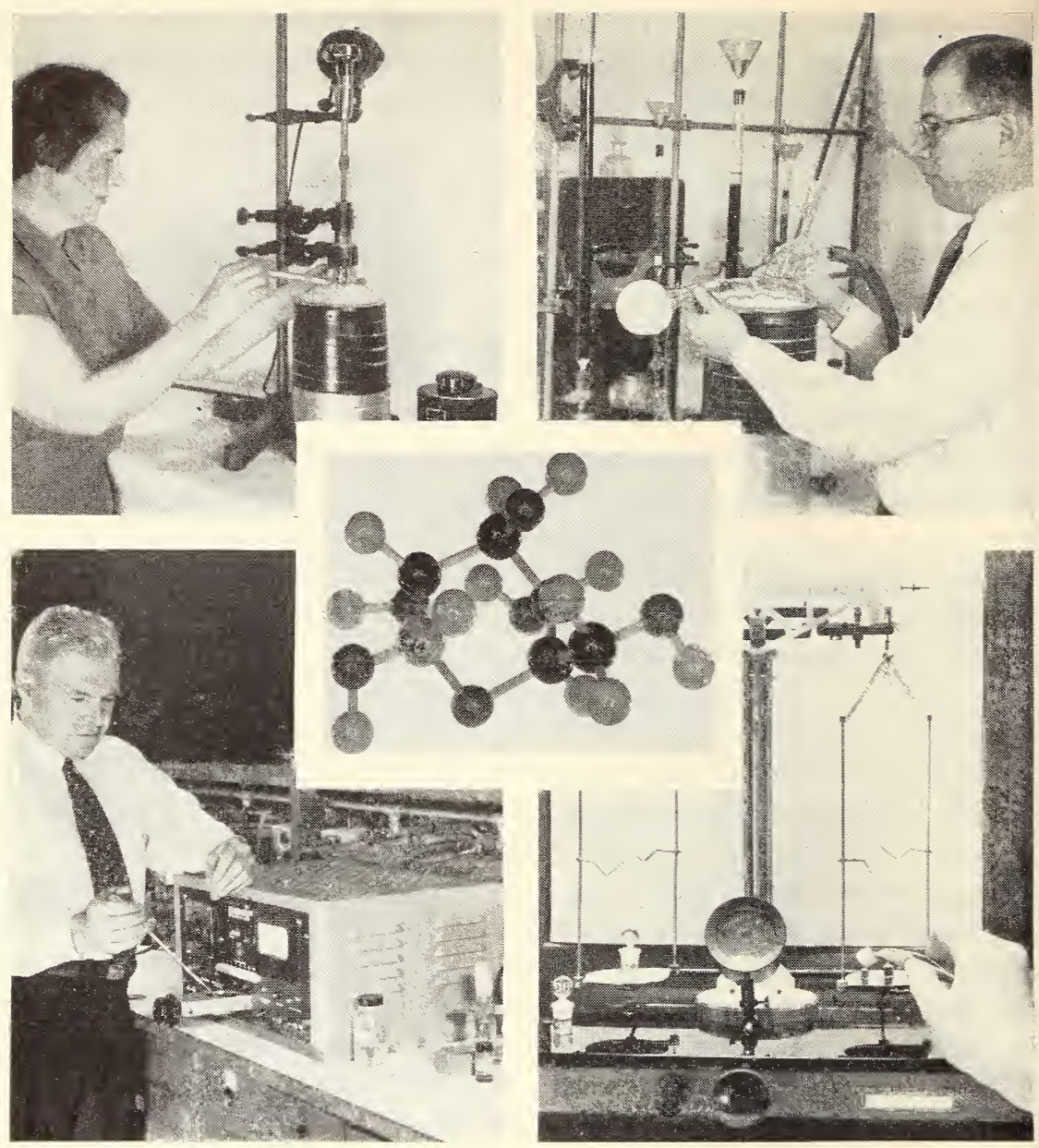

Sugars having radioactive atoms of carbon 14 in specific positions within the molecule (center) were prepared for the first time in good yield and high activity (p. 36). In the NBS procedure, the lactone containing carbon 14 is reduced to the radioactive sugar by adding specially prepared sodium amalgam (upper left). To remove water from the solutions, a convenient vacuum drying technique (upper right) is used which avoids dispersal of the activity. Before distribution, the radiation emitted by the sugars is measured on a radiation counter (lower left), and the exact weight of each sample is determined (lower right).

Extensive studies were made on various prototype models. One major advance was the change from oil to gas insulation in the full-wave generator. This change reduces weight, greatly facilitates replacement of rectifier tubes and repair operations, and permits the unit to be shipped filled with the gas and ready to operate. The selection of standard shockproof cable terminals was another big step. Up to that time the units procured by the military services were of different manufacture and had different types of cable terminals. Now that these have been standardized, maintenance and replacement are greatly simplified. The advances in 
design resulting from this program promise also to be of significance in the improvement of civilian X-ray equipment.

\section{Atomic and Molecular Ions}

At the request of the Naval Research Laboratory, the NBS radiofrequency mass spectrometer, which separates ions by means of a readily produced radio-frequency electromagnetic field, has been further developed so that a rapid analysis of light gases may be made, and the results of the analysis continuously displayed on a cathode-ray tube. The instrument takes the form of a compact unit that is reasonably portable and relatively inexpensive. While its resolution is not at present as good as conventional magnetic mass spectrometers, it is sufficient for many practical analytical problems, such as the detection of poisonous or explosive gases in mines or submarines. Similar instruments, without cathode-ray tube presentation, are now being used at NBS for the study of chemical reactions that are of importance in the ionized gas layers of the upper atmosphere and for the study of the formation of ions by electron bombardment of gases.

\section{Electron Physics}

To devise electrode systems that will produce the force fields required for driving a beam of electrons in a predetermined path is a fundamental problem in electron physics. Analytical solution of such problems is timeconsuming and tedious, and empirical methods are used in practice. During the year an adaptation of the resistance-network analog computer was constructed: by short-circuiting the network in a pattern simulating the shape of electrodes, it is possible to obtain the necessary data for axially symmetrical systems. Measurements on the network can be accurate to one part in 50,000. The machine was used successfully for the determination of the potential distribution between components of an electron gun, proving both efficient and convenient in determining the electrode shapes that best satisfy the essential conditions. While the method has resulted in considerable saving of labor, its greatest advantage lies in the increased accuracy that can be obtained. Problems in hydrodynamics, aerodynamics, heat transfer, and other fields can also be solved with this computer.

An electron optical bench was developed to measure the optical characteristics of electron lenses, and an electron optical disk was devised for the study of electron beam focusing and deflection problems. The optical disk was found very useful not only for demonstration purposes but also for semiquantitative work such as determining the optimum shape of pole pieces for a simple type of beta-ray spectrograph.

\section{Tables of Nuclear Data}

The first edition of Nuclear Data was issued as NBS Circular 499 on September 1, 1950, and the first supplement to the circular appeared on April 25, 1951. These tables represent a comprehensive collection of ex- 
perimental values of important physical constants, such as half-lives of radioactive materials, radiation energies, relative isotopic abundances, nuclear moments, cross sections, and nuclear decay schemes.

Investigations in nuclear physics have progressed so rapidly during the last decade that it has been impossible for individual research workers to keep currently informed on all of the data being accumulated. New properties have been published in a number of different publications, none of which covered the entire field and none of which contained provision for revision of the data to include new or more complete results. This has led to much duplication of effort. The Atomic Energy Commission therefore requested the Bureau to undertake the preparation of an exhaustive compilation of the more recent measured values of nuclear constants and properties. Plans have also been made for the periodic revision of this compilation by means of supplements to cover results appearing since the publication of the initial volume.

\section{Atomic Energy Levels}

Volume II of Atomic Energy Levels was completed. Designed to meet the needs of workers in nuclear and atomic physics, astrophysics, chemistry, and industry, this volume gives all known facts concerning atomic energy levels for the 18 chemical elements with atomic numbers from 24 (chromium) to 41 (niobium), inclusive, as derived from the analyses of 152 optical spectra. The data also include electron configurations, spectral term designations, energy intervals, and magnetic splitting factors of many of the levels. Volumes I and II of Atomic Energy Levels are the first of a series being prepared at NBS as part of a general program on atomic energy levels derived from observations of the optical spectra of atoms and ions.

\section{Chemistry}

A wide range of fundamental and applied research is conducted in physical, analytical, organic, and inorganic chemistry. Special laboratories are devoted to organic protective coatings, detergents and absorbents, carbohydrates, metals and alloys, pure substances, electrodeposited coatings, gases, and acid-base indicators and $\mathrm{pH}$ standards. Representative activities include the development of new methods of chemical analysis, studies of the nature and causes of chemical reactions, determination of the physical constants of substances of interest to science and industry, and development of specifications for commodities used extensively by the Government. Most of the NBS standard samples, critical in industrial quality control and in research throughout the Nation, originate in this division.

\section{Radioactive Carbohydrates}

A program was initiated to develop practicable methods of preparing sugars and other carbohydrates with radioactive carbon atoms located in specific positions within the molecule. The so-called "cyanhydrin syn- 
thesis" was chosen for development, and each step in the procedure was studied and improved, with the result that the over-all radiochemical yield of the sugars was increased 5- to 10 -fold over that obtained by previous workers. Glucose, mannose, galactose, and lactose having an atom of radioactive carbon 14 located in "position one" of the carbon chain were prepared for the first time in good yield and high activity. The practical and theoretical applications of these labeled compounds are numerous in chemical and biological laboratories, and small amounts are being supplied to qualified investigators; larger quantities will be available in the near future.

In the course of the work, a method was developed for estimating the radioactivity of $\mathrm{C}^{14}$ compounds by direct count in formamide solution. The method greatly decreases the time and labor required for the determination of $\mathrm{C}^{14}$ in tracer experiments. A simple procedure was also devised for estimation of the molecular weight of polysaccharides and for obtaining labeled polysaccharides for biological and other studies. The process involves the addition of $\mathrm{C}^{14}$-labeled cyanide to the terminal reducing group of the polysaccharide; this is followed by conversion to the corresponding radioactive carboxylic acid. The procedure not only provides a simple, reliable method for the determination of molecular weight but also offers a means for preparing radioactive polysaccharides for clinical and biological use. The procedure has made possible the accurate characterization of commercial dextran blood plasma substitutes and their fractions with regard to average molecular weight.

\section{Dextran as a Substitute for Blood Plasma}

Under the sponsorship of the Office of the Surgeon General, Department of the Army, an investigation of dextran as a blood plasma extender is being carried out. Various samples of dextran are being characterized with regard to molecular weight, molecular weight distribution, size and shape distribution, and other properties that affect their utility as plasma substitutes. The physico-chemical methods employed are fractionation, viscometry, osmometry, ultracentrifugation, and light-scattering. In addition, a method of labeling dextran with the radioactive $\mathrm{C}^{14}$ isotope has been devised. This achievement makes available for clinical use a supply of dextran that can be easily followed during its physiological life; it also appears to make possible an extremely simple determination of the average molecular weight of dextran.

\section{Acidity and Basicity in Organic Solvents}

Until about 25 years ago, knowledge of acids and bases was restricted almost entirely to their behavior in aqueous solutions. More recently, the importance of understanding acid-base reactions in nonaqueous media has become evident as a result of their deleterious effects in such materials as lubricating oils and dry-cleaning solvents. A fundamental study of acidity 


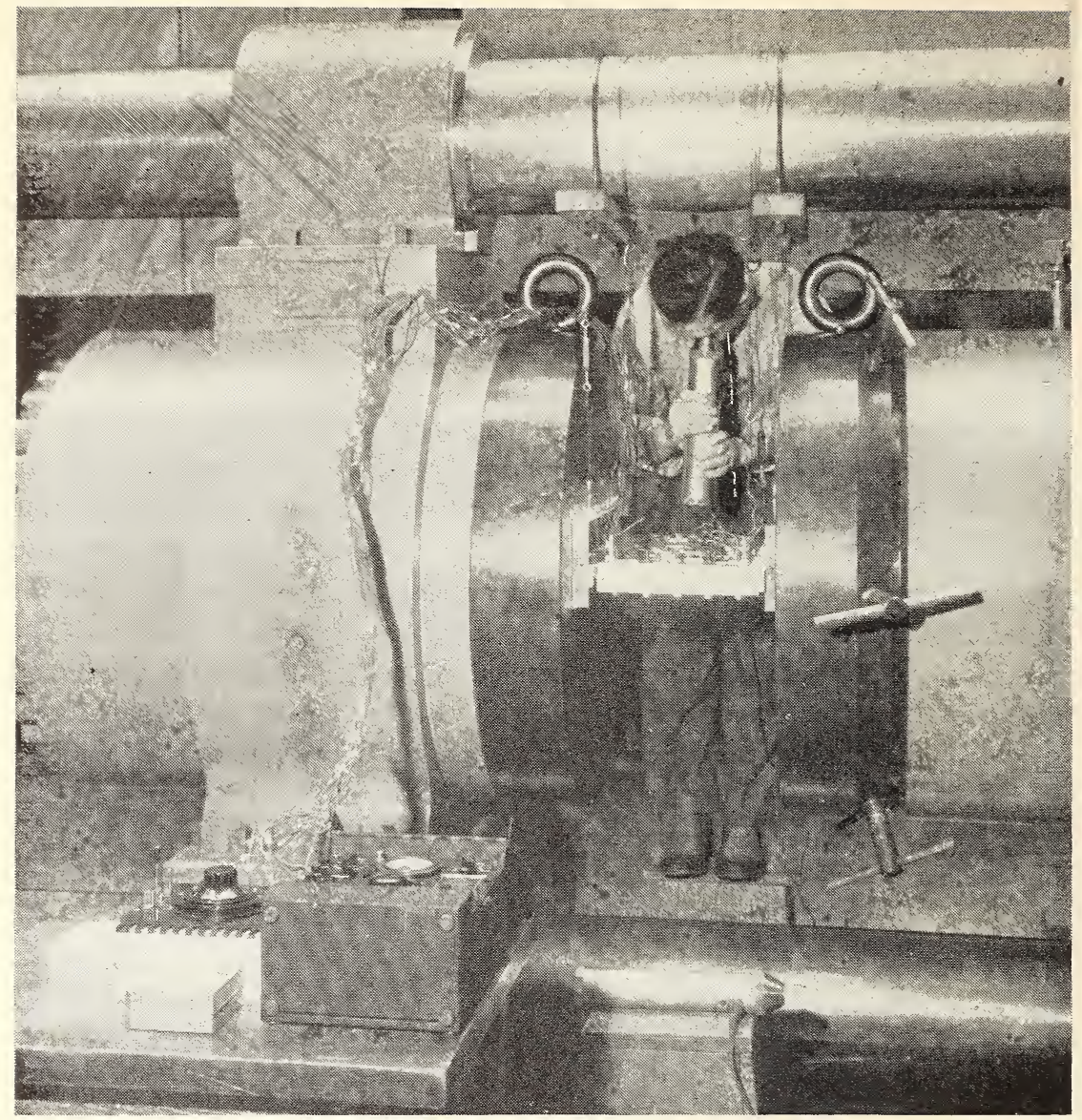

An airplane wing panel (right of center) is tested in the Bureau's 120,000-pound compression testing machine.

and basicity in inert solvents, supported in part by the Office of Naval Research, is in progress. These investigations have resulted in the development of new indicators which show the presence of acids or bases in organic media by sharp changes in color. Of particular interest has been the discovery that various types of organic bases show specific differences in their reactions with acids in an inert solvent; this is in contrast to their uniform behavior in water.

\section{Interchangeability of Fuel Gases}

When gas-burning appliances have been adjusted for gas of one composition, flame characteristics will generally change if another kind of gas is substituted. While some substitutions will be entirely satisfactory, others will result in dangerous or unsatisfactory operation. For example, flames may go out or carbon monoxide may be liberated. Because city gas systems must sometimes change from one source of supply to another, or must 
temporarily supplement their primary source to meet unusual conditions, it becomes important to be able to predict the effect of a proposed change. During the year, a new method was formulated for predicting the extent to which different gases will depart from exact interchangeability. Using six "indexes," four of them new and all easily computed from the gas composition, this prediction method appears to be more accurate than any method hitherto proposed.

\section{Los Angeles "Smog"}

"The Los Angeles (California) "smog" is an example of a type of industrial air pollution that is becoming increasingly troublesome and hazardous. Prior to the summer of 1950 , three years of intensive investigation had failed to disclose definitely the origin of this smog. At that time experiments in plant damage at the California Institute of Technology first suggested that the products of oxidation of unsaturated hydrocarbons in the smog might be the cause of eye and respiratory irritation. Shortly thereafter, NBS began an examination of the Los Angeles County air, using a new method. In this method, the smog was first concentrated on a filter at liquid oxygen temperatures; the concentrate was then separated into fractions by isothermal distillation, and the distillates were analyzed in the mass spectrometer. Many compounds were isolated from the Los Angeles air, and about 60 of these were identified or tentatively identified. The gaseous phase of the smog appears to be largely composed of hydrocarbons and their products of reaction with ozone and nitrogen dioxide. The oxidation products produced in these reactions are apparently responsible for the injurious effects on plant and animal life. While the analytical problem was very complex, the new method made it possible to isolate and identify the important gaseous pollutants, which were present in extremely small amounts, and indicated the measures necessary to eliminate this disturbing part of the smog.

\section{Infrared Spectra of Alcohols}

In many chemical compounds, hydrogen bridges between adjacent molecules are known to be responsible for such physical properties as unusually low boiling points, high viscosities, and tensile strengths. In preparation for an investigation of the molecular structures of plastics, sugars, and cellulose, hydrogen bridging was studied in a series of 11 alcohols by means of infrared spectrometry. The information obtained will aid in the interpretation of the spectra of these substances and should lead to a better understanding of their molecular structure. This, in turn, will help explain some of their physical properties.

\section{Electrodeposition}

The work on electrodeposition was principally concerned with the application of electroplating to military devices, but some effort was also devoted 
to projects of broader interest. The staff continued its investigations of methods for depositing in good physical form unusual metals such as molybdenum, tungsten, titanium, and zirconium. Both fused salts and organic baths are being intensively investigated. In the course of this research a new type of organic bath was developed from which dense, ductile deposits of aluminum can be produced. This plating bath may have important applications in electroforming articles such as waveguides.

A microhardness tester was developed for measuring the hardness of electrodeposits at elevated temperatures. The new apparatus is based on the diamond-indentation method now used to measure the high-temperature hardness of bulk metals. However, because of the relative thinness of electroplated coatings and their softness at high temperature, the device has been especially designed to make indentations of microscopic depth under very low loads. Other advantages over previous instruments should also make the tester of value for determining the hot-hardness of bulk metals; in particular, it is expected to find important application in studies of the properties of new types of high-temperature alloys.

\section{Development of Analytical Methods}

Spectrochemical analysis is based on measurement of spectral line intensities, which vary as a function of the concentration of the emitting element and of the conditions of excitation. Little quantitative data have been available regarding the effects on intensity of changes in the excitation conditions. To learn more about these effects, an investigation was made of the excitation of iron spectra by the spark obtained from condensers charged to comparatively low voltages. Mathematical expressions were derived in convenient form for the peak current of a discharge, the time at which it occurs, and its dependence on resistance. Measurements were also made of the intensities of spectral lines of neutral and ionized atoms from oscillating, critically damped, and overdamped discharges. It was found that although the inductance exerts the controlling influence on the excitation when capacitance is small, the effect of resistance predominates when capacitance is large. The degree of excitation increases nearly in proportion to the peak current of the discharge.

A new spectrophotometric method was developed for the determination of bismuth. This method will make possible more rapid and accurate acceptance-testing of solders, type metals, and other lead-tin alloys.

Special methods of analysis were designed to determine very accurately the sodium and potassium content of three high-purity sodium and potassium alloys used in an investigation to measure the heat capacities of these materials for the Atomic Energy Commission. The analysis revealed significant, hitherto unrecognized errors in the compositions originally given for these alloys.

Spectrochemical analysis usually provides high sensitivity for the detection and determination of trace elements without prior chemical treatment 

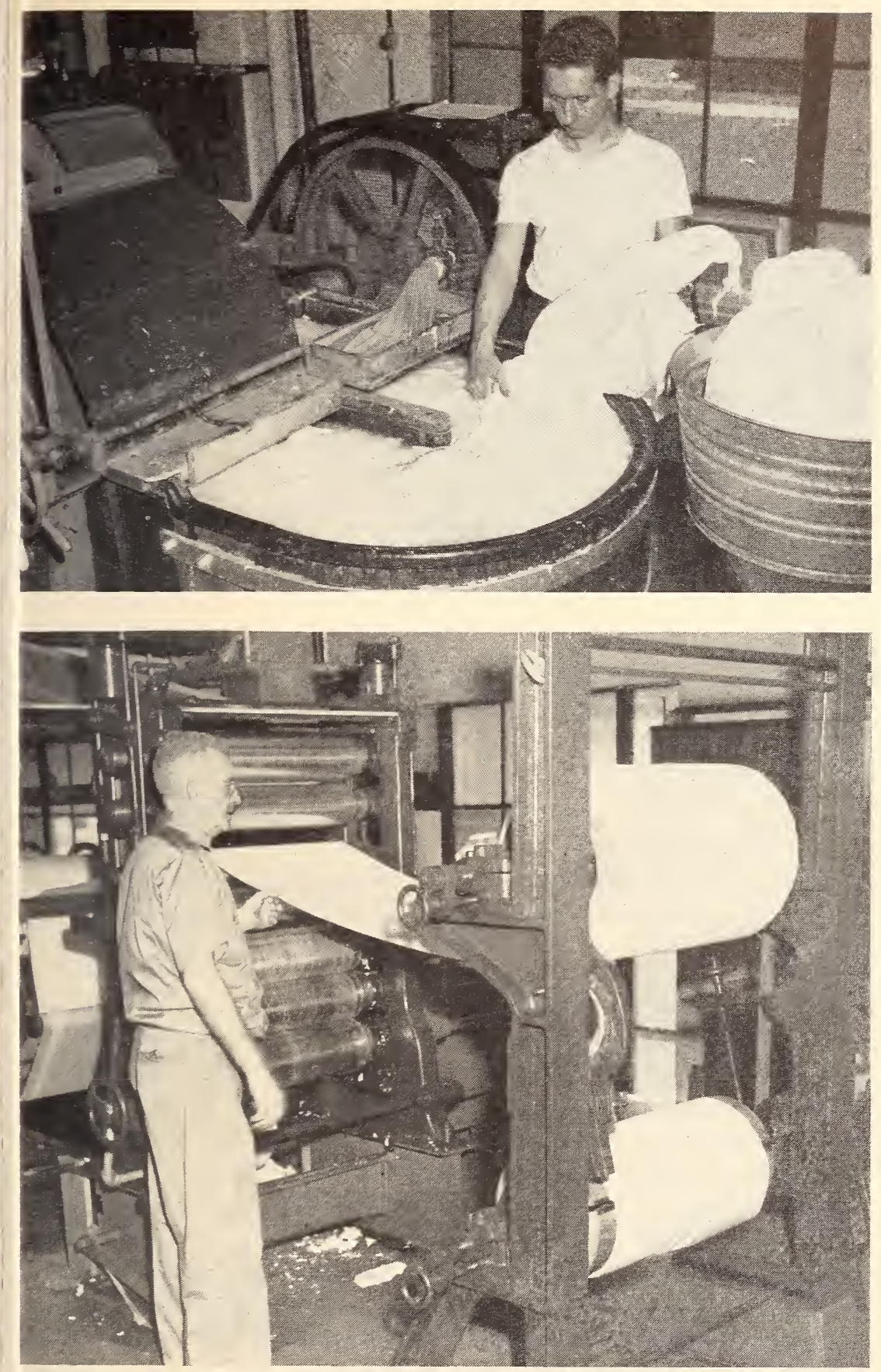

The first paper composed entirely of glass fibers was made at NBS with the cooperation of the Naval Research Laboratory (p. 48!. In the first step (above), bundles of commercial glass fiber are mixed with water in a beater. Below: The finished all-glass paper is wound on rollers at right. 
of the sample. However, in the analysis of very pure iron recently prepared at NBS, the usual method of spectrochemical analysis was not capable of detecting the very small amounts of impurities present. The concentration of impurities by removal of iron by ether extraction was studied, and a satisfactory method was developed in which the limits of detection of the impurities were lowered by a factor of 250. By use of this method, most of the elements found in iron can now be detected at concentrations of a few tenths of a part per million.

A chromatographic method for the analysis of corn sirups was developed. In this method, a mixture of dextrose, maltose, and dextrins is separated into fractions by selective adsorption on a commercial type of carbon.

\section{Physical Constants}

The need for a systematic presentation of all available data on infrared spectra has been so great that NBS has undertaken the arrangement of these data on punch cards. This task is now largely completed. The system developed has made all relevant phases of the data readily available to the many users, and the project has been favorably received by industrial and research laboratories.

Work continued on the compilation of tables of selected values of chemical thermodynamic properties for use by scientific and technical investigators throughout the country. Thermodynamic properties were calculated and compiled for the simple sulfur compounds which are products of combustion or explosion of compounds containing sulfur. Thermodynamic and physical properties of compounds found in liquefied petroleum gases were also compiled.

A comprehensive tabulation of the dielectric constants of liquids, inorganic and organic, was completed. This table will have both scientific and industrial uses.

\section{Mechanics}

The mechanics of solids, liquids, and gases are the broad topics of research in this field. In scope the work varies from long-range investigations of basic mechanical phenomena to short-range studies of the mechanical action of practical apparatus.

Research and development projects now under way in mechanics include the development of methods for measurement of sound pressure at low frequencies, studies of sound transmission through soils, the precise measurement of pressures as high as $100,000 \mathrm{lb} /$ in. $^{2}$ and as low as $0.00000001 \mathrm{lb} /$ in. $^{2}$, the production of atmospheres with closely controlled humidity for the calibration of hygrometers, performance studies on anemometers, investigation of the strength of light-weight high-strength structures at elevated temperatures, extension of precise calibration methods to compression testing machines of very large capacity (up to $10,000,000 \mathrm{lb}$ ), studies of the transient vibration of aircraft structures during landing impact, investigation of the 
strength of riveted joints subject to vibratory loads, analysis of the growth of water waves under the influence of wind, improvement of quartz-fiber microbalances for use in laboratories concerned with atomic energy problems, and determination of densities of irregular hygroscopic bodies.

\section{Turbulent Flow}

One of the problems in fluid mechanics which is still far from solution is that of turbulent flow. This is principally due to the lack of a physical concept of turbulent motions on which to base a sound theory. As a result, technical progress in several fields, notably aeronautics, has been impeded.

Recent experimental investigations, conducted under the sponsorship of the NACA, have contributed significantly toward an understanding of turbulent flow through the direct study of the turbulent motions themselves. Most attention has been given to turbulence in the boundary layers which occur on all surfaces moving through the air. By measuring the interaction, size, and strength of turbulent motions, a clearer physical picture of the nature of turbulence has been obtained. For example, it has been learned that turbulence is not solely a fine structure of motions within a well defined layer, but that it also consists of comparatively large motions that jut out into the free stream enveloping air that was not previously in the turbulent state. The limit of a boundary layer at any instant is therefore very "ragged" and can be defined only in a statistical sense. These findings show the reason for the failure of the older semi-empirical laws based on the Prandtl mixinglength theory. However, it has not yet become possible to formulate a correct theory. This must await further investigation directed toward a complete statistical description of turbulent motions. Such investigations are now in progress, dealing not only with the boundary layer but also with shear flow having axial symmetry, as found in pipes.

\section{Turbulence at Supersonic Speeds}

Equipment for the measurement of turbulence at supersonic speeds was completed under a development program sponsored by the NACA and carried on in cooperation with Johns Hopkins University. The equipment makes use of the hot-wire anemometer, as does all turbulence-measuring equipment, but the frequency response has been extended from the usual upper limit of about 10,000 to 70,000 cps. Several other improvements have been made to increase the accuracy and versatility of the hot-wire anemometer.

\section{Dynamic Properties of Materials}

In recent years, engineering materials have been put to many new and exacting uses involving unusually high rates of loading. It is now recognized that the behavior of materials under the dynamic conditions of loading which exist in service cannot be predicted satisfactorily on the assumption that the stress-strain relationship under static conditions holds for high 
rates of loading. Hence, to develop improved methods of design, information is needed on the elastic and plastic properties of materials at high rates of loading.

Since 1936 the rate of loading in dynamic tests has been increased to the point where the finite velocity of propagation of strain must be taken into account. The usual method of constructing the stress-strain curve from test data requires that both stress and strain be uniform over a specified gage length on the test specimen. However, sudden loading of the specimen, such as that due to impact, produces strain waves which are propagated rapidly from the point of loading. Under these conditions the stress and strain are not uniform along the longitudinal axis of the specimen, and it is erroneous to associate the stress measured at one point in the specimen with the strain measured at a different point.

During the year a testing method was developed by which the engineering stress-strain relation for the dynamic condition of loading may be derived from measurements of the velocity of propagation of strain waves in a long bar. The new method is expected to provide a means of extending mechanical measurements into new regions and of improving the accuracy of constants which must be evaluated when calculating critical impact velocity and impact strength.

\section{High-Frequency Vibrations}

Work was begun on an acoustic method for the absolute measurement of vibrations having very small amplitudes. An instrument was designed and built for accurate measurement of vibration amplitudes extending from 0.6 angstrom to 60,000 angstroms, throughout the frequency range from 20 to 6,000 cycles. This instrument has already proved useful for calibrating gages for measurement of vibrations in machinery, buildings, and the soil.

\section{Hearing Loss}

The accurate measurement of hearing loss, known technically as audiometry, continues to be an important problem to otologists. Research on this problem led to a simple method for determining the correct sound pressures which must be produced in the ear canal by the audiometers used for measuring hearing loss. Equipment for direct measurement of both the phase and amplitude of sound pressures developed in the ear canal by earphones was constructed. Equipment is also being developed for measurement of the intensity and phase of sound radiated into the bones of the head by a specially constructed bone conductor.

\section{Physical Properties by Sonic Methods}

The work on determination of physical properties of substances by sonic methods was extended with the initiation of two new major investigations. One is for the design of an instrument for measurement of the 

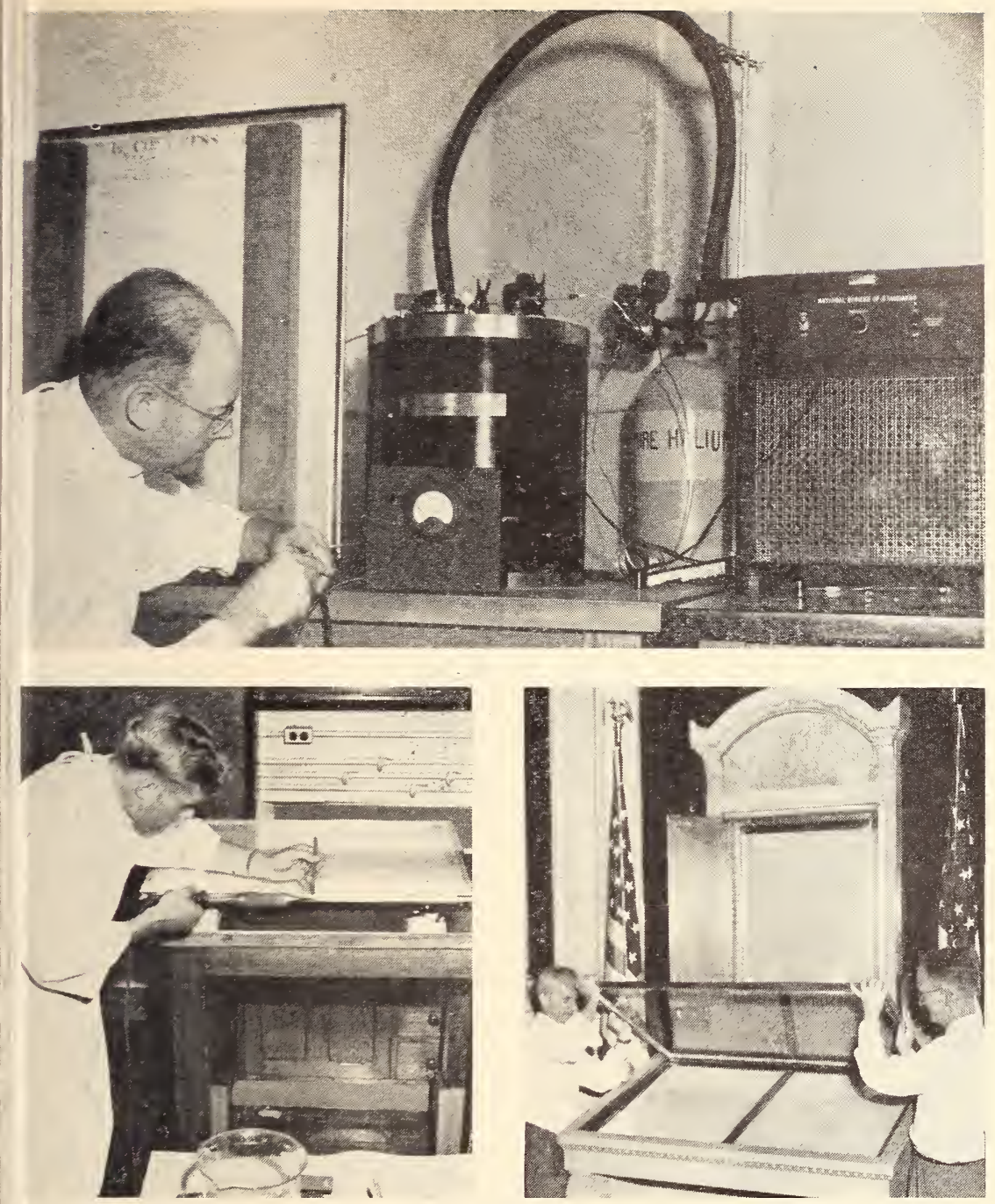

As a result of research conducted by the Library of Congress, the National Bureau of Standards, and the Libbey-Owens-Ford Glass Company, the Declaration of Independence and the Constitution of the United States are now permanently preserved in glass enclosures filled with helium ( $p$. 48). After each document had been completely sealed from the outside atmosphere (lower left), helium was flushed (above) through the enclosure for several days to replace the air with an inert atmosphere. Lower right: Lowering of the cover glass lid over two enclosures containing the first and second leaves of the Constitution in the Shrine at the Library of Congress.

viscosity of gases; the other involves the development of an instrument to indicate continuously, as a function of time, the velocity of sound in a liquid. Construction of an acoustic interferometer, for measurement of velocity and absorption in gases at low pressures, was largely completed. An experimental study of the dielectric and anelastic anomalies in quartz 
was begun, and a laboratory investigation into the structure of ice was initiated using a piezoelectric technique.

\section{Water Waves}

Field data dealing with wind tides produced in Lake Erie by storms were analyzed, and the hydrodynamical theory of the phenomenon was carried practically to completion. A difficult problem in this connection has been the determination of the effective "roughness" of a city in order to predict what its effect will be on the winds blowing over it.

\section{Density Currents}

A comprehensive theoretical and experimental investigation of the flow of stratified liquids, known as density currents, was continued with the support of the Office of the Chief of Engineers, Department of the Army. An important objective of this work is to develop laws pertaining to models of rivers, harbors, and canals, where density currents are involved. The information thus obtained will apply to contamination of public water supplies and of farm lands by instrusion of salt water.

Work on this project has consisted mainly of a study of the problem of the instrusion of salt water from the sea up the mouth of a river. In the course of the study, experimental determinations were made of the salinity distribution near the entrance of the channel to the model sea, the velocity of the salt front when there is a flow of fresh water in the model river, the height and form of the front, the slope of the interface, velocities in the interface, and the slope of the water surface.

A meter was designed for recording the salt concentration at different depths in a body of water. This instrument, called the salinimeter, is equally effective in still or flowing water. Although the salinimeter was built originally for laboratory use, it may be adapted easily to observations in rivers and other navigation channels.

\section{Precision Weighing}

Equipment was assembled for a thorough re-examination of the equalarm balance, both as to theory of operation and as to materials and procedures for construction. Particular attention will be given to knife edges and bearings. The purpose of the study will be to correct such conspicuous defects in the more precise balances as excessively long period, reduction in accuracy due to surrounding temperatures or changes in relative position of knife-edges, and faulty design.

\section{Viscosity of Gases}

Apparatus was constructed for determining the viscosity of gases at temperatures up to $1,000^{\circ} \mathrm{F}$ and at pressures up to $10,000 \mathrm{lb} / \mathrm{in}^{2}$ The principal problem was the design of a suitable flow meter. The flow meter that was developed is unique in that it serves both as a meter and as a flow 
regulating mechanism. Calibration trials of the complete assembly using dry air have shown agreement within 0.25 percent of the best published values.

\section{Evaporated Thin Films}

Techniques are being developed for making evaporated films suitable for resistors, pressure transducers, and other instrumental applications. A heating source has been devised and methods of operation have been developed which make possible the evaporation of a number of high-melting point materials previously difficult to evaporate, e. g., boron and silicon. The heating source is essentially a carbon crucible properly shaped for the charge of material and for the heating current.

\section{Organic and Fibrous Materials}

The Bureau investigates rubber, plastics, textiles, leathers, and papersorganic materials whose characteristic properties are due to the long, chainlike structure of their molecules. Such compounds are formed in nature by a process known as polymerization, in which as many as several million individual molecules may be joined by chemical reaction. The complex molecular structure of high polymers, combined with their refusal in many cases to follow the laws of classical physics, has made it very difficult in the past to obtain definite fundamental knowledge of their properties. In recent years, however, rapid progress has been made in the theoretical science of high polymers, and new techniques have been developed for measuring their properties and studying their reactions. Many of the new techniquessuch as X-ray diffraction, infrared spectroscopy, and electron microscopy - are being employed by the Bureau to obtain a better understanding of the fundamental properties of high polymers, both natural and synthetic, and are leading to more adequate methods and equipment for developing and evaluating commercial products composed of these materials. During the past year, for example, information obtained in fundamental studies of the molecular dimensions of high polymers was utilized in an investigation of blood-plasma substitutes undertaken for the Department of the Army.

Applied research on polymeric materials was given added impetus because these materials have important military applications and because the supply of many of them has been adversely affected by dislocations in international trade. Thus, the needs of the military agencies led to efforts to make papers and plastics having properties outside the range of those previously thought possible. Other research was undertaken to extend the uses of organic materials to replace metals and other substances that are in even shorter supply. Also, the reopening of the Government synthetic rubber plants greatly increased the demand for standard rubber samples and called for investigations leading to better methods of quality control. 


\section{Glass-Fiber Paper}

In cooperation with the Naval Research Laboratory, a paper composed entirely of glass fibers, with no additive, was produced in the NBS experimental paper mill. Developed primarily for use in gas masks, the paper is much more effective for such use than other filters; yet it does not increase the normal breathing resistance of the mask. Tests in a smokefilled room showed that only one particle of smoke in 100,000 passed through a filter using the paper. The new material should also have extensive use in electronic and other electrical equipment because of its excellent electrical insulating properties which are combined with very high resistance to heat.

The paper was made on a semicommercial Fourdrinier paper machine without important modification of the machine. Commercial glass fiber in the form of "glass wool" was used. No difficulty should be experienced in commercial manufacture of the paper with conventional papermaking equipment.

\section{Preservation of Historical Documents}

The Declaration of Independence and the Constitution of the United States have been permanently preserved in glass enclosures filled with helium, as a result of research conducted for the Library of Congress by the National Bureau of Standards in cooperation with Libbey-Owens-Ford Glass Company. Each manuscript sheet is sealed in an air-tight envelope, consisting of two panes of glass bonded to a metal frame, and rests upon special cellulose backing paper prepared in the NBS paper mill. The glass enclosure is filled with helium to protect the documents against decomposition by oxygen and sulfur dioxide and against attack by insects. Moisture is added to the helium to establish a relative humidity of 25 to 35 percent, which tests indicate is optimum for the parchments; high humidity leads to fungal attack and deterioration while a very dry atmosphere causes dehydration, brittleness, and cracking. To detect any possible leakage of air into the enclosures, the Bureau developed a simple leak detector which makes use of the difference in thermal conductivity of air and helium. To protect against deterioration by ultraviolet light, a laminated yellow glass filter has been installed in the cover door of each case of the Shrine at the Library of Congress. The cases have been illuminated by spotlights, which are covered by identical filters. Thus the documents are thoroughly protected, and the combination of colored lights and filters greatly improves the conditions for viewing them.

\section{Blood Plasma Substitute}

At the request of the Surgeon General's Office, Department of the Army, the Bureau participated in a nation-wide research effort to assess various materials for possible stockpiling as blood plasma substitutes. One of the 


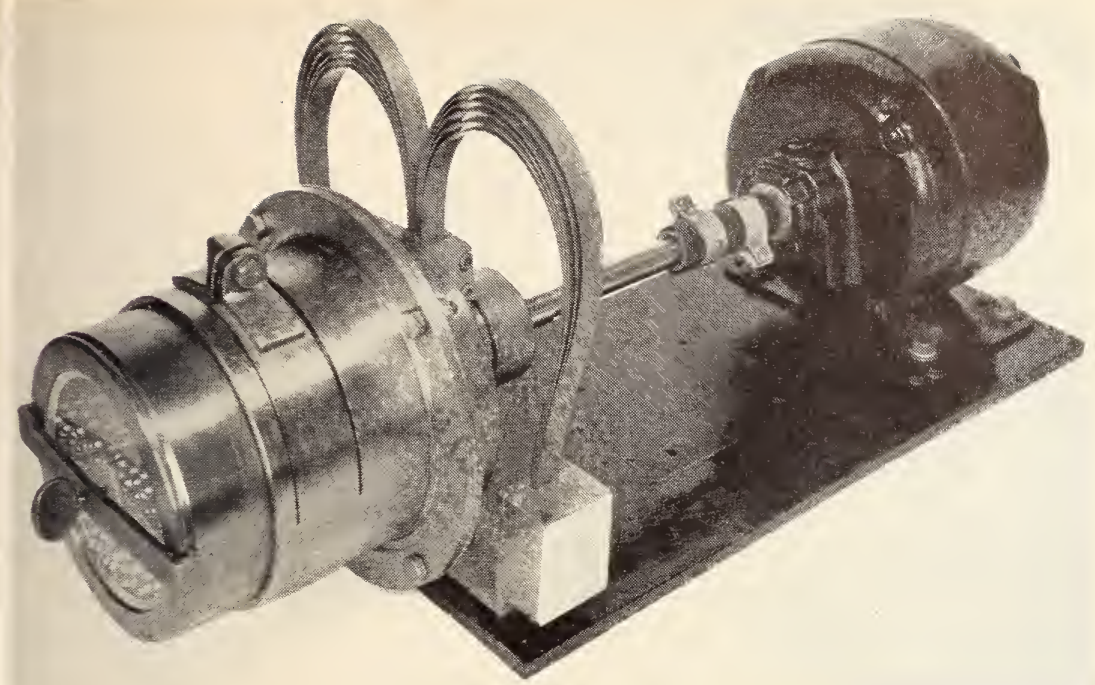

A vibratory ball mill was developed (p. 50) that rapidly and completely grinds cotton into particles a few microns in length.

more promising of the substances under consideration as a plasma extender is dextran, a large-molecule type of polysaccharide produced from sucrose by bacterial action. The molecular structure of samples of dextran produced by British, Swedish, and American manufacturers was evaluated, and a radioactive corbon 14 atom was built into the molecule so that it could be traced through the body of a test animal. The tagging of the carbon atom will aid in determining the fate of the dextran in the body; it also promises to make possible extremely precise measurements of number average molecular weight. The information thus far obtained has assisted in the interpretation of clinical data as well as in the preparation of specifications for plant production and purchase control.

\section{Effect of Moisture and Ozone on Cotton Textiles}

The rapid deterioration of cotton textiles when exposed outdoors is usually attributed to the action of light, heat, and micro-organisms. At the request of the Office of the Quartermaster General, the effects of two other agents, moisture and ozone, were studied.

Rapid oxidation and weakening of cotton were found to occur at the boundary between wet and dry areas when, for example, one end of a piece of cotton cloth remained wet and the other end remained dry. The brown line which forms is frequently seen on cotton that has dried faster at one place than another after laundering or wet processing. The oxidation appears to occur, in part at least, at the primary hydroxyl group of the cellulose, with the formation of polyglucuronic acid and the splitting of soluble low-molecular weight fractions. The deterioration proceeds 
even at moderate temperatures and in diffused light. It undoubtedly contributes significantly to degradation of cotton during production, processing, and use.

Ozone in the very small amounts which may occur in air at the earth's surface was found to cause the deterioration of wet cotton but not of dry cotton. The study indicated, however, that deterioration from the action of atmospheric ozone is small in comparison with that from other elements of weathering.

\section{Vibratory Ball Mill}

A vibratory ball mill was developed which rapidly and completely grinds cotton into particles a few microns in length with little or no oxidative change or contamination of the cellulose. Grinding takes place as 3,700 steel balls, colliding over 100,000 times per second, pulverize the material caught between them. As the new mill produces a more uniform powder and is more efficient and easier to operate than previous devices of this kind, it is expected to find extensive application in the grinding and blending of a variety of substances such as pigments, ceramic materials, metal powders, resins, and plant and animal tissues.

The mill was constructed in connection with a program sponsored by the U. S. Department of Agriculture on the chemical deterioration of cotton during processing and use. To learn more about the chemical changes which occur when cotton deteriorates, the Bureau undertook to apply the techniques of infrared spectrophotometry to cotton cellulose. As the spectra obtained from fibers laid side by side were not satisfactory, it was decided to reduce the fibers to a powder and measure the spectral absorption of the powder in a mat or in suspension in a suitable liquid. Several well-known methods for grinding materials were therefore tried, but the products contained much coarse matter. In an effort to provide a method which would reduce the entire sample to a finely divided state without contamination and with a minimum of chemical change, the NBS vibratory ball mill was developed.

\section{Silicone Resin Pigment for Clinical Thermometers}

Thermometers used in hospitals must undergo constant immersion in detergents or soap solutions and germicides such as phenol. Loss of pigment due to the action of these cleansing agents has been a major cause of thermometer failure. The Hospital Bureau of Standards and Supplies and the American Hospital Association therefore requested the National Bureau of Standards to make a study of the situation with a view to the development of a pigment that would withstand normal hospital usage. A large number of formulations were investigated, as well as various methods of etching. Finally a pigment based on silicone resin and carbon black was developed, and long-term immersion tests showed that this pigment was the answer to the problem. 
In simulated service tests, thermometers marked with the new NBS formulation successfully withstood more than one year's continuous or intermittent exposure to a large number of disinfectants, soap solutions, detergents, and other chemicals. Most of the commercial marking compounds now in use failed in less than one month under the same conditions of exposure; none of them withstood more than five months' exposure. Likewise, all of the experimental compounds tested, except those which were modifications of the NBS silicone compound, failed in less than five months.

\section{Degradation of Polystyrene}

Information regarding the chemical changes that take place when plastics and rubbers are exposed to heat, light, water, and oxygen is needed in order to select stabilizers that will increase the service life of these polymers and to develop improved accelerated methods of test for their aging characteristics. As a part of a broad investigation of polymer degradation mechanisms, a study was made of the decomposition products formed when polystyrene is exposed to heat and to ultraviolet radiant energy in the presence of oxygen. Infrared, ultraviolet, and mass spectrometry were used to identify the very small amounts of reaction products obtained under conditions closely simulating those encountered in service.

The results of this investigation reveal that the degradation of polystyrene takes places in two stages. First, there is a breakdown of unstable groups present in the polymer; this reaction occurs on exposure to heat or ultraviolet light and does not lead to discoloration. Second, oxidation of the polymer takes place; this reaction is caused by exposure to ultraviolet radiant energy in the presence of oxygen and results in discoloration. Insoluble polymer was produced on exposure to the heat and ultraviolet treatments and increased in amount with progressive degradation. Mechanisms for these reactions were postulated. The insight provided into the behavior of polystyrene should be helpful in interpreting the reactions which occur in the degredation of the more complex system represented by GR-S synthetic rubber.

\section{Analytical Methods}

An improved method for determining the quality of cellulose was devised. The new method is a simplification of the cuprammonium viscosity determination, which is widely used as an aid in determining the effect of light, heat, and chemical reagents on the cellulose in paper and textiles. Advantages of the NBS procedure are ease of preparation of the cuprammonium reagent and a reduciion in sources of error during the reaction. A method for determining the aldehyde content of cellulose, sensitive to less than 0.001 millimole of aldehyde, was also developed. This method is based on the oxidation of the aldehyde to carboxyl in a slightly acid medium. 


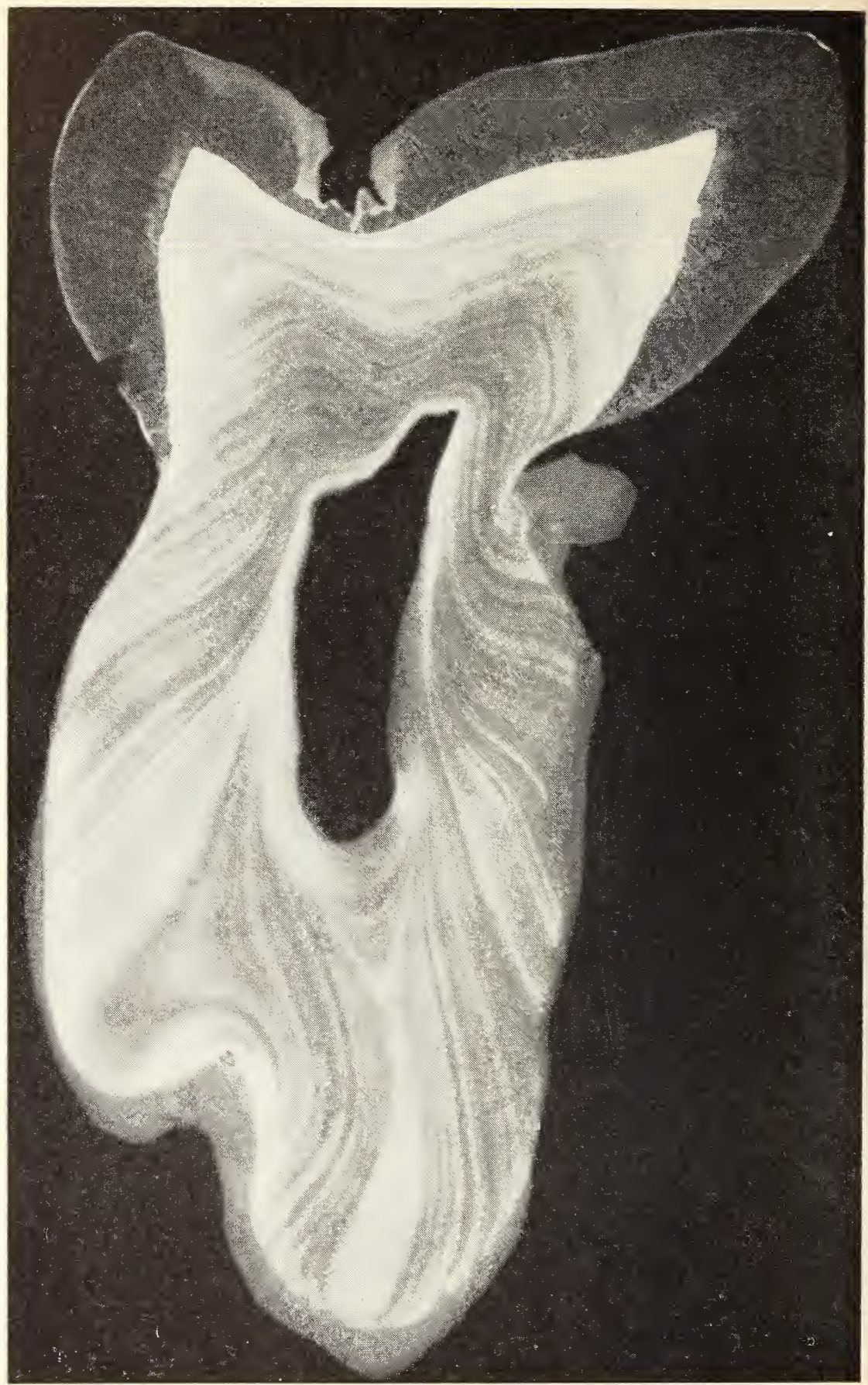

Fluorescent photomicrograph obtained from the visible light emitted by a very thin tooth section when illuminated with high-intensity ultraviolet radiation. The Bureau has developed a new method, utilizing the natural fluorescence of human teeth, for investigating the structure of enamel and dentin (p. 54). 
An improved technique for the determination of hide substance, one of the fundamental steps in the analysis of leather, was worked out and is being. adopted as an official method by the American Leather Chemists Association. A modification of the former Kjeldahl method, it employs mercuric oxide as the catalyst, carefully controls the composition and temperature of the digestion mixture, and uses a mixed indicator for the final titration. Cooperative studies by several laboratories have shown that this procedure, known as the Dahl method, is capable of high precision and gives comparable results when performed by different laboratories.

A simple, rapid method for the quantitative determination of rubber hydrocarbon in crude natural rubber was developed. As the new method requires only the measurement of the refractive index of a solution containing a known weight of rubber in a known weight of solvent, a single operator can make a large number of separate determinations in a short time. The NBS procedure is thus expected to find application in the rubber industry for the evaluation of crude rubber, especially where thelower grades are used.

An improved apparatus for precise determination of moisture in rubber was designed and constructed. Possessing significant advantages over devices now available commercially, the new apparatus should provide a rapid, simple means for accurate determination of water in leathers, textiles, oils, dried foods, and other organic materials. At the same time it offers a convenient tool for basic research in these fields.

\section{Electrical Properties of Collagen and Leather}

As part of a study of the fundamental properties of natural high polymers, measurements of the electrical properties of leather and collagen were recently completed. This work was undertaken as a result of recent interest in the use of dielectric measurements for quantitative determination of moisture in leather and collagen. Studies of the effects of temperature and moisture content on measured values of dielectric constant and power factor for chrome and vegetable leathers as well as untanned hide were carried out over the frequency range 0.75 to 96 kilocycles; the dependence of direct-current resistance at room temperature on moisture content was also studied. In addition, the true dielectric constant of dry leather was also measured by the immersion method at $22^{\circ} \mathrm{C}$ and 3 kilocycles.

\section{Sampling of Shoe Upper Leather}

In cooperation with the Office of the Quartermaster General, NBS. obtained information on the sampling of shoe upper leather that will eliminate laborious and wasteful testing of individual hides. The results make it possible to select for testing a single location, in each hide of the lot, which gives a more reliable value for a specified property than that previously obtained from the sampling of three or more different locations in the same 
hide. The results also permit the exact determination of the number of hides required for a representative sample of a lot.

\section{Synthetic Rubber Tires}

One of the chief hindrances to the wider use of synthetic rubbers has been the difficulty of making satisfactory truck and bus tires with these materials. NBS has cooperated with the Office of Rubber Reserve in its study of the problem, particularly in the application of time- and labor-saving statistical methods to the design of the largest road test of tires ever conducted (almost a million vehicle-miles), in the statistical analysis of the results, and in the measurement of power loss on experimental tires constructed from synthetic rubbers. These tests have revealed much new information on the road wear and power loss of tires. For example, it was found that rate of wear is influenced by both the type of rubber and the type of black, but that power loss is influenced more by type of rubber than by type of black. Another unexpected result was the wear behavior at different temperatures of tires made from synthetic rubbers and furnace blacks. These tires wore more slowly as the temperature increased, an effect opposite to that obtained with tires made from natural rubber and channel black.

\section{Structure of Tooth Enamel and Dentin}

In an investigation of the fundamental character of tooth structure, progress was made toward understanding the structure of the basic calcium phosphates which comprise the major portion of the inorganic constituent of teeth. Evidence was obtained which indicates that certain differences in the properties of hydroxy apatite and tricalcium phosphate hydrate can be explained by postulating a 6-percent phosphate-ion inclusion in the entrapped surfaces of the hydroxy apatite crystal. A similar explanation would account for the differences in calcium-phosphate ratios observed in enamel and dentin.

Studies of the fluorescent characteristics of enamel and dentin revealed a number of areas having a higher fluorescence than most of the tooth structures. The greatest intensity was observed at the enamel-dentin junction, along lamellae, and to a shallow depth below the exposed surfaces of the enamel. Evidence was obtained which indicates that the fluorescence is associated with the organic component of tooth structures.

Because of the lack of information on the electrical and optical properties of tooth structures, the scope of the program was expanded to include dielectric properties, electrical resistance, and light transmission.

\section{Dental Materials for the Military Services}

Large quantities of dental supplies that were sent to the South Pacific and other remote areas in World War II were quickly rendered useless by the severe climatic conditions. For example, compounds for taking impres- 

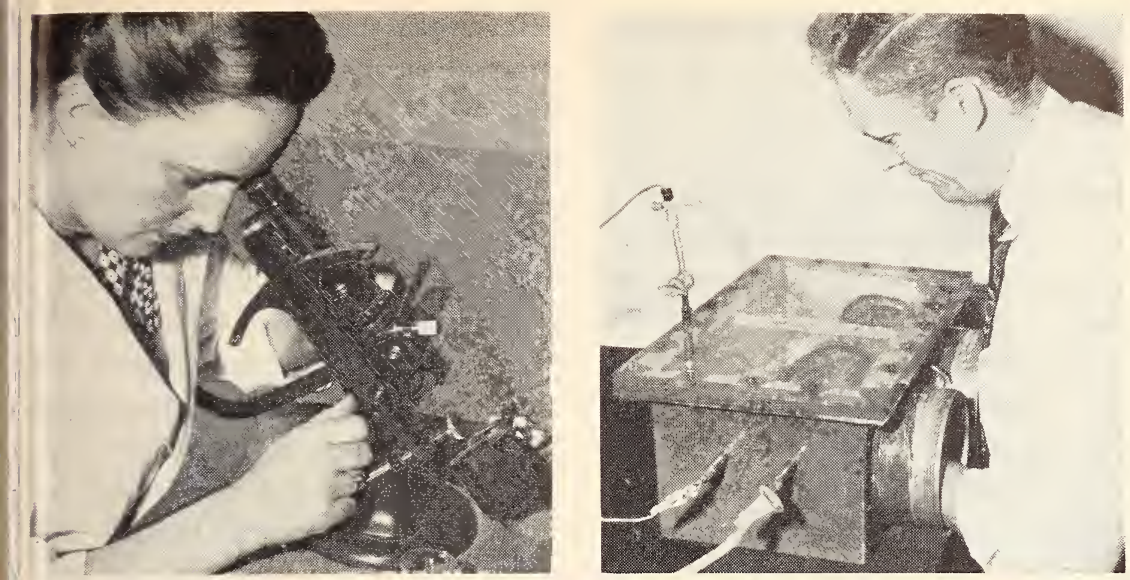

Left: A simple, rapid method was developed for determining the percentage of rubber hydrocarbon in crude natural rubber by measuring the refractive index of a rubber solution (p. 53). Right: For stress-corrosion studies, metal specimens are abraded in an argon atmosphere to remove the film due to atmospheric exposure.

sions of ten deteriorated completely in the few weeks required for shipment. To develop methods for overcoming these difficulties, a joint research program was established at NBS by the dental services of the Army, the Air Force, the Navy, and the Veterans' Administration. This program has been extended to provide fundamental information on all kinds of dental materials and equipment of interest to the military services. During the past year studies were made on acrylic resin dentures, plastic teeth, base metal alloys, hydrocollid compounds, waxes, gypsum products, amalgams, precious metal alloys, cements, denture reliners, and a variety of dental instruments. Specifcations that have been developed and recommendations that have been made on the basis of this work have aided the dental services in the procurement of satisfactory materials, often with a substantial monetary saving. Work has recently been undertaken on the development of instruments for diagnostic purposes.

\section{Metallurgy}

The work in physical metallurgy is concerned with the melting, working, and heat treatment of metals and alloys; determinations of their structure and properties; and studies of the effect of various factors on structure and behavior under normal and abnormal conditions of service. In general, this program is directed toward a better understanding of the properties and behavior of metals in order that new or improved metals and alloys may be developed for better performance in established uses and to meet the requirements of new applications.

During 1951, both fundamental and applied research in physical metallurgy were greatly stimulated by the need for new and improved metals and 
alloys in connection with the defense effort. In the course of the work, new information was obtained on the effect of prior stressing of aluminum alloys on fatigue strength. An evaluation of the use of aluminum and its alloys as roofing and sheathing in housing construction was completed. Investigations of the creep of metals at low temperatures were continued. In an extended study of ship plate, it was established that carbon, phosphorus, manganese, and silicon contents, as well as grain size, are significant factors in determining whether or not a particular plate will be susceptible to the propagation of cracks. New theories were developed regarding the mechanism of underground corrosion and the protection of underground metallic structures. A study of the corrosion of aluminum and magnesium sheeting for aircraft use in a marine atmosphere was continued, and exposure of specimens of titanium and some of its alloys was begun. An extensive investigation of the formation of nodular graphite in cast iron was completed.

\section{Mechanism of the Deformation and Failure of Metals}

The failure of metals due to fatigue under stress begins as a brittle crack, which spreads until the remaining metal can no longer carry the load; sudden and complete fracture then occurs. The Bureau is attempting to learn more about the mechanism of this process.

Studies completed during the year showed that static and dynamic stressing of aluminum alloys prior to testing produced either beneficial or detrimental effects on the fatigue strength, depending on the extent of stressing. In an investigation of the creep of metals at temperatures below the recrystallization temperatures, it was shown that annealed high-purity copper fails with increasing brittleness, i. e., with decreased ductility, when the temperature is raised or the stress is lowered, because of changes within the crystalline and molecular structure of the metal. It was also shown that copper cold-drawn to 40-percent reduction in area has appreciably improved creep properties in comparison with the same metal in the annealed condition. Refined measurements demonstrated that both copper and aluminum flow intermittently rather than continuously during creep, and that relaxation or recovery of the metal during intermissions sometimes results in temporary but actual increases in the diameter of the specimen.

The behavior of metals at low temperatures is of vital importance to peacetime industry as well as to the military services, both in connection with the performance of machinery in polar climates or at high altitudes and for industrial or experimental operations at liquid air temperatures. Recent work at NBS showed that, in contrast to ingot iron, which is embrittled at low temperatures, copper, nickel, and some copper-nickel alloys exhibit increased ductility as well as increased strength at low temperatures, down to $-190^{\circ} \mathrm{C}$.

In an extended study of ship plate, it was established that carbon, phosphorus, manganese, and silicon contents, as well as grain size, are 
significant factors in determining whether or not a particular ship plate will be notch-sensitive, and therefore susceptible to the propagation of cracks. An equation including weighted values for each of these factors was successfully applied to the data obtained from examination of hundreds of specimens of commercial ship plate and was found to be equally applicable to data from a limited number of high-purity alloys.

\section{Corrosion}

Studies of the corrosion of metals have been intensified because of the increasing awareness of the tremendous loss to the National economy from this source. Recent estimates indicate that the annual cost to the United States of metallic corrosion is in the neighborhood of 5 or 6 billion dollars. Current NBS efforts to reduce this yearly loss include studies of the basic mechanisms of corrosion; determinations of the relative merits of known materials to resist corrosion in various environments; and evaluation of protective coatings and protective devices.

In a continuing investigation of the underground corrosion of metals, additional data were secured from exposure sites maintained throughout the country, new theories of the mechanism of the corrosion of metals underground and of protection against this corrosion were developed, and experimental confirmation of the more important of these theories was obtained. Marine-atmosphere studies of the corrosion of light metals for aircraft were continued. Exposure of specimens of titanium and some of its alloys was also begun. A study of the use of aluminum and its alloys as roofing and sheathing in housing construction was completed. To provide basic information on the nature of corrosion, the effect of crystalline orientation on the corrosion rate of a metal is being studied by means of single-crystal specimens of known orientation, and efforts are being made to determine the cause, mechanism, and manifestations of the phenomenon of stress-corrosion.

\section{Pure Iron}

The preparation of "pure iron," i. e., iron that is free from appreciable amounts of all impurities, has been a subject of investigation for many years and in many laboratories. Because as little as 0.001 percent of an impurity may have a decided effect on certain properties of the metal, it is evident that the properties of elemental iron, which is the basis of all commercial irons and steels, can be determined only from material of the highest possible and most accurately known purity.

Two years ago, techniques were developed at NBS for the preparation of "pure iron" with almost no contamination. However, because of the very high purity of this material, accurate determination of impurities has constituted a problem. Analysis of some of the most recently prepared ingots now indicates that purity of the order of 99.995 percent has been obtained, a purity higher than has been established for any other iron. 
Determinations of the properties and behavior of this unique metal are in progress.

\section{Nodular Cast Iron}

Because of its ductility and superior strength, cast iron having a nodular graphite structure has excited considerable interest since its production was first described in 1948. A recent study by NBS substantially increases available information on the effects of different additives on the formation of nodular graphite in this material. Both cerium and magnesium, added in small amounts to the molten iron, have been used successfully to produce nodular cast iron. Additives investigated by the Bureau were magnesium, magnesite, iron sulphide, calcium, nickel-chromium-molybdenum, and boron. Cerium was not included, because published information on its application as a nodulizing agent was relatively complete when the study was begun. The investigation also included such variables as composition, melting and pouring temperatures, and cooling rate.

\section{Mineral Products}

Research in the general field of nonmetallic mineral products was concerned with pottery and porcelain, the high-temperature oxides, glass, refractories, ceramic coatings, building stone, concreting materials, inorganic adhesives, lime, and gypsum. The efficient application of these products in commerce, industry, and national defense requires an understanding of their chemical and physical properties. Advances continued in the application of ceramics to high-temperature uses in jet and rocket propulsion and as specialized electronic components. Large alkali halide crystals with improved transmission of infrared light were grown. Studies were initiated to improve the resistance of concrete in air-field runways to blasts from jet engines. Flame photometer methods for the analysis of alkalies in cements were explored and improved. Refined measurement of such properties of molten glass as viscosity and surface tension gave a clearer picture of the underlying structure of glass. A survey of the physical and chemical properties of ceramic materials of potential value for nuclear reactors provided background information of value to the Atomic Energy Commission.

\section{Graphite Crucibles}

The principal use of the so-called "natural flake" graphite is for crucibles that are widely used in the melting of nonferrous metals. This type of graphite, which is considered a strategic mineral, is normally imported from Madagascar; flake graphite from domestic deposits has never been utilized in the manufacture of crucibles. The desirability of a domestic source of supply of flake graphite led to an accelerated investigation of the service life of crucibles manufactured from domestic as well as Madagascar graph- 
persion, and improved transmissivity in both extremes of the spectrur Notable progress was made in the development of continuous methods melting optical glass which meets the rigid requirements of optic: homogeneity.

\section{Durability of Ceramic Coatings}

Under the sponsorship of the National Advisory Committee for Aerc nautics, two fundamental investigations were carried on which are expecte to lead eventually to more durable and resistant ceramic coatings both fc military and commercial applications.

One of these studies concerns the source of the hydrogen which is a majc cause of coating defects when porcelain enamels are applied to a steel bast Previous attempts to eliminate the hydrogen from the enamel-metal syster have been largely unsuccessful because little was known as to its sourct However, experiments performed during the past year have eliminated thi uncertainty. In these experiments, heavy hydrogen (deuterium) was sut stituted for ordinary hydrogen at each of five possible hydrogen-producin operations in the coating process. Conditions were adjusted to favor th production of defects that are induced by evolution of hydrogen fror coated specimens, and the escaped gas was collected and analyzed with th mass spectrometer. The content of the deuterium isotope in the collecte gas was then taken as a measure of the relative importance of the sourc under study. The results show very clearly that the dissolved water i: the coating material is by far the most important source of the defect producing hydrogen. The hydrogen is generated during the firing opera tion by a reaction between the dissolved water and the hot iron base.

The second study seeks to determine the fundamental mechanism of th adherence of ceramic coatings to metals. Although it is well known tha small amounts of certain metallic oxides, such as cobalt oxide, are necessar for the firm adherence of ceramic coatings to metals, the reason for thi behavior has been obscure in spite of considerable research. In the presen study the radioactive isotopes of cobalt and of iron have been used a "tracers." In this way it was shown that part of the cobalt is reduced to th metallic form at the enamel-metal interface during firing. The nature 0 this very thin deposit and the mechanism by which it promotes adherenc are still being studied. When complete information on these topics $i$ obtained, it will contribute to the conservation of critically short supplie of cobalt and to the improvement of coatings for use in jet motors, rocket and other high-temperature applications.

\section{High-Temperature Equilibrium Studies}

The determination of high-temperature equilibria in silicates and othe refractory oxides continued to provide useful information for the develop ment of jet engines and the manufacture of glass, refractories, and portlan cement. Development of a workable high-temperature centrifuge per 
mitted accelerated progress in the study of equilibria in cement and refractory systems at temperatures up to $1,500^{\circ} \mathrm{C}$. A study of the system berylliaalumina-titania, which is of importance for very high operating temperatures in jet and rocket engines, was completed under the auspices of the Office of Naval Research. Investigation of the important glass-making system, barium oxide-boric oxide-silica, is nearing completion.

\section{Formation of Chemically Active Phosphates and Silicates}

The dehydration by heating of certain silicates, phosphates, and related materials produces chemically active materials which are useful for various industrial applications, such as in detergents and ceramics. A study was begun to learn the mechanism of formation of such chemically important materials. It was found that in one stage of the dehydration a fine-grained, noncrystalline material is produced. Because of its high surface, this mateial retains a large percentage of the original water, which can only be removed by longer or higher heat treatments.

\section{Building Technology}

The National Bureau of Standards continued to conduct laboratory esearch on technical problems relating to building construction and mainenance, and to assist Government and industry in applying scientific priniples and data to building design and standardization. Over 50 projects vere active in structural engineering; fire protection; heating and air onditioning; wall, floor and roofing materials; and safety engineering. An increasing proportion of the work related to projects specifically equested by the Department of Defense.

Investigations in structural engineering dealt with lightweight-aggregate , oncretes, resistance of concrete to impact, properties of light-gage metal olumns filled with concrete, masonry and masonry units, cracking of lasonry, measurement of internal strain in concrete, properties of reinsrced concrete, and development of nondestructive testing methods for uilding materials. In the field of fire resistance, projects were under ay on the fire-resistant properties of walls, columns, and floors; the valuation of fire-retardant treatments; spontaneous ignition of various laterials; fire hazards of chimneys; and fire detection and extinguishment. fubjects of studies in heating and air conditioning included the performance ating of various heating systems, air infiltration into buildings, developient of thermoscreens for weather stations, heat-transfer properties of uilding materials and structures, development and evaluation of air conitioning and cooling equipment, and development of substitute materials or heating ducts. In the field of interior and exterior coverings, investiations were undertaken on the development of water-vapor barrier aterials, the constitution and weathering properties of asphalts, the 


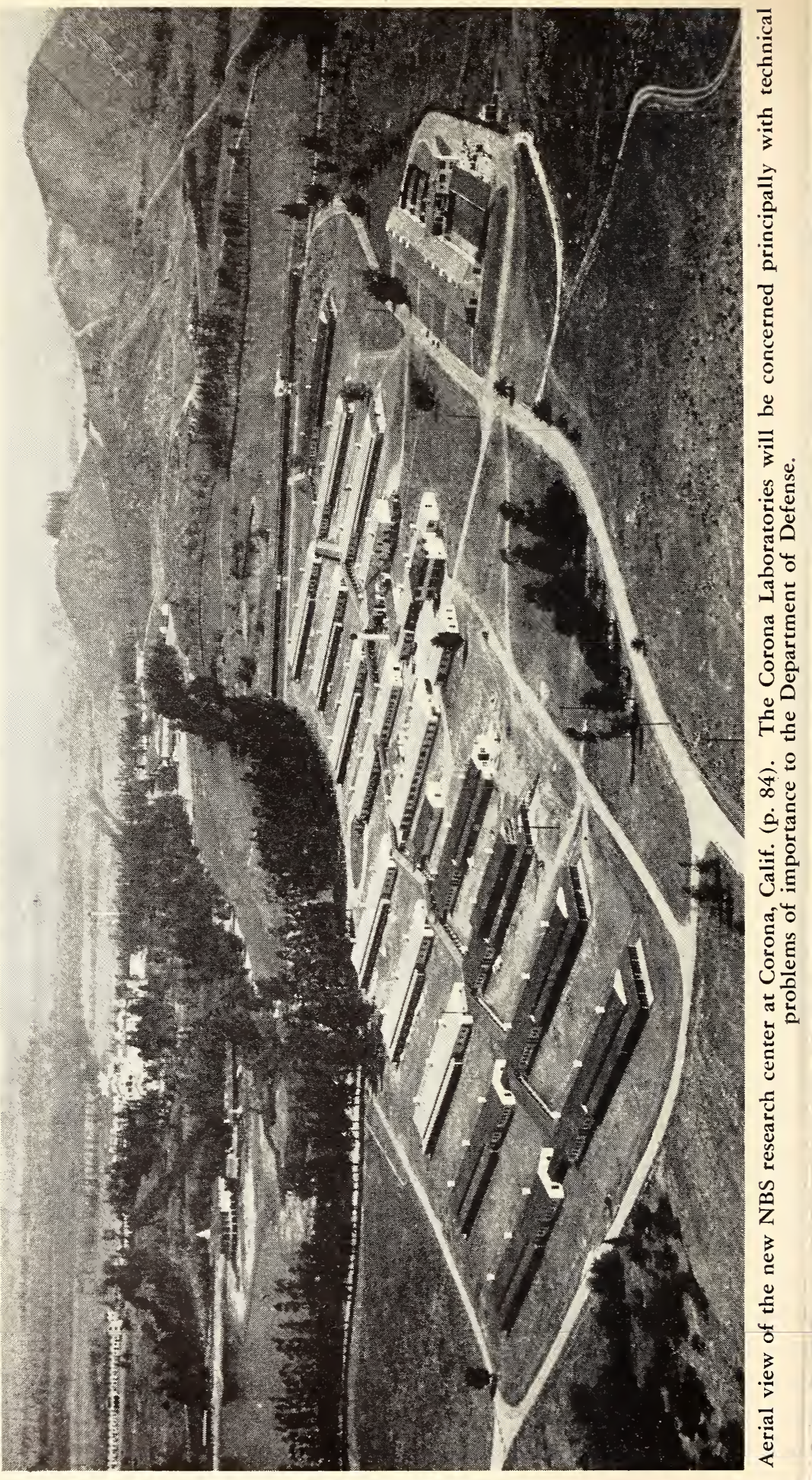


slipperiness of floor surfaces, and on bituminous roofing, road materials, and flooring materials. Other investigations were concerned with the development of safety standards for industry and government and adequate building codes for municipal and Federal use.

\section{Strain Gage for Embedment in Concrete}

Development of a waterproof internal strain gage provided a simple method for determining internal strain, thermal expansion, or drying hrinkage in hardening concrete. The gage can be embedded in concrete turing fabrication of a test specimen or structural member. The development follows an earlier study of the volume changes in concrete during reezing and thawing, in which a mercury-displacement dilatometer was used and which indicated a possible relationship between the resistance of a concrete specimen to frost action and the strains produced during reezing and thawing. The dilatometric method, although satisfactory for he exploratory phases of the study, was slow and imposed a limitation. ipon the maximum size of the aggregate that could be used in preparing he concrete.

The internal gage has performed satisfactorily in stress-strain deterninations made upon cylindrical concrete specimens in compression, in neasurements of drying shrinkage of concrete prisms dried for 100 days, nd in the measurement of linear thermal expansion. Work is now under vay to evaluate the stability of the internal gage over longer periods and o compare directly the performance of the gages with that of the mercuryisplacement dilatometer. The testing of mortar or concrete models of tructures appears to be a promising field of application for internal strain ages.

\section{mpact Resistance of Concrete}

While considerable data have been collected on the strength of various pes of concrete under static conditions, relatively little is known about zeir resistance to impact. Yet such information is of vital importance 1 designing structures to withstand explosive blasts and earthquakes. To btain quantitative data, a program was begun four years ago in cooperaon with the Department of the Navy. Small concrete cylinders of various ompositions and strengths were subjected to impact of controlled magniide and duration. Stress-strain curves were obtained, and the strength ind other characteristics of the concrete were calculated. It was found lat the average dynamic strength of the concrete was about 10 percent gher than the static strength, and the modulus of elasticity about 25 arcent greater. Apparatus is now being designed which will allow greater introl over the shape and duration of the applied impact. The investiition will be continued to provide complete data for designers and builders. 


\section{Spontaneous Ignition of Fibrous Materials}

Investigations provided conclusive proof that closely packed fibrous materials can ignite by self-heating. The tests show that these materials, after standing in quantity for some time, may develop an internal temperature higher than that of the surroundings. The extent of the temperature rise depends upon the material, its density and packing, and upon the surrounding temperature and the length of time this state is maintained. This work thus gives strong evidence that suitable precautionary procedures should be taken in the storage and use of such commodities. As a result of the study, control of shipping and storing temperature and of stack size is being recommended to reduce the probability of ignition due to selfheating.

\section{Cigarette Hazards of Mattresses}

A study of the hazard presented by a burning cigarette in contact with mattresses and other bedding, which had been undertaken at the request of the Veterans' Administration, was completed during the year. Early tests indicated that sheets and pillow slips present little danger of ignition from glowing cigarettes. Through the cooperation of interested manufacturers, 28 small sample mattresses and four mattress covers or pads were obtained for the tests. The mattress samples represented various degrees of fire-retardant treatment, from the usual untreated mattresses to those made entirely of materials treated to make them flame-retardant. Severa] hundred tests with burning cigarettes were made on the mattresses, including tests after spot-cleaning with soap and water and after steam sterilization to determine something of the permanence of the flame-retardant treatment: used. It was shown that treatment of the entire mattress padding is un. necessary, but that careful construction providing a complete outer layer or shell, of well-treated materials about an inch deep would produce mattress well protected from ignition by a burning cigarette.

\section{Heating Devices}

A study of heating methods for small homes was continued in the NBs test bungalow. Investigations were made of commercial models of forced warm air furnaces and distribution systems that are typical of new method row being used. Of particular interest to the Federal housing agencie sponsoring the investigations were the vertical and horizontal air tempera ture distributions in the house, heat loss of the house for design temperatur conditions, and the noise level produced by the furnace and blower. Th heating systems studied included a wall heater and a gas furnace installe in the attic, which could be equipped with either a centrifugal blower or propeller fan for circulating the heated air. Two duct systems were in vestigated with each piece of air circulating equipment, one employin high side-wall supply registers and a common return near the center of th 
house, the other employing subfloor ducts and floor registers with high side-wall returns. An investigation of ceiling panel heating is also in progress.

\section{Air Infiltration in Houses}

An investigation of methods for measuring ventilation rates in attics and crawl spaces and air infiltration rates in buildings was undertaken for the Gorernment housing agencies. Tracer gas methods, calorimetric techniques, and pressure difference methods for determining infiltration rates were studied. Two tracer gas techniques using helium gas with a katharometer and ethane gas with an interferometer were selected. A heatedthermocouple anemometer was designed and constructed for measuring air motion. Calibrations of the device indicated a probable accuracy of \pm 2 percent for air flow rates in the range from $5 \mathrm{ft} / \mathrm{min}$ to $140 \mathrm{ft} / \mathrm{min}$.

\section{Water-Vapor Barrier Materials}

In a program sponsored by the Department of the Navy, a study of the vater-vapor permeability of 53 coating materials was undertaken. In zeneral, filled bituminous cut-back coatings showed the highest resistance o water-vapor passage. Although all the data have not been evaluated, he indications are that, with some exceptions, the filled, bituminous cutJack coatings show no appreciable change in permeability with time, while he clay-type bituminous emulsions and the resin emulsions have a somewhat lower permeability after exposure to an accelerated durability test.

Under the sponsorship of the Housing and Home Finance Agency, a tudy was made of the effect of washing and scrubbing on the water-vapor permeability of interior paints used as water-vapor barrier materials. Six nterior paints and three types of detergents were subjected to mechanical washing and scrubbing operations. The cleaning operations did not aprreciably change the permeance of the enamel paints, and no appreciable hange occurred with the flat white paint except during scrubbing with a raint cleaner contairing a synthetic detergent. On the other hand, the esin emulsion paint was completely disintegrated by the cleaning operaions. Water-vapor permeability investigations were also begun for the ) epartment of Agriculture on specimens of asphalt-prepared, smooth-suraced roll roofings and asphalt-saturated felt to determine the suitability of uch materials for the control of condensation in the crawl spaces of baseientless houses.

\section{sphalt Stabilizers}

A survey was made of the materials used by the asphalt roofing industry stabilize the asphalt used in coating prepared roofings. Eighty-two abilizers were evaluated in accordance with a tentative specification proosed by the Asphalt Roofing Industry Bureau in cooperation with the ational Bureau of Standards. The principal materials in use are finely 

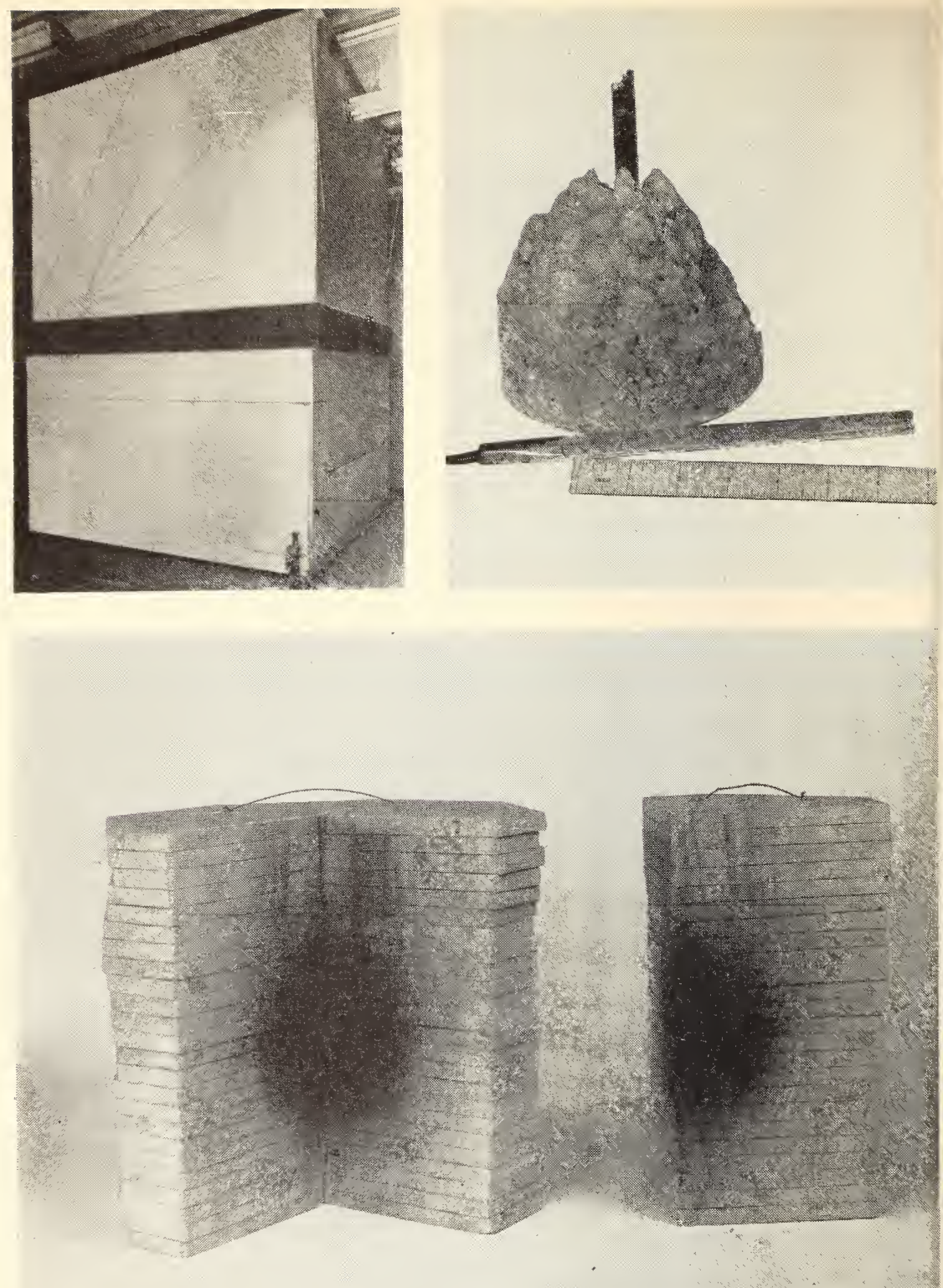

Upper left: Home heating panel (center) installed in a calorimeter for study (p. 64). Upper right: A water-proof internal strain gage that can be imbedded in concrete during fabrication was developed (p. 63), providing a simple method for determining internal strain, thermal expansion, or drying shrinkage in hardened concrete. Below: Laboratory tests of fiberboard and similar materials (p. 64) showed how spontaneous ignition starts at the geometrical center of the specimen. 
ground slate, limestone, dolomite, and oyster shells; others are silica, greenstone, granite, and rejects from the manufacture of portland cement. The desirable properties emphasized by the tentative specification were low moisture content, small loss on ignition, low water solubility, and small amount of free alkali.

\section{Applied Mathematics}

The NBS mathematics laboratories were established in recognition of the need for a centralized national computational facility equipped with highspeed automatic machinery, capable of providing a computing service for other Government agencies, and staffed to undertake further development of numerical techniques for exploiting the advantages of electronic computing machinery. In this area the Bureau engages in basic mathematical research and in addition acts as a service organization, particularly in the fields of engineering statistics and quality control, for the Armed Forces, other Government agencies, and industry.

\section{Numerical Analysis}

Emphasis was placed on the study of matrix inversion and methods of integrating partial differential equations, two topics important in the solution of many problems in aerodynamics and other branches of physics. Considerable attention was also given a third topic, the mathematical theory of program planning.

The type of partial differential equation which represents diffusion phenomena was studied intensively, and a complete and usable theory was formulated concerning the relationship between the discrete and continuous diffusion formulations; this theory is applicable even to the very general nonlinear cases. Other research on differential equations involved the extension of the theory of Monte Carlo solutions of differential equations. Significant work was done on determining the mean duration of a random walk in many dimensions, a subject which has application in connection with the statistical sampling process known as sequential analysis. In the course of the studies on matrix inversion, a new gradient method for solving differential equations was developed which is very effective in minimizing computing time.

\section{Zomputation}

In addition to performing computations requested by Federal agencies, JBS works continuously to create a stockpile of mathematical tables which an be used to facilitate such computations. At the same time, an effort $s$ made to develop new or improved techniques for numerical computation, Jarticularly those adaptable to automatic computing machines, and to train nathematicians in the application of numerical methods. In this way, the 
use of mathematical techniques for the solution of technical problems is promoted and extended, bringing increased effectiveness to the national research program.

Four new mathematical tables [tables to facilitate sequential $t$-tests, tables for conversion of X-ray diffraction angles to interplanar spacing, tables of $n$ ! and $\Gamma(n+1 / 2)$ for the first thousand values of $n$, and tables of Bessel functions $Y_{0}(z)$ and $Y_{1}(z)$ for complex arguments] were issued during the year, and revised editions of a number of earlier tables now out of print were in process of preparation. In general, the tables prepared by NBS are of a type essential in the solution of problems in such fields as atomic energy, aerodynamics, radio and radar navigation, and military ordnance.

About half the computing time of SEAC (National Bureau of Standards Automatic Computer) was spent on Project SCOOP (Scientific Computation of Optimum Programs), undertaken by the Bureau for the Office of the Air Comptroller, U. S. Air Force, which sponsored the construction of the machine. Mobilization plans for the Air Force are now being computed. Unclassified problems on which work was done included the design of supersonic nozzles, crystallography of cement compounds, and penetration of X-rays. Much attention was also given to experiments in Monte Carlo techniques.

\section{Statistical Engineering}

The program in statistical engineering is concerned with the application of modern statistical inference to complex engineering experiments and sampling problems and with the analysis of data arising in physical experiments. Work in this field at NBS has shown that statistical principles and techniques are even more useful in physical-science and engineering measurement than they are in agricultural and industrial work, where many of them were first developed. Thus, special statistical designs, such as crossovers, Latin squares, and Youden squares, have been adapted in precise determinations of radioactivity, in fatigue studies of alloys, and in high. precision temperature measurements.

A large part of the statistical engineering program takes the form of co. operation with other laboratories on the statistical phases of scientific ex. perimentation and engineering tests. In addition to these consulting serv. ices, several other activities are carried on which contribute to the furthe development of statistical theory and statistical methodology. Manual on selected phases of statistical methods, glossaries of statistical engineering terms, and guides to statistical literature are prepared; special tables of statis tical functions, as well as other aids to the application of modern statistica methods, are compiled and published as the need arises; and basic researcl is conducted on appropriate topics in the mathematical theory of probabilit and mathematical statistics. 


\section{Electronics}

In electronics, the National Bureau of Standards carries on a broad, diversified program of research and development important both to national defense and the peacetime economy. The research is concerned principally with basic electronic phenomena and the properties of materials of potential significance to electronics. Development includes not only the design of electronic circuitry for the performance of new functions but also the broader phases of fabrication technology by which optimum designs for electronic equipment may be achieved. Emphasis is placed on improvement of the operational reliability of electronic equipment through the development of new components and the application of new materials and techniques of assembly. This phase of the work is of special value in the adaptation of military electronic devices to increasingly severe conditions of operation.

During the past year, a large and increasing proportion of the electronics program was classified and was carried on for the Department of Defense; much of the remainder consisted of projects in basic and applied electronics conducted primarily for other Government agencies. Unclassified projects included the development of several subminiature electronic devices, design of equipment for printing electronic circuits; investigation of possible methods for prediction of failure in electronic equipment; investigation of the functional behavior of cathodes and gases in electron tubes; development of evaluation procedures and test equipment for electron tubes; developnent of special-purpose electron tubes; development of high-speed multihannel temperature monitors for shipboard use; development of a low-cost, nass-production design for a portable radiation detector; investigation of ircuits for conversion of electrical signals from analogue to digital form; urvey and analysis of the applicability of electronic information handling echniques to problems of large-scale information processing occurring in he Treasury Department and the Social Security Administration.

Also reported in this section are several unclassified projects that were arried on in connection with the NBS electronic ordnance program. hey include a quick-action piezoelectric clutch, a new casting resin for the otting of electronic circuits, a mechanism to increase the capacity of punchard sorting machines, and a method for the rapid checking and adjusting resistance values in printed radio circuits.

\section{Liniaturization of Airborne Electronic Equipment}

A program of electronic miniaturization was continued under the sponrship of the Bureau of Aeronautics, Department of the Navy. This ogram is aimed at the development of techniques applicable to the manucture of airborne equipment. During the year, three models of a iniaturized radio range receiver and an air-sea rescue transceiver were mpleted. The miniature range receiver is a 12 -tube radio receiver packed 

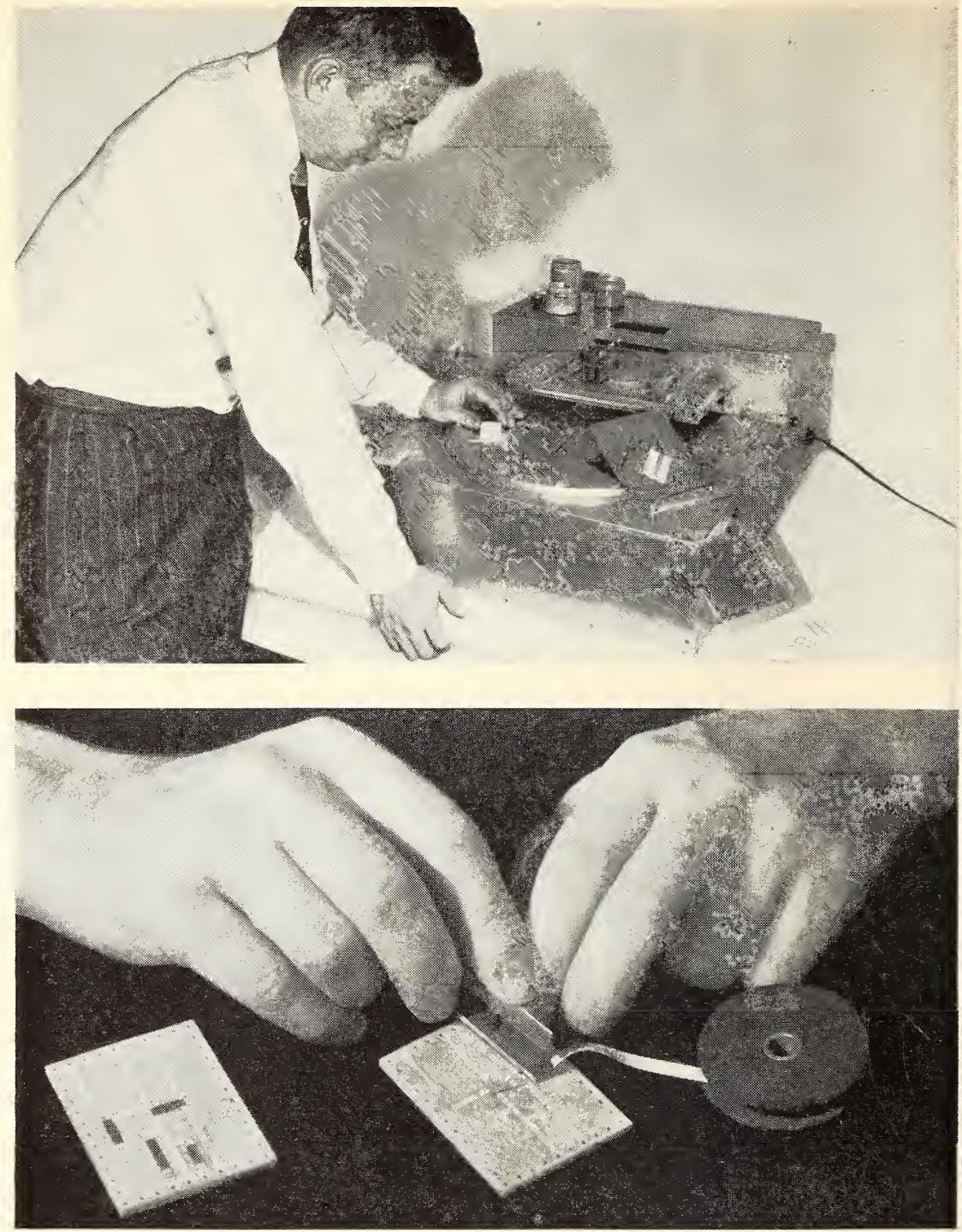

Above: A semiautomatic machine developed by the Bureau to print electronic circuits on flat surfaces (p. 71) has a capacity of over 1,000 plates per hour. Below: One of the new NBS adhesive tape resistors (p. 71) is set in place in a printed circuit.

into a sealed envelope $6 \times 5 \times 13 / 4$ inches in size; it is divided into nine replaceable subassemblies for ease of production and maintenance. Several ingenious mechanisms were devised to perform switching, tuning, and volume-control functions within the small space available and at the high temperature which of necessity accompanies extreme miniaturization. The air-sea rescue transceiver is a battery-powered unit roughly $101 / 2 \times 21 / 2 \times 21 / 4$ inches in size, including the battery-pack but exclusive of the antenna; and it can transmit and receive on two distinct frequencies. 


\section{Adhesive Tape Resistor}

Printed electronic circuits-in which components and wiring are superimposed directly on insulating bases-are being used increasingly because of their adaptability to economical mass production and because they facilitate miniaturization of equipment. A major disadvantage of the printed circuit method, however, has been the difficulty of incorporating satisfactory resistors in the circuits. During the year this difficulty was largely overcome by the development of an adhesive tape resistor method in connection with the electronic miniaturization program sponsored at NBS by the Navy Bureau of Aeronautics.

In the past, the usual method of introducing resistances into printed circuits has been to paint or spray a strip of resistance material directly on the base plate. In the new technique, circuits are first printed in narrow metallic bands on insulating bases, leaving a small gap at each point where a resistance is required; one of the self-adhesive resistors is then cut from a strip and pressed into position. Much better control of resistance values is possible than with previous printed resistor methods, and higher yields of acceptable assemblies are assured. The new method thus appears to combine the advantages of printed resistors and of separately manufactured resistors. The NBS tape resistor was developed to withstand the high temperatures of very compact equipment and operates satisfactorily at temperatures up to $200^{\circ} \mathrm{C}$; in other electrical characteristics it is similar to present film-type carbon resistors.

\section{Circuit Printers for Flat and Cylindrical Surfaces}

Two semi-automatic machines for printing electronic circuits, one for flat surfaces and the other for cylindrical surfaces, were developed. The new NBS printers are products of a continuing program of printed circuit development sponsored by the Navy Bureau of Aeronautics. Although few if any automatic printers have hitherto been developed for printed circuit applications, such printers appear to offer two important advantages. First, they are faster than hand printers and more economical for use in quantity production. Second, and perhaps equally important, they give a more uniform product.

The NBS cylindrical-surface printer was developed for the printing of cylindrical ceramic forms less than 0.5 inch in diameter. Such small ceramic cylinders are usually out-of-round and present a much more difficult printing problem than larger, more regular forms. The cylindrical-surface printer is loaded manually by slipping the cylinder to be printed over a mandrel. A single stroke of a hand-operated control lever then puts the machine through the entire printing cycle and operates a release mechanism which drops off the printed cylinder.

The NBS printer for flat plates is motor-driven and more fully automatic than the printer for cylindrical surfaces. In the flat plate printer, a turn- 
table accepts the unprinted plate at a loading position, carries it to a printing position, then carries the printed plate to an urloading position, where it is automatically flipped into a chute.

\section{Microphonic Study of Microwave Tubes}

Microwave tubes, such as Klystrons and Magnetrons, are used by the Armed Forces in aircraft, mobile ground equipment, ships, and guided missiles. As such tubes must operate under conditions of severe vibration, a method of measuring their microphonic output has been greatly needed. During the year, instrumentation was devised to give independent measurements of amplitude and frequency modulation of X-band reflex Klystrons under vibration. Measurements were made in Klystrons at vibration frequencies up to 50 kilocycles. The method is readily adaptable to other $\mathrm{r}-\mathrm{f}$ frequency bands.

\section{Miniature Piezoelectric Accelerometer}

To determine the effects of shock and vibration on electron tubes, a miniature piezoelectric accelerometer was developed in the NBS basic instrumentation program sponsored by the Departments of the Navy and the Air Force and the Atomic Energy Commission. The new accelerometer, which employs a piezoelectric compressive element, measures high-frequency vibrations directly and also checks the frequency response of vibration generators. Although the device is extremely small, it is in many ways superior to instruments now used to measure mechanical vibration and shock. Its construction is so simple that it can be produced for only a fraction of the cost of a conventional vibration pickup.

The piezoelectric compressive pickup is designed to detect a variety of vibratory movements. As an example, the unit responds to the characteristic vibration frequencies generated by faulty bearings in an electric motor. The accelerometer is equally useful for calibrating other vibration pickups, shake tables, and low-frequency noise detecting devices.

\section{Radioactivity Survey Instrument}

Effective radiological defense requires instruments which can be used in surveying disaster areas for extent and level of radioactivity. For maximum effectiveness, such instruments must be small, self-contained, and inexpensive enough to be distributed in large quantities to all defense activities.

In the course of an investigation of radiation detectors, undertaken at the request of the Bureau of Ships, Department of the Navy, a portable gamma survey instrument was developed. The principal feature of this instrument is the elimination of the usual fragile and expensive microammeter for measuring the current flow in the gamma detection tube. This is accomplished by the use of a bridge circuit including a calibrated potentiometer.

In addition to measuring the quantity of gamma radiation, the instrument provides for the usual detection of low-level radiation by earphones. Ex- 


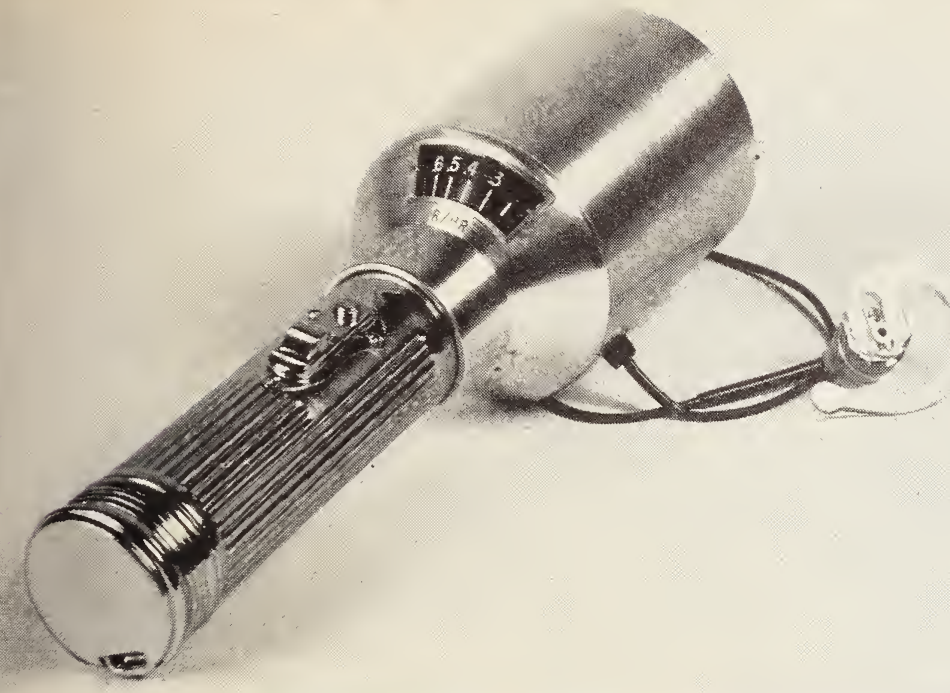

Portable radioactivity survey instrument developed by NBS for gamma radiation (p. 72). The device is extremely rugged and compact.

tremely rugged and compact, the device has the appearance and approximate size and weight of an ordinary flashlight.

\section{Analogue-to-Digital Converter}

The conventional electrical indicating meter provides an analogue measurement system, in which a steady increase of the electrical quantity being measured causes a corresponding stepless increase in the deflection of the pointer. On the other hand, electrical measurement can be performed upon a digital basis, in which a count is made of the number of times that a basic electrical unit is contained in the quantity to be measured. The count can be displayed upon an array of discrete indicators, e, g., a bank of indicator lamps.

During the year, research was carried out on electronic systems and system lements for an all-electronic analogue-to-digital converter for electrical quantities. A principal contribution was a basic improvement in analogue ntegrator design permitting the attainment of increased accuracy. Another ontribution was an improved potential balance indicator. These comsonents have been combined in an experimental instrument, the Anodige. $\mathrm{n}$ this instrument, the voltage to be measured is repeatedly balanced to he required precision against an integration of voltage increments, the ount of which provides the measurement. The system is inherently stable, ccurate, and linear to within 0.1 percent of its full scale range of about Do volts. 
The Anodige should have wide application in fields where direct application or recording of parameters expressed in three digits is desired. Moreover, the instrument provides a coded-pulse output that is well suited for direct retransmission in a telemetering system or for magnetic-tape recording in memory systems of electronic computers. In these uses, no auxiliary equipment is required to maintain the inherent maximum accuracy.

\section{Temperature Monitor Set}

A temperature monitor set was developed which flashes a warning if the temperature at any one of up to 48 points rises above an individually predetermined safe value. From the centrally located monitor unit, pairs of wires run to individual thermocouples mounted at the critical points. A master alarm light goes on if any of the 48 points become too hot, and an alarm bell will ring simultaneously if desired. The difficulty is then promptly localized by a separate indicating unit. On the panel of this unit are 48 lights, one corresponding to each of the 48 thermocouples. These lights go on to show which thermocouples are over temperature. The actual temperature at any single point can be measured, if desired, by plugging a microammeter into the appropriate circuit. The monitor covers the range from $100^{\circ}$ to $400^{\circ} \mathrm{F}$, and each circuit can be individually set to trigger its warning signal at any temperature within this range.

\section{High-Speed Crystal Clutch}

An experimental crystal clutch, believed to be the first of its type, was developed. In the new clutch, application of a direct-current voltage to the electrodes of three piezoelectric crystal elements causes bending of the elements; this bending presses the clutch output disk against the rotating input disk. The new experimental unit was devised as part of a program for the development of fast-acting clutches suitable for use in high-speed computers. Distinguishing features of the crystal clutch are high speed of response and almost negligible current drain. No current flows, other than insulation leakage, after the applied voltage has charged the capacity of the crystals. The clutch therefore creates no magnetic field, an advantage in some applications.

\section{Low-Cost Casting Resin}

A new casting resin which possesses certain advantages over the original NBS Casting Resin was developed for the potting of component parts of electronic circuits. Although the electrical efficiency of this resin is less than that of the original resin at extremely high frequencies, the new resin is more economical to produce because of the availability of its constituents and the ease with which it may be stored. These factors make it a desirable material for numerous high-frequency applications where optimum electrical properties are not essential. 


\section{Rapid Adjustment of Printed Resistors}

The mass production of printed radio circuits requires some method for the rapid checking and adjusting of resistance values. During the year, NBS developed a system, based on the Stupakoff method, which automatically abrades material from the printed resistors until they have reached the desired value. The resistors are intentionally printed with an excess of resistive material so that their values are initially below the desired level. The printed circuit is then fed into an automatic device which measures the values of the resistors. Those which show too high a resistance are automatically rejected and are permanently discarded. On the other hand, the units which show too low a value are automatically fed to a slotted rotating drum. Here they are brought across a sensing element and subjected to a stream of air carrying a fine abrasive material. This abrasive removes some of the resistive material until the resistance measurement, as shown on a resistance bridge coupled to the resistor, indicates that the resistance is within 1 percent of the desired value.

\section{Card-Sorting Machine}

A mechanism to increase the capacity of punch card-sorting machines was under development. Ordinary machines of this kind, which separate cards by means of several separating channels, can make only 12 stacks at each sorting because the number of such channels is mechanically limited. In the system under design, it will be possible to sort the cards into any desired number of stacks; the first model is being built for 256 stacks instead of 12 , thus greatly simplifying the sorting operation.

\section{Automatic Electronic Computers}

During its first year of operation, SEAC (National Bureau of Standards Eastern Automatic Computer) was operated on a 24-hour-a-day, 7-day-aweek schedule to solve a wide variety of important problems for the Departnent of Defense, the Atomic Energy Commission, and the NBS laboratories. SEAC was completed the previous year by the NBS staff under the sponsorhip of the Department of the Air Force to provide a high-speed computing ervice for Air Force Project SCOOP (Scientific Computation of Optimum rograms), a pioneer effort in the application of mathematical techniques o large-scale problems of military procurement and administration. SEAC also available for solving other important problems of general and special cientific and engineering interest.

The new electronic computers are highly intricate, with tremendous umbers of components and connections, and the reliability demanded of tarts and wiring in such machines is exceptionally high. SEAC, for exmple, contains some 11,000 germanium diodes, 800 vacuum tubes, 500 ulse transformers, and 100,000 soldered connections. Failure of a single ne of these myriad connections and components, even for a millionth of a 


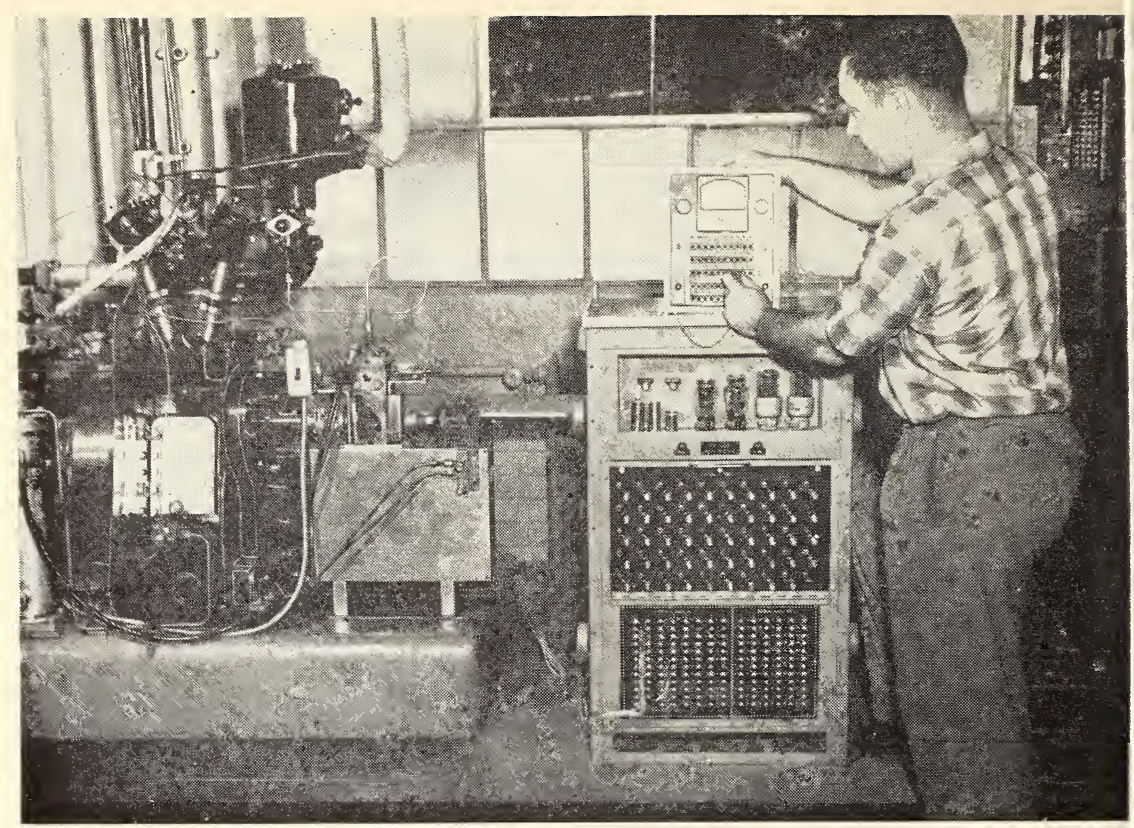

The NBS 48-point temperature monitor (right) gives an alarm-a light, a bell, or both-when the temperature of any one of 48 remote points rises above a predetermined safe level (p. 74). Here the set is connected experimentally to thermocouples mounted at a number of critical points on a test engine (left).

second, will result in computer misfunction. Despite these severe operating requirements, SEAC was maintained in good working order over 4,000 hours during the past 9 months. In addition to production-scheduling problems for the Air Force, work was done on such varied problems as electronic circuit design, optical lens calculations, calculations relating to the relative abundance of the chemical elements in the universe, statistical sorting and tabulating studies for the Social Security Administration and the Bureau of the Census, and many classified problems for military agencies and the Atomic Energy Commission.

The speed, economy, and flexibility of electrostatic information storage systems following the general lines proposed by F. G. Williams in England recommend these systems for broad-scale computer applications. However, incomplete understanding of the basic phenomena, as well as significant engineering difficulties, has greatly hampered their successful application. As a result of an extensive study of operating parameters of Williams tube systems, a more complete explanation of the complex phenomena that take place has been achieved, and a large-scale Williams memory using 45 cathode-ray tubes, about 200 vacuum tubes, and 2,000 germanium diodes has been incorporated into SEAC.

The SEAC control system was expanded with the installation of an automonitor and a new control console. These additions enable the machine to print out all the steps of a computation automatically, as an 
aid in checking the correctness of new codes. The operating time lost on the machine was held to a remarkably low level while these extensive changes in the control were being made.

A magnetic input-output system was completed and incorporated into the machine and is now in regular operation. A punched-card-to-magnetic-tape converter was also completed and put into operation.

The design, construction, and operation of SEAC has been part of a much broader NBS program on automatic electronic computers. This program has four principal phases: fundamental research, engineering development, machine design and construction, and technical coordination. The fundamental research includes basic studies in numerical analysis, logical design, programming techniques, and circuit efficiency. The longrange objective of this research is faster, simpler, and more versatile computers, and more effective use of the machines already in existence. Development work has been concentrated on certain critical computer needs: efficient memory systems, high-speed switching, and increased reliability of electronic components. The design and construction phase represents the application of the knowledge derived from NBS research and development work and from current advances in the computer field.

The final phase of the NBS computer program consists in providing technical services for other Government agencies. This involves, in addition to mathematical and electronic consulting services and the construction and operation of NBS computers, technical coordination of Government contracts placed with industry for other large-scale computers.

\section{Radio Propagation}

The NBS Central Radio Propagation Laboratory is the primary agency ,of the United States Government for research in radio wave propagation , and for the centralization and coordination of information in this field. The laboratory is also responsible for the development and custody of the ational primary standards for electrical quantities at radio frequencies.

Comprehensive programs of basic and applied research are undertaken $\mathrm{n}$ radio physics and associated geophysical phenomena of the upper atnosphere and the troposphere. Extensive laboratory studies are also under vay dealing with properties of matter at radio and microwave frequencies ind the development of techniques for precise measurement of electric juantities in this region. In addition to such research activities, NBS does large amount of advisory and consulting work on radio for other agencies if the Government such as the Department of Defense, the Civil Aeronautics Idministration, and the Federal Communications Commission, and particivates in an advisory capacity in international radio conferences.

The work in radio propagation is divided into three branches: The Ionopheric Research Laboratory, the Systems Research Laboratory, and the Ieasurement Standards Laboratory. The Ionospheric Research Labora- 
tory conducts basic research on the nature of the upper atmosphere and its ability to reflect radio waves. The Bureau maintains a widely separated network of 17 ionospheric sounding stations extending over the American continents and the Pacific area, the largest network operated by any one government. Ten of these stations are controlled directly; the other seven are operated in close cooperation with other agencies. Data supplied by these observatories provide basic material for scientific research and for determining frequencies to be used in long-distance radio communication. In addition, a permanent radio propagation field station at Sterling, Va., and a number of temporary field stations are operated for performance of special experiments. Because of the important influence of extraterrestrial effects on ionospheric phenomena, solar and cosmic phenomena are studied. These include radio waves emitted by the sun and other celestial bodies, which also afford a new means for exploration of the universe.

The Systems Research Laboratory applies radio propagation information to the practical problems involved in such uses of radio as communication, navigation, and traffic control, with particular consideration to the advantages and limitations of the types of radio systems concerned, receives data from a large number of ionospheric stations operated by other nations throughout the world, integrates these data with the observations of NBS stations, and prepares and publishes a monthly series of charts predicting, three months in advance, the best frequencies for long-distance communication throughout the world. It also conducts propagation research at the higher frequencies, such as are used for FM and television, which are not reflected by the ionosphere.

The Measurement Standards Laboratory conducts research in methods for measuring electric quantities at radio and microwave frequencies. Advances of the last few years have carried this work to higher and higher frequencies, across the border where classical electromagnetic theory and quantum theory overlap, and have opened up a new field of basic research in physical science. An important function of this laboratory is the maintenance of standards of electric quantities at all radio frequencies, including time and frequency standards which are broadcast continuously from the Bureau's radio station, WWV, at Beltsville, Md., and from the experimental station, WWVH, at Maui, T. H.

\section{Propagation Effects on Air Navigation and Traffic Control}

Plans now being coordinated by the Air Navigation Development Board call for the use of frequencies in the range from 1,000 to 1,600 megacycles for air navigation systems. A broad program of propagation research to provide the necessary information on long-distance propagation characteristics in this relatively new portion of the radio spectrum is under way at NBS. A 5-kilowatt Klystron transmitter has been developed and installed on Cheyenne Mountain, Colorado, at an elevation of 9,000 feet above sea level, overlooking a plain at 5,000 feet which gradually slopes to 4,000 feet. 
A wide variety of terrain conditions is available in different radial directions from this transmitter site. Especially designed narrow-band receivers are being installed in six receiving sites on the plain. This combination of transmitter and receivers should provide detectable signals at distances much greater than any other presently available system. In addition, the low-level sounding equipment will be used for further studies of the effects of climate on radio propagation conditions. This program should insure proper allocation of available spectrum space before these frequencies are extensively used.

\section{Theoretical Investigations of Radio Wave Propagation}

A new theory was developed which explains experimentally observed propagation of very-high-frequency radio waves beyond the horizon and has significant practical applications with respect to television and other high-frequency communications services. The persistent anomalous VHF and UHF field strengths measured far beyond the horizon are explained on the basis of partial reflections produced by the atmospheric gradient of refractive index. A hybrid wave-and-ray theory formulation indicates signal strengths of the order of magnitude of those measured; in addition, the wavelength, antenna height, and angular dependences appear to be in agreement with observation. The reasons for the failure of the current wave theories to obtain this signal component have been ascertained, and vork is continuing on a rigorous wave formulation which avoids this failure. An explanation was evolved for the anomalous polarization data obtained experimentally for low-frequency waves reflected from the ionosphere at vertical incidence. This explanation is predicated upon the assumption hat the collisional absorption condition required for the transition from fuasi-longitudinal to quasi-transverse propagation occurs in the region of ritical electron density for low frequencies. A quantitative investigation of the mode coupling that occurs under these conditions indicates that the nergy transfer is a function of the gradient of electron density in the region ind of the departure of the collision frequency from its critical value. The bserved correlations of the polarization measurements with height and vith frequency are accounted for in a straightforward fashion by this theory.

\section{Radio Astronomy}

Cosmic and solar radio waves reaching the earth from outer space limit he range and minimum useable signal levels for FM broadcasting, teleision, and communication and radio navigation services in the very-highrequency range. In recent years, the techniques of radio astronomy have een developed for receiving and analyzing these longer wavelengths. This ad made it possible to obtain information about the positions of stellar odies and the matter in interstellar space that could never have been btained with an optical telescope. 


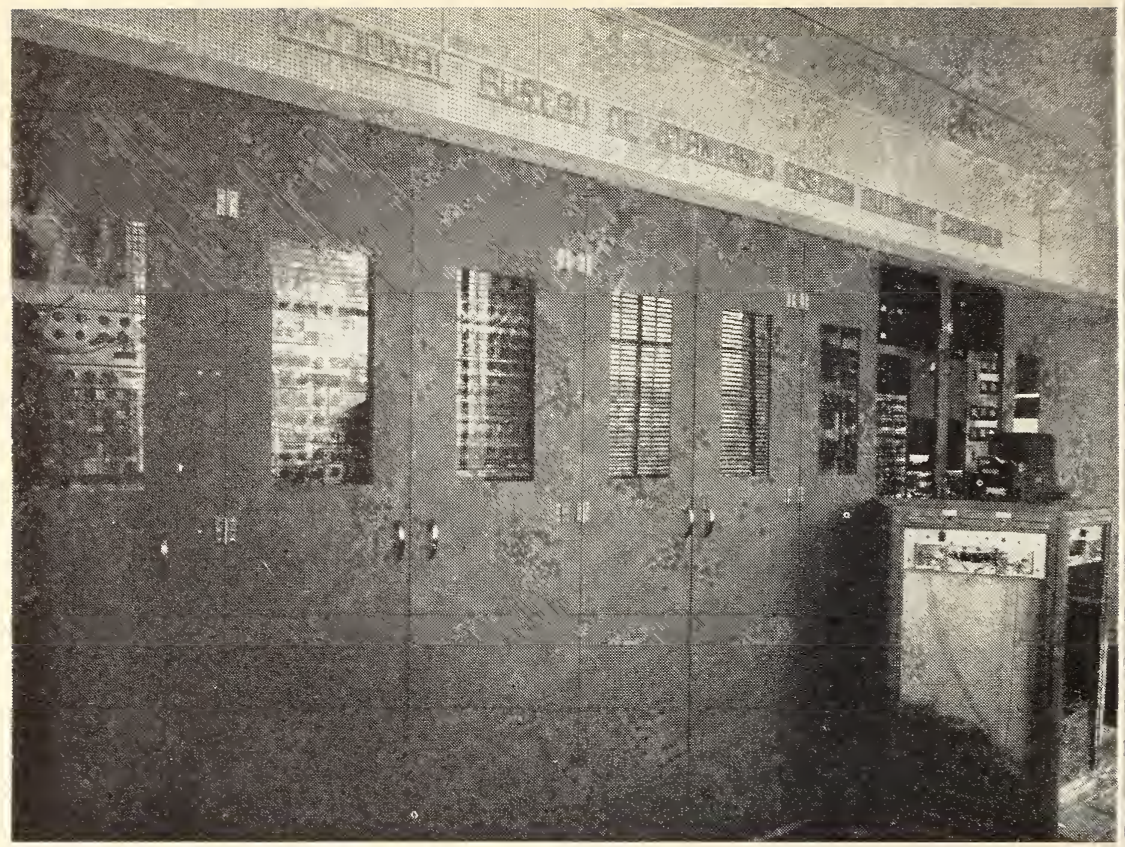

Research and development on electronic computers actively continued. Above: Front view of SEAC (National Bureau of Standards Automatic Computer) (p. 75).

During the year, considerable work was done on the theory of the origin of solar noise bursts as a result of radio wave generation by multistream charge interaction. Work was initiated on a nonlinear theory of plasma oscillations which demonstrates that a direct conversion of longitudinal plasma oscillations into transverse radiation field occurs if the rate of growth of the oscillations is sufficiently rapid.

NBS participated in an expedition to Attu Island, Alaska, to observe the total eclipse of the sun by the moon on September 11, 1950. The expedition was organized by the Naval Research Laboratory, primarily to apply the methods of radio astronomy to the study of the eclipse at various radio frequencies. As the radio waves given off by the sun are received without difficulty through rain or fog, the radio methods proved particularly valuable for observations in the cool, damp climate of Attu Island, where the eclipse was accompanied by a severe rainstorm.

\section{Radio Observations of Meteors}

A program of coordinated radio and visual observations of meteors was carried out on four nights during the August 1950 occurrence of the Perseid shower. A total of 1,500 visually observed meteors were recorded, and amplitude records of radio echoes from meteors were made simultaneously with visual observations. Echo range-time records were also made. Analysis of the data showed that the amplitude of most meteor echoes tends to 
decay exponentially with time. The only process known to produce this form of echo decay is ordinary diffusion. Diffusion coefficients deduced from the echoes seemed to be considerably larger than values expected on the basis of ionic mobilities. However, a theoretical investigation of the effect of laminar flow, acting together with diffusion, on the rate of decay of echo amplitude, showed that laminar flow may increase the duration by a factor of 4 .

To determine the variation of rate of decay with height, means were devised for determining the true height of a meteor from the slant range and zenith angle. The zenith angle was obtained from the relative intensity of the meteor echo as picked up on two antennas with different known vertical pickup characteristics.

\section{Storms in the Ionosphere}

A study of the geographical distribution of ionospheric storm characteristics was initiated. Observations of F2-layer critical frequencies at all stations in North America were used to study characteristics of subauroral ionospheric disturbances on a continental scale. Contour maps of percentage deviation from the monthly median were drawn at 2-hour intervals for four storms. Positive and negative deviations as great as 60 percent were noted. The maps reveal that two of these disturbances had rather welldefined centers, 2,000 to 3,000 kilometers in diameter, which moved across the continent. The other two storms had no centers but exhibited a marked dependence upon geomagnetic latitude. During these latter disturbances, which occurred in winter, the critical frequency was enhanced in regions below approximately $50^{\circ}$ geomagnetic latitude and reduced in regions above this latitude. Some additional evidence indicates that the reversal takes place at a lower latitude in the summer.

\section{Dielectric Measurements}

In connection with studies of tropospheric propagation, a microwave reractometer was developed for continuous recording of the index of refracion of the atmosphere as changes are caused by various meteorological -ffects. The refractometer employs a frequency modulation technique to neasure small changes in frequency differences between two cavities, one sed as a reference cavity and the other arranged to permit a flow of atnosphere through the cavity.

The dielectric constant of water vapor at room temperature was measred at a wavelength of 1.25 centimeters. The results were in excellent greement with those obtained previously at 3.2 centimeters, showing that there is no measurable dispersion in this wavelength region. The dipole roment of water vapor was derived from these measurements.

\section{licrowave Equipment}

From information gathered on the properties of polyiron used as an bsorptive load for microwave energy, a form of coaxial attenuator was 
developed which can be controlled by an electromagnetic field. Such a derice is useful not only for the remote control of UHF energy in a coaxial system but also as a modulator and as an electronically controlled amplitude stabilizer for UHF oscillators or signal generators.

A 40-inch coaxial standing-wave machine of special design and precision construction marked a new achievement in such machines. An over-all deviation of not more than 0.0002 inch in any given dimension was obtained, including the concentricity of inside and outside conductors. The inner conductor is supported over its entire length on a mica strip.

\section{Microwave Spectroscopy}

Work proceeded on the investigation of nuclear electric quadrupole absorption in crystals. The 332.4-megacycle absorption line in crystalline iodine was located, and experiments were carried out which provide information for the design of a precision Zeeman-modulation research spectrograph. The quadrupole absorption permits the use of solid-type frequency standards (rather than a gas or atomic beam), which are insensitive to mechanical shock and aging. The method should therefore be particularly applicable to all portable frequency and time standardization equipment. Another advantage is the wide range of frequencies obtainable in the previously inaccessible UHF region, where good tubes are available, pointing to the possibility of a portable atomic clock and applications in television, communications, navigation, and radar. A theoretical investigation of quadrupole resonance was initiated.

A program is under way for the development of a precision microwave spectrograph for measurement of fluctuations in the length of the day of about 1 part in 60 million each year. This spectrograph is driven by a quartz-crystal oscillator through a frequency multiplier chain using new type tubes, making possible the accuracy needed for the project.

\section{Atomic Standards of Frequency and Time}

Because of fluctuations and secular changes in the length of the solar day, unchanging standards of frequency and time are needed by science. Since the first atomic clock, based on the constant natural frequency associated with the vibration of atoms in the ammonia molecule, was announced by NBS in 1949, an intensified program has been carried on which now comprises the investigation of four different types of atomic clocks.

A second model of the first type of atomic clock has now reached the stage of preliminary testing and adjustment. This unit uses a conventional quartz crystal clock which is automatically regulated by the 23,870-megacycle line of ammonia through a single servomechanism. Achievement of accuracy is greatly aided by limiting operation to only one servomechanism. This clock has a sensitivity of one part in 100 million, correcting changes in the quartz clock rate of that magnitude. Its long-term stability is not known, but preliminary tests show constancies of one part in 50 million 
during intervals when the quartz oscillator frequency, under similar conditions, would have drifted by five times this amount. A third model of this clock is now under development, employing new tubes, more reliable components, and improved circuits for greater accuracy.

A second type of ammonia clock using a self-excited oscillator and frequency divider exactly analogous to a quartz crystal clock is also being developed. The success of this clock is dependent on the availability of suitable microwave amplified tubes. Such tubes, the first high-performance amplifiers in the 24,000-megacycle region, have recently been developed, and construction of a complete unit can now be undertaken.

A third clock using cesium in an atomic beam technique is nearing the stage of manual operation. Elimination of collision and Doppler broadening and power saturation allows the highest potential accuracy of any of the methods under development. A spectral line width 300 times narrower than ammonia is expected, with the possibility of accuracies of one part in $10^{9}$ to $10^{10}$ or better. The beam equipment and all precision electronic units for exciting the beam have now been completed.

\section{Noise Standards}

The noise figure, a fundamental measure of the quality of linear electrical networks, is of basic importance in radar, telemetering, and all communications. During the year, noise figure standards to 30 megacycles, accurate i: 0.2 decibels, were successfully completed. In radio-frequency noise work, definitions were formulated determining the exact meaning of bandvidths. A new, simple, and effective method of accurately measuring the ittenuation coefficient of balanced television transmission lines was dereloped. The range of 1 -percent attenuation measurements up to 300 negacycles was considerably widened by improved design features in newly :onstructed waveguide-below-cutoff attenuators and by the development if several highly stable electronic monitoring circuits. Analytical and xperimental studies resulted in a useful nomogram providing simultaneus connections for skin depth and cut-off frequency effects in piston ttenuators of various diameters and conductivities.

\section{mpedance Standards}

The art of impedance measurements was considerably advanced by the evelopment of a precision solid-dielectric 2.5 -meter slotted line having a niformity of distributed constants of 0.2 percent-about one order of magitude better than any hitherto attained. In connection with the developlent of power standards, several methods were employed to obtain a device rat can be used as an impedance standard or a termination of known reflecon properties. Such components, if of wide-band characteristics and of nown and predetermined reflection properties, are of great usefulness in ne microwave laboratory. These devices took several forms. One type a form of discontinuity in waveguide, but to be accurate it must be con- 


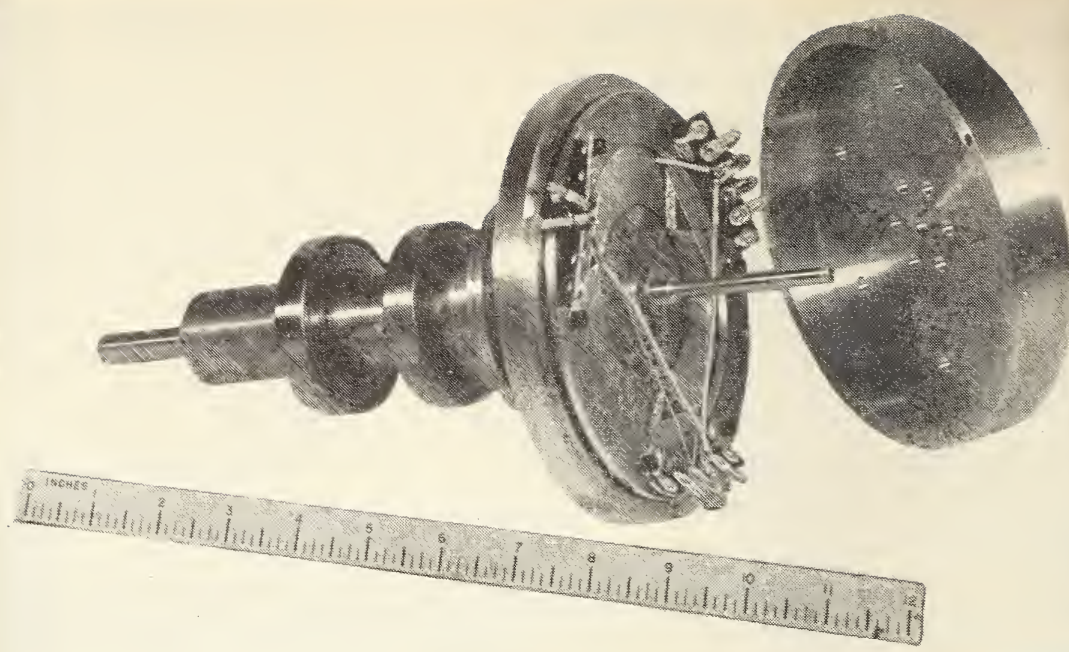

The NBS high-speed crystal clutch (p. 74), unmounted, with cover plate re moved. The new experimental clutch is actuated by the bending of three piezo. electric crystal elements when a d-c voltage is applied.

structed with great precision. Another type takes the form of $\mathrm{H}$-plane junctions constructed to precise dimensions by electroforming. Still another combines an accurately matched and calibrated attenuator with a movable short.

\section{Electronic Ordnance}

The classified program for the development of new weapons for the Department of Defense was greatly intensified during the fiscal year. This program has two major phases: proximity fuze development for the Department of the Army and the design, development, and performance testing of guided missiles for the Department of the Navy. The Bureau pioneered in the development of proximity fuzes for nonrotating projectiles during World War II; more recently the work relating to projectile fuzes has been expanded, and the program has been enlarged to meet the special requirements of fuzes for guided missiles.

At the close of the year, a new laboratory center was established at Corona, Calif., primarily to provide facilities for electronic research and development of importance to the Department of Defense, and the missile development activities were transferred to the new center. Most important phases of missile development will be covered at the Corona Laboratories, from theoretical and applied research to construction of experimental parts and units. An analogue computer is now being set up for use in flight simulation problems where trajectories of guided missiles must be computed mathematically. The computer, occupying about 1,000 square feet of floor 
space, can solve problems in minutes that would take trained mathematicians weeks to solve.

In connection with the electronic ordnance program, developmental work on nonmilitary devices employing similar electronic or electromechanical principles was also carried on for various Government agencies. These unclassified projects are reported under Electronics, page 69.

\section{Testing, Calibration, and Standard Samples}

The Bureau's testing and calibration activities are an outgrowth of its zustody of the Nation's basic physical standards. In many cases master standards used in industry or by other laboratories must be checked periodically against these national standards. NBS is also responsible for testng many of the materials purchased by the Government to assure conformance with specifications. In the course of this work, many new instruments, zew methods of measurement, and much technical data on the properties of naterials are developed.

During the year, over 300,000 tests and calibrations, having a total fee ralue of more than $\$ 1,600,000$ were performed for other Government agenies and the public. In addition, about 25,000 standard samples were presared and distributed. Typical services of this kind included the sampleesting of over 300,000 clinical thermometers purchased by the Government, he life-testing of about 6,000 light bulbs (a sampling of nearly 7,000,000 urchased by the Government this year), the calibration of approximately , 500 gage blocks, over 800 measurements of radon in breath samples from adium dial painters or in the workroom air, the testing of 150 ores and udges for radium content, the calibration of more than 900 water current leters, and the calibration of 35,000 capacity measuring devices.

One of the largest testing projects is the cement testing program, which conducted to insure compliance with Federal specifications. More than $0,200,000$ barrels of cement were sample-tested during the year. The icrease of approximately 1,200,000 barrels over the previous year was rgely due to increased Federal construction. The tests, consisting of hysical and chemical analyses, were carried out at four separate field ations established for this purpose as well as at the central laboratory in ashington. In addition, shipments of more than 9,000,000 barrels of ment were inspected and certified at various cement mills.

Closely related to this work is the program of the Cement Reference aboratory, which inspects the apparatus and test methods of cement-testing boratories. This laboratory is located at NBS and is jointly supported by e Government and the American Society for Testing Materials. The ablic Roads Administration contributes to the financial support of the oject and requires that laboratories testing cement for Federal-aid projects ust be inspected regularly by the Reference Laboratory. 
For many years, all radium preparations sold in the United States have been tested and certified by the Bureau. During the year 885 tests of such materials-principally medical preparations for hospitals and clinics-were made for the Government and private concerns. Over 1,300 radioactive standards were distributed, reflecting the constantly increasing demand throughout the country for this service by the Bureau. These includec radium gamma-ray standards, alpha-ray standards, radium $\mathrm{D}+\mathrm{E}$ standards radioactive iodine, radioactive phosphorus, radioactive carbon, radioactive cobalt, radon standards, and rock samples.

To protect the health and safety of workers in occupations involving the handling or processing of radium, the Bureau maintains careful chect over the quantity of radium ingested by such workers and over the quantit: of radon present in their working areas. The breath of these workers 0 the air in the workroom is sampled periodically and is measured for it content of radon, the gas produced by radioactive disintegration of radium This analysis reveals the amount of radioactivity present and provides th basis for the establishment and maintenance of proper safety measures

Standard Samples are materials that are certified for chemical com position or for some physical or chemical property, such as heat o combustion, melting point, or index of refraction. Standard samples o steels help to control the quality of the steel industry's output. Primar chemical standards and metals with certified melting points make possibl uniform measurements of heat and temperature in the same way that stand ard weights provide uniformity of measure in buying and selling. Standare pigments define the colors of paints, and a large variety of hydrocarbons supplied as single substances of high purity, calibrate the instruments tha control the composition of motor gasolines, aviation fuels, and syntheti rubber. The list of standard samples issued by NBS now includes abou 500 materials.

\section{Electricity}

Approximately 17,000 separate exact determinations were made o standard apparatus submitted for test by manufacturers, electric powe companies, State public utility commissions, university laboratories, an private testing laboratories. Standard apparatus which is to serve as th basis of the national electrical standards of the governments of the Unio of South Africa, India, Canada, and Israel was examined and certified i terms of the standards maintained by NBS. This apparatus include standard cells, standard resistors, inductors, ammeters, wattmeters, an voltmeters.

\section{Optics and Metrology}

Requests for testing and calibration service were much greater in 195 than the previous year. Among the items tested or calibrated were af proximately 4,500 gage blocks, over 500 sieves for grading cement and othe 
materials, nearly 2,000 haemacytometer chambers and 15,000 cover glasses, 289 photographic lenses, 280 optical instruments or optical systems, 650 measuring tapes, and 5,976 light bulbs (a sampling of nearly 7,000,000 purchased by the Government this year). Another service was the testing of 1,143 samples of microfilm for hypo content to make sure that the records would be permanent when stored in the archives.

\section{Heat and Power}

A total of 2,043 liquid-in-glass laboratory thermometers, 141 resistance thermometers, and 352 thermocouples were calibrated. In addition, 37,006 clinical thermometers were tested; 30,722 of these represented a sampling of over 300,000 thermometers purchased by the Veterans' Administration and the U. S. Public Health Service. Tests and calibrations were also made on special types of thermometers and thermometric devices.

Thirty-seven viscometers were tested or inspected, and 523 standard viscosity samples were supplied to other laboratories for use in the calibration of viscometers. Ninety fuels and lubricants, 80 miscellaneous samples, and 13 oil filter cartridges were tested for compliance with Government speciications. Automobile gasoline economizers, fuel additives, and other autonotive devices and materials were tested for the Federal Trade Commision and the Post Office Department. Simulated service tests of several ıutomotive antifreezes were made for the General Services Administration ind for the Federal Trade Commission. Sixteen nonroutine tests on airraft electrical network equipment and tests and calibrations of flowmeters ind aircraft carburetors were conducted for the Bureau of Aeronautics, )

\section{stomic and Radiation Physics}

More than 500 chemical and isotope analyses were carried out. A total f 1,318 radioactive standards were distributed, and 839 measurements of adon in the breath of workers or in the workroom air were made. In ddition, 885 radium, mesothorium, and cobalt preparations were measured nd certified for radioactivity; 149 ores and sludges and 41 water samples ere tested for radium content; and 17 miscellaneous gamma-ray determinaons were made. X-ray equipment and accessories were tested for the 'eterans' Administration and the Armed Services Medical Procurement gency. Other items tested for Government agencies included leadnpregnated building blocks for use in radiation protection, lead glass for rotective windows, lead-impregnated plastics, and lead aprons and gloves. hirteen of the new spectroscopic lamps containing a single mercury isotope ere distributed to cther laboratories to provide them with an unvarying andard of length.

\section{hemistry}

A total of 4,139 samples were received for acceptance and regulatory sting. The materials tested included paint, varnish, lacquer, enamel, 


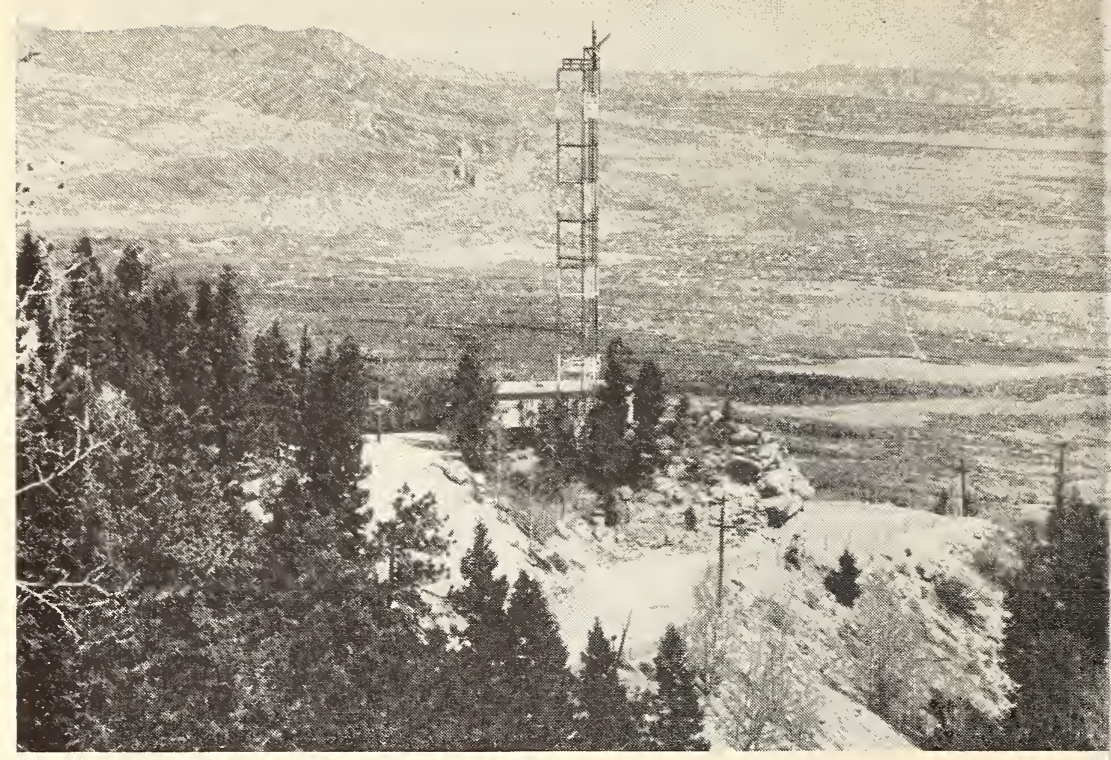

For intensive investigation of radio propagation phenomena, the Bureau has $\mathrm{r} \epsilon$ cently installed a 5-kilowatt transmitter on the summit of Cheyenne Mountair Colo., at an elevation of 9,000 feet (p. 78). The essentially sheer, 2,000-foot dro from summit to base makes this site ideal for simulating communication betwee aircraft and ground.

soaps, waxes, raw sugars, inks, typewriter ribbons, carbon paper, ferrou and nonferrous metals, precious metals, ores, and reagent materials. A the result of a statistical study of sampling procedures made by NBS, it wa possible to reduce the number of raw sugar determinations made for th Bureau of Customs. Umpire analytical work on classified materials wa continued for the Atomic Energy Commission in connection with contrac negotiations, inventcries, and process efficiencies. More than 300 Magne gages were calibrated for measuring the thickness of electroplated coat ings, an increase of about 60 percent over last year.

A new standard titanium-bearing carbon steel was added to the list 0 standard samples. Other standard samples under preparation include tantalum-bearing stainless steel, a chromium-nickel electrical heating alloy and a ferroboron.

\section{Mechanics}

Testing for other Government agencies continued at its previous hig level. Sound absorption was determined for 61 samples of acoustici material, and sound transmission loss was determined for seven panel representing many types of building construction. More than 90 pressure measuring instruments (including pressure gages, piston gages, manometer and mercurial barometers) were calibrated for government and industr. largely for use as secondary standards. Tests were made on 726 timepiecf 
and a number of ballistic chronographs, sidereal clocks, and stop watches. Eighty-nine wind-measuring instruments were tested, representing nearly all types of commercial anemometers and pitot tubes. Calibrations of 274 elastic calibration devices (proving rings, Amsler boxes, aircraft weighing cells, etc.) were completed in 1951. Almost 1,000 water current meters were calibrated for other Government agencies and the public. Accurate calibration of master beer meters is essential for the correct computation of the Federal tax on beer, amounting to about $\$ 800,000,000$ a year: 267 were tested. Calibrations were completed on 7,558 weights, representing an increase of 15 percent over 1950. Volumetric calibrations were made on 35,120 pipettes, burettes, flasks, and other apparatus for measuring iolume.

\section{Jrganic and Fibrous Materials}

With the reopening of the synthetic rubber plants that had been on a tand-by basis, there was a large increase in the demand for the standard amples for rubber compounding. Three of the seven samples originally et up have been exhausted and replacements obtained. A new sample, henyl-beta-naphthylamine, was established. Road tests for determining he tread wear of both passenger and truck tires were continued.

\section{Metallurgy}

Over 200 types of devices and materials were tested for quality and comliance with specifications. One large group consisted of 112 fusible boiler lugs for the U. S. Coast Guard. Material submitted by the Civil Aeroautics Board, Civil Aeronautics Administration, and other Government gencies was tested to determine causes of failure during transportation. wo hundred fifty-five salt-spray tests were made, and 614 samples were eat-treated for various Government agencies. The experimental foundry repared 2,201 castings of aluminum alloys, copper alloys, cast iron, lead, $\mathrm{n}$, and special compositions for Government agencies. Miscellaneous rvices included rolling, forging, swaging, and wire-drawing of metals and tetallographic and X-ray diffraction examinations.

\section{lineral Products}

More than 10,200,000 barrels of cement, an increase of 1,200,000 barrels ver the previous year, were tested to insure compliance with Federal recifications. Shipments of more than $9,000,000$ barrels of cement were spected and certified. Also inspected and tested were approximately 3,000 tons of fly ash, used as an admixture for concrete, and a considerable lantity of other silicious materials. Tests for other agencies were made 2,600 samples of concrete, 1,200 samples of aggregates, and 400 samples soils. In addition, 375 tests were made for Federal agencies on building ones and associated mortars and compounds. Testing of safety glass for mpliance with the American Standards Association code was continued 
for the various States. Various acceptance tests were conducted on re fractory materials, such as fire-clay brick, air-setting mortars, insulating refractory bricks, flake graphite, and mullite brick.

\section{Building Technology}

Many varieties of building materials, constructions, and equipment wert tested for other Government agencies. These included water coolers, ice cube makers, ice cream plants, refrigerating units, an oil-burning range, coal-burning space heater, fire extinguishers, rolling shutters for escalato: openings, masonry chimneys, matches, mattresses, sludge solvents, soot re movers, concrete and cinder blocks, concrete pipes, brick, structural tile fire-retardant paints, materials for heating ducts, and heat-insulating mate rials and panels. Bituminous roofing and water-proofing materials (173) and samples of bituminous road material $(1,882)$ were tested. Full-scal fire resistance tests were made on seven floors, eight walls and partitions and 19 steel columns. Other fire tests were conducted on safes, insulatins panels, and ships' windows.

\section{Electronics}

Various types of electronic equipment and components were tested anc calibrated for other Government agencies. An example is the testing o electron tubes. Specially designed, highly accurate, and extremely flexibl equipment has been installed for measuring the characteristics of a wid variety of tubes, ranging in size from subminiature types to large power tube and ranging in frequency from direct-current to microwave. Typical o the tests conducted during the year were (1) determinations of the con formance of tubes to specifications, (2) evaluation of the suitability of tube for special circuit applications, (3) examination and evaluation of tube in electronic equipment which had failed or deteriorated, (4) measuremen of the static curves of vacuum tubes in the positive grid region, (5) meas urement of characteristics of tubes operating under nonstandard conditions (6) evaluation of sample tubes which had been subjected to high-impac shocks and to conditions of extreme vibration, and (7) evaluation of foreign made tubes and determination of their characteristics.

\section{Radio Propagation}

Instruments and devices tested includer vacuum-tube voltmeters, dielec tric samples, field-intensity meters, $r-f$ ammeters, voltage generators, capaci tors, transmission lines, frequency standards, quartz-crystal units, antennas and frequency meters. Standard frequencies and standard time signals wer broadcast continuously by NBS radio stations WWV (Beltsville, Md.) an WWVH (Maui, T. H.), for use in the calibration and test of frequenc and time standards by the armed services, research laboratories, and variou industries. 


\section{Weights and Measures}

Tests and calibrations were made on master railway track scales, railway test cars, commercially operated railway track scales, and other large-capacity scales. Multiple-draft weighings of highway vehicles were carried out. Special tests were concluded on cordage-measuring devices.

\section{Cooperative and Consulting Activities}

\section{Advisory Services}

The Bureau's consulting and advisory services for other Government gencies arise from the diversity of its program, facilities, and staff in the ohysical sciences and mathematics. These services constitute an important shase of the Bureau's activities and are performed for all agencies of the Federal Government, as well as many State and municipal governments. Thus, during the year, advisory and consulting services were rendered the Departments of the Army, Navy, and Air Force; State Department; epartment of Agriculture; Post Office Department; Department of Justice; ttomic Energy Commission; Federal Communications Commission; Civil teronautics Board; Federal Trade Commission; Interstate Commerce Aommission; Library of Congress; U. S. Capitol; Veterans' Administration; ood and Drug Administration; Weather Bureau; Rural Electrification dministration; National Research Council; Central Intelligence Agency; oast and Geodetic Survey; Federal Bureau of Investigation; National dvisory Committee for Aeronautics; Munitions Board; District of Coimbia; Federal Housing Administration; Housing and Home Finance gency; U. S. Maritime Commission; Office of Rubber Reserve; Public oads Administration; Federal Prison Industries; Panama Canal; U. S. ariff Commission; General Services Administration; Economic Cooperaon Administration; Patent Office; U. S. Bureau of Mines; Social Security dministration; Civil Aeronautics Administration; Public Buildings Service; ureau of Foreign and Domestic Commerce; Office of International Trade; ational Production Authority; Office of Technical Services; Bureau of deral Supply; U. S. Coast Guard; Public Health Service.

Continuous and more extensive work is undertaken through various ientific and technical committees. The Bureau is represented on numeris committees, panels, and commissions of other Government agencies. rese include the Research and Development Board of the National Mili-

Establishment, the Federal Interdepartmental Safety Council, the deral Fire Council, the Interdepartmental Radio Advisory Committee, National Conference on Weights and Measures, the National Advisory mmittee for Aeronautics, the Interdepartmental Committee on Photoaphic Papers and Films, the Interdepartmental Screw Thread Committhe Joint Committee on Unification of Building Codes, and a number similar groups. 

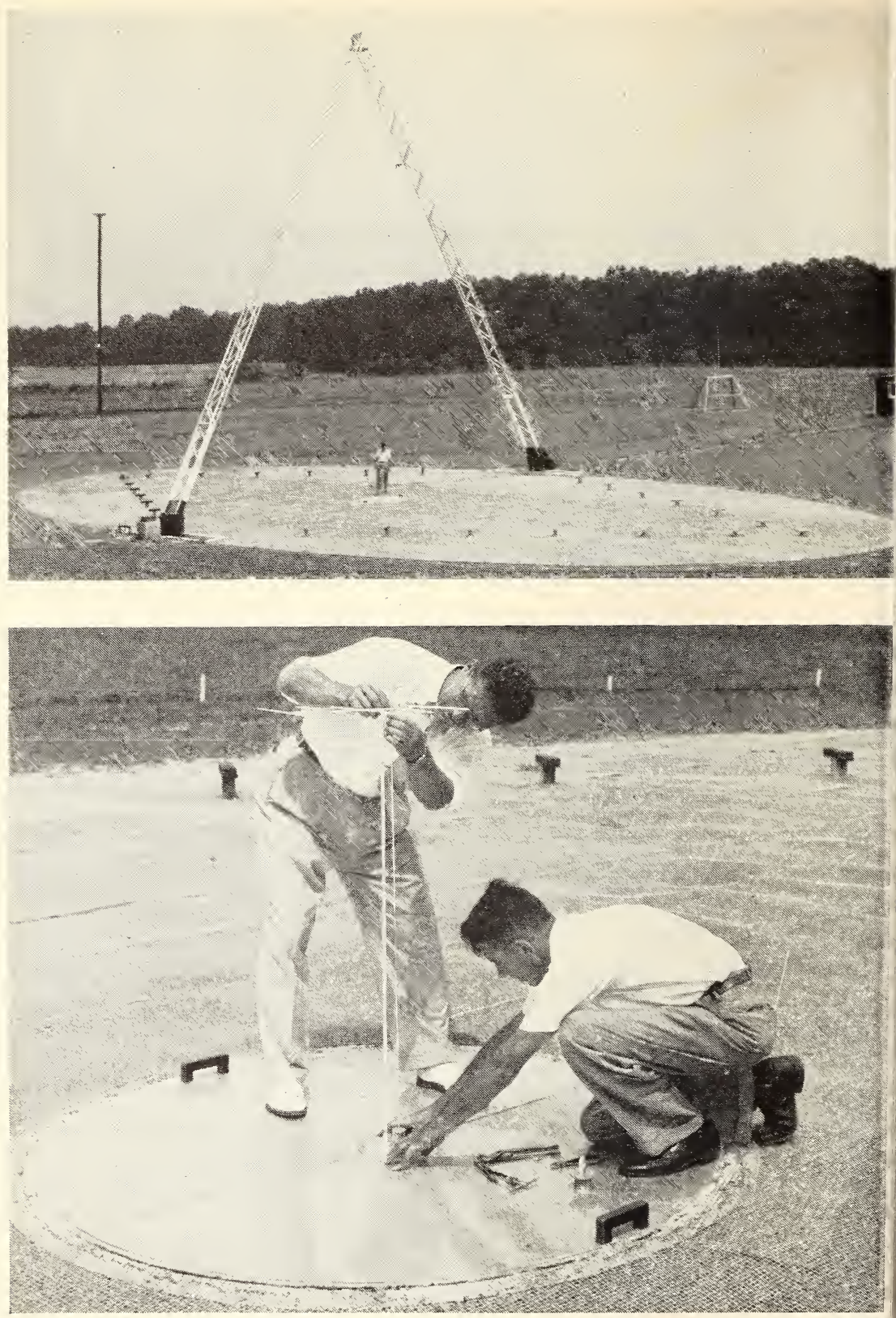

Above: A new model antenna range to facilitate the measurement of antenna radi tion patterns in the vertical plane has recently been completed by NBS. Belov Adjusting a test antenna on the new range. 


\section{Federal Specifications}

An important phase of the Bureau's work consists in cooperation with the Federal Specifications Board and other standardizing agencies in the development and improvement of specifications. To avoid duplication of effort in Government procurement, the Federal Specifications Board compiles and adopts specifications for the purchase of supplies by the Federal Government. The Board discharges its functions through 70 technical committees. A total of 120 positions on these committees, including 25 chairmanships, are filled by specialists of the NBS staff. Considerable experimental investigation is carried on at the Bureau in the development of test methods, which are so often indispensable before a specification can be framed or applied. Other laboratory studies become necessary in connection with the continual revision of the specifications to keep them abreast of industrial practice and the changing needs of the Government. More than 2,200 Federal specifications are now in effect.

\section{Radio Propagation}

The Bureau was consulted by other Government agencies on a variety of problems in the radio field. For example, the International Broadcast Division of the State Department was advised as to the maximum usable frequencies and field intensity for several trans-Atlantic and trans-Pacific paths. Information on the probable trend of the current sun-spot cycle over the next few years was given the National Production Authority for use in the allocation of strategic materials for antenna construction. At the request of the Office of Civil Defense Communications, frequency and power requirements were investigated for amateur radio bands in defense communications. The Air Force was given information on the best frequency for use with its proposed electronic rescue system. Advice was given to the Civil Aeronautics Administration in connection with a problem of erratic direction-finder behavior in aircraft homing on low-frequency beacons in the North Pacific. A study of the effect of propagation phenomena on the VHF air-ground allocation problem in the United States was made for the Radio Technical Commission for Aeronautics.

\section{Color Television}

Technical tests on color television systems were made for the Advisory Committee on Color Television to the Committee on Interstate and Foreign Commerce of the United States Senate." These tests, covering flicker and color fidelity, were included in the Advisory Committee's report on the resent Status of Color Television.

\section{Jperation Greenhouse}

For the past 2 years, the Bureau has been engaged in an extensive program of development and instrumentation for the Atomic Energy Commis- 
sion. These studies culminated in active field participation in the final rests at Eniwetok by 24 members of the NBS staff. A large amount of new data were obtained. This information is now being analyzed and correlated with that obtained by other participating groups.

\section{Ballisto-Cardiography Measurements}

The Civil Aeronautics Authority sought the advice of the Bureau regarding methods for making more refined measurements in ballisto-cardiography (measurement of the motion of the body due to reactive forces accompanying the heart beat). The Bureau suggested the application of mutual inductance transducers to the problem and loaned the necessary equipment. The resulting experiment was highly successful and resulted in what is understood to be the first absolute displacement measurements made in this field.

\section{Building Technology}

The Bureau assisted other Government agencies in the solution of a wide range of technical problems relating to building materials, building construction, and the protection of buildings. The Army Corps of Engineers was given information on the properties of prefabricated panels and on test procedures for fire-retardant paints. 'The National Archives, Department of the Treasury, Public Building Administration, Army, Navy, Department of the Interior, National Institutes of Health, and Veterans Administration were advised on various problems concerned with fireresistive construction, fire extinguishers, storage of motion picture films protection of records, performance of elevators, and transportation of hazardous materials. Assistance was given the Army, Navy, Federal Housing Administration, and a number of other agencies on roofing, flooring, siding, and related problems. Large hangars and warehouses werc inspected for the Navy. The Bureau was asked to determine the cause of masonry cracking and plaster failure in several Government buildings Assistance was provided the Housing and Home Finance Agency on build ing problems such as thermal insulation of buildings, condensation in walls properties of reflective insulation, and vapor barriers. Information or refrigeration and air conditioning was giver the Office of the Quartermaste General, the Marine Corps, the Office of the Chief of Engineers, and the Navy.

\section{Federal Color Card for Paint}

As the result of several years of cooperative effort by NBS and the Federa Specifications Board, a uniform means of indicating paint colors has now been adopted by the Federal Government. The new Federal specification better known as the Federal Color Card for Paints, reduces the more thar 600 paint colors formerly used by the Government to 187 by eliminatins unimportant variations of different shades. 
The various branches of the United States Goverment collectively form the largest single purchaser of paint in the world. The color card, which consists of actual spots of the colors deposited on charts in a loose-leaf binder, is expected to contribute materially to governmental purchasing economies; paint suppliers will be able to supply paint more quickly and economically, and Federal agencies will no longer have the trouble and expense of maintaining their own color standards for distribution to prospective bidders.

\section{Architectural Acoustics}

Advice on the construction of partitions with adequate sound insulation was given to the architect in charge of renovation of the White House. The Architect of the Capitol requested and received advice on improving the acoustics of the House and Senate Chambers. A public address system was recommended for the Supreme Court Chamber. Other consulting services in architectural acoustics were rendered to the National Gallery of Art, the Army Chemical Corps, the Army War College, and the Veterans' Administration. The General Services Administration was advised on the painting of acoustic plaster at the Pentagon, and the acoustical effect of the painting was determined by the long-tube method recently developed by NBS.

\section{Mineral Products}

A wide variety of consulting services was rendered to other agencies in connection with the technology of mineral products. The Architect of the White House and the Committee on Alterations of the White House sought advice on sandstone weathering problems and on damage to stone masonry due to roof leaks. The General Services Administration, the Folger Library, the American Battle Monuments Commission, the Federal Trade Commission, the Munitions Board, and others were given information on building stones, abrasives, and related problems. An investigation was made of the Japanese optical industry. The Army Map Service was aided in the solution of a problem concerning materials to be used in making topographic models.

\section{Fire Protection}

The Bureau cooperated in the revision and development of flame-resistance standards to cover fabric types. Attention was given to clothing fabrics, carpeting and floor coverings, mattresses, and upholstery and decorative fabrics, including coated and synthetic materials. In connection with proposed Federal legislation on hazardous clothing fabrics, the Bureau joined with commercial and State laboratories in a series of test programs designed to éstablish a basis for the legislation. The cooperative work effected closer agreement among the interested agencies on the selection of a practicable test method and led to improvements in both the equipment and test procedures. 


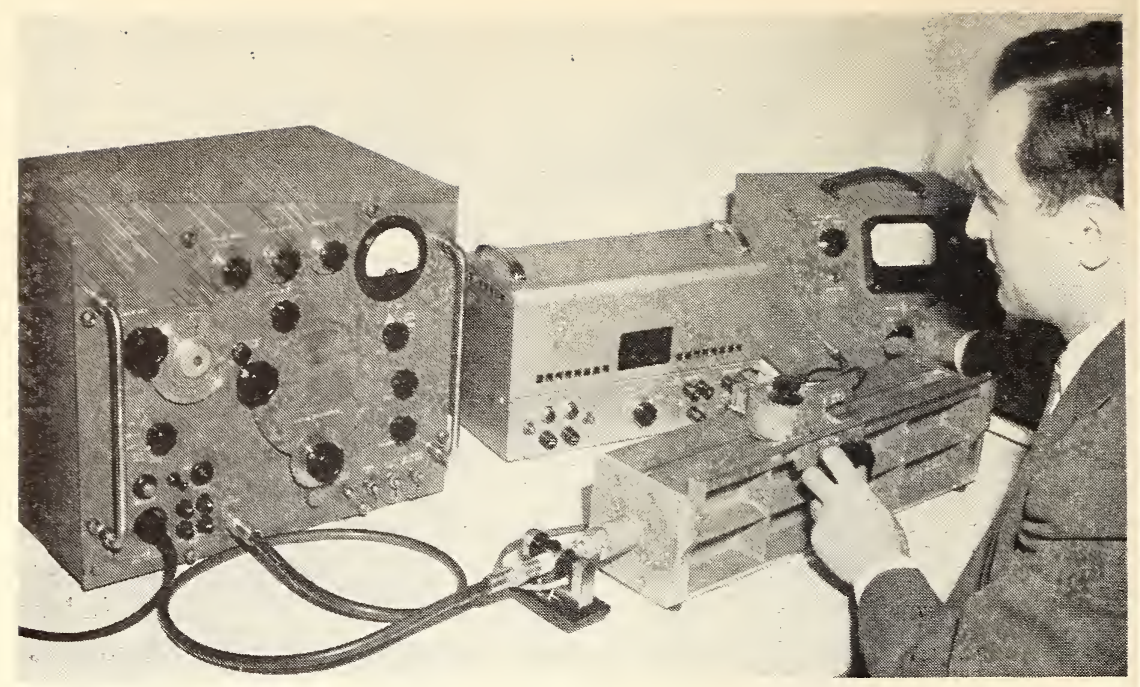

An inexpensive type of magnetic attenuator (right foreground) was developed (p. 81) for use in coaxial transmission lines. The new device, an outgrowth of NBS research in power measuring techniques at microwave frequencies, requires no movable components, mechanical controls, or slotted sections in the waveguide or coaxial transmission line.

\section{Army Shoes}

A survey by the Office of the Quartermaster General indicated that about 50 percent of the failures in combat boots occurred in the bond between the rubber outersole and the leather midsole. $\Lambda$ t the request of the Department of the Army, the Bureau made an examination of the adhesives in general use for bonding the midsole to the outersole and found that some adhesives greatly increase the strength of this bond. As a result, a simple lever-type device for rapidly checking the strength of the bond in the finished shoe was developed. The device can be applied in the manufacturer's plant to any number of shoes in order to ascertain the minimum strength of the bond without the destruction of a large number of shoes.

\section{Bristle Brushes}

Inquiries were received from purchasing officials of the City of New York, private testing laboratories, and Government agencies, such as the Federal Trade Commission and the Department of Justice, regarding means of detecting adulterants in bristle brushes. As a result of the shortage of Chinese hog bristles, brushes purporting to be bristle brushes were appearing on the market adulterated with horsehair, which cannot be distinguished from bristle by ordinary examination. A satisfactory procedure, based on the different pigmentation patterns of the two types of hair in cross section, was furnished to the inquiring agencies. 


\section{National Cooperation}

As custodian of the national standards of measurement, the Bureau provides calibration services not only to the Federal Government but to State and municipal governments, universities, industry, and private laboratories. In addition, the Bureau offers a program of assistance to State and local departments of weights and measures, coordinating their efforts and advising them on technical matters. NBS also cooperates extensively with technical and trade groups, on a national basis, where the interests of the Government are involved. Such cooperation is not only of value to the Government but provides a means of disseminating the results of the Bureau's work to the Nation in a direct fashion.

\section{Weights and Measures}

While the National Bureau of Standards is the custodian of the Nation's standards of length and mass, the Congress has left to the control of the individual States the regulation of commercial weighing and measuring devices and operations. As the Bureau has no regulatory authority over the weights and measures activities of the States, it functions only in an advisory and coordinating capacity in this field.

The translation of the basic standards of length and mass and of the derived standards of capacity to the channels of industry and trade is a matter of great economic importance to the producing, manufacturing, processing, and distributing agencies in this country and to all purchasers of commodities. To aid in this work, the Bureau established late in 1947 an Office of Weights and Measures whose over-all function is to promote the extension, raise the standard of efficiency and coverage, and increase the degree of uniformity of State weights and measures supervision throughout the United States. A definite program of assistance to State and local departments of weights and measures as well as to business and industry has been set up and successfully pursued.

A large part of the activity of the Office of Weights and Measures consists of consultative services rendered through correspondence; through visits to the office by representatives of Federal agencies, business and manufacturing concerns, and weights and measures officials; and through visits of members of the Office to weights and measures officials in their own jurisdiction. The field of inquiries is broad, embracing the drafting of new legislation; the interpretation of laws, specifications, tolerances, and regulations; the design of testing equipment; methods of test of commercial equipment; the reporting of activities in different weights and measures jurisdictions; problems of and plans for weights and measures administration; planning and conducting weights and measures conferences; training schools for State departments; and other similar problems. Visits were made to State weights and measures offices in 13 States and the District of Columbia, and to several 
county and city offices. As a result of the consultation services of the Office, a new weights and measures law was enacted in the State of Maryland, amendments were enacted to existing laws in several other States and in Hawaii, and plans were made for further enactments.

A major medium of cooperation with weights and measures officials, equipment manufacturers, and associated interests is the National Conference on Weights and Measures, of which the Director of the Bureau is president. The 36th meeting of this organization was held in Washington in May 1951 under the sponsorship of the National Bureau of Standards. The official registration of 338 included 153 weights and measures officials from 33 States and the District of Columbia, 150 representatives of business and industry, and 26 persons from Federal agencies. Guests were also present from Canada, Sweden, and Syria.

The most important action of the Conference was a complete revision of the Model State Law on Weights and Measures. The model law, published by NBS, is a guide to the States on weights and measures legislation. A new code for prepackaged ice cream containers was tentatively adopted. A resolution was passed suggesting enactment and enforcement of laws governing the sale of commodities by net weight.

\section{Research Associate Program}

The research associate plan is an arrangement under which technical, industrial, and commercial organizations can support work at NBS on projects which are of special interest to them, yet of sufficient general interest to justify use of Government facilities. Research associate projects must not only be of value to all groups concerned in the particular field and to the Federal Government, but must also be important from the standpoint of the Nation's sum total of technologic knowledge. While the arrangement is preferably made with an association or group representing a major part of the industry concerned, projects may be undertaken in cooperation with single companies or individuals when the results may be expected to be of value to the general public. In any case, the results become a part of the public domain and are published by the Bureau. Research workers acceptable to both parties are either assigned by the Bureau or employed by the supporting organization, which pays their salaries and other expenses incident to the project.

Since the research associate plan was established in 1920, more than 175 organizations and individuals have supported cooperative research at the Bureau. Many of the projects have been extremely specific and therefore of relatively short duration. Others, such as that supported by the American Dental Association, have been directed toward fundamental research in the field; this project has been active since 1930 .

Nine groups are now supporting 57 research associates at NBS. Cooperative projects are under way in dental materials, electrodeposition, 
commercial adsorbents, plumbing systems, fuels, structural steel, asphalt roofing, fire protection, and applied mathematics.

\section{Scientific and Technical Groups}

Through active participation in the projects of professional societies and standardizing bodies, the Bureau plays an important part in the development of test methods and criteria, in the application of scientific discoveries, and in fundamental research programs of a national nature. It thus aids in developing and improving engineering standards, purchase specifications, and building and safety codes. Bureau staff members now hold approximately 1,700 positions on committees of over 100 national groups such as the Acoustical Society of America, American Society for Testing Materials, American Standards Association, American Society of Textile Chemists and Colorists, American Concrete Institute, American Geophysical Union, American Institute of Electrical Engineers, American Society of Heating and Ventilating Engineers, American Society of Mechanical Engineers, Institute of Radio Engineers, Instrument Society of America, National Fire Protection Association, Optical Society of America, Society of Automotive Engineers, Society of Plastic Industry, American Petroleum Institute, American Ordnance Association, American Chemical Society, and National Association of Corrosion Engineers.

\section{National Committee on Radiation Protection}

Upon the recommendation of the International Commission on Radiological Protection, the Advisory Committee on X-ray and Radium Protection was formed in 1929 under the sponsorship of the National Bureau of Standards and with the cooperation of the leading radiological organizations. This committee, small in size, functioned effectively until the advent of atomic energy introduced a large number of new and serious problems in the field of radiation protection.

At a meeting of the committee in December 1946, the representatives of the participating organizations agreed that problems in radiation protection had become so manifold that the committee should enlarge its scope and membership and should appropriately change its title to be more inclusive. Accordingly, the name of the committee was changed to the National Committee on Radiation Protection. At the same time the number of participating organizations was increased, the total membership was considerably enlarged, and eight working subcommittees were established.

With the increasing use of radioactive isotopes by industry, the medical profession, and research laboratories, it is essential that certain minimal precautions be taken to protect the users and the public. Each of the subcommittees is charged with the responsibility of preparing protection recommendations in its field. When one of them prepares a set of recommendations on a certain phase of radiation protection, it is published as a National Bureau of Standards Handbook. Two handbooks were 
completed this year: Control and Removal of Radioactive Contamination in Laboratories and Recommendations for Waste Disposal of $\mathrm{P}^{32}$ and $\mathrm{I}^{131}$ for Medical Users.

\section{NBS Semicentennial}

The year 1951 marked the 50th anniversary of the National Bureau of Standards, in honor of which some 30 major scientific and technical societies elected to hold their meetings in Washington. The sessions were technical in nature; they were of considerable importance to the Government, particularly to the scientific laboratories of the various Departments. In addition, 12 special symposia, on subjects of current importance to the Bureau and to the Department of Defense, were sponsored by the Bureau with the cooperation and assistance of the Office of Naval Research. The subjects of the symposia were low-temperature physics, influence of low temperature on the mechanical properties of metals, gravity waves, solution of simultaneous equations and the determination of eigenvalues, mass spectrometry, energy transfer in hot gases, electrochemical constants, polymer degradation mechanisms, evaluation of optical imagery, electron physics, characteristics and applications of resistance strain gages, and electrodeposition researches in progress. Many of the societies and associations awarded scrolls to the Bureau, in recognition of its contributions to various fields of science and technology.

\section{International Cooperation}

The National Bureau of Standards is active in such groups as the International Union of Chemistry, International Telecommunications Union, International Committee on Weights and Measures, International Scientific Radio Union, International Commission on Illumination, and International Commission for Uniform Methods of Sugar Analysis. These societies deal largely with the establishment and maintenance of international scientific standards and the establishment of values for scientific constants. Another phase of international cooperation involves a program whereby scientists or diplomatic representatives from other countries are accepted at NBS as guest workers or visitors. Both aspects, which are important to the United States in terms of commerce and trade as well as the international policies of the Government, are coordinated on the diplomatic level by the State Department. During 1951, the Bureau was host to a large number of scientists from the United States and abroad, who attended a series of symposia on topics of current scientific interest. These symposia were held at NBS in connection with the Bureau's fiftieth anniversary.

\section{International Intercomparison of Standards}

The National Bureau of Standards participated in two important international intercomparisons conducted under the auspices of the International 
Bureau of Weights and Measures. In one of these, the lamp standards of candlepower and luminous flux of six national laboratories were intercompared. In the other the spectrophotometric and photometric results obtained in the national laboratories of 10 countries on four colored filters were intercompared. In both cases the results from NBS compared favorably with the mean results from all the laboratories participating.

\section{Unification of Standards for Screw Threads}

Further progress was made in the unification, among Canada, the United Kingdom, and the United States, of standards for screw threads and threaded products through cooperation of the Interdepartmental Screw Thread Committee; ASA Sectional Committee B1 on the Standardization and Unification of Screw Threads; ASA Sectional Committee B18 on Jimensional Standardization of Bolts, Nuts, Rivets, Screws, and Similar Fasteners; and the National Bureau of Standards. Agreement was reached on a series of five sizes of screws smaller than $1 / 4$ inch for limited applications uch as the attachment of instruments to panels. It was agreed that the 12-13 size should replace the $1 / 2-12$ size in the Unified coarse thread series. )f major importance was the conclusion of an accord on widths across flats nd other dimensions of hexagon bolts and nuts, an essential step in the nification of standards for flange widths, wrench openings, and similar ems in mechanical design. It is estimated that at least 60 percent of comnercial nuts, bolts, and screws manufactured in the United States now Jllow the Unified standards.

\section{uropean Aid}

At the request of the Economic Cooperation Administration, a member the NBS staff visited 11 European countries for the purpose of furnishing formation and assistance to textile research and testing laboratories, textile anufacturers, and instrument manufacturers on the application of Ameran methods and instruments to technological and production problems ncerning textiles. Approximately 100 educational institutions, research id testing laboratories, and manufacturing plants were visited. Through eetings, conferences, lectures, and group discussions, over 2,000 scientists, gineers, technologists, and educators were furnished information and istance. The project was found to be of benefit to textile scientists in th Europe and the United States and should lead to closer and more ective cooperation in the establishment of international standards.

\section{ernational Relations}

Scientists and engineers from other countries are permitted to participate certain normal work of the Bureau as guest workers and trainees. The gram is conducted under procedures of the Department of Commerce 1 the Department of State, in accord with such legislation as the Fulbright (Public Law 584, 79th Cong.) and the Point Four Program (Public 
Law 535, 81st Cong.). The Bureau's Office of International Relations makes arrangements for foreign scientists to be accorded guest privileges at NBS; receives official visitors from abroad; correlates NBS activities with those of other Federal committees handling international relations; and assists the Bureau in its own representation abroad at international meetings. Such a program not only strengthens the relations of this country with other nations but also permits the Bureau to keep more closely in touch with foreign developments and provides it with additional expert temporary staff associates.

During the fiscal year, approximately 800 persons from other countries were visitors or guests of NBS. Included were directors of foreign research institutions, research scientists, engineers, university professors, government officials, trainees sponsored and supported by the Department of State, and technical students of graduate level.

A. V. Astin, Director, National Bureau of Standards. 


\section{SCIENTIFIC AND TECHNICAL DIVISIONS AND SECTIONS ${ }^{1}$}

\section{ELECTRICITY}

esistance Measurements. Inductance and Capacitance. Electrical Instruments. Magnetic Measurements. Applied Electricity. Electrochemistry.

\section{OPTICS AND METROLOGY}

1otometry and Colorimetry. Optical Instruments. Photographic Technology. Length. Gages.

\section{HEAT AND POWER}

mperature Measurements. Thermodynamics. Cryogenics. Engines. and Lubrication. Engine Fuels.

\section{ATOMIC AND RADIATION PHYSICS}

\section{ATOMIC PHYSICS}

ectroscopy. Radiometry. Mass Spectrometry. Physical Electronics. Electron Physics. Atomic Physics. Neutron Measurements.

\section{RADIATION PHYSICS}

clear Physics. Radioactivity. X-rays. Betatron. Nucleonic Instrumentation. Radiological Equipment.

\section{CHEMISTRY}

ranic Coatings. Surface Chemistry. Organic Chemistry. Analytical Chemistry. Inorganic Chemistry. Electrodeposition. Gas Chemistry. Physical Chemistry. Thermochemistry. Spectrochemistry. Pure Substances.

\section{MECHANICS}

1d. Mechanical Instruments. Aerodynamics. Engineering Mechanics. Hydraulics. Mass. Capacity, Density, and Fluid Meters. 
Rubber. Textiles. Paper. Leather. Testing and Specifications. O, ganic Plastics. Dental Research.

\section{METALLURGY}

Thermal Metallurgy. Chemical Metallurgy. Mechanical Metallurg Corrosion.

\section{MINERAL PRODUCTS}

Porcelain and Pottery. Glass. Refractories. Enameled Metals. Buil, ing Stone. Concreting Materials. Constitution and Microstructur Chemistry of Mineral Products.

\section{BUILDING TECHNOLOGY}

Structural Engineering. Fire Protection. Heating and Air Conditionin Exterior and Interior Coverings. Codes and Specifications.

\section{APPLIED MATHEMATICS}

Numerical Analysis. Computation. Statistical Engineering. Machi Development.

\section{ELECTRONICS}

Engineering Electronics. Electron Tubes. Electronic Computers. Ele tronic Instrumentation.

\section{ORDNANCE DEVELOPMENT}

ELECTROMECHANICAL FUZING

Mechanical Research and Development. Electromechanical Fuzes. Tec nical Services.

\section{GUIDED MISSILE FUSING}

Missile Fuzing Research. Missile Fuzing Development.

\section{PROJECTILE FUZING}

Projectile Fuzes. Ordnance Components. Ordnance Tests. Ordnar. Research. 
CENTRAL RADIO PROPAGATION LABORATORY IONOSPHERIC RESEARCH

Jpper Atmosphere Research. Ionospheric Research.

SYSTEMS RESEARCH

legular Propagation Services. Frequency Utilization Research. Tropospheric Propagation Research.

MEASUREMENT STANDARDS

ligh-Frequency Standards. Microwave Standards.

MISSILE DEVELOPMENT

fissile Engineering. Missile Dynamics. Missile Intelligence. Missile Instrumentation. Technical Services. Combustion. 




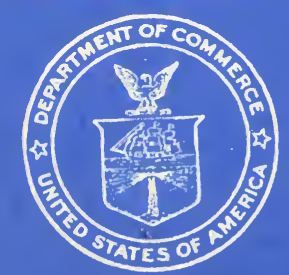

